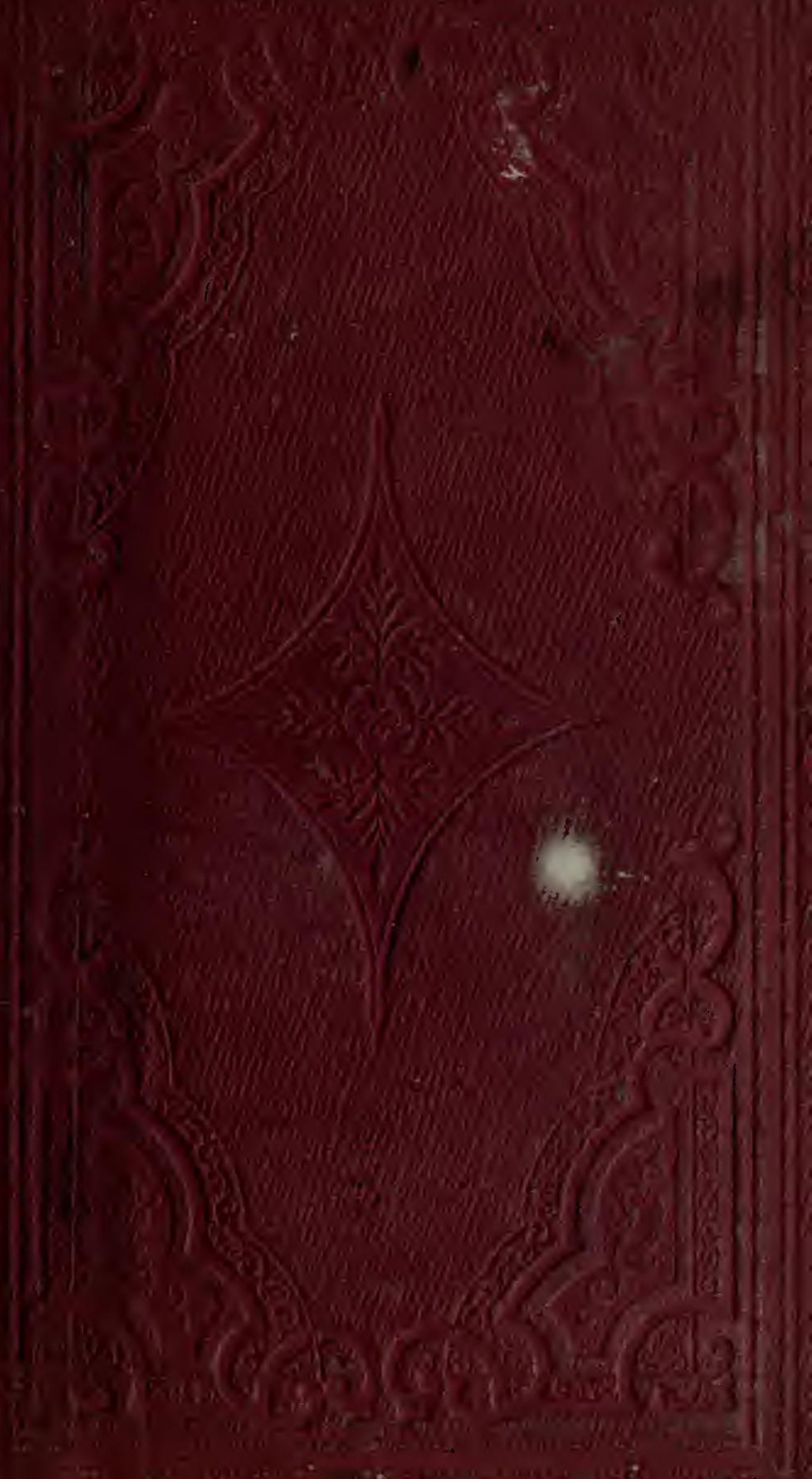




\section{do \\ 50}

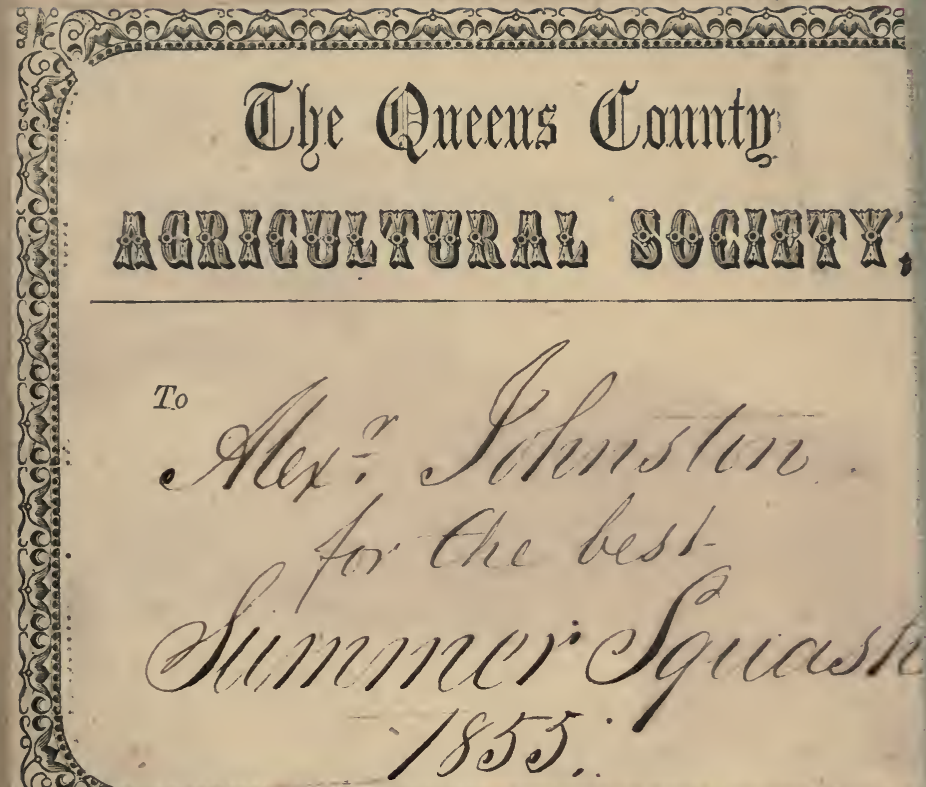

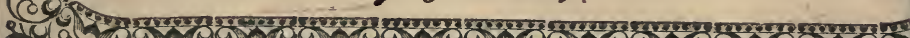

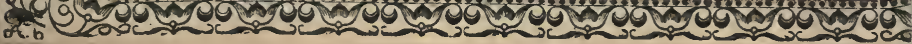


fhe d wherese Jpone 5. 1901

Presented. \% "Sother Arratut. His Leletraind tief a dosurtow. fanuary 1896 


\section{GIFT OF}

Thomas H. Means
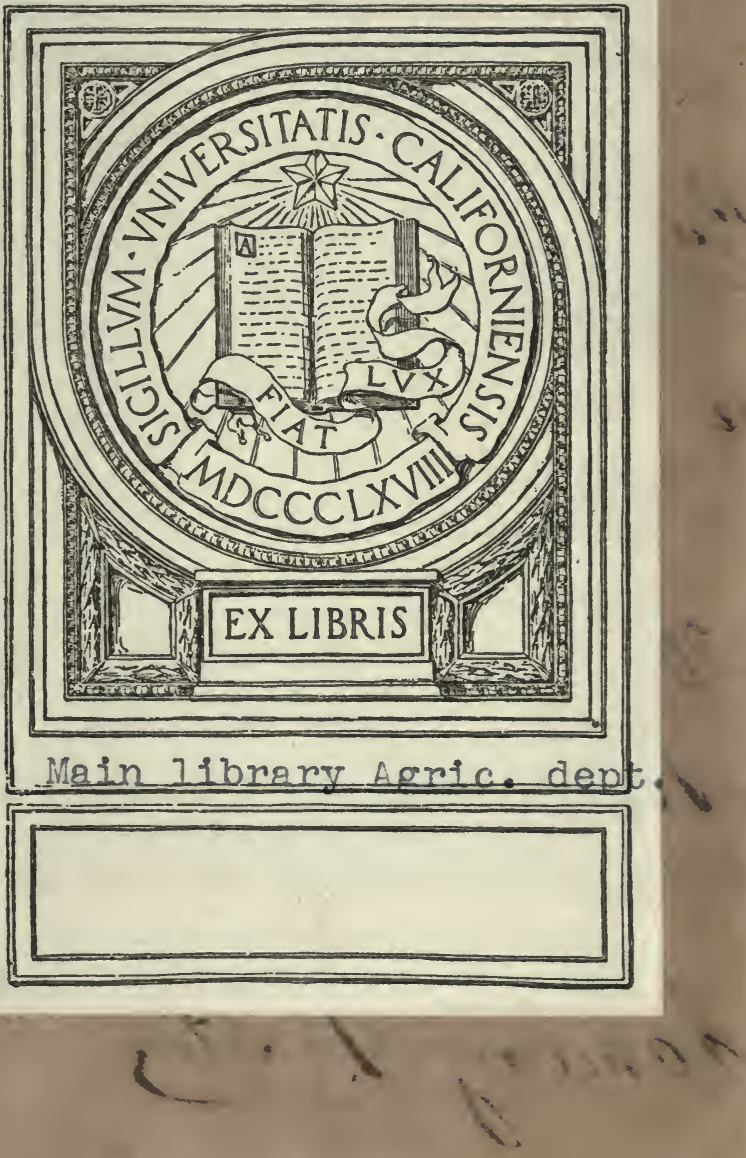


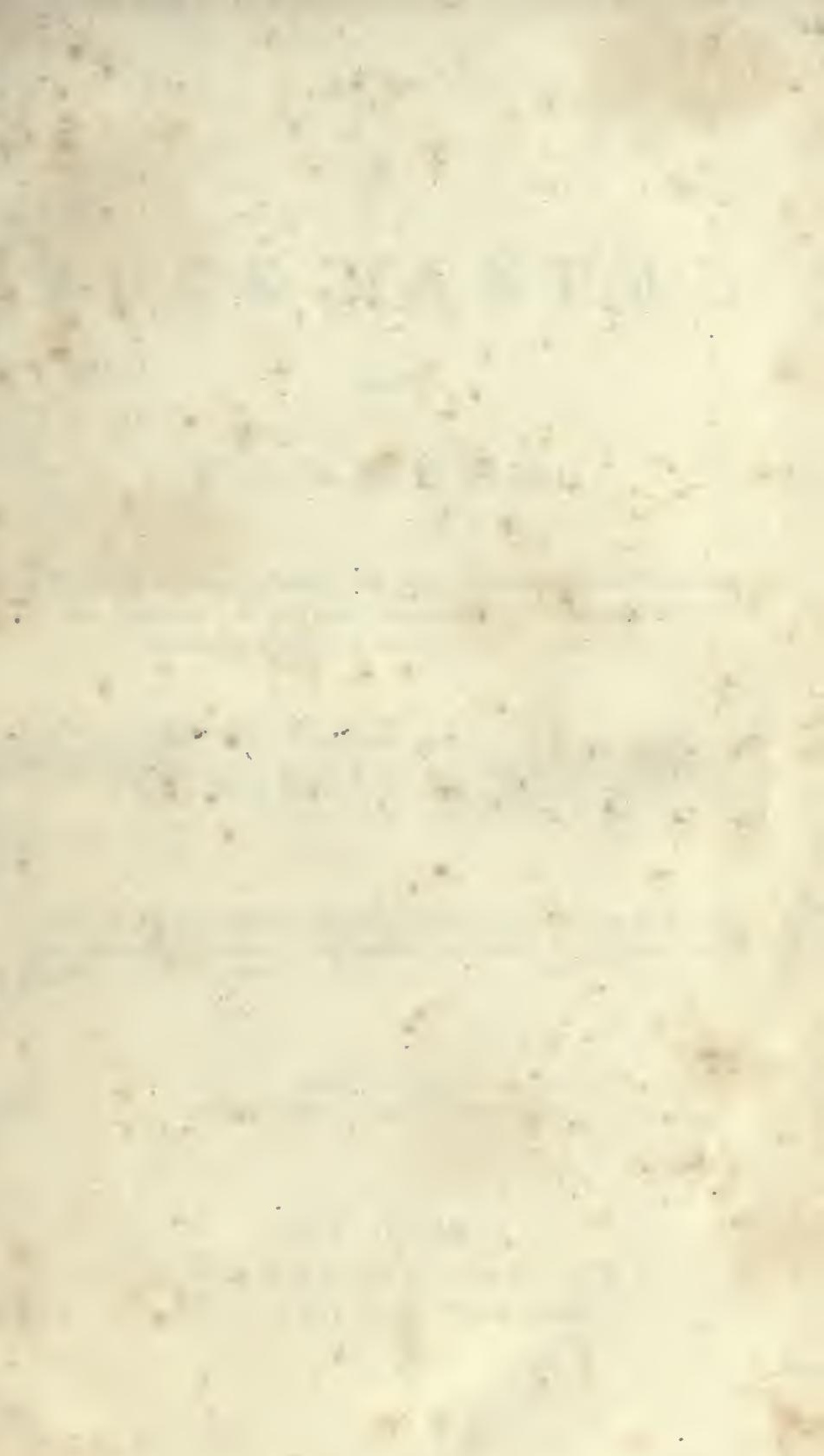


Digitized by the Internet Archive in 2008 with funding from Microsoft Corporation 


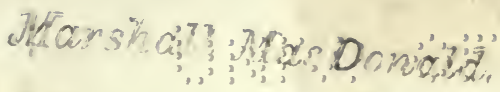

A

\section{U C K M A N U A L}

FOR

\section{FAR M ERS:}

a tReatise on the PHYSICAL AND CMEMICAL PROPERTIES OF SOILS; THE CHEMISTRY OF MANURES; INCLUDING ALSO THE SUBJECTS OF COMPOSTS, ARTIFICIAL MANURES AND IRRIGATION.

B Y SAMUEL L. D A N A.

"It is usual to help the ground with muck, and likewise to recomfort with muck, put to the roots; but to water it with muck-water, which is like to be more forcible, is not practiced."-BAcos.

FOURTH EDITION, With s new Chapter on Bones and Superphoephates.

\section{NEW YORK :}

C. M. SAXTON \& COMPANY. AGRICULTURAL BOOK PUBLISHERS

1856 . 
Lift of this. N. Tenno Drain Library- Ag. dept.

Entered, according to Act of Congress, in the year 1855 , by S. L. DANA, in the Clerk's Office of the District Court of the District of New York. 
TO THE

\section{CITIZENS OF LOWELL,}

THESE PAGE, THE PITH OF EIGHT LeCtuRes ON THE CHEMISTRY OF SOIL AND MANURE, DELJVERED BX THETR REQUEST,

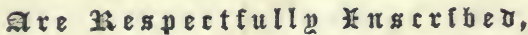
BY THE AUTHOR. 
<smiles>C1CC1</smiles>

4 


\section{PREEACE.}

THE dedication of this volume shows its origin and object. The Author is not an agriculturist, he does not assume the name even of agricultural chemist. Practical chemistry is his profession, and has been for some thirty years. During the greatest portion of this time he has been attached as chemist to the Printworks of the Merrimack Manufacturing Company, in Lowell. While pursuing there, during the years 1835, '36, and ' 37 , researches on the action of cow-dung in calico dyeing, he pushed his inquiries, as a recreation during his few leisure hours, into the nature and action of manures and of soil.

Conversation on these matters with the geological surveyor, and with the agricultural commissioner of Massachusetts, led to a correspondence between the parties, which partly appeared in the published reports on the geology and agriculture of Massachusetts. This 
induced some zealous and active citizens of Lowell, to ask me to deliver a course of lectures on agricultural chemistry. My reading on that subject had been very limited; yet, willing to contribute my mite to so good a cause, and to embody my own notions on this subject, notes for the lectures were prepared week by week as they were delivered; and urged to their publication, the notes were thrown into chapters and sections, and so the book appeared at last, divested of the colloquial style befitting the lecture room, and so much condensed as to be scarcely recognizable as lectures. The work was favorably received at home and abroad, where a considerable portion was reprinted. It has passed through several editions, each being enlarged by the addition of new matter, to keep pace with the times. To the present edition is added an entire new chapter on bones, and superphosphates of lime and alkalies. Should another edition be called for, I trust it will be then and there shown in a new chapter on the analysis of the mineral part of soil, that, agriculture in demanding of chemistry any real practical result from such analyses of soils beyond this, their great uniformity of composition, is asking 
an impossibility. That is my opinion. Not so with the vegetable part of soil. I have endeavored in the following pages to set forth the high importance of determining the state and condition of this; to show that its presence in soil is of the utmost consequence, and that, without it, full crops are not to be raised. This is my conviction.

One word respecting the title of my book. It is my own. I have neither begged, borrowed, or stolen it. That last has been done by an English Author, who seems to be ashamed not of the act, but of the name he has filched from me, and so eases his conscience by apologizing for his "homely title."

I shall not discredit my child by being ashamed of his name. It was good at the christening, and I trust will be thought respectable in manhood.

S. L. D.

Loweur, June 1st, 1855. 


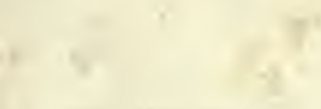

$+2$

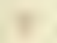

* 1

$+$

(n)

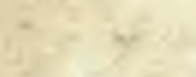

$7=$

8

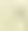

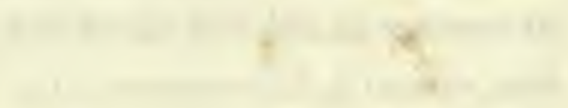

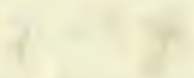
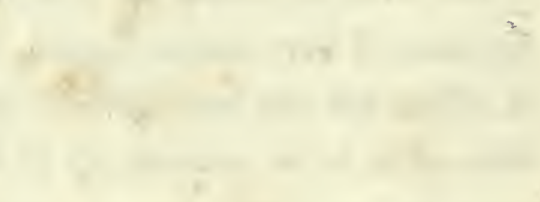

$-+$

$\sqrt{2}$

$4=$

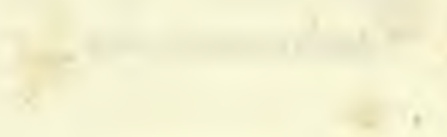




\section{N T E T T.}

\section{CHAPTER I.}

Grologr of Sorr . . . . . . . . . . . . . Page 17

Objects of agricultural chemistry; objects and nafurc of agricultural geology ; definition of the terms, primary and secondary ; rocks have one common origin ; the terms primary and secondary soil are useless ; rocks and soil are to be classed by their origin and distribution; in their origin all rocks are igneous or by fire ; chemical constitution of all rocks similar ; there is one rock and one soil ; chemical constitution of rocks does not affect the vegetation over them; geographical distribution of plants; the laws which govern it; rocks do not form the soil which covers them; general uniformity of chemical composition of soil ; proofs of general uniformity of composition; from Massachusetts soil, 146 specimens, and from various parts of the world, 267 specimens ; remarks on soil analyses, all are imperfict approximations only to truth ; the largest portion of soil, least liable to be affected by different modes of analysis; by any mode, soil divides itself into two portions-soluble and insoluble; several elements in soil often educed by analysis, which should be included in the insoluble portion of soil ; carbonate of lime, too often a product, not an educt of analysis ; potash and soda of soil to be considered generally as combined with the organic matter; clay, iron, magnesia to be included in the insoluble ingredients; plaster, phosphate of lime, or bone-dust in the soluble ingredients of soil ; division of elements of soil into soluble, insoluble, and salts of lime ; table of analyses of 413 soils from all parts of the world ; principles deduced from this table and its results; rule for calculating the amount per acre from results per 100 parts of soil ; analyses of vine grown on soils formed from different geological districts.

\section{CHAPTER II.}

Chimacal Constrtumon of Rocks and Solrs . . . . . . . . . . 38 Different views taken of rocks by geologists, mineralogists and chemists ; farmer takes only the chemical view ; nature of agricultural mineralogy ; farmer must understand the results of the analysis of minerals ; division of the thirteen sub- 
stances forming rocks, into silicates, metalloid compounds, salts, -explanation of these terms; chemistry of soil; chemical notation; the three laws of affinity explained; constitution of simple minerals composing rocks ; rocks are masses of silicates; the whole is dived into three classes only.

\section{CHAPTER III.}

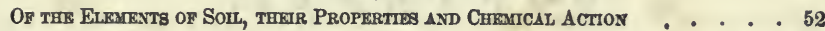

The common properties of the bases of silicates; characters of the class metalloid compounds; particular description of silicon, or the base of flinty earth ; composition of granite and the soil which it forms; quantity of alkalies in barren plains ; all soil contains lime, alkali, \&c.,-enough for any crop grown on it ; action of air and moisture upon soil, produces salts; origin of sulphate and phosphate of lime in soil ; all soil contains these substances.

\section{CHAPTER IV.}

OF the Organc Constrtuknts of Soll . . . . . . . . . . . . 64

Number of substances forming plants ; what the organic constituents of soil are ; they are formed by the action of the living plant; plants draw their inorganic constituents ready formed from the soil ; two great divisions of the elements of soil into the organic and inorganic; soil composed of either division alone, barren; of the laws of substitution and replacement, which affect agriculture, organic matter in soil must be undergoing change ; fertility depends on chemically induced motion; of decay and putrefaction; difference of products of putrefaction in free or confined air; in free air, products are water, carbonic acid, and ammonia : in confined air, besides these, various compounds of sulphur, phosphorus, and carbon, with hydrogen; products vary according as the decaying body is on the soil, in the soil, or in the subsoil ; hydrogen always in excess; importance of this principle; decay always results in a substance termed geine ; this is a generic name including several products; at least seven well-defined substances found in geine, viz. : ulmin and ulmic acid, humin and humic, geic, crenic and apocrenic acids; division of these forms of geine into the hydrogen, oxygen, and neutral groups; of the order of the products of decomposition, of decaying matter in soil ; ultimate products are carbonic acid and water; crenic and apocrenic acid when pure contain no nitrogen; no ground for division of forms of geine into nitrogenous and non-nitrogenous; all forms may contain nitrogen as ammonia ; geine divided into soluble and insoluble ; characters of the two classcs ; how distinguished by their relation to acids; the organic acid seldom found frec in soil ; several bases may be found in combination with one acid forming soluble salts, which coutribute to the growth of plants ; detailed account of crenic and apocrenic acids; two constant sources of reproduction of these acids; of the formation of nitric acid, and nitrates and 
apocrenates in soil, by transformations of geine; crenic and apocrenic acids mutually convertible; all the transformations of geine, worthy of study ; geine is essential to agriculture, APPENDIX to Chap. 1v. p. 100 ; of the chemical history of geine and recent researches of Mulder on this subject ; reasons why geine iø essential may be deduced from Mulder's researches.

\section{CHAPTER V.}

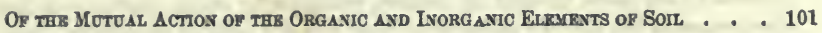

Theoretical and practical farmers both aim at the same object; the action of the elements of soil to be considered in two ways-1st, the mutual chemical action of the organic and inorganic parts-2d, the influence of growing plants on this action; of the importance of salts to this action; of the action of carbonic acid and the carbonates upon the silicates of soil ; of the modification produced upon this action by the presence of life ; of catalysis or the action of presence, by which life acts ; of the action of mineral manures in agriculture ; their earthy or alkaline part always acts one way ; their acid part produces differences of action; illustration and explanation of the action of salts or mineral manures; of the action of nitre; of lime; of ashes; of the composition of leached and unleached ashes. -

\section{CHAPTER VI.}

MANURR . . . . . . . . . . . . . . . . . 131

Manures contain all the elements which plants want-are divided into three classes; choice and determination of a standard of value for manures; nitrogen. geine, and kind of salts determine the value of manure; pure cow-dung the type of all other manures ; its composition and analysis ; yearly produce of salts and geine by one cow ; the action of manure referred to the joint effect of all its components; its action due chiefly to its ammonia ; origin of this in dung; of the composition and value of horse-dung; fermented horse-dung less valuable than cow-dung ; reasons why; mode of making good yard manure from horse stable-dung ; of yard 'manure ; importance of kind of litter ; relative value of different straws; fermentation and age; its effects on value of yard manure ; long and short, or strong and fat muck; loss of bulk by age ; statement of composition of yard manure; its amount of nitrogen and ammonia ; comparative weights of equal bulks of $\mathrm{xx}$ and horse manure; drainings of manure heaps; their composition and value; of the composition and value of human excrement; analyses of human excrement by Berzelius, and by Fleitmann; great amount of phosphates found by the last-named chemist ; night-soil, what ; its quality ; how affected by its source; of hog-manure ; sheep-manure; of the quantity of manure from 1000 sheep daily; table of composition of ashes of the excrements of pig, cow, sheep, and horse ; relative effect of these manures, and of night-8oil ; on what it chiefly depends; nitrogen expresses the true value of manure ; circum- 
stances which limit and modify this principle ; state in which nitrogen should exist in manure, to become a measure of its value; nitrogen must exist as ammonia, or in a combination which readily permits the formation of ammonia : in salts, the ease with which nitrogen is given up by different salts contrining it, affocts their value; time an element in determining value of manure; in organic Inatter, nitrogen effective in proportion to rapidity of decay; distinction to be noted in salts, between the action of the base, and a nitrogenous acid combined with it ; influence of pure salts of ammonia ; their value is almost in direct ratio to their nitrogen, modified by ease of decomposition ; proofs from Kuhlman's experiments ; 100 parts nitrogen in manure, whatever its origin, produces in like circumstances like effects ; influence of moist and dry seasons on manure ; ammonia in manure is ordinarily in the statc of carbonate; comparative effects of carbonate and sulphate of ammonia, used as manure ; Jacquemart's experiments with these salts; proof of the principle that nitrogen determines the value of manure, drawn from effect of nitrate of soda ; nitrogen enables plants to grow more in given time; general account of its effects in agriculture; of gadou or Flanders' manure, mode of preparing ; its value and effects ; poudrette, what 'it is ; preparation of ; description of the process for preparing poudrette in France, the birth-place of this manufacture; suggestions for making poudrette near all large cities and towns ; "animalized black," what ; cost and value of poudrette; of the composition and effects of guano; its actual money value to the farmer; of the value of the droppings of domestic fowls ; of the composition of fish, flesh, fowl, gristle, skin, sinews, \&c. ; they all aford mineral, vegetable and animal galts; of the composition of the great bulk of animal bodies, fibrine, albumen, caseine ; vegetables afford similar products ; these similar and identical products form proteine ; of its composition and value as a manure ; of the value of sinews, gristle, skin, hair, horns, nails, wool, and feathers; all animal and vegetable products form two classes, that which does and that which does not contain nitrogen; of the composition and value of bones as a manure ; of fats and oils ; of soot; of spent lye ; of artificial spent lye ; of liquid animal manures ; of the peeuliar principle which gives them their value; its analysis, composition and action; of the analysis of cattle urine-its value as a manure ; urine of the horse, sheep, and hog ; of human urinc-its value and composition.

\section{CHAPTER VII.}

ARTIFICIAL MUNURKs, AND IRRIGATION, . . . . . . . . . . . 206 Of the nature, analysis and composition of peat, swamp-muck and pond mud ; what is wanting to give these the value of cow-dung is alkali ; of the relative value of ammonia, potash, soda, and ashes, which may be used for this purpose; of the quantity in which these may be added to a cord of peat; of the compost of peat with animal manure ; of the various substances used for forming artificial manure with peat, and their relative value; of the use of peat recently in France ; use of dried peat and ammoniacal salts; its value compared with poudrette; of gas liquor and peat ; mode of forming gas or peat poudrette at gas works; of composts without neat or stable nanure ; of Jauffret's principles of composting . 
of the value of different straws for this purpose ; of the principles of irngation ; of the action of pure and impure water; of the composition of the deposits from freshets ; the nature, action, and value of rain and snow, in agriculture ; "snow the poor man's manure,"-how far this is true ; of paring and burning; of turning in green and dry crops.

\section{CHAPTER VIII.}

Peysical Proptrtiks or Soll, . . . . . . . . . . . . . . 242

Great differences in soil depend upon physical not upon chemical properties ; physisical properties independent of chemical constitution; opinion of Liebig on this subject ; physical characters of soil are dependent on its relation to heat, moisture, consistency, and electrical state ; in all these relations, geine acts the chief part; of the quantity of water produced by the decomposition and waste of geine; the amount evaporated per acre from this source; the quantity evaporated from woodland, exceeds the amount of rain which falls; of the waste of geine caused by this evaporation of water ; of the proportion of carbon which is derived from the soil, and from the air by forest trees.

\section{CHAPTER IX.}

BoNEs, SCPERPHOBPHATE OF LIME, AND ITS PREPARATION, . . . . . . . . . 251

Of the composition of bones; consist of an animal and of a mineral part ; bones act as forcing vegetation or as developing and forming seed ; the first depends on the fermentation of the animal part of boae, producing ammonia; the second action depends on the mineral part of bone; bones seed formers, or root, leaf, and stem formers; bones to be studied as eutire, or partially, or wholly deprived of their gelatinuns parts; composition of entire bone; no practical use to be made of bone by the farmer, till the bone is reduced to powder; of the composition of bone partially deprived of its animal parts : how this is to be effected ; of boiling and steaming bones; how such bones are best used; of bone ash, or bone deprived of all its animal matter; of sugar-house refuse, and animal black ; of the treatment of hones and bone ash by acids, as oil of vitriol, to produce superphosphate of lime ; no solution of bone in this case, is rather a pap-forming process; explanation and illustration of the process; account of the properties of phosphoric acid; final result of the action of oil of vitriol on bones, in the right proportion, is the formation of plaster, and superphosphatc of lime with free oil of vitriol; of the quantity of oil of vitriol required by raw bones; by bones partly cooked; by bone ash ; of the composition of superphosphate of lime; of its solubility in water; of the process to be followed to prepare supcrphosphate of lime, and of the cost of that product; it should contain all the phosphoric acid of bone in a soluble state; great importance of this point; how best effected; phosphoric acid must not be frce ; soluble alkaline phosphates most desirable for 
the farmer ; recipes for forming such salts ; how these are to be used ; of their effects, and of their general application; of the effects of nitrogenous compounds mixed with alkaline phosphates; of the mixture of nitrates with alkaline phosphates ; and their cost ; recommendation of trial of mixture of superphosphates and of fowl droppings.

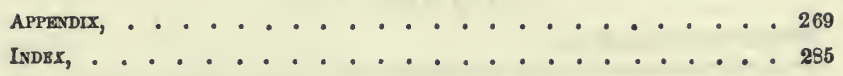




\section{U C K II A N U A L.}




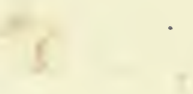

$$
\text { • }
$$$$
+2+1
$$$$
x^{2}-1
$$
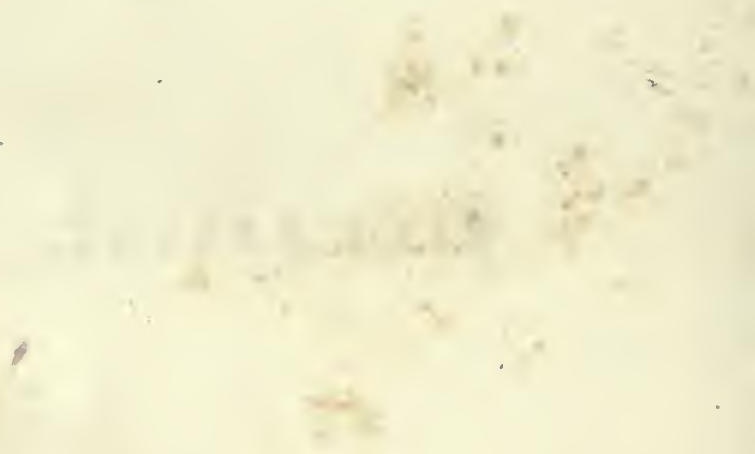

$+$

(1) 


\title{
MUCK MANUAL.
}

\author{
CHAPTER I. \\ GEOLOGY OF BOIL.
}

1. Agricultural chemistry aims to explain all the actions of earth, air, and water, upon plants. It refers to all their chemical relations, to the geology, mineralogy and chem. istry of soil.

2. Agricultural geology explains the relations which soil bears to plants, and the manner in which that affects vegetation.

3. Agricultural geology confines itself to facts. It digs into the earth, observes what composes that. Conversant only with facts, or logical deductions from these, it leaves to geology proper, the vast mass of observations, supported by the highest modern science, which teaches the origin, mode of formation, original condition of our globe, and the successive changes which it has undergone.

4. The terms, primary and secondary, used by geologists, are almost parts of common language,-yet need to be explained to the farmer.

5. Large tracts of all extensive countries are composed of rocks of a granitic texture. This needs no definition. Such rocks having been observed to underlay all others, in the scale of rocks composing the earth's crust, were called primary. It was supposed that these were first formed. Out of the ruins of these, no matter when or how ruined, 
other rocks have been made, called secondary. The ruins of the primary rocks have been transported by water, and then gradually deposited layer upon layer. Under immense pressure, these layers of mud, sand, fine gravel, rolled stones, \&c., have been hardened into solid rock, and have formed sandstones, slates, or even rocks presenting the crystalline structure or texture of granite, by the action of heat, which the facts of modern geology teach exists in the interior of our globe.

6. This internal heat is supposed to be the cause of volcanoes, and the primary rocks to have been the ejections under circumstances unknown, of the melted mass of the globe; ejections similar in kind to those of modern lava, but greater in degree.

7. Intermediate between modern lava and primitive rocks, and actually passing into either, is a large class of ancient volcanic rocks, called trappean; such are basalt, trap, greenstone and highly crystalline porphyry.

8. However named and classed are the rocks of the earth's surface, they have had one common origin, the molten matter of the globe. Hence, having a common origin, their ultimate chemical constituents are similar. If granitic rocks have a certain chemical constitution, then sandstone, slate, \&c., having been formed from worn-out and worn-down granitic rocks, have a constitution chemically like them.

9. To the agriculturist, the terms primary and secondary are unnecessary. Equally so are all distinctions of soil based on these terms.

10. Soil is the loose material covering rocks, and it is supposed to have been formed from their decay. Both are to be classed by their origin. The origin of rocks refers not only to the mode of their first formation, but to their subsequent arrangement. The origin of all rocks, geology 
teaches, is from the molten matter of the globe. These have been afterwards, in some cases, removed by water, and in part remodified by heat (5). Referring rocks to their origin, they are divisible into two great classes.

1st. Those formed by fire.

2d. Those formed by water.

11. This division relates both to the origin and distribution. In their origin all rocks are truly igneous, or from fire. In their distribution they are aqueous, or by water. This is the only division necessary to the farmer. It is the division taught and demanded by agricultural geology.

12. The first class includes all the highly crystalline rocks, granite, gneiss, sienite, greenstone, porphyry; it includes, also, basalt and lava. The products of volcanoes, whether ancient or modern, agricultural geology places in the same class, including thus all that portion which forms the largest part of the earth's surface.

13. The second class includes sand, clay, gravel, rounded and rolled stones of all sizes, pudding-stone, conglomerates, sandstones, slates. When these various substances are examined, a large part of sand is found to be composed essentially of the ingredients of the igneous rocks. This is true, also, of sandstone, slate, of conglomerates, of bowlders.

14. There is a large deposit, or formation, in some districts, composed almost wholly of some of the chemical constituents of the igneous rocks, united to air. The constituents are lime and magnesia; the air is carbonic acid, forming, by their union, carbonates of lime and magnesia. Marble, limestone, chalk, belong to this formation. These are not to be ranked as original igneous products subsequently distributed by water. The lime, originally a part of igneous rocks, has been separated and combined with air, by animals or plants, by a living process called secretion. The 
modern production of carbonate of lime is still going on, under the forms of shells and corals. Though belonging to neither division, the subject will be simplified by referring limestone to the second class of rocks; but it is truly a salt, and it will be discussed hereafter.

15. The chemical constitution of all rocks is similar. If rocks are divided into two classes, the first composed of those usually called primary, such as granite, gneiss, micaslate, porphyry; and the second class, composed of rocks usually called trappean, as basalt, green-stone, trap, then the great difference in their chemical constitution is this :

The first or granitic class, contains about 20 per cènt. more of silex, and from 3 to 7 per cent. less of lime and magnesia and iron, than the second or trappean class.

16. If the language of geology is borrowed, and rocks which present the appearance of layers, or a "stratified structure," are divided into two classes, fossiliferous and nonfossiliferous, or those which do, and those which do not contain remains of animals or plants, it will be found, that the fossiliferous are neither granitic nor trappean, yet are they to be classed with the last, agreeing with these, in containing less silica, and more lime, magnesia, and alumina.

17. The stratified, non-fossiliferous rocks agree in chemical composition with the granitic, and the fossiliferous with the trappean and volcanic.

18. The trappean and fossiliferous contain the most lime and magnesia; the granitic and non-fossiliferous, the most. silex. The great difference in chemical composition between the two classes, is produced by lime and magnesia, two substances which, more than all others, have been thought to influence the character of soil.

19. The amount of this difference is about from 3 to 7 per cent.; yet notwithstanding this, the general chemical 
constitution of all rocks approaches so nearly to similarity, that this may be laid down as the first principle in agricultural chemistry, that there is ONE ROCK, CONSEQUENTLY ONE SOIL.

20. To the farmer all soil is primary. The question then arises, How do rocks and soil affect vegetation? As a collsequence of the first proposition, it may be laid down as the second principle of agricultural chemistry, Rocks Dо Nот AFFECT THE VEGETATION WHICH COVERS THEM.

21. This is opposed to the geological doctrine of the times, and may seem to be opposed to the statement in section 18. The difference there stated may be thought to produce corresponding effects in vegetation. This would be true if rocks exerted any influence on soils, due to their chemical constitution. A survey of the geographical distribution of plants, used for food, will show that the common doctrine of the chemical influence of rocks on vegetation is not so well supported as to be considered an established principle. It is not intended to deny that rocks do, by their physical condition, affect vegetation. Unless it is shown that their physical state depends upon their chemical constitution, the second principle must be admitted as a general truth.

It has been distinctly avowed by Johnston in his "Lectures," since the appearance of the first edition of these pages, "that where the soil forms only a surface layer of considerable depth of transported materials, it may have no relation whatever, either in mineralogical characters or in chemical constitution, to the immediately subjacent rocks."

This is the general disposition of soil. It is admitted by the author above quoted, that, in Great Britain, in some counties, and in nearly all the coal-fields, "the general character and capabilities of the soil have no relation whatever to the rocks on which the loose materials immediately rest." 
A distinguished authority in our country, Prof. Norton, of Yale, formerly the pupil and assistant of Prof. Johnston, speaking of very fertile soils, says that these always contain "appreciable quantities of some ten or twelve substances. It makes no difference from whence you bring such a soil, from what part of the world it comes, it will invariably contain these elements in greater or less quantity." (Agr. Address, Northampton, 1849.) Fertile soils are not confined to particular rock formations; they are found overlying all formations,-they are so independent of the rock beneath, that they invariably contain similar elements. Though it may seem premature to place before all who may read this work the results of analysis, before they have become familiar with chemical names; yet those here used are so common, that the proof adduced may not be misunderstood.

The analysis of the ashes of plants grown on different geological formations, in soil which is stated to have proceeded from the decomposition of the underlying rock, proves how little dependent is the plant on the chemical constitution of the soil. The ashes of the grape-vine, grown on four different soils, afforded,

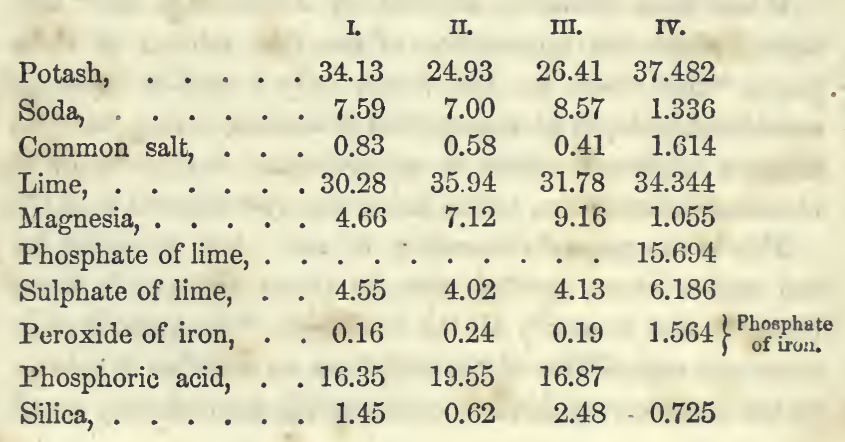


In No. 4, all the phosphoric acid is ineluded in the phosphate of lime, and iron. This analysis is by Crasso, the others by Hruschauer.

No. 1 was grown on soil formed from the debris of quartzose rocks, by the decomposition of gneiss, mica-schist, clay-slate, chlorite, hornblende, quartz, and a little lime.

No. 2 , from soil formed of decomposed limestone, variety called transition.

No. 3 , from soil formed of decomposed mica-slate.
No. 4, "
" "
"6
porphyry.

It is evident, that where the soil has not proceeded from geological drift, as in No. 1, widely different geological formations afford all the mineral elements of plants.

22. The plants used for food are cultivated on every variety of rock foundation which the earth presents. Their cultivation is limited neither by granitic nor trappean, by fossiliferous or non-fossiliferous rocks. Their product varies not more on different than ou the same geological formation. Everywhere, over every variety of rock, the cultivation of the food-bearing plants repays the labor of the farmer.

23. Surveying Massachusetts, it is evident the grain crops are not influenced by the peculiar rock formations over which they are gruwn; for in this State, with the exception of modern volcanic rocks, all the various formations which the earth presents are found. Yet no difference in the quality and quantity of crops of rye, oats, barley, wheat, Indian corn, is found, which can be attributed to different geological tracts.

24. All plants have a natural limit, a peculiar region, in which, unaided by the human race, they flourish and spread spontaneously. The smaller the limit of this natural boundary, the more difficult is the cultivation of the plant, yet we find that the natural boundary is passed, and so plants come 
to live in an artificial region. There is a natural, and there is an artificial "habitat" or region; and this last is either horticultural, or agricultural. The first is unlimited, the second is limited by the great external circumstances of temperature and moisture.

25. The extreme north and south limits, which bound the cultivation of the food-bearing plants, are determined wholly by physical, physiological, and social causes. Temperature is the great agent which limits the agricultural "habitat" of the grain-bearing plants.

26. The distribution of plants is governed by the two following laws:

1st. The polar agricultural limits are bounded by lines passing through places of equal summer heat.

$2 d$. The equatorial limits, by lines of equal winter heat.

These lines are called respectively, isotheral, and isochimenal. They by no means coincide. They often cut each other at right angles, and generally, from about the 45th degree north latitude, they are parallel neither to one another, nor to the latitude. They are often highly curved.

And now for the proof of these general laws. Beginning with barley, the grain which has been cultivated the farthest north, its fields are found in the extremity of Scotland, in the Orkneys and Shetland Isles, 61 degrees N.; in the Faroe Islands, between 61 and $62 \frac{1}{2}$ degrees N. ; in Western Lapland, near North Cape, in latitude of 70 degrees; on the borders of the White Sea, in Western Russia, between 67 and 68 degrees, and near to Archangel, in Eastern Russia, about 66 degrees ; in Central Siberia, the limit of barley is between 58 and 59 degree $\mathrm{N}$. There are no extended observations of the temperature of the northern portions of our own continent, and therefore the limit of barley in Northern America is left urdefined. But its European line 
will probably define that which will limit grain cultivation in America.

Tracing a line through the points above named, it is the northern boundary of all the cereals, or graius. A little beyond this line is the boundary of the potato, and the belt between the two is remarkable. It is the zone between agriculture, and fishing, and hunting; between races of men, subsisting on animal and on vegetable diet, and those whose chief food is animal. The northern cultivation of barley is bounded, if its course be traced, by a very curved line. Is this determined by geological causes, or do causes purely physical erect a barrier to its further ncrthward advance? The answer will be found in tracing the temperature of the seasons of the different places, through which the limit of the northern cultivation of barley passes. It will be evident that the line of this limit is isotheral, for the mean temperature, Fahrenheit, is as follows:

Faroe Isles,

W. Lapland,

Russia, at the mouth of the White Sea, $66^{\circ}-684+32^{\circ}\left|+10^{\circ} 2-8^{\circ} 8\right|+46^{\circ} 3$

Casting the eye on this table, it is evident that the annual and the winter temperature have little influence on the barley limit, and that a mean summer temperature from $46^{\circ}$ to $47^{\circ}$ is the only indispensable physical condition to the cultivation of barley. On the Atlantic islands, a mean temperature from 3 to 4 degrees higher is necessary, which compensates for excessive humidity. It is remarkable, that all the cereals have failed in Iceland, though its mean temperature is above that necessary for barley. Nor is this owing to its geological structure. In that it agrees with the fertile shores of the Mediterranean. It is volcanic. So far as nitrogen, car- 
bonic acid, and ammonia, may be supposed to be evolved from the earth, and to contribute to the growth of grain, Iceland should equal fertile Italy. But such is not the fact, and it goes to prove that rocks affect very little the crops grown orer them, even when the great physical element, temperature, is as high as is necessary. That grains fail in Iceland, is due to the excessively tempestuous rains with which that country is visited. If then the limit of barley is defined by an isotheral line of $46 \frac{1}{2}$ degrees in Europe, that will also limit its cultivation in America. So far as observation has extended, this is true, and the line of boundary is equally curved, and winding. If a similar table for the limit of wheat is constructed, by drawing a line through the most northern places, where this grain has been cultivated, the physical conditions essential to its cultivation will be found as follows :

\begin{tabular}{ll|l|l|l} 
& \multicolumn{4}{c}{ Mean Temperature, Fahrenheit, of the } \\
& \multicolumn{1}{c}{ Latitude. } & Year. & Summer. & Winter. \\
Scatland, (Inverness) & $58^{\circ}$ & $+46 \circ 3$ & $+57^{\circ} 3$ & $+36^{\circ} 5$ \\
Norway, (Drontheim) & $64^{\circ}$ & $+39 \circ 5$ & $+59^{\circ}$ & $+23^{\circ} 5$ \\
Sweden, . . . & $62^{\circ}$ & $+39^{\circ}$ & $+59^{\circ}$ & $+23 \circ 5$ \\
St. Petersburgh, : & $-60^{\circ} 25$ & $+38^{\circ}$ & $+60^{\circ} 8$ & $+15^{\circ} 6$
\end{tabular}

North latitude 64 degrees appears, then, to be the utmost limit of wheat. It is evident by inspection, that this is not determined by the cold of winter; for spring wheat would not be affected by it; and even if sown in autumr, in these far northern regions, the seeds would be effectually preserved from the rigors of winter, by that thick mantle of snow which becomes thicker and more lasting towards the north. The temperature of the air exerts no influence on seeds of plants buried under snow. Nor does the mean temperature of the year exert any effect; it is seen ranging 9 degrees, while the summer temperature varies only $3 \frac{1}{2}$ degrees. The summer temperature alone defines the limit 
of northern wheat cultivation, and this is an isotheral line of 57.4 degrees. Yet it is found that there are places where, as in Russia, the mean of spring and autumn, both depending on that of winter in part, are too low to allow wheat to be raised under this line of $\mathbf{5 7 . 4}$ degrees. In truth, the relation of climate to cultivation earnot be accurately determined without observations on the mean temperature of the days which elapse between sowing and harvest, and to this point the philosophic farmer should direct his attention. In our country, the isotheral line of 57.4 degrees, starting from Labrador, 51 degrees, and passing between Hudson's Bay and Lakes Superior and Huron, 50 degrees, then turns north and approaches 58 degrees. At Cumberland House, 54 degrees north, Capt. Franklin found fields of barley, wheat, Indian corn. When the line approaches the Pacific Ocean, it turns more southerly to compensate the increasing humidity. As the limits of barley mark the boundary, between the races of shepherds and hunters and fishers, and thus presents itself in a moral view, so the limit of wheat becomes interesting, from coinciding in some parts with that of fruit trees, as apples and pears, and also with that of the oak. The whole aspect, not only of agriculture, but also of the orchard and forest, changes at once on approaching the isotheral line of 57.4 degrees, the northern limit of wheat. It would be easy to extend these remarks to rye, still the staple food of a large part of the population of Europe, and to oats, little used for food for man out of the "land o' cakes," yet growing in Norway, as high as latitude 65 degrees. Each of these grains has a distinct isotheral line parallel to that of wheat and barley. Indian corn and the potato have each its isotheral line. Turning to the equatorial limits of the grains it will be found, that extreme heat arrests their cultivation. 
Observations in these regions, and experiments performed by profound vegetable physiologists, confirm this statement. They have proved that the seeds of the food-bearing plants, even after germination has begun, can support greater degrees of drought and heat, than ever occur in the hottest climates. The grains all germinate in the soil of a temperature from 104 to 105 degrees, and require at least from 116 to 120 degrees to arrest this process. Barley ceases to germinate at the lowest temperature. After barley, follows wheat, then rye. Indian corn endures the highest heat, viz., 120 degrees, before its germination is arrested. The grains flourish under a mean annual temperature of from 77 to $80 \frac{1}{2}$ degrees. Defining their equatorial limits, they are bounded not by lines of equal summer, but equal winter temperature; the reverse of their polar limits. Hence, climate always determines the sowing season: In Bengal, wheat, barley, oats, are sown in October, and harvested in March and April, while rice and maize are sown in May, to be harvested in October. It is this line of equal winter temperature, or rather that of the coolest months, which allows the grains to be cultivated in many places within the torrid zone, and the line of 68 to 70 degrees Fah., which constitutes the tropical limit of wheat culture, varies between 20 and 23 degrees of latitude. The other grains enduring from 5 to 7 degrees lower temperature, are found in higher latitudes.

27. The wide belt of our globe, comprised within these limits, extending from 20 to 70 degrees north latitude, presents every variety of geological structure; yet nowhere, in all this space, is the quantity or quality of crops affected by the chemical nature of the underlying rocks.

28. A similar principle governs the growth and cultivation of the grain-bearing plants on mountains. Their limits are found at heights which correspond to the latitude which 
marks the isotheral line. In the Swiss Alps, the grains cease growing at the following heights :

Wheut at 3400 feet, corresponding to lat. 64 degrees.

$\begin{array}{lllllll}\text { Oats " } 3500 & \text { " } & \text { " } & \text { " } & 65 & \text { " } \\ \text { Rye " } 4600 & \text { " } & \text { " } & 67 & 67 & \text { " } \\ \text { Barley " } 4800 & \text { " } & \text { " } & \text { " } & 70 & \end{array}$

This shows a beautiful correspondence between latitude and altitude, and leads a step farther in the proof of this principle, that rocks do not affect the vegetation which covers them.

29. The space which has thus been surveyed, presents, amid great variety of rocks, a singular similarity in chemical composition of the soil. These facts lead to the third principle of agricultural chemistry, ROCKS HAVE NOT FORMED THE SOIL WHICH IMMEDIATELY COVERS THEM.

30. Everywhere, with the exception of the tops of some mountains, the rocks of the globe are covered, from a few inches, to some hundred feet in depth, with gravel, sand, clay, rolled stones, sometimes alternately with each other, sometimes in confused heaps. The best attested and most universally admitted fact of geology, is, that the loose materials of our globe have been transported, from a few, to many hundred miles from their original situation. With a few exccptions, the soil, which now covers rocks, has been derived from places distant, and from rocks distinct, fiom those on which it now reposes. This is peculiarly true of soil on limestone districts, which does not contain more lime than the soil reposing on granite.

31. Transportation of soil is a fact so well established, that it needs only to be mentioned. There has been a universal ningling of the loose material, soil, derived from worn-down and mingled rocks.

32. The same uniformity of chemical composition charac- 
terizes soil, which characterized rocks ; that is, great similarity, but not identity, and it is on limited patches only, that soil partakes decidedly of the character of the underlying rocks.

33. The extensive analyses of soil, executed by the geological surveyor of Massachusetts, taken from every variety of rock formation, present a remarkable uniformity, both of chemical constitution, and mineralogical composition of the earthy ingredients. In one hundred and forty-six soils of Massachusetts, the combinations of lime, clay, iron, \&e., estimated as in the state of bone-dust, are per 100 parts, . . . . . . . . . . . . . . 0.859 Similar matters in the state of plaster are per 100

parts, . . . . . . . . . . . . 1.823 The surveyor suggests the subtraction of $\frac{1}{3}$ from the amount representing matters allied to bone-dust, to reduce that to pure bone-earth. A less amount should be allowed in the matters allied to plaster. If 31 per cent. be deducted from the sum of the plaster and bone-dust, the result is 1.851 .

Lime, in the state of marble or limestone, was found in fourteen of one hundred and forty-six soils. Except in limestone regions, the natural existence of lime in the state of marble or chalk in soil is very questionable. Adding its average amount as found in the soil of Massachusetts, viz., 0.916 , the result is, - lime in various forms, -2.047 , fine earthy matter insoluble in weak acids, 89.305. What is true of the soil of Massachutetts is true of all soil-great similarity of its mineral constituents, both in kind and proportion. This is the truth, deducible from the average results of analyses of soil from various parts of the world. But it may be said that the above numbers have been deduced from the results of the examination of a very lim- 
ited portion of our country; that the analyses have been conducted by a new process; that the soil examined rests chiefly on granitic rocks, and has been thence derived. Had the field been wider, or the process different, the results would have been different.

All analysts, from the earliest times, have found a very large per centage of soil insoluble in acid or alkali. The object of chemists has been, by the aid of water and weak acids, by the gentlest means to separate the elements of soil. Others have used fiercer means, and have attacked the insoluble portion of soil, by means common to the analysis of intractable stones, by fusion with alkali, followed by treatment with acid. By either mode the mineral part of soil is separated into two general divisions, into soluble and insoluble portions.

This is to be observed of all soil analyses, by whomsoever or howsoever made, that while all are imperfect approximations only, to truth, yet the insoluble ingredients are the substances which from their chemical constitution are least affected by the various modifications to which soil analyses have been subjected. Whatever modes may have been used, in all, the insoluble substances make up the great bulk of soil presented in the per centage result, as, "silica, silicious residuum, sand and clay, insoluble mineral matter, fine earthy matter, sandy residuum."

In the analytical results, alumina, or clay, oxide of iron, or iron rust, and magnesia, are frequently stated in separate amounts. These substances have been educed by analysis from their combinations, yet are they for the most part a portion of the insoluble compounds variously designated above, and should be included in that class. The "aluminous residuum," or clay, is certainly an earthy compound only. 
Lime generally exists in the state of plaster, or bone-dust, or sometimes as limestone. In truly calcareous or limy soil, lime may form several per cents. But such soils are the exception, not the rule, of the earth's covering. It is soil, in its universal features, to which attention is here directed. Lime has been very often, perhaps generally, separated from its earthy combinations, and has been separately stated as carbonate of lime in soil; as such it has been too often a product, not an educt of analysis.

So, too, of potash and soda, when these exist in other forms than as common salts, they are usually in soil in combination with its vegetable matter, and are to be considered with that element.

- These considerations authorize the inclusion of clay, iron and magnesia in the insoluble division of soil, while the bone-dust and plaster naturally existing and soluble by the aid of natural water, or more easily by rain water, are to be included in the soluble portion.

Bearing this division in mind, let the examination of soil be extended to other districts of our country, where the soil resting on an immense field of limestone, underlaid by the rocks which were referred to (16) as fossiliferous, has been examined by the process applied to Massachusetts suils-yet with such modification as to procure a portion of clay, iron and magnesia separately from the insoluble substances.

Fifteen soils, from Wisconsin and Iowa, gave per 100 parts-

Insoluble in weak acid, • • • . 82.500

Clay, iron, magnesia, • $\quad$ • $\quad$ - $\quad 5.600$

Adding these, the sum is . . . . 88.100

Lime in varions forms of limestone and plaster, $\quad 1.860$

The soil of these immense regions shows not so intimate 
a relation to the underlying rock as do the soils of New England. These western soils are convincing proof of the third principle (29).

But the same proof of the independence of soil and of its uniform composition, is afforded by the results of the examination of the continental European soils. Forty-eight soils, from Germany, Holland, Belgium, Hungary, Bohemia, by a process very different from either of those which had been used in the analyses above stated, by an acute and intricate mode of operation affurded

Insoluble,

Soluble clay, iron, magnesia

87.053

5.853

92.906

Lime in various forms, - as plaster, bone-dust, limestone, . . . . . . . . 1.860

Taking these several results, we have

\begin{tabular}{|c|c|c|c|c|}
\hline Soils. & & Insoluble. & & Forms of lim \\
\hline 146 Massachus & etts, & 89.305 & . & . $\quad 2.047$ \\
\hline 15 Wisconsin & and Iowa, & 88.100 & . & 1.860 \\
\hline 48 European, & . $\quad$. & - 92.906 & - & 1.860 \\
\hline & , & 3) 270.311 & & 3)5.767 \\
\hline Mean, & - & 90.103 & 3 & 1.922 \\
\hline
\end{tabular}

Excluding that form of lime whose existence as limestone naturally in Massachusetts soil is very questionable, the lime in her soil would be represented by 1.851. The average of the forms of lime.would then be in the above 209 soils, 1.857, which is only 0.006 more than that of Massachusetts, while the insoluble portion of her soil is actually very near the mean of the whole.

But if the comparison is to be made with other soils, the 2* 
limestone is to be retained. Other soils have this element included in the result of their analyses; and it is with the like exceptions, as liable to be there misplaced as in the soils of Massachusetts. Retaining, therefore, all the lime, a still wider examination will show the great uniformity in chemical composition of all soil.

The results may be tabulated as follows, dividing, as has been explained, all soil into insoluble, soluble, and forms of 'lime. The soluble includes clay, iron, magnesia, the forms of lime, plaster, bone-dust and limestone. 


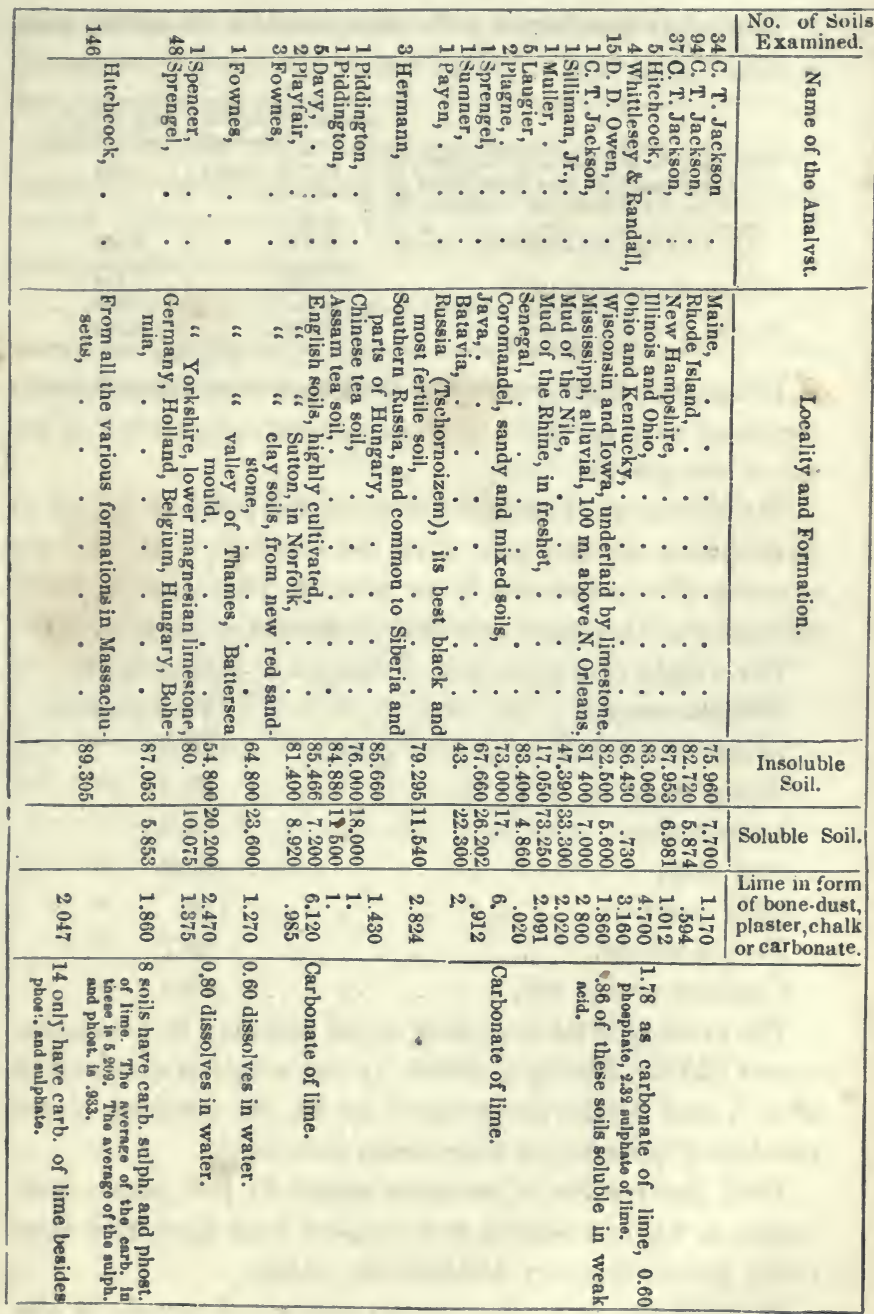


The whole number of soils comprised in the above table is 413 .

\begin{tabular}{|c|c|c|c|}
\hline & Insoluble. & Soluble. & Salts of lime. \\
\hline $\begin{array}{l}\text { Deducting the } 146 \text { soils of Massachusetts, } \\
\text { the remaining } 267 \text { give an a verage of }\end{array}$ & 71.733 & 15.604 & 2.075 \\
\hline $\begin{array}{l}\text { By adding the soluble and insoluble, the } \\
\text { result is, } \\
\text { while } 146 \text { Massachusetts soils contain }\end{array}$ & $\begin{array}{l}8733^{7} \\
89.30^{5}\end{array}$ & the & 2.047 \\
\hline The sum of the whole 413 , & 176.642 & & 4.122 \\
\hline And the average is & 88.321 & & 2.061 \\
\hline
\end{tabular}

This examination proves that the 146 soils of Massachusetts represent very fairly the average mineral composition of the soil of the globe.

The results of chemical analysis stated per cent. to two or three places of decimals, give the farmer no idea of the quantity of any element in an acre, at the usual depth of cultivation. A simple rule will make this amount evident.

The weight of a cubic foot of dried soil is as follows:

Silicious sand, . $\quad$. $\quad$. 111.3 pounds.

Calcareous sand, . . . . 113.6 "

Sandy clay, • • • • • 97.8 "

Loamy clay, - • . - 88.5 "

Stiff clay, - • • • 80.3 " 8

Slaty marl, • . . . . 112. "

Fertile mould, . • . . 68.7 "

Common arable soil, . . . . 84.5 "

The average is 94.58 , which in the ordinary wet state becomes 126.6. Multiply 43560 by the weight of a cubic foot of soil, and divide the product by 12 , the quotient is the number of pounds per acre at one inch deep.

Read the results of analyses stated in 100 parts, decimally, as whole numbers, and consider each ingredient as so many pounds in every $100,000 \mathrm{lbs}$. of soil.

Multiply any ingredient by the number of pounds in one 
inch deep, and cut off the five right-hand figures; the remainder is the number of pounds of that ingredient per acre, at one inch deep.

Let it be required to know how many pounds of salts of lime are contained in eight inches deep of a soil which weighs 126.6 pounds per cubic foot, and contains 2.047 of salts of lime in 100 parts.

$43560 \times 126.6=5514696$ pounds per acre one foot deep. $5514696 \div 12=459538$ pounds " " one inch deep. $459558 \times 2.047=940776636$.

Cutting off five figures, leaves 9407 pounds at one inch deep.

$$
\frac{8}{75250} \text { " at eight inches deep. }
$$

It is to be remembered that this immense quantity is that contained only in the finer portions of the soil; there yet remain about eighty parts in every hundred of soil as undecomposed silicates, ready to yield their lime to the wants of agriculture.

Tried by the above rule, the smallest quantities which the chemist obtains in his analysis become tons per acre, and that which is too small to be weighed by any balance, the "trace" only of an element rises to an amount which astonishes by its magnitude. 


\section{CHAPTER II.}

CHEMICAL CONSTITUTION OF ROCKS, AND SOIL.

34. Tur geologist, the mineralogist, the chemist, each views rocks with a different eye. The geologist regards the rocky mass; the mineralngist, the simple minerals cornposing the rock; the chemist, the simple elements which compose the minerals.

35. Elements are substances which have not as yet been proved to be compound, as oxygen and hydrogen among the gases, or iron or lead among metals. Minerals are called simple which have certain definite, external, physical characters, though they may be composed of several elements. Rocks are called compound, which consist of several simple minerals, as granite, which consists of quartz, felspar, and mica.

36. The only point of view which the farmer takes, is that of the chemist; his pole-star is "fruit and progress;" and his philosophy, guided by this, teaches the nature and mode of action of the several elements of minerals. 'Without a knowledge of the chemical constitution of minerals, the science which classifies and labels these is useless. The mineralogist merely names his mineral, labels it, and places it in his cabinet; yet a farmer must know a few of these names, and talk to the mineralogist in terms which he can understand. He must give to the assemblage of elements which composes a mineral, that name which the mineralo- 
gist bestows on the assemblage of external characters, which determines the species.

37. The mineralogy of agriculture is no more than this, that the farmer be able ever to connect with a certain name a certain chemical composition. Hearing mica (which is isinglass) named, he immediately connects with that, the chemical properties which belong to the species, as he would connect with the term isinglass, the physical properties of that substance; such as transparency, divisibility into thin plates, which are flexible and elastic.

38. The amount of this mineralogical knowledge is very limited. Seven simple minerals compose all rocks, viz.: quartz, mica, felspar, hornblende, talc, serpentine, carbonate of lime. Other ininerals are found in rocks, but these seven compose all those termed geological formations, and which form the crust of the globe.

39. The chemical constitution of rocks, the nature, properties and relations of their elements, prove to be of the highest value, when it is known that the elements of these seven minerals are also the earthy part or ashes of all plants. The farmer should therefore be so far a chemist as to understand the results to which the analysis of minerals conducts.

40. The number of elements which chemistry has detected is sixty-two; probably sixty-three. All are either metallic or unmetallic. Of these some are gaseous, others earthy, others combustible. The last are also called metalloids, by which term they are designated in these pages.

Of the simple or elementary bodies, thirteen chiefly compose all rocks, and the mineral portion of soil. Six of this number are unmetallic and seven are metallic substances. 
The unmetallic are:

1. Oxygen,

2. Hydrogen.

3. Silicon.

4. Carbon.

5. Sulphur.

6. Phosphorus.
The metallic are:

1. Potassium.

2. Sodium.

3. Calcium.

4. Magnesium.

5. Aluminium.

6. Ferrum.

7. Manganesium.

Restricting the term metalloids to the $3 \mathrm{~d}, 4 \mathrm{th}, 5$ th and 6 th unmetallic substances in the above list, the other two stand out distinctly, separated by their want of properties common to the remainder. They stand each alone, being wholly unlike each other. These are oxygen and hydrogen, known in their uncombined or free state only as gases, whose union produces water. It is as a part of water that hydrogen enters into the composition of rocks. It is comparatively of little importance.

Not so with oxygen. No other known substance has such a wide range of affinities. Its combinations produce a change of properties in the several elements above enumerated, whose names end in $u m$, by which these are converted into substances whose common name reveals their wellknown characters.

41. With the metalloids, oxygen forms acids, and with the metals, oxides or earths, rarely acids.

\section{OXYGEN,}

with silicon forms silicic acid/with potassium forms potash.

" carbon " carbonic " " sodium " soda.

" sulphur " sulphuric " " calcium " lime.

" phosphorus " phosphoric" " magnesium " magnesia.

" aluminium " alumina, or clay

earth.

"ferrum " iron oxyde or rust.

" inanganesium" manganese oxide.

42. The oxides or earths are termed bases. Potash, soda, lime, magnesia, are termed alkaline bases; the others, metallic bases. Acids and bases unite and form salts in 
rocks or soils. Metalloids also unite with metals and form a class of compounds of great importance in agriculture. These may be termed metalloid compounds when speaking of such agriculturally.

43. It is seen, therefore, that the elements composing rocks are reduced to salts and metalloid compounds.

But the peculiar character of the salts formed by silicic acid, will be easier understood by separating these from the others, and studying them under the name of silicates. These form the great bulk of the earth's crust. The distirguishing character of the silicic acid salts is either a crystalline appearance, with the transparency and lustre of glass, united to the hardness of flint, or opacity, with the stony and earthy look and common characters of mineral substances composing rocks. The compounds of silicic acid would be hardly recognized as salts in the common and popular sense of that term, with which is associated the ideas of softness and solubility. In the opinion of some chemists of the highest authority, silicon, or silicium as they term it, is a metal. Its combination with oxygen produces an acid. IIence, perhaps, its salts derive their peculiarity. Silicic, acid is a metallic acid, which forms with bases, silicates; these are generally insoluble in water, or soluble by the aid of an excess of alkali. Carbonic, sulphuric, and phosphoric acids are metalloid acids, which form with bases, salts, in the usual sense of the term. Nor is silicium, if a metal, the only one of the class which acts as an acid, combined with oxygen. Alumina acts so occasionally, so does manganese, so does iron.

44. The elements of water being included in silicates and salts, all the substances which compose rocks may be divided into three sections; a. silicates, b. salts, c. metalloid compounds. 
45. The elements which compose silicates may be enumerated in pairs, as a help to the memory -

The alkalies-potash and soda.

" alkaline earths-lime and magnesia.

" metallic acids or earths-silex and alumina.

2 alkalies, 2 alkaline earths, 2 metallic acids. The last have all the characters of earths, and silica, whose acid properties were first noticed by Smithson, was and is still called the earth of flints, while alumina is known as the earth of clay.

46. The terms, salt, silicate, and metalloid compound may need a further explanation. Pearlashes and vinegar, are well-known substances. One is an alkali, the other an acid. Pearlash has the alkaline properties of a bitter, burning taste, the power of changing vegetable blues to green, and pinks to blues. Vinegar has the acid property of sour taste, of causing a hissing or effervescence, when poured on pearlash. This action ceasing, there are neither acid taste nor alkaline properties. The characters of the vinegar and pearlash have disappeared. These substances have united; they have formed a new substance called a salt. Their properties are neutralized, and lost in the salt. This is no longer either pearlash or vinegar.

47. The fact to be observed in the action (46) is, that an acid and alkali mutually neutralize each other. The vinegar is said, in this case, in common language, to "kill" the pearlash. So soda, potash, lime, magnesia, iron, and manganese would all be killed or neutralized by vinegar; they would all be dissolved by it, and lose their distinguishing characters. In either case, a neutral salt would be formed. Such a class of salts is termed acetates, being formed of alkalies, alkaline earths, or metallic oxides united with acetic acid. 
48. Silex or silica, or the earth of flints, as it has been called, is in its pure state a perfectly white, insipid, tasteless powder. In various combinations of minerals, it unites with the bases (41), forming neutral salts, termed silicates, from the silicic acid. Thus is formed, as in the case of vinegar, or acetic acid (47), a large class in which are found silicates of soda, of potash, of lime, of magnesia, of alumina, of iron, and of manganese. This class forms the great bulk of all rocks and soil.

49. The seven substances last mentioned (42) are all metals united to oxygen. They are metallic oxides. If the oxygen is removed, and replaced by carbon, sulphur, phosphorus or silicon, combinations are formed, called sulphurets, carburets, phosphurets, siliciurets.

50. Metalloid compounds are combinations of metalloids with metals, in their pure, or unoxidated state.

51. Salts are combinations of metalloids with oxygen, and the metals in their rusted or oxidated state.

52. The formation of carbonic, sulphuric, phosphoric acids, has been explained (41). When these acids unite to the bases, salts are formed, called carbonates, sulphates, phosphates.

53. Hence, when a substance is named, for example, sulphate of lime, a definite idea of the nature of this is conveyed. It is, on the principles stated, at once known to be a salt, that is a sulphate, that is, sulphur and oxygen united to lime. So, too, phosphate of lime is seen to be a salt of lime.

54. If the thirteen elements which enter into the composition of rocks, had each an equal tendency to unite with the other; or, in other words, if their affinities were mutual, then there would be as many different combinations as it would be possible to form with thirteen different substances. 
If these combined in all proportions, then the possible number of combinations would be infinite.

55. This can never be. Affinity is not equally powerful. There is election or choice among the particles of inanimate matter. When the Creator impressed this property upon matter, $\mathrm{He}$ also limited its combinations. $\mathrm{He}$ assigned to each element power to combine with other elements, only in fixed, definite, invariable proportions. He gave to each its form, weight, and measure. And thus were limited the number of combinations, and the proportions fixed, in which these combinations should ever, from the dawning, to the end of time, occur. The Genius of modern chemistry has taught that all bodies combine only by infinitely small particles. Holding her balance over invisible elements, she has taught that each can be weighed.

It is the relative, not the absolute weight, which chemistry determines. The mode may be thus illustrated: "Take 9 lbs. of water, pass its steam over a known weight of pure iron turnings, heated red hot in an earthen tube. No steam escapes from the tube, only air which may be inflamed and burned. It is hydrogen gas, one of the constituents of water.

That liquid has been decomposed. What has become of its oxygen? It has united with, and oxidated the iron. What proportion of the $9 \mathrm{lbs}$. of water did it form? 8-9ths. If the iron is weighed, it will be found heavier in proportion of $8 \mathrm{lbs}$. for every $9 \mathrm{lbs}$. of water evaporated and decomposed. Whatever is the proportion of water used, $8-9$ ths are oxygen. Deducting from the $9 \mathrm{lbs}$. of water, 8 oxygen, the balance 1 is hydrogen. These are respectively the weights of their combining proportions. Chemical theory supposes combination occurs, only by the ultimate, indivisible particles or atoms of matter. Hence, the combining number is the relative weight of these atoms, referred to 
some one as unity. In these pages, hydrogen is considered as 1 , or unity. As the atoms may be thus expressed by numbers, it is customary, in referring to chemical compounds, to speak only of the number of atoms, in which each element enters into their composition. The modern system of chemical notation, substitutes for the name of the elements its first, or two first letters, and writes after it the number of atoms, existing in any compound, as the powers of roots are expressed arithmetically by exponents. Where only single atoms combine, their exponents are omitted. Thus, $\mathrm{H}$ is hydrogen, $\mathrm{O}$ is oxygen; then water is $\mathrm{H} \mathrm{O}$, that is one atom each of hydrogen and oxygen. $\mathrm{C}$ is carbon, $\mathrm{O}$ oxygen; then $\mathrm{C} \mathrm{O}^{2}$ is carbonic acid, that is, 1 carbon and two of oxygen. The combining number of carbon is 6 , and of oxygen 8 , then 1 carbon $=6$, and 2 oxygen $(8 \times 2)=16$. Then the atomic number of carbouic acid is $22,(6+16=22$. One little conversant with chemistry is apt to confound the combining number with the number of atoms, especially when the first is called "atomic number." A distinction is to be here remembered, the atomic number is one thing, the number of atoms another. When it is said, that water is composed of 8 parts of oxygen to 1 part of hydrogen, by weight, an ultimate fact only is expressed. When it is said that water is composed of an atom of oxygen united to an atom of hydrogen, we express a theoretical opinion. The difficulty lies, in understanding how water can be both a combination of 1 to 1 , and of 1 to 8 ; that 9 of water can yet be only composed of 1 to 1 . This discrepancy vanishes, where the distinction is remembered, between the combining or atomic number, and the number of atoms. Water is an example, where single atoms are united. But cases continually occur where the combining number of one body unites to more than one combining proportion of another. In this 
case, as the atoms are indivisible, combination can occur only, by twice, thrice, \&c., the quantity of that of the first compound; for iristance, 1 carbon may be combined with 1 oxygen, forming oxide of carbon, or with 2 of uxygen, and form carbonic acid. There is, and can be no intermediate step. Having determined the combining atomic number of oxygen, that of all other bodies may be found by determining how much of each is necessary exactly to unite with 8 of oxygen. For instance, the iron used in the experiment of decomposing water, increases in weight; if it is all equally oxidated, it is found to increase $8 \mathrm{lbs}$. for every 28 lbs. of iron used. If, therefore, $28 \mathrm{lbs}$. of iron are used, and 9 lbs. of water, the iron may be wholly oxidated by the 8 lbs. of oxygen of the water. Deducting this from the total weight of the oxide of iron, $36 \mathrm{lbs}$, the balance is the combining or atomic weight of iron. The sum of $8+28=36$ is therefore the atomic weight of oxide of iron. The atomic weight of all compounds is the sum of the atomic weight of their constituents. The number of atoms in any compound, whose proportional constituents by weight are given, is found by dividing each by its respective atomic weight. For instance, the composition of carbonic acid above, gives in 22 parts, 6 of carbon, and 16 of oxygen. Each divided by its atomic weight, gives 1 carbon, 2 of oxygen, $=22$ of carbonic acid. So in a compound of several elements, having their proportions per cent. given, each divided by its atomic number, gives the relative proportion of the atoms. These reduced to simplest terms, and affixed to the letters or symbols of the elernents, constitute what is called the chemical formula of this compound.

Three laws discovered by multiplied observation, confirmed by repeated experiments, govern all chemical science. These laws are: 
1st. Bodies combine only in definite proportion.

2d. " " " " multiple proportion.

3d. " " " " equivalent proportion.

These are the laws of chemical combination. The atomic theory attempts to, and does account for them. Once admit the principle that bodies combine only by indivisible atoms, these laws follow as consequences. If bodies only unite by atoms, atom to atom, their composition must be definite. If a body unites an atom to two or more of another, then as atoms are indivisible, the second, or other added portion, must be a multiple of the first, by a whole number. When bodies unite in proportions which imply half atoms, it is because union has occurred between two atoms of one, and three atoms of another, as iron may unite with oxygen so as to be seemingly a compound of 1 iron to $1 \frac{1}{2}$ oxygen. Truly this is a compound of 2 iron to 3 oxygen. Alumina always oxidates itself in this proportion, but it will simplify our views to consider it as uniting atom to atom. Again, if bodies unite only by atoms, the atom of one may be replaced by that of another; or, which is the same thing, the combining proportion of one may replace the combining proportion of another, for they are equivalent to each other. One body may be thus successively united to others, in doses which represent their atomic weights.

56. Calculating on this fixed principle, that the combining weight of any substance is the quantity necessary to unite with 8 of oxygen, it is found, that the proportions in which the bases of silicates combine, are

\begin{tabular}{|c|c|c|c|}
\hline \multicolumn{4}{|c|}{ oxygen, } \\
\hline & $"$ & 10 aluminum & $=18$ alumina, \\
\hline & & 20 calcium & $=28$ line, \\
\hline & " & 12 magnesium & $=20$ magnesia, \\
\hline & “ & 40 potassium & $=48$ potash, \\
\hline
\end{tabular}


8 oxygen, 24 sodium

8 " 28 iron

8 : 28 manganese $=36$ oxide of manganese.

When any of these oxidated substances unite to an acid, it is only in these proportions. The numbers are equivalents - that is, 48 of potash are equal in saturating power, to 32 of soda, or 28 of lime. All equivalents, entering into the composition of soil, contain the same quantity of oxygen. Hence, if from each of the above numbers in the third column, 8, the constant quantity, is deducted, the remainder represents the equivalent of the respective pure metals, which chemists represent by the termination in um or ium; and hence are formed, potassium, sodium, \&c. (40), (41).

57. The equivalent of sulphur is 16 , adding 3 oxygen $=$ 24 parts, sulphuric acid is formed $=40$.

The equivalent of phosphorus is 32 , adding 5 oxygen $=$ 40 parts, phosphoric acid is formed. The equivalent of carbon is 6 , adding 2 oxygen $=16$ parts, carbonic acid is formed.

Hence, the equizalents of these acids are $40,72,22$, numbers produced by adding the proportions of oxygen to the respective bodies. These acids combine, in their above equivalent proportions, with the bases of silicates, forming neutral salts, or with two or more proportions of acid form super-salts, or with a larger portion of base, form sub-salts, and thus form fixed and invariable compounds. Sulphate of lime is, therefore, in proportion of 28 of lime to 40 of acid. Carbonate of lime, 28 of lime to 22 of acid. Phosphate of lime has a larger proportion of base, 3 parts or 84 of lime to 72 of acid; this is bone earth, so called; and the equivalent of each of these salts is the number produced, by adding that of the lime to that of the acid.

58. If sulphur, phosphorus, carbon, silicon, are united to 
the bases (40), combination can take place only in the equivalent proportions. It is thus evident, that soil, cor-sisting of silicates, metalloid compounds, and salts, is a fixed, unvarying, chemical combination of these substances, though mixed in proportions, somewhat varied by local causes, yet presenting, in the mass, a great similarity of composition. When the subject of the composition of the vegetable portion of soil is discussed, the value of a slight knowledge of chemical notation and of combining propurtions, will be manifest. It is not to be neglected, however unconnected it may seem with practical farming. The doctrine of chemical equivalents is important to the farmer, even if he pursues it no farther than to understand and remember the combining proportions of a few substances, known to him only by name; such are the common acids, oil of vitriol, aquafortis, spirits of salt, or sulphuric, nitric, and muriatic acids; the usual alkalies, ammonia, potash, soda, lime; acids and bases, which combine only in their equivalents. It is sometimes remarked, in agricultural experiments with different salts, that equal quantities, if correct comparative trials are to be made, should be used. The doctrine of equivalents teaches not an equal, but an equivalent portion-that is, 28 of lime are equal to 48 of pure potash. It may assist the memory here, and furnish a good "rule of thumb," to recollect, that the three alkalies, ammonia, soda, potash, are to each other, as $17: 32: 48$, or as $1: 2: 3$, nearly. When the subject of manures is considered, the doctrine of equivalents will be found important, in determining their relative value. Though the numbers here used are those of some chemists of high authority, they are not all universally admitted. They have the convenience of being small whole numbers. They are readily retained in the memory, and simplify the subject, by freeing the calculation from multiplication and 
division of fractional equivalent numbers. They are easily apprehended, and, for all practical agricultural purposes, correct.

59. Viewed by the light of chemistry, rocks are masses of silicates. The simple minerals composing rocks are truly only. silicates in fixed proportions. The simple minerals are quartz, felspar, mica, hornblende, talc, serpentine. Their composition is presented in the following

TABLE OF CONSTITUTION OF SIMPLE MINERALS.

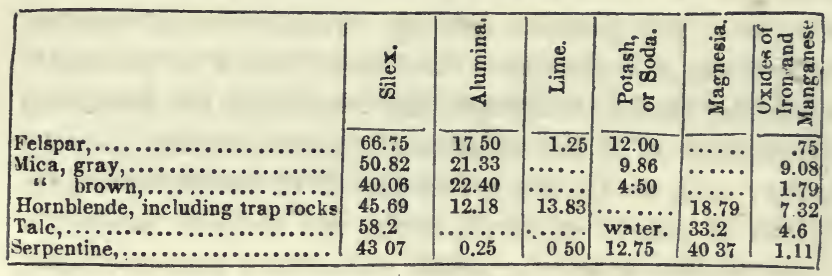

In each the silex acts as an acid. This is not only the most constant, but the most abundant ingredient of rocks. Next is alumina. The average quantity of these elements in the most important rocks, is silica 62.79 , alumina 25.15 per cent.

60. In each simple mineral, the bases (41) being combined with silica, a compound, or silicate is formed. In this case, the few simple minerals forming rocks, may be arranged in three classes, and it will be perceived that, notwithstanding their great variety of external appearance, their ultimate chemical composition resolves itself into classes of double, or simple silicates, in which silicate of alumina is united with potash, or lime, or with magnesia, forming thus three classes only of simple minerals, which compose rocks and soil.

1st. Silicate of alumina and potash forms felspar and mica. 
2d. Silicates of alumina and lime with magnesia form hornblende.

3d. Silicate of magnesia forms serpentine and talc; and silica almost pure, is quartz.

61. The iron and manganese in the table (59), are regarded as accidental mixtures of silicates of these metals. Silicate of soda is often present in place of potash, and this constitutes an extensive varietv of the felspar family. 


\section{CHAPTER III.}

OF THE MINERAL EleMENTS OF SOIL, THEIR PROPERTIES, AND CHEMICAL ACTION.

62. The bases of the silicates have common properties, which are:

1st. Alkaline. Whatever may be our idea of the effect of an alkali, as exhibited by potash or soda, the same in kind, but in degree less, is exhibited by lime, magnesia, and alumina. Placing potash as the type of alkaline power, the same power in a decreasing order is found in lime, magnesia, and alumina.

$2 \mathrm{~d}$. They are, most of them; soluble in water. Potash stands here also first, and the solubility decreases in lime, magnesia, and totally disappears in alumina. This may have some connection with the fact, that, widely diffused as it is in all soil, it is very seldom found in plants.

$3 d$. They exhibit great affinity for carbonic acid. The order of affinity is potash, soda, lime, magnesia; alumina, if it possesses it at all, exhibits it only feebly. The alkalies form soluble, and the alkaline earths, and alumina insoluble compounds with carbonic acid.

4th. They have all great affinity for water, combining with it, and forming what are called hydrates. Potash parts not with this chemically combined water, by any heat which has been produced; lime and magnesia give up their water readily, at a red heat: alumina requires, for this purpose, a 
full white heat. This is the only case where alumina stands next to potash.

5th. They are all fusible, in the order of potash, lime, magnesia, alumina.

6th. They have already been described as definite combinations of metals and oxygen (56). The same law governs their combinations with water. Such compounds are termed hydrates, from "udor," water. Water is a compound of eight parts of oxygen, and one part of hydrogen, forming one part of water, whose equivalent is 9 . Taking the number representing the base (56), or rather the basic oxide, the equivalents of the hydrates are obtained by adding to each, 1 part $=9$ of water. Thus-

Potash, 48 united with 9 water, forms 57 caustic potash.

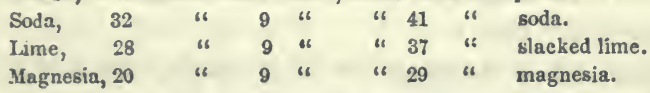

63. The same law pervades all these various combinations. There are strong resemblances in the alkaline family, which show their relation, yet each is marked with its individual peculiarities. Alumina stands alone, and seems a natural link, connecting the silicates with the metalloids.

64. The gradual passage of the characters of the metallic elements of the silicates, into that of the metalloids, is to be observed.' The first show alkaline powers by combining with oxygen. Exhibited in the highest degree by potash, and lowest in alumina, which shows both alkaline and acid properties. By the last, it is allied to silicon, sulphur, phosphorus, carbon. The three last are so well known that they need only to be mentioned.

65. The metalloids have common properties.

1st. They all combine with the pure base of silicates (46), and form siliciurets, phosphurets, carburets, sulphurets. Thus are formed carburet of iron, or plumbago, sulphuret 
of iron, or iron pyrites, sulphuret of potassium, or liver of sulphur.

2d. They chemically combine with each other. Thus are formed sulphuret of carbon, and sulphuret of silicon.

3d. They all form acids, by combining with oxygen. Thus are formed sulphuric, carbonic, phosphoric, silicic acids (41).

66. While the metals combine with oxygen only in one proportion, to form alkalies, producing it always, for each, of one uniform strength, the metalloids combine with different proportions, and form acids of different strength. The rule followed in naming the acids, is, first, that each is called after the substance forming it, the metalloid having ous added to it to designate the weaker, and $i c$, to designate the stronger acid; thus :

Sulphur $16+2$ oxygen $=16$ is sulphurous acid. " $\quad 16+3$ " $=24$ is sulphuric acid.

So are formed phosphorus and phosphoric acids. Silicon forms but one acid, the silicic. It is the only member of its class which requires a detailed notice of its properties.

67. Silicon, the base of the earth usually called silex or silica, forms, next to oxygen, the largest part of all rocks and soil. It has been already noticed (64), how the earthy character gradually increased from potash to alumina; and how this last connected itself with the metalloids, and in the first member of this series, the earthy character appears fully developed when united with oxygen. It is the earth of flints, it is pure rock crystal, it is common quartz, agate, and calcedony, and cornelian. All these are silicon acidified by oxygen, hence called silicic acid. It is this which forms, with potash, the hard coat of the polishing rush, the outer covering of the stalks of grasses. Wheat, rye, oats, barley, owe their support to this covering of silica. It cases the 
bamboo and rattan with an armor of flint, from which may be struck sparks. Entering into the composition of all soil, and hard and unyielding as it appears, furming not only the solid rock, but the delicate flower, which that supports; forming combinations with the metals of soil whose gradual decomposition is the birth of fertility, silicon demands a detail of its properties, commensurate with the high functions it performs.

68. Silicon, in the purest state yet obtained, is a dull brown powder, soiling the fingers. It dissolves in fluoric acid, and in caustic potash. Heated in air or oxygen gas, it burns vividly, and is partly converted into silica. Heated in a closed crucible, it shrinks very much, but does not vaporize. Heat has altered all its properties. It has become a deep chocolate color. It sinks in oil of vitriol, one of the heaviest of fluids; it will dissolve in no acid, except a mixture of nitric and fluoric; caustic alkali has no action on it, nor will it burn in the intensest flame of air or oxygen gas. No other simple substance is so changed by heat. The only substance exhibiting analogous properties, is carbon.

Silicon burns in vapor of sulphur, and forms sulphuret of silicon. This easily dissolves in water, sulphuretted hydrogen escapes, and silica remains in solution. These are facts of the highest importance in agriculture.

69. Whether heated or not, silicon is oxidated when heated with dry potash, and converted into silicic acid. In its pure state, this is a rough, gritty, tasteless powder. When heated, it runs like red-hot ashes, and the lightest puff blows it away. It is not melted in the strongest heat of a wind furnace. Silicic acid exists in two states, soluble or insoluble in water. It is perfectly insoluble, after having been heated red-hot. Sulphuret of silicon, as has been noticed 
(68), dissolves in water, and gives silica, in solution. If this is evaporated, a jelly-like, sizy mass is obtained, which may be again dissolved in water. Acid, added to the solution, when evaporating, renders silica insoluble. Alkalies, boiled with insoluble silica, render it soluble, no change occurring in the alkali. These singular changes are due, probably, to a new arrangement of the particles of silica, produced by that power called catalysis, or the action of presence, that is, by the presence of a third body, taking no part itself in the action, but simply influencing the changes which occur.

70. Soluble silica exists in some minerals, and is produced when a silicate is melted with an alkali, and dissolved in dilute acid. It is in consequence of this ready solubility of silica, that a small quantity is contained in all natural waters; associated with alkaline carbonates in mineral springs, it is often an abundant product.

71. The general properties which silicic acid exhibits in its combinations, are these :

1st. All its compounds, with excess of alkali, are caustic, and soluble in water. Those with an excess of silica, are mild and insoluble. Glass is an example of the last, and so are the rocks. Green bottle glass is but a fused rock, a mixture of silicates of potash, soda, alumina, lime, magnesia, and iron. These are the silicates which have been already enumerated (60), as composing rocks; and the arnount and origin of these several elements of soil can now be conveniently understood. This is practical ground, and shows the value of chemical analysis of rocks. Whatever opinion respecting their origin is adopted, and whether or not granite is supposed to have produced the soil above it, or that it is only overlaid by granite drift, it is evident, from the table (59), that all granite rocks contain lime and alkali. These 
will be in proportion to the mica and felspar, for granito (35) is composed of these and quartz.

72. The composition of granite, composed of two-fifths quartz, two-fifths felspar, and one-fifth mica, is in every 100 parts, -

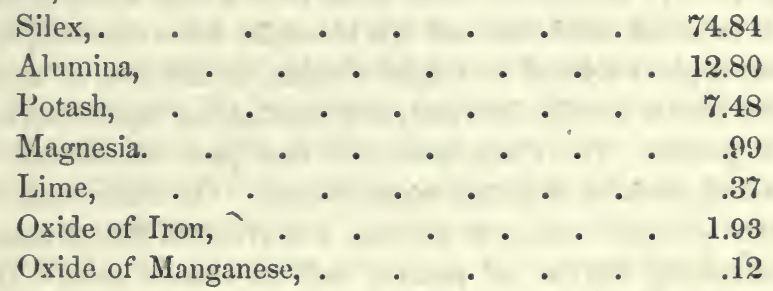

In every $100 \mathrm{lbs}$. of granite, $7 \frac{1}{2} \mathrm{lbs}$. of potash, and $\frac{3}{8} \mathrm{lb}$. of lime. Differ, as opinions may, about the how, and the why, of the operation of lime and alkali, it is evident, that unexhausted and exhaustless stores of these substances are already in barren pine plains.

73. Let it be supposed that these are formed of the drift of granite, composed as stated (72), and the amount per acre of lime and alkali, taking the soil only six inches deep, would be as follows: The cubic foot of such soil weighs about $90 \mathrm{lbs}$. or at six inches deep, $45 \mathrm{lbs}$. The acre at this depth contains 21,780 cubic feet, which will afford $3626 \mathrm{lbs}$. of lime, and 73,311 lbs. of potash, or nearly a ton and a half of lime, and thirty-six tons of potash.

74. The lime in such a soil would be enough to supply that contained in a crop of rye, at 20 bushels per acre, for 7400 years; for at 20 bushels per acre, and at 50 lbs. per bushel, each acre would afford 1000 lbs. of grain, which contain nearly $\frac{1}{2}$ lb. of lime, or 0.49 (Schroder), dividing 3626 by this, the quotient 7400 is the number of years the lime would supply the grain. Wheat will not differ much from rye, and if the time is diminished, by the amount of 3 * 
lime contained in the straw, it will be seen that the actual amount of lime and potash, in what is called poor soil, will hardly begin to diminish at the end of a long lease, cropping every year 30 bushels of wheat. Allowing thus, for exam ple, the proportion of straw which such a crop would afford, to be about $5000 \mathrm{lbs}$., and this is not far from the truth, the straw gives 4.40 of its weight of ashes, or $220 \mathrm{lbs}$., of which one-fifth is soluble in water, and one-half of that dissolved is potash. The spent ashes, or that part not soluble in water, contains 5.80 per cent. of lime. On these data, an acre of wheat straw, or $2 \frac{1}{2}$ tons, will give $220 \mathrm{lbs}$. of ashes, containing $22 \mathrm{lbs}$. of potash, and $10 \mathrm{lbs}$. of lime. The potash will last at this rate for the straw, over 3000 years! It will be hereafter shown, that when the lime fails, the crop will not.

Since the first edition of this work appeared, numerous ash analyses of rye have been made by the first chemists and analysts of the day. Calculating the lime in rye on the average of these results, $1000 \mathrm{lbs}$. of grain would give 23 lbs. of ashes. Of this amount, $1.145 \mathrm{lb}$. is lime; and even at this rate the grain of 20 bushels of rye per year, from an acre, would exhaust the soil of lime in the first six inches from the surface, only in 3166 years. Allowing $4000 \mathrm{lbs}$. - of straw annually, the lime in this is $11.25 \mathrm{lbs}$., equal to 322 annual crops, or the lime would last for the grain and straw 293 years.

75. Were similar calculations extended to soil supposed to be formed of any other rock, the amount of lime and alkali would still be seen to be almost inexhaustible. And whether rocks be supposed or not, to form the suil over them, it may be established, as the fourth leading principle of agricultural chemistry, that SOILS CONTAIN ENOUGH OF ALL THE MINERAL RLEMENTS, TO GROW ANY CROP. 
76. These elements do not exist in soil, free; they exist as silicates, or salts, compounds regulated by the unbending laws of affinity, and fixed as are the laws of gravitation. The decompounding of these combinations, or the gradual decay of rocks and soil, takes place also by similar laws. Gradually acted upon by the carbonic acid of the air, the agency of growing plants, the action of various salts, formed by metalloids in atmospheric exposure, the silicates yield to new affinities. The alkalies, freed partially or entirely from the embrace of silica, dissolve, and are borne seaward; the silica itself is dissolved by the water used for drink; the iusoluble alumina, still combined with a portion of potash and silica, remains, forming the great mass of clays, or mixed with granitic sand, forms loam.

77. Felspar, mica, hornblende, are constantly acted upon by air and moisture. This action is chemical. It is twofold. 1st. The action of the carbonic acid of the air, or of carbonates, upon silicates. The potash, or alkaline part of the silicate is by this means separated. The mineral, no longer held by the bond which had united its components, falls into dust. The silica, lime, alumina, magnesia, thus form the finer portions of soil. In obedience to a well-established fact in chemistry, the seemingly insoluble silica, and alumina, and magnesia, in the very moment of their disunion, are each soluble in water. They may then ba taker up by plants, or dissolved by various acids found in the soil, form salts.

78. The second mode of action, of air and moisture, is upon the sulphurets, the phosphurets, and siliciurets. The action of air upon all these is, to oxidate, both the metallic and the unmetallic element. In a word, the metalloid compounds, by air and moisture, become salts; the unmetallic part becoming acid, and the base an oxide, which combine. 
79. The fact most important to the farmer in these changes is, that these compounds are continually, in' all soil, becoming salts. Whenever iron pyrites, or sulphuret of iron, is found, and it is very widely diffused, exposure to air and moisture acidifies the sulphur, it forms oil of vitriol, or sulphuric acid. This immediately combines with iron, and forms copperas, or sulphate of iron, or with alumina, forming alum, or with lime, forming plaster of Paris, or with magnesia, forming Epsom salts; all these are salts, and liable to be decomposed by any free alkali which may be produced by the decomposition of silicates.

80. Among the most abundant salts in soil, arising from the actions (79), are those which are very insoluble in water, and not liable, therefore, to be drained off, when not required by plants. These are sulphate of lime, and phosphates of lime, and of alumina, and iron. The sulphate of lime is partially soluble, and hence, is found in all river and spring water; but phosphates are more insoluble, and are always found in soil.

81. That sulphate of lime might possibly exist in soil, has been admitted by all who understood the actions (79), and adding to this the fact of the gradual decomposition of the silicates by carbonic acid, the function of sulphate of lime in soil was easily admitted. The double silicates of lime and potash are universally diffused, and in the order of affinities sulphates of alkalies and of lime result.

82. It is not so easily understood how phosphate of lime should exist in soil. The true source, both of sulphate and phosphate of lime, and of the solubility of silica is yet to be detected by exact chemical analysis. It is to be looked for in the sulphurets and phosphurets of silicon, which probably exist in rocks. The action of sulphuret of iron, as explained, would demand its universal diffusion, to account for the 
presence of sulphate of lime. Sulphuret of iron must either now exist, or have ages ago existed, as widely diffused as the silicates. But though common in rocks, its presence as a sulphuret will not account for the quantity of sulphate of lime found in soil. Vast quantities of this salt are annually borne off in crops; while at the same tinıe, a large portion of that hardest, and, as is generally supposed, utterly insoluble earth, silex, is withdrawn by every plant which grows. How is this rendered soluble?

83. This question may be answered, if it be admitted that a portion of the silica of rocks exists as a sulphuret of silicon. The action of air and moisture upon this will be understood by reference to section 68 , where it is stated that sulphuret of silicon is decomposed by water. The sulphur, in this case, is evolved as sulphuretted hydrogen-gas, the siliea deposited, and in this state is abundantly soluble in water. The sulphuretted hydrogen would act on the lime of the silicates, and gradually sulphate of lime would be formed. Here is an abundant source, not only of the solubility of silica, a point always of difficult explanation in vegetable physiology, but also of the production of sulphate of lime.

84. Similar remarks are applicable to the presence of the phosphates of lime, and iron, and alumina in soil. Phosphate of lime is not a very abundant ingredient in rocks, except in certain localities; yet its occurrence is tou rare to account for the vast amount of phosphate of lime in soil. The phosphorus possibly exists in combination with silicon, as phosphuret of silicon. The effect of air and moisture on this has already been explained, and accounts for the production of phosphates in soil. Similar remarks are applicable to the source of the chlorides or muriates; for instance, common salt in the potash of commerce. May not their 
source be in chloride of silicon? These are conjectures, but conjectures only, because, refined as modern chemical analysis is, it may not be so delicate as to detect the possible combinations, which nature presents in silicates. What is the source of that phosphoric odor, produced by the friction of fragments of pure quartz on each other? If not due wholly to electrical excitement, may it not arise from the presence of phosphoric elements? The elements are Protean, and assume new dresses, by the very processes adopted to unfold them. Whatever may be their origin, their constant presence leads to this fifth principle of agricultural chemistry, ALL SOIL CONTAINS SULPHATE AND PHOSPHATE: OF LIME.

85. This principle is of the highest importance in agriculture. The author of these pages stated the fact to the Geological Surveyor of Massachusetts, in 1837, and it was published in his report. Slowly admitted at first, the fact that phosphates exist in all soil, has been established by the widest observations. Its proofs are both chemical and agricultural. The chemical proof is found in the extensive analyses of soil contained in various Geological Reports, espeeially those of Massachusetts, published within a few years. Since the first edition of this work, phosphoric acid has been found in basaltic and hornblende rocks.

86. The agricultural proof may be stated in a few words. The bones of all graminivorous animals contain about half their weight of phosphate of lime. It can be derived only from their food, and that only from the soil. Hence the soil contains phosphoric acid in some chemical combination. Secondly, the actual result of chemical analysis confirms this statement. Beets, carrots, beans, peas, potatoes, asparagus, cabbage, afford phosphates of lime, magnesia, and potash. Indian corn, rice, wheat, barley, oats, all contain nota- 
ble portions of sulphate and phosphate of lime, not only in the grain, but in the straw. Smut and ergot show free phosphoric acid. Cotton gives 1 per cent. of ashes, of which 0.17 are phosphates of lime and magnesia. The cotton consumed weekly, in the Lowell Mills, is $400,000 \mathrm{lbs}$, containing $680 \mathrm{lbs}$. of phosphate of lime; and this would furnish the bone-earth for the bones of seventeen horses, allowing 90 lbs. to each skeleton, of which $40 \mathrm{lbs}$. would consist of phosphate of lime. That beautiful yellow powder, shed by pine forests, the pollen of its flowers, wafted about in clouds, and descending with the rain, covering the surface of water with its sulphur-like film, is composed of 6 per cent. of phosphates of lime and potash. The ashes of all wood contain sulphate and phosphate of lime. Garget contains in its leaves beautiful crystals of phosphate of lime and ammonia; and every exact analysis of the ashes of trees, shrubs and plants of every kind, cultivated or wild, shows the presence of phosphoric acid 


\section{CHAPTER IV.}

OF THE ORGANIC CONSTITUENTS OF SOIL.

87. The mineral elements of soil become part of plants. Under the influence of the mysterious principle of life, they no longer obey the chemical laws, but are parts of a living structure. Life suspends all chemical laws. It organizes inorganic matter. To what laws obedient, to what purposes subservient, are the elements of soil during the brief moment in which they are endowed with life, it is not intended to inquire. Plants, by their living power, select from the sixtytwo elementary substances, sixteen or perhaps eighteen. Of these, four exist as airs or gases in their uncombined state, viz.: oxygen, hydrogen, nitrogen, and chlorine; seven are bases, and four metalloids, described (41). "These fifteen elements, alumina excepted, are generally constant constituents of plants. Iodine, once supposed peculiar to marine vegetation, has very recently been found in land plants. Bromine is also found in seaweed, and fluorine has occasionally been found in the ashes of rye.

88. Every plant does not, nor does every part of the same plant contain the same elements; but similar parts of the same plant, at the same age, probably contain the same elements, united in definite proportions. Whenever plants die, their elements are again subject to the laws of affinity, and during the decay of vegetables, they return to the earth not only those substances which the plants had taken 
from the soil, but also those which have been elaborated by their living structure. The former are silicates and salts, or the inorganic elements; the latter are the organic parts of soil.

In the first edition of this work, chlorine was not enumerated as an element of plants. Its presence in them was considered accidental, because its source had not been detected in the rocks, from whose ruins soil has been formed. Dr. A. A. Hayes has detected alkaline chlorides in the primary rocks of Vermont. The possible existence of chloride of silicon has been noticed. If this is not the source of the chlorine of plants, that may be supposed to be evaporated as a chloride from the ocean, and consequently to exist in that state, dissolved in air. If derived from this salt in soil, then that is extraneous. Its origin was suggested to be oceanic. An examination of the rain-water, of each fall, during the year 1842, in Lowell, has shown that this suggestion is correct. Probably muriates are universally contained in rain-water. As, therefore, common salt, the chlorine and soda of plants is derived by evaporation from sea-water, then as sulphate of lime has been detected in snow and hail, it becomes a question, whether other inorganic salts of plants may not have a similar origin, and exist dissolved in air.

Continued examination of rain water has shown that all the mineral elements of plants are traceable in it.

89. It is thus seen, that soil presents itself in a new view. Soil consists of two grand divisions of elements. Inorganic and organic. The inorganic are wholly mineral, they are the products of the chemical action of the metallic, or unmeetallic elements of rocks. They existed before plants or animals. Life has not called them into existence, nor created them out of simple elements. Organic elements are the 
product of substances once endowed with life. This power influences the elements, recombines them in forms so essentially connected with life, that they are, with few exceptions, produced only by a living process. They are the products of living organs, hence termed organic; and when formed, are subject to chemical laws. The number of elements in the inorganic parts of soil is twelve. Oxygen, sulphur, phosphorus, carbon, silicon, and the metals, potassium, sodium, calcium, aluminium, magnesium, iron, and manganese (56). The number of elements in organic parts of soil, does not exceed four, viz. : oxygen, hydrogen, carbon, and nitrogen.

90. The great difference between these two divisions is this, that while the inorganic are simple combinations of two elementary substarices, the organic are combinations of three or four elements, but never less than three. These are variously combined. They have formed the great body of vegetable products; continually changing, the mere abstraction of a part of one of their elements forms a new product. The three elements (89), exist generally in such proportion, that the oxygen and hydrogen would, by their union, produce water, without excess of either element, while the carbon would thus be liberated. It would be found free were it not also acted upon by air and moisture, and changed to carbonic acid. There is not oxygen enough in the organic part to convert the carbon into carbonic acid, and the hydrogen into water. They are constantly changing, assuming new forms. This susceptibility of change is the foundation of tillage.

91. The relation of agriculture to silicates and salts, and to the composition of plants, which has been alluded to (89), is of the highest interest. As silicates and salts compose all the earthy ingredients of soil, so are they equally con. 
stant in plants. The deduction to be drawn from this is, the sixth principle of agricultural chemistry, sorL, consistivg CHIEFLY OF ONE SILICATE, OR SALT, IS ALWAYS BARREN.

92. It is not probable that soil thus chemically constituted, exists. Admitting such to occur, even then, when dressed with the food of plants, it would not be fertile. The want of a mixture of earthy ingredients, which are as essential to the growth of plants as are air and moisture, would effectually prevent the growth of crops. Only a portion of the elements thus essential to plants exists in them in that state in which they exist in soil. The silica, and potash, and lime, exist in plants as in soil, as silicate of potash, and sulphates and phosphates of lime and potash. When the ashes of plants are examined, we find carbonates of bases which did not exist as such in the soil. A large portion of carbonates of lime and potash is found in ashes.

93. The origin of these is to be sought in acids which, by heat, produce carbonic acid. This is the effect of heat upon all salts formed of vegetable acids. Such are tartaric, malic, eitric, oxalic, and acetic acids. The inorganic elenients of plants exist in combination chiefly with organic or vegetable acids. Each plant forms acids, in definite quantity, proportionate to the size, age, and part of the plants ; the acid being constant, the bases to saturate them will be equally constant.

94. A beautiful chemical law governs this saturation of the vegetable acids. It is the law of substitution, analogous in part to the law of isomorphism, or the law of similar forms; it is perhaps connected with that, so that the elements of isomorphous groups only can be substituted for one another. In minerals which are crystallized it was formerly thought that similarity of external form indicated identitv of chemical composition. Later observation has 
established the fact, that minerals and salts exist, with perfect similarity of external form, yet of totally different chemical constitution. For example, the a!umina in alum may be replaced by oxide of iron. The form will not be changed, but all its chemical properties and relations are destroyed. This is called an isomorphous replacement of one element for another, which produces a like form. The law of this substitution is, that the body replacing another, must be, not an equal, but an equivalent proportion (56); that is, replaced by a proportion containing the same quantity of oxygen. Replacement retains the form, not the properties of the displaced body. Substitution may retain the form, but always the properties and functions of the element whose place is thus occupied. Like replacement, substitution occurs in equivalent proportions.

95. The relation between agriculture and this law is so wisely and beneficially ordained, that it might well be called a law of compensation, by the Natural Theologian. It is a well-established fact, that plants growing on soil containing a due mixture of earthy ingredients, always select a due proportion of each, according to their functions; yet, if to such soil an excess of either of the alkalies, or of the alkaline earths is given, an excess of potash, soda, lime, magnesia, may be taken up by the plants, to the exclusion of the usual proportion of another; hence, it may be established as the seventh principle in Agricultural Chemistry, ONE BASE MAY BE SUBSTITUTED FOR ANOTHER, IN AN EQUIVALENT PROPORTION.

96. This is a very important law in the agricultural relations of the inorganic parts of soil. Whatever may be the office performed by these, in the living structure, none is of higher value than this, that they may be thus substituted, the one for the other. It is a fact of the highest practical 
value. Its value will be perceived when it is considered that if soil containing originally all the elements essential to a crop becomes exhausted of one, yet another may be substituted, which, combining with the organic acid of the plant, enables this to perform and perfect all its functions. If a crop fails, this is often charged upon the deficiency of lime in the soil. It has been already shown that this is quite impossible, yet granting it true, so long as the law of substitution exists, so long may potash, soda, magnesia, that is, ashes, supply the place of lime.

Ashes are the product of combustion, or its equivalent, decaying and mouldering vegetable matter.

97. Substitutions in plants, relate chiefly to the bases combined with the vegetable or organic acids. The mineral or inorganic acids exist already saturated in the soil, as sulphates, phosphates, or muriates.

It has been observed, however, in recent investigations, that phosphoric acid is not always united to the same number of equivalents of base, in the ashes of seeds; all the leguminous seeds have three of fixed base, to one of phosphoric acid, while the cereal grains contain two of base to one of acid. The quantity of oxygen contained in the bases of these seeds is so nearly alike, that Drs. Will and Fresenius think that the law of substitution applies to the phosphates.

98. In consequence of the law of substitution, the oxygen in the bases of organic acid salts is a constant quantity, although ashes of the same plant may, by analysis, show a great diversity of composition; this can arise only from the fact that the organic acids exist probably in a definite proportion in each family of plants. The acids are formed by the essential vital functions of the plant. To the perfection of this process the silicates and salts of the soil are not less 
necessary than is life to the vegetable; but though one element may be substituted for another, yet no one element may supply the place of all others. This is a problem yet to be solved. Nor may any possible mixture of mere silicates and salts give fertility to a barren soil. Fertility depends on the presence in soil, of matter, which has already formed a part of a living structure, or the organic eleinents of soil. This matter must be undergoing chemical change. Change implies motion, motion induces motion in the sur rounding elements. Without this chemically induced motion, there is no fertility.

99. The inorganic elements are simple combinations; the organic are simple in number, but wonderfully complex in their combinations. It is an established fact that all complex compounds are unstable. They are prone to form new combinations. The more complex, the easier decomposed is any compound. The more complex, the more liable to decomposition. Hence, the moment life departs, the plant or animal speedily undergoes new changes; its elements, which life had organized, obey now, not the law of life, but the laws of chemistry. The solids and fluids of a living body, when life ceases, escaping in part as air or gas, leave in a solid form, a substance, differing equally from any living organic product, and from inorganic elements. The product of the spontaneous decomposition of organic substances still may exhibit the character which distinguishes this division, viz. : complexity, great susceptibility and ease of decomposition. This is a great practical agricultural fact. When decomposition ceases in organic matter, the result is barrenness.

100. In the products of the decomposition of organic bodies, a variety is formed, differing according to the circumstances, and the time and progress of decay. However 
varied, there are constant products of organic decomposition in soil, which are ever the result of that process in or upon the earth. These products are termed Geine. This term designates a class of chemical compounds, allied by similarity of constitution and properties. $G \bar{e}$ is the Greek for earth, and the suffix ine, is in conformity to chemical names given to those vegetable or other organic products, whose independent existence has been determined; for example, quinine, morphine, \&c.

It is necessary to note the difference in the products of putrefaction in free or confined air.

In free air, the chief products are water, carbonic acid and ammonia. In confined air, the carbon not obtaining oxygen enough to be wholly converted into carbonic acid, combines with a smaller quantity and forms carbonic oxide. The hydrogen, deprived of oxygen sufficient for its total conversion into water, combines with carbon, and thus produces marsh gas, or light carburetted hydrogen, the gas of street lights, while another portion of hydrogen combines with the sulphur and phosphorus of the decaying body, and forms those airs so offensive in putrefaction, sulphuretted and phosphuretted hydrogen gases.

In all the transformations of organic matter in soil, there is ever produced an excess of hydrogen. This is a highlyimportant fact.

A principle is here to be stated and remembered. Hydrogen, at the instant of becoming free, in the act of being born, in its nascent state, as it is called, in warm and moist air, unites with nitrogen. This union produces ammonia. The nitrogen of putrefying bodies is thus removed as ammonia. Thus are removed all the nitrogen, and a portion of the carbon, hydrogen, and oxygen of the decaying organic body. There remain the several forms of geine. 
These details may be tabulated, and thus the products of putrefaction being seen at a glance, may be readily sealed on the memory.

Free air,

PUTREFACTION PRODUCES IN

Water,

Carbonic acid, Ammonia.
Confined air,

Water,

Carbonic oxide,

Carburetted hydrogen,

Sulphuretted hydrogen,

Phosphuretted hydrogen,

Ammonia,

Geine.

In soil, the air being partly free, partly confined, all =the above products may be found. These vary, therefore, according as the putrefying body may be on the soil, in the soil, or in the subsoil.

101. There are at least seven well-defined substances included in the class geine. Two of these are indifferent in their relations, viz.: ulmin and humin; five exhibit acid properties, these are the ulmic, humic, geic, crenic, and apocrenic acids. These seven substarces are compounds of carbon, with oxygen and hydrogen, in proportions just sufficient to form water, or compounds having either the hydrogen or the oxygen in excess. They may be therefore grouped in three sections.

1st. Carbon and water form humin and humic acid.

2d. Carbon and water with hydrogen in excess, form ulmin and ulmic acid.

3d. Carbon and water with oxygen in excess, form geic, crenic, and apocrenic acids.

These may be termed the neutral, the hydrogen, and the oxygen groups.

The first products of decay are ulmin and ulmic acid: By the continued absorption of oxygen from the air, humic acid 
and humin, geic, apocrenic, and crenic acids are formed in the order in which they have been named. Each is derived from the substance immediately preceding it in the list.

The ultimate product of their decay is carbonic acid and water.

The acids of geine easily and rapidly absorb ammonia and water. They also chemically combine with water and ammonia.

They are seldom found free in soil, ana so energetic is the affinity between crenic and apocrenic acid and ammonia, that these have been considered as essentially different from ulmic, humic and geic acids. These contain carbon, hydrogen and oxygen, while crenic and apocrenic acid were supposed to contain in addition, nitrogen. Hence, a distinction was pointed out in the last edition of this work, in which geine was divided into nitrogenous and non-nitrogenous.

The progress of discovery has shown that crenic and apocrenic acid may be derived from geic acid, free from nitrogen.

102. Still there are wide differences in the relations of these several substances. The most easily marked characteristic is, that some are easily, others difficultly soluble in water, and others are insoluble in this element.

The relations of the acids and neutral substances of geine to alkalies, is also remarkable. All the geine acids readily dissolve in carbonated or caustic alkali; in either of which the neutral geine substances are wholly insoluble.

Of the dissolved acids, three are precipitable and two not precipitable by acids. Hence, we have two divisions of geine founded on their relations to alkali and water; 1st, soluble, and $2 d$, insoluble. The insoluble substances are ulmin and humin. The soluble substances are all acid, and these may be still further distinguished by their relations to acid. 
First. Those which are soluble and precipitable by acid, viz. : ulmic, humic, geic acids.

Secondly. Those which are not precipitated by acid, viz. : crenic and apocrenic acids.

In consequence of the ammoniacal combinations with the acids, these are usually found in water drained from soil. Hence, long before the existence of crenic and apocrenic acid was suspected, the substance given up by soil to water was called extract of mould; the substance dissolved by alkali was called humic acid, from humus, the Latin for soil, or mould. These several substances are convertible. The insoluble becomes soluble, the difficultly soluble in water becomes easily soluble by air and moisture. Ulmic, humic, and geic acids are seldom, and crenic and apocrenic acids are never found free in soil. Hence, in soil, no less than five separate and distinct salts of any one base may be found, but generally the salts are chemical combinations of several bases with each acid, which compound salts are soluble, though singly some may be insoluble in water. These compound salts minister to vegetation in various ways.

103. Great difference of opinion has prevailed respecting the real constitution and uses of the substances of the class geine. It is practically useful to discuss the question, whether plants draw their carbon, hydrogen, oxygen, nitrogen, from the air, or from the soil. The nourishment drawn from air, depends on the great physical elements, air, temperature, moisture. Agriculture may not control these. It can palliate them only by controlling that within its power, the state of the soil. With all above ground, the farmer has little concern. If plants are nourished chiefly from the air, it is evident that the farmer is concerned only to produce that state of the development of the organs of plants, best adapted to the aspiration of the aërial elements. This 
state is influenced chiefly by the soil. There is the farmer's true field of action.

104. Differ as opinions may about the ultimate chemical constitution, and the mode of action of geine, whether by being taken up as a solution of geine, and of its compounds with the earths and metals, called geine compounds, or only as a source of carbonic acid, the great practical lesson of all agricultural experience teaches that geine is essential to the growth and perfection of seed, that without geine crops are not raised. Geine is as essential to plants as is food to animals. So far as nourishment is derived from the soil, geine is the food of plants. It may be laid down as the eighth principle of agricultural chemistry, GEINE, IN SOME FORM, IS ESSENTIAL TO AGRICULTURE.

105. In all its forms, it is agriculturally one and the same thing. They are all included in the terms humus, or mould, or geine. Geine, in its agricultural sense, is a generic term. It includes all the decomposed organic matter of the soil. It concerns the farmer less to know the ultimate chemical constitution, than it does the practical, agricultural value of a class of compounds termed geine. Restricting that term to the definite compound which chemists have called humic acid, an account of its relations will convey a full idea of whatever other organic compounds are found in soil.

In describing geine thus specifically, the properties of the whole class are described under its generic name.

106. It has been stated already, that geine is the product of decomposition of bodies once endowed with life. For the present purpose, it may be considered as the result of vegetable decomposition.

107. Life, and the manner how plants grow, may not be understood. Growth is a living process. Decay is a chemical process. Its laws are not only understood, but its pro- 
ducts may be limited, controlled, hastened. Decay is fermentation, and this, marked by its several stages, ends in putrefaction. Putrefaction is the silent and onward march of decay. Its goal is geine.

108. If dry vegetable matters are soaked in water that is soon discolored, a product of decomposition is obtained; its peculiar character is solubility in water. This solution, being exposed to air, soon becomes filled with little flocks, which gradually subside. This sediment is still a very little soluble in water, but so very sparingly that it may be said to be insoluble. If the sediment is exposed a little time to air it regains the property of solubility in water, is easily dissolved in part, by potash lye, or any alkaline lye, whether caustic or mild.

109. The original brown solution may be considered as extract of mould. The sediment as a compound of the several acids of geine and carbonaceous mould. These are either soluble or insoluble in water or alkali; and hence, geine is divided into soluble and insoluble. The soluble is dissolved by water, by alcohol, by alkalies. The insoluble cannot be dissolved by any of these agents, nor by acids. The properties of geine, in water and alkali, or its behavior, as it is termed, is of the highest importance to the farmer, and are to be considered in detail.

110. The first and earliest product of decay, is that which is so easily soluble in water (108). If it could be at once seized upon, it would be, doubtless, a perfectly colorless solution, but it changes to a brownish color by exposure to air. This character is very common in solutions of organic matter. It is due in this case to the formation of the insoluble state.

111. If a little alum is dissolved in the watery solution of geine, and then a few drops of spirits of hartshorn, or sal 
volatile, or as it is termed by chemists, water of ammonia, are added, the earth alumina will be let loose from the alum, and it will immediately combine with, and precipitate the geine, that is, little flocks fall down gradually in the liquor. Hence is derived an important character. Geine has a great affinity for alumina. If lime had been added to the solution of geine, the same effect would have followed. The same effect would be produced by magnesia, by oxide of iron, and by manganese.

112. Alumina, lime, magnesia, oxides of iron, and manganese, will, therefore, in soil, immediately seize upon any soluble geine, and, forming compounds with it, detain it there. The air and water will have now little action upon it.

113. But supposing that none of these elements (112) are present in soil, the fact stated (110) shows that all soluble geine, or solution of extract in water, soon passes to a mixture of soluble and insoluble, forming a dark brown powder. This is thus withdrawn, deep in the soil, from the immediate action of the air, and undergoes no further change. It may remain unchanged an indefinite time. If ploughed up, exposed anyhow to the action of air or moisture, it again becomes partly soluble in water, and exhibits its former characters, viz.: great affinity for earths and metallic oxides. In this state it is VEGETABLE Mould.

114. Vegetable mould, then, is a mixture of the organic and inorganic elements of soil. It is a compound of soluble geine with earths and metals, mixed with soluble and insoluble geine. It is a chemical compound of organic with inorganic parts of soil, mixed with a large portion of free organic mattèr.

115. The inorganic elements of mould are, 1st. The bases found in the soil, produced by the decomposition of silicates, as lime, potash, soda, magnesia, alumina, iron, \&c. 2dly. 
Those which already had existed in plants, combined with vegetable acids. These last, by decomposition, escape as carbonic acid, or in acid vapors and water, while the bases, or earths and oxides with which they were combined, remain, and are immediately seized upon by the forming geine; while the uncombined geine passes to the state of a brown coal-like powder.

116. The properties of this brown powder of mould are, 1st. Partial solubility in water. Cold water dissolves only about one twenty-five-hundredth part of its weight, hot water a little more. $2 \mathrm{~d}$. It is a perfectly neutral substance, exhibiting neither acid, nor alkaline properties, but all alkalies develop it in acid properties. In this state it is termed geic or humic acid. It is evident, therefore, that geic or humic acid can never exist free in soil, so long as free bases are there present, as lime, alumina, iron, \&c. It is produced by the action of alkaline bases, and immediately combines with them, forming salts, which are termed geates.

117. A third property of the brown powder of mould is, that after alkalies have acted on it, and developed acid properties, its solubility in water is considerably increased, while it continues in a moist state. If dried, in this acid state, it becomes almost insoluble in water.

118. The geates found in soil have the following characters: 1st. All the alkaline geates are very soluble in water. The solution is of a brown color, according to its strength, from a light brown to a deep coffee color, or almost black; acids precipitate this solution, and the geine falls in light brown flocks, exceedingly bulky. This precipitate may be washed in water, rendered a little acid; but simple water, in consequence of the great solubility of geine, developed by its combination with alkali, will dissolve nearly all the precipitate. 
2d. Lime water, added to a solution of an alkaline geate, forms a precipitate of geate of lime. It is to be observed, that a cautious and gradual addition of lime water forms a precipitate, which immediately re-dissolves. This is soluble geate of lime. It requires 2000 parts of water to dissolve it, being a very little more soluble than geine itself and only half as soluble as lime alone. 'An excess of lime water precipitates all the geine as insoluble geate of lime. The properties of this insoluble geate of lime, are,

119. 1st. Almost perfect insolubility in water and alkalies.

2d. Decomposable by alkalies.

120. Geate of magnesia is easily soluble in water. It is the most soluble of all the earthy geates. It requires only 160 parts of water to dissolve one of geate of magnesia. It is decomposable by alkalies, and then both acid and base are dissolved. The geates of lime and magnesia, when exposed to air, absorb carbonic acid; a salt is formed, containing an excess of geine, that is, the carbonic acid unites with a part of the lime. These super-geates, as they are termed, are always much more soluble than the neutral geates.

121. Geate of alumina is soluble in water, and in alkali, without decomposition. It requires 4200 parts of water to dissolve it, but is abundantly soluble in alkali.

122. Geate of iron requires 2300 parts of water to dissolve it. Like geate of alumina, it dissolves easily in alkaline carbonates.

123. Geate of manganese requires 1450 parts of water to dissolve it, and though soluble in ammonia, is insoluble in potash or soda.

124. The properties of the geates are of the highest practical importance. The three earths, lime, magnesia, and 
alumina, are universal constituents of soil, and the two first are constantly present in plants. In their relation to geine, these all combine with that, they all form soluble compounds in the moist state, but after having been thoroughly dried, these geates are insoluble, even sun baking diminishes their solubility. In this dried state, they are earthy powders, and have long been mistaken for earthy portions of soil. The fict that lime and magnesia form super-salts (120), may help to explain why the free use of lime may often require a long time to develop any beneficial effects. At first, its action renders the geine insoluble; and it is only when, by exposure, the lime is changed in part to a carbonate, and thus rendered inert, that a super-geate of lime, which is very soluble, forms and begins to show its effects upon vegetation. The easy decomposition of geate of lime, by alkaline carbonates, teaches also, that if to geate of lime is added an alkaline carbonate, the geine may be dissoluble, and brought into use. It is probable, that when land has been overlimed, the evil can be corrected only by the use of ashes. The carbonate of lime will act on the silicates, as will be hereafter shown.

125. The properties and relations of geine with water, are also of the highest agricultural value (116). The great insolubility shows at once how small must be the amount of this portion of soil, which can be ever removed by drainage or filtration, by flood, or rain, and that, in the practice of irrigation, very little effect can be due to the solvent power of water on geine. Its almost total insolubility, seems a wise provision of a far-reaching Providence, that an element of soil, which has been and can be produced by the decay of organic bodies only, and chiefly by plants on the earth's surface, should not be borne away by the first falling shower, 
126. Not less important to the farmer are the relations of geine to alkalies, its solubility is wonderfully increased by their action; this is a most valuable, because available property; it allows the farmer to bring into use, by the application of alkalies, the geine, which, in its insoluble state, is quite valueless. This remarkable property is not confined to that portion of geine which, it may be supposed, is chemically combined with alkali. Alkali, by the mere action of presence, by its catalytic action, which will be hereafter explained, renders an indefinite, but large quantity of geine soluble in water. This is a principle of high practical value, and were the results of the principles detailed in the foregoing pages to terminate in this fact, that alone rightly pondered, would account for a vast number of facts in vegetable physiology, and lead to new views in the pursuit of agriculture, not less important than practical.

The organic matter of soil contains within itself the element of its own partial solution, that is, ammonia. This is generally combined, as has been shown (101), with crenic and apocrenic acids. Of the seven organic matters found in soil, these acids compose the smallest proportion. Their importance, however, is in the inverse ratio to their quantity. Their properties require a distinct account, allied as they are, for the most part, to those of the other geine acids.

Crenic and apocrenic acids are many-based acids; that is, they saturate several proportions of one base, or one proportion of several bases at once.

Crenic acid saturates four, and apocrenic acid five equivalents of bases. Compound salts are thus formed by these acids, with the various alkaline, earthy and metallic bases found in the soil. Thus, one proportion of apocrenic acid may be found with one of ammonia, one of potash, ore of lime, one of iron, one of magnesia. These, by their union, 
though in part insoluble, form a compound soluble salt. These double salts are, therefore, those which the plants chiefly abstract from the soil. Hence, that there may be, as there must be in fertile soil, a continued supply of these salts, nature has provided constant sources of their reproduction. The sources are two-fold. This is a point of too much importance to be passed by without fuller elucidation.

It has been stated (100) that the union of hydrogen and nitrogen forms ammonia. This alkali, by the action of the oxygen of the air, becomes nitric acid. These are the facts. Ammonia in air, in contact with porous or decaying matters, becomes aqua fortis. Moist decaying substances induce the nitrogen of air inclosed in their pores, to become first ammonia, and then an acid. There is then a constant formation more or less, according to circumstances, of nitric acid in the transformation of geine. What now becomes of this nitric acid? It forms either nitrates or apocrenates.

If abundant alkaline bases are present, as potash, soda, lime, magnesia, the nitric acid unites with these, one or all, according to quantity and varieties of saltpetre-that is, nitrates result. If alkaline bases are absent, then nitric acid converts humic acid into apocrenic acid and ammonia, itself furnishing the nitrogen for that alkaline base. The kind of change need not be detailed, or here illustrated. It is enough to state, that nitric acid and humic acid, by their mutual reactions, produce apocrenate of ammonia, water, and carbonic acid. This is one source of the reproduction of apocrenate.

A second source is found in an abundance of decaying organic matter in soil. Ammonia is here copiously produced, but not a corresponding proportion of nitric acid, for the oxygen of the air essential to this change, is seized by the carbon and hydrogen of decaying matter. 
Where then there is abundance of organic matter without alkaline bases, there is also fully evolved ammonia and apocrenic acid, and apocrenates result. Where, on the contrary, little organic matter and abundance of alkaline bases are present, there the ammonia, both of the air and of the decaying body, is converted to nitric acid, and nitrates result. If the nitric acid which is produced, meets with humate of ammonia, the acid is decomposed into apocrenic and ammonia, while the ammonia of the humate is transferred to other portions of geine acid, always forming in the soil.

The crenic and apocrenic acid are mutually convertible, but with very different results. Freely exposed to air, oxygen is absorbed by crenic acid; apocrenic acid and water result. While apocrenic acid by nitric acid is changed to crenic and carbonic acid.

All these changes are worthy of study. The ultimate results of all are the formation of water and carbonic acid. The intermediate products are ammonia and nitrates, and soluble salts of the bases in soil, essential to the growth of plants.

Here then is at once opened to view the necessity of the presence of geine in soil. No practical farmer ever had other opinion than this, that decaying vegetable matter in soil, matter in an active state of decay, is essential to a good crop. It is the experience of ages, the result of observation and experiment from the remotest times. Though, in the conflict of opinion, attempts have been made to set aside this experience and practice, it may be assumed that science has now shown the specific grounds of this universal belief.

127. Hitherto the action of geine on soil only, has been considered, and its chemical composition pointed out, sufficiently for all practical purposes. The chemical proportion of the elements of geine is unconnected with the practical 
question, how far it is essential to plants. The fact that the most barren soil contains these elements in vast quantity, that exhausted land is nearly equally rich in these, as is the highly-productive, has been overlooked. The amount of nitrogen in geine, even in exhausted soil, is sufficient to supply that element to several crops of grain. The amount of carbon, oxygen, hydrogen and nitrogen, in a poor, sandy, barren soil, has been proved, by chemical analysis, to be not less than thirty-four tons per acre, taking the soil at only a foot in depth. If the light of modern chemistry shall hereafter teach that these are never taken from the geine of soil, it will teach also what the true action of geine is. If no approach to the solution of this important question has yet been made, still, the absolute necessity of geine in soil is admitted by all practical men.

Some further attempt to explain this subject will be made in the next chapter, and the following appendix may be omitted by those to whom practical results are of more value than philosophy. It is hoped, however, that the new and important analyses, contained in this appendix, will amply repay the labor of studying their results, for the first time laid before the American farmer, in the second edition of this work. 


\section{APPENDIX TO CHAPTER IV.}

\section{HISTORY OF GEINE.}

Some account of the chemical history of a substance which has caused no little discussion in late agricultural reports and publications, may not be here misplaced. It may tend to soften the doubts of those who are, and with reason apt to mistrust the utility of a substance, upon whose chemical nature there is such an apparent difference of opinion. If farmers are to wait till doctors agree, there will be no harvest. Happily this discussion is in nowise connected with the practical application of geine. It is a difference about names, not things. In 1797, Vauquelin, a distinguished French chemist, gave an account of a substance which had exuded from the bark of an elm tree. It was a shining, brittle, black substance, insoluble in alcohol, soluble in hot water, with a brown color, and contained potash.

In 1802, Klaproth, a Swedish analyst, received from Palermo a specimen of this elm gum, and found it contained a portion of resinous matter, and confirmed Vauquelin's observations. In 1810, Berzelius, the most acute chenist of the age, in experimenting on the barks of various trees, noticed products similar to the elm gum, particularly in pine bark, Peruvian bark, and especially in the elm, whose properties will be presently mentioned; but he not only gave these products no name, but pointed out marked differences between them. The substance found in pine is 
allied to what is called pectic acid, that in Peruvian bark approaches starch, while that from the elm is only a variety of vegetable mucilage.

In 1812, James Smithson, an English chemist, and the munificent founder of the "Institute" which bears his name, gave to the Royal Society of London an account of his experiments on elm gum, which he had received from the same place and person who originally sent the article to Klaproth. Smithson thought the substance more allied to extractive matter, than to resin, and noticed that it contained 20 per cent. of potash. A similar substance obtained from the exudation of an English elm, contained a larger per centage of potash, but no trace of this new substance was detected in elm sap.

In 1813, Dr. Thomas Thomson, the Coryphæus of British chemists, experimented on this elm gum in its several varieties, and embracing the prevalent opinion of its distinct nature, not, however, because prevalent, but from his own researches, erected it into a distinct vegetable principle, under the name of uLMrs, from ulmus, the Latin for elm. He confounded under this name the several products noticed by Berzelius, in bark; and hence, thinks there are several varieties of this substance, though Berzelius does not countenance this idea. Thomson was the first who ever procured ulmin pure, but this was not the elm mucilage, but the extractive matter, and he thus gave the name ulmin to the apotheme of Berzelius.

Not long after this name had become the property of chemists, Braconnot found, in experimenting on the action of alkali on woody fibre, that a substance was produced analogous to elm gum and the varieties of ulmin, and, in 1830, Boullay noticed that ulmin had acid properties, and gave to it the name of ULMIC ACID. 
The properties and relations of ulmin and of ulmic acid, now engaged the attention of many expert chemists. It was found to be the product of a great many vegetable decompositions by various agents, by alkali, by acids, earths, oxides, by fire, by water. All these hasten the process of decay. As a general law, it may be stated that all substances oxidating, and gently acting on organic matter, produce ulmin. Hence, it was found in a vast variety of substances, and even cast-iron was found to contain about 2 per cent. of a compound so analogous to ulmin, that it is so called. But, above all, it was found to be the great product of spontaneous decay of plants, and hence existed abundantly in peat and soil. Sprengel, directing his attention particularly to its existence in soil before that form of it was universally allowed to be identical with ulmin and ulmic acid, bestowed on it the rame of humic acid, from the Latin, humus, or mould. - Sprengel investigated minutely the various salts of this substance, and first endeavored to determine its chemical constituents.

Boullay soon followed in the same path of investigation, and with almost similar results. There were marked differences between all the forms yet observed, that is, between elm gum of Palermo, the product of bark, the artificial ulmin of Braconnot, and that of soil. A multitude of different but analogous substances were confounded under a common name, which began to be applied to the matter of all vegetables, which, after having been treated with alcohol and water, yielded to alkali a solution precipitable in brown flocks, by an acid. Under these circumstances, Berzelius objected to the term altogether, and if there is a substance to which he would apply the name ulmin, it is to the mucilage of elm. As this has been the source of no small confusion, an account of it may be here introduced. Elm bark 
is treated with alcohol. The tincture is evaporated dry, and the extract treated with water, which dissolves a brown extractive matter, leaves an insoluble residue, which being treated with ether, leaves a small quantity of a brownish matter, analogous to the extractive of chemists, or the brown apotheme of Berzelius. The sap of elm contains acetate and carbonate of potash. Here, then, are all the elements of elm gum, as examined by Vauquelin, Klaproth, Smithson, Thomson. Not only the elm, but other trees, under diseased action, exude these matters, and under the influence of air, and the potash, the diseased exudation from the elm bark is changed to true ulmic acid, which unites with the potash, and both with the mucilage. The mucilage may, by processes not here necessary to be detailed, be procured pure, as a hard, opaque, colorless, insipid, and inodorous gum. It moistens easily, swells in water, becoming a semi-transparent mucilage. It is insoluble in alkali, affords no ammonia by dry distillation. Boiled with alkaline lye, it affords a clear mucilaginous liquor, which browns by being exposed to air. If this lye or solution is exactly neutralized by acetic acid, lime water and salts of lime produce no precipitate in it, and it is only rendered slightly turbid by sulphuric, nitric and muriatic acids. It is not precipitated by acetate of lead, nor by sulphate of iron. With alcohol and sub-acetate of lead it affords a mucilaginous precipitate. It is evident that it differs widely from artificial ulmin, and from ulmin of soil, and, therefore, when Berzelius turned his attention to that, having advised the abandonment of the name ulmin, as inapplicable to any one substance, he bestowed on the ulmin of soil the name of GEINE, from the Greek $g \bar{e}$, earth. If a distinction is therefore to be maintained, it may be said that ulmin is the product of life; geine, of decay. 
The mass of matter called mould or humus, has many analogies with the artificial ulmin of authors, but taken as a whole, there are decided differences. These were noticed by Berzelius, and hence he divided, in an edition of his chemistry (French translation of 1832), the constituents of the organic part of mould or humus, into,

1st. Extract of mould. 2d. Geine. 3d. Carbonaceous mould, or coal of humus, as it is often termed. He noticed that these mutually passed into each other. This shows a great similarity if not identity of chemical constituents. He did not pretend to determine that, but by his citing, in order to determine the elements of his No. 2 , or geine, the analysis by Sprengel of humic acid, and of that of ulmic acid by Boullay, it is evident that he considered his geine identical with their humic and ulmic acids; but still he considered new researches to be necessary to determine accurately the composition of either. Later experiments have proved the perfect identity of geine, and of humic acid, and hence, Berzelius has withdrawn the name geine, and returned to that of humic acid, the usual term applied to the organic acid of soil. He could not, consistently, have gone back a step further, and substituted ulmin for geine, particularly after he was violently attacked by Raspail, for abandoning that ancient and much abused name.

The great distinction pointed out by Berzelius, in his three varieties of mould, was founded on their solubility or insolubility, by water and by alkalies. The author of these pages, while engaged in researches upon the action of mordants, and of cow-dung, in calico printing, began in 1833, before he had met with the work of Berzelius, had also noticed this marked distinction, and several other new and important facts, relating to what he then called, from its analogies, ulmin. For all oractical purposes, the distinction 
was enough. When, a few years after, his attention was accidentally called to soil, the name of Berzelius, geine, was given by him to the whole organic matter of mould, or humus, and that matter was also, as a convenient practical division, separated into soluble and inseluble, including the various geic salts which he detected in soil. In the edition - of Berzelius above cited, two other organic compounds are noticed, as being among the general products of putrefaction, traces of which Berzelius noticed in soil. These were called crenic and apocrenic acids, from "krēnēe," Greek, for fountain, having been first detected in spring water.

The presence of nitrogen was detected by Berzelius, in crenic and apocrenic acid. This sufficiently diștinguished them from geine, extract of, and carbonaceous mould. Though these acids were detected after the name of geine had been applied, yet the presence of nitrogen in these, would at once have led Berzelius to examine geine anew, if he had any suspicion that it contained that element, or that he had mistaken the chemical nature of that substance. Unless we suppose, with Raspail, that nitrogen in these acids exists and acts only as he supposes it does in gluten, as an accident, or as an ammoniacal salt, it cannot be supposed that geine and these aciảs are identical, or can ever pass into each other. Nor has the progress of chemical discovery led to the abandonment of geine as a distinct principle. The whole doctrine of naming the elements of soil may be tabulated.

THE ORGANTC RLENENTS OF MYULD, OR HUMUS, BY BERTELIUS'S METHOD.

\begin{tabular}{|c|c|c|}
\hline 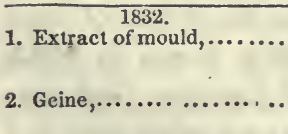 & $\begin{array}{l}1840 \\
\text { 1. Extract of mould,......... } \\
\text { 2. Humic acid,............. }\end{array}$ & $\begin{array}{l}\text { Vegetable extract of } \\
\text { authors, apotheme of } \\
\text { Berzelius. } \\
\text { Ulmic of Boullay and } \\
\text { others, sacchulmic of } \\
\text { Liebig. }\end{array}$ \\
\hline $\begin{array}{l}\text { 3. Carbonaceous mou'd,.... } \\
\text { 4. Crenic acid, } \ldots \ldots \ldots \ldots \ldots \\
\text { 5. Anocrenic acid, } \ldots \ldots \ldots \ldots\end{array}$ & 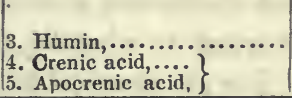 & $\begin{array}{l}\text { Ulmin of authors, sac- } \\
\text { clulmin of Liebig. } \\
\text { Admitted by most au- } \\
\text { thors. }\end{array}$ \\
\hline
\end{tabular}


It becomes, therefore, a question, whether the term geine is not the only proper term to be retained, applicable to the various forms found in soil ; and its distinction into soluble and insoluble, well founded for all practical purposes. This question may be answered by a reference to the analysis of geine. It includes not only that, so called in 1832 by Berzelius, the equivalent of which, by the table, is ulmic and humic acid, but also all the forms. On this subject, during the imperfect state of organic analysis ten years ago, there may have been room for doubt; especially when the most consummate organic analyst of the age, Liebig, asserts that it is exceedingly difficult to estimate quantities less than one half per cent. Even now, when the results of the most expert analysts have thrown a shade of doubt over the determination of the true proportion of carbon in carbonic acid, a proportion for so many years considered one of the best established facts of chemistry, it may be doubted whether later analyses of geine approach nearer practical truth than those executed almost in the infancy of the science. The constitution of geine, as determined by Boullay and Malaguti, admitted by all to be worthy of confidence, is thus stated :-

\begin{tabular}{|c|c|c|c|}
\hline P. Boullay, (Thomson) & $\begin{array}{l}\text { Carbon. } \\
56.7\end{array}$ & $\begin{array}{c}\text { Hydrogen. } \\
4.8\end{array}$ & $\begin{array}{l}\text { Oxygen. } \\
38.50\end{array}$ \\
\hline " Jr. (Lassaigne) & 57.64 & 4.70 & 37.56 \\
\hline Malaguti, (Dumas) & 57.48 & 4.76 & 37.06 \\
\hline Average, & 57.30 & 4.75 & 37.70 \\
\hline
\end{tabular}

But it may be said that these refer only to the artificial productions. These may be quite other compounds from that found in the soil. Let the analysis of geine of soil, as determined by the latest researches, answer such objection.

During the last two or three years. Muldez in whose ana- 
lytical tact chemists generally place the utmost confidence, has examined the various forms of geine. He has now published the elaborate results of his long labor. The following sketch of these, which shed such a new light over this complicated subject, is chiefly drawn from Berzelius's Report for 1841, in which he speaks of them in high praise. While it will be seen that Mulder refers to the various forms of geine, under names used by Berzelius, he confirms the fact that their great difference depends upon their being soluble or insoluble in alkalies, and has added a crowd of new facts, which connect all the forms in a beautiful and consistent manner. Malaguti had procured, by boiling sugar with dilute acid, ulmic acid in distinct crystals. By long boiling in water, it is converted into ulmin, losing its solubility in alkali without any change of composition.

Stein had already, by repeating the experiments of Malaguti, arrived at products whose analytical results differed from Malaguti's. Mulder, repeating the process of boiling sugar with weak acid, and examining the product, has confirmed Stein's results, and also what has been advanced, that the forms of geine thus produced are, as Malaguti had observed, identical in composition; and has shown that the various forms depend on the circumstances of the manipulation.

The cataly tic action of weak acid, boiled upon sugar, produces first ulmin, and ulmic acid. It is remarkable that these products are not formed in vacuo. This is due, not to the want of oxygen, but to the want of pressure. Boiled, under the pressure of hydrogen, or nitrogen gas, ulmin and its acid are produced. The products formed from sugar and weak acids, in a vacuum, are humin, and humic acid. Ulmin, and ulmic acid, are therefore the primary products of this action in air or under pressure. If these are separated and again boiled with weak acid, in contact with air, they are 
changed into humin, and humic acid. These are therefore secondary products. Humin, and humic acid, are produced directly, by allowing a free and abundant access of air. Ulmin, and ulmic acid, are then rapidly transformed to humin, and humic acid. Strong acid also hastens this transformation, but at the same time changes humic acid to humin. Formic acid is always produced, and distils off during the process; and also two other new acids. The discoverer of one, was Peligot, in 1828, which Mulder now calls glucic acid, and he himself has added another, produced from this, which is called apoglucic acid. Passing over these, it is difficult to procure the other acids and neutral bodies free from mixture. Whatever may be the quantity of sugar, or the circumstances of the manipulation, it is impossible to convert more than one-fifth of the sugar into ulmin, and humin, and humic and ulmic acids. The other four-fifths are changed into formic, glucic, and apoglucic acids.

Having effected the change of one-fifth of the sugar, the ulmic and humic acids are separated from ulmin and humin by potash. Ammonia cannot be used for this purpose. The reason will appear in the sequel. Having separated the several substances, their analysis presents the following results. The proportion per cent. the author has deduced for the greater part from Mulder's formulæ. What a chemical formula is, will be readily understood from (55). A formula is merely the true expression of an analysis by the number of combining proportions. It presents to the eye at once the constitution of any compound, and affords a readier mode of comparing several bodies like-constituted, than does the proportion per 100 parts. That is added for those whose taste may have led them to omit the details (55).

But it may here be stated that $\mathrm{C}$ stands for carbon, $\mathrm{H}$ 
hydrogen, $\mathrm{O}$ oxygen, Am. ammonia, a compound of 3 hydrogen and 1 nitrogen; and Aq. stands for water (aqua), a compound of one of hydrogen and 1 of oxygen; 2 aq. is 2 water.

TABLE OF COMPOSITION OF ULMIN, ETC.

Per 100 parts.

Formula. Carbon. Hydrogen. Oxygen.

\begin{tabular}{|c|c|c|c|}
\hline Ulmin, & $\mathrm{C}^{40} \mathrm{H}^{16} \mathrm{O}^{14}$ & 65.30 & 4.30 \\
\hline Ulmic acid, & $\mathrm{C}^{40} \mathrm{H}^{14} \mathrm{O}^{12}$ & 68.95 & 4.23 \\
\hline Humin, & $\mathrm{C}^{40} \mathrm{H}^{15} \mathrm{O}^{15}$ & 64.67 & 4.32 \\
\hline Humic acid, & $\mathrm{C}^{40} \mathrm{H}^{12} \mathrm{O}^{12}$ & 69.25 & 3.42 \\
\hline
\end{tabular}

It is thus seen that ulmic and humic acids differ from ulmin and humin, by containing, the first, two, and the second, three, atoms of the elements of water less than the neutral bodies from which they are formed. The ulmic and humic acids above, are supposed to be perfectly dry. Each may combine with a definite proportion of water, forming hydrated acids. In this case they contain the same absolute and relative number of the same elements as do ulmin and humin. They are thus said to be isomeric with them. The composition of the hydrated acids is-

Ulmic, $\mathrm{C}^{40} \mathrm{H}^{14} \mathrm{O}^{12}+2$ aqua or 2 hydrogen and 2 oxygen. Humic, $\mathrm{C}^{40} \mathrm{H}^{12} \mathrm{O}^{12}+3$ aqua or 3 " " 3 "

These acids combine with bases. If these acids are dissolved by ammonia, and precipitated by an acid, they fall combined with ammonia. Ulmate of ammonia, precipitated by metallic salts, forms double salts of ammonia and a metallic oxide. The composition of these salts of ammonia is- 
Ulmate of ammonia, $\quad \mathrm{C}^{40} \mathrm{H}^{14} \mathrm{O}_{1}^{12}+$ ammonia +2 aqua. Humate " $\mathrm{C}^{40} \mathrm{H}^{12} \mathrm{O}^{12}+$ ammonia +3 aqua.

$\begin{array}{lcccc}\text { Or, per ent. } & \text { Carb. } & \text { Hyd. } & \text { Oxy. } & \text { Nitrog. } \\ \text { Ulmate of ammonia, } & 64.75 & 5.06 & 26.22 & 3.97 . \\ \text { Humate " } & 64.58 & 4.22 & 27.46 & 3.74 .\end{array}$

Mulder, having thus shown the composition of these artificial products, proceeds to trace similar natural products in peat, decayed wood, and soil. Here his labors have a direct bearing on agriculture. He points out their relation with those above in so clear and masterly a manner, that it is impossible not to believe that, in agriculture, the artificial and natural products would produce like effects. In the natural formation of these substances, Mulder remarks, generally, that, during decay, without free access of air, ulmin and ulmic acid are formed, as in peat of a brown color, while, as in black peats with free access of air, humin and humic acids are produced from the primary products. This agrees with his experiments in air, and a vacuum. Peat, of a brown color, having been treated with alcohol, to remove all resinous matter, was then treated with carbonate of soda. All the soluble matter was thus extracted, that is, the ulmic acid. The insoluble geine is ulmin. The soluble, precipitated, has all the characters of the ulnic acid of sugar. It differs only in this, it may not be heated above $284^{\circ}$ Fahrenheit, without decomposition, and then produces formic acid and water. Sugar-ulmic acid undergoes this change at $383^{\circ} \mathrm{F}$. Humic acid was prepared by a similar process, from black peat. It has all the external characters of sugarhumic acid. It differs by containing ammonia. Its soda solution, precipitated by muriatic acid, gave a precipitate containing one atom of humic acid, to one atom of ammonia. It loses no water at $284^{\circ} \mathrm{F}$; ; at about $365^{\circ} \mathrm{F}$. it evolves 
ammonia; at $383^{\circ}$ F. acetic acid. Humic acid was also prepared from the black mould of an old white willow, by a similar process as above. It suffers no change below $302^{\circ}$ F., and at $325^{\circ}$ it evolves water and acetic acid. Digested with caustic potash, it evolves ammonia. Continuing this digestion for twelve hours, and then precipitating the humic acid, it is found converted into ulmate of ammonia, with two portions of acid. It is a biulmate of ammonia, similar to that from peat. If digested with carbonate of soda, the product then is biulmate of ammonia, like that from sugar. Soil was treated by Mulder, first, with boiling alcohol, then with water, then with carbonate of soda, and the acids precipitated as usual, by muriatic acid. These precipitates were with difficulty obtained pure. They were repcatedly washed in cold water, dried, and again treated with alcohol, to remove every trace of crenic and apocrenic acid. These being removed, the precipitates were again dried, as in fact were all the products above described at $284^{\circ} \mathrm{F}$. They were then analyzed. It is remarkable that all these products are ammoniacal combinations. It is a combination, not as a salt, in which case the geine of soil would be at once soluble in water, but a compound of humin and ulmin, or of their acids with ammonia, probably like the compounds of ammonia with sulphates and other salts. The whole may be best presented in a table, and that these natural may be at once compared with the artificial products, these are also included. 


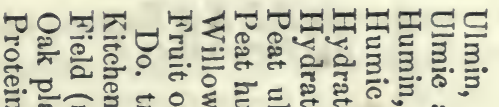

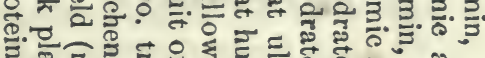

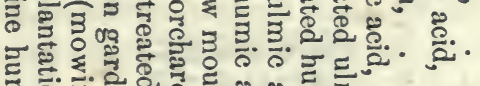

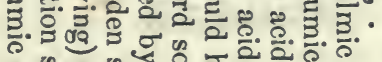

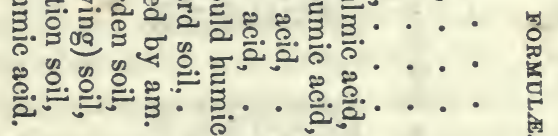

㤩

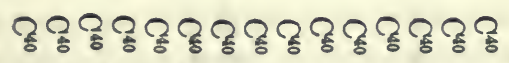

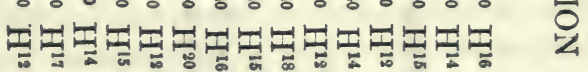

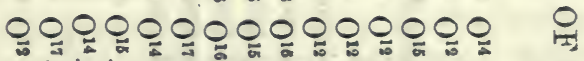

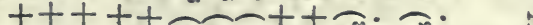

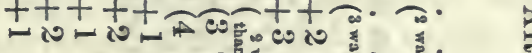

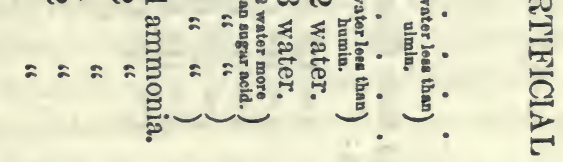

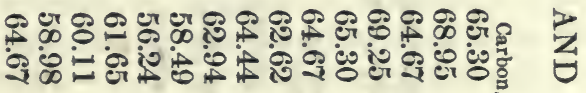

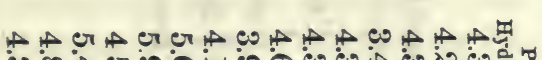
엉

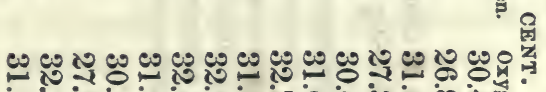

里

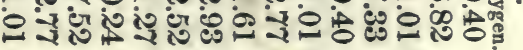

स्व

- los cos a co.

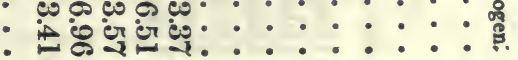
5 
HISTORY OF GEINE.

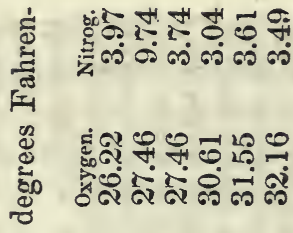

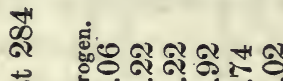

गु

के

อ รี่

I

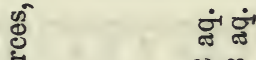

5

o t

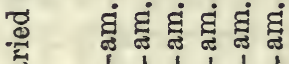

t $t+t+t$

ฤ

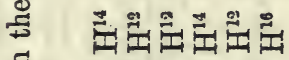

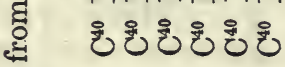

물

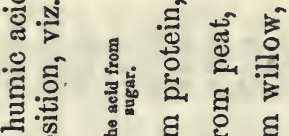

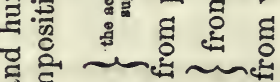

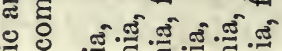

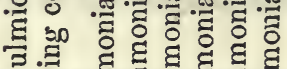

ए. ह ह ह ह ह घ 을 है हี हี हี

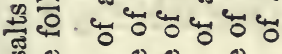
\%

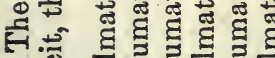

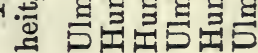


These are beauliful and valuable results. Executed by one of the great masters in organic analysis, they show a wonderful coincidence between the artificial and natural products. This has a direct connection with agriculture. The source of the nitrogen of plants depends upon these compounds of ammonia with the geine of soil. The composition of that substance shows that, by making it soluble, the farmer commands the same beneficial effects which may be produced by nitre. But the researches of Mulder do not terminate with the analyses. He has examined the compounds which these forms of geine produce with other acids, particularly with muriatic and nitric. The compound of nitric and humic acids is called nitro-humic acid; ulmin and ulmic, humin and humic acid are decomposed by weak nitric acid. They are converted by gentle heat immediately into a rust-colored powder, and by prolonged action evolve oxalic and formic acids and nitrate of ammonia. Nitro-humic acid, the rusty brown powder above, is soluble in water. Alkalies evolve ammonia from it. Late researches have shown that this compound is apocrenate of ammonia.

It is highly probable that this product is connected with the action of nitrates, or saltpetre in agriculture. All these products, observes Berzelius, are connected by an unknown thread. These black and almost insoluble acids, have a very weak saturating power, in comparison with their oxygen. This last exceeds that of the base, by 10,12 , or 14 times. Hence, Berzelius suggests that all these organic acids may have a composition analogous to sulpho-benzoic acid.

Notwithstanding the objections raised by Berzelius, founded upon a want of correspondence between the oxygen and saturating power of some of these forms of geine, they are probably modifications of one principle, differing not so much in their physical properties as do fibrine, albumen, and 
caseine, or flesh, white of egg, and curd of milk. These are identical in composition, modifications of a common princiciple to which the name, proteine, is given by Mulder, its discoverer. It is not among the least curious of his results that proteine is, by weak acids, changed into humate of ammonia, its acid being perfectly identical with that from sugar. In 1838, Prof. Hitcheock, in his report, published the following extract from one of the author's letters, when speaking of geine as the product chiefly of vegetable matter, it was added: "Animal substances afford a similar product, containing nitrogen." The author supposed at that time that the nitrogen in geine was of animal origin; but since it has been proved that proteine is derived from vegetables, the results of its decomposition by Mulder, leave no doubt that the proteine of vegetables is the source of the ammoniacal compounds of geine found in soil. That neither Mulder nor Berzelius have the slightest doubt that these ammoniacal compounds are wholly distinct from crenic and apocrenic acid, is evident from the care of Mulder to separate these last from the soil, and from the total silence of Berzelius respecting any mistake he may have been supposed to commit, by confounding geine with them.

It will be seen from the account of Mulder's researches, that geine is produced chiefly from the decay of woody fibre. All its forms are thence derived. It is from woody fibre, by the absorption of oxygen, by the access of air and moisture, that ulmic acid is first formed, and from this, by absorption of another portion of oxygen proceeds humic acid, and thus also, from this last again comes geic acid, and thence crenic, which by still a further change becomes apocrenic acid. All these transformations are continually occurring in soil. These occur not without the production of carbonic acid, water and ammonia. 


\section{CHAPTER V.}

THE MUTUAL ACTION OF THE ORGANIC AND INORGANIC ELEMENTS OF SOIL.

128. Is agriculture, little and seemingly unimportant discoveries are valuable. Nothing is to be despised, which may lead to a rational and true theory of agriculture; this only can lead to successful practice. Practice, founded on sound principles, can be taught only by a knowledge of the manner how the elements of soil affect each other, and vegetation. This knowledge cannot be obtained without the application of theoretical opinions. The opinions of merely scientific men, may be wholly theoretical; but what is science?

It is, says Davy, "refined common sense, the substitution of rational practice, for unsound prejudice."

In no department of human industry is there so great a demand for the union of theory and practice, as in agriculture. The book farmer and the practical farmer, must now shake hands. They have been too long wrestling, and trying to get each other down, at arm's length, and now grappling in side hug, they find the closer the embrace, the longer they stand. So it should be; theory and practice should mutually support each other.

129. The theoretical and the practical farmer aim at one common object. The latter is employing certain means to effect certain ends; the former unfolds the laws of nature, 
which limit and control the operations which are performed to effect that end. Theory may teach a rational and successful practice; this last may lead to a rational theory. But without a knowledge of the elements of soil, and of their mutual action, which is to be learned from chemistry only, the practical application of science to agriculture is but the draam of enthusiasts.

130. How do the elements of soil act? The answer involves two important considerations. 1st. The mutual chemical action of the elements of soil, their organic and inorganic parts on each other; and $2 \mathrm{~d}$. This action, as influenced and modified by the presence of living, growing plants.

131. The elements of soil are silicates, salts and geine. The silicates, as such, have no tendency to react on each other. These are-gradually decomposed by the action of the air. The great agent in this action is its carbonic acid, which gradually combines with the alkaline base of the silicates, and the potash and soda are converted into soluble salts, while the silex and alumina remain.

132. The result of this action is, that the land pecomes gradually more clayey and tenacious; while the alkaline bases, carried away by drainage or filtration, enter brooks and rivers, and are finally found in sea water. The potash of the ocean arises from the decomposition of rocks and soil. This action, though very marked on felspar, is comparatively nothing except on the naked and exposed surface of rocks. Soil suffers but little from this cause. The silicates of soil may be considered as stationary.

133. Let the class, salts, be now introduced into the soil ; of these the earthy carbonates only act upon silicates by mutual decomposition. The silicic acid acts on the lime, forming silicate of lime, while the carbonic acid, now let 
loose, acts as such upon other silicates, and eliminates or frees the alkaline bases. Let it be supposed that there is clay, or silicate of potash and alumina in the soil. Let carbonate of lime, that is marble, or air-slacked lime, shells, \&z., be added to the soil. The result is, that slowly but surely, chemical action takes place, the silicic acid pulling one away and the carbonic acid another, the lime is changed to silicate of lime, and the carbonic acid escapes, and now in its turn acts upon silicates as did carbonic acid of air. The alumina remains, the soil becomes more clayey. Thus sands by liming are amended.

134. This principle, of the action of carbonates, unravels the agency of a vast variety of substances, which appear to be very inert and inefficient. It must be remembered, that the action of silicates and salts is alone under consideration, uninfluenced by the presence of geine or plants. That action in its simplest form constitutes the following, which may be laid down as the ninth principle of agricultural chemistry, Carbonic acid, and the Carbonates, decompose the EARTHY, ALKALINE, AND METALliC SIliCATES OF SOIL.

135. The result of this action is, that the potash, soda, lime, magnesia, alumina, and metallic oxides are set free, and where silicate of alumina exists, the soil becomes more clayey, while the carbonic acid again acts upon silicates ot alkalies and forms carbonates of alkalies. A clue is thus given to the action of peat ashes, or coal ashes in amending a sandy soil. These ashes act by their carbonate of lime as above stated, freeing the alkali of the silicate of potash.

136. Hitherto, the action of the inorganic elements has been explained, uninfluenced by the organic or by geine. Referring to the properties of this substance, it will be recollected, that it is soluble or insoluble, that it combines with alkalies, earths, and metals. It exerts a twofold action. 1st. 
The geine combines with the potash, soda, lime, alumina, magnesia, which have been let loose by the action of carbonic acid, and of carbonates, and forms geic salts or geates, while the carbonic acid which may be let loose from any carbonate of lime, acting upon these geic salts, forms supergeates, which readily dissolve. It is thus evident, that geine exerts an important and powerful influence upon soil. It is the agent, prepared by nature, to dissolve the earthy constituents of soil, rendering them so soluble, that they become fit for food, or constituents of plants.

$2 \mathrm{~d}$. The free alkalies, produced as has been described by the influence of carbonic acid, and carbonates, act on geine. They render this soluble. The curious and important fact, that a small quantity of alkali renders an indefinite quantity of geine soluble, has been noticed (117); and it may now be added, that probably all the alkaline earths, and oxide of iron and manganese, possess this power of converting vegetable fibre into geine. This effect has long been known to be produced by potash and lime. These hasten decay; and next in power to lime, in this singular process, is alumina, then oxide of iron, in passing from a lower to a higher state of oxidation.

137. This remarkable process, this power, energy, function, influence, property, called by whatsoever name it may be, which is thus exerted, by the elements of silicates upon vegetable fibre, and insoluble geine; and the power of Ceveloping acid properties in that principle, is intimately connected with the action of growing plants upon soil. The joint effect of organic and inorganic elements of soil and plants may be better understood by adverting to the probable cause of this property of earths, alkalies and oxides; though in the present state of science, this cause may be apprehended only by giving it a name, which arranges only 
many facts under one view. The cause of this effect of alkalies upon geine, is to be sought in that power which has been denominated catalysis, and which French authors designate as the action of presence; that is, the mere presence of a body influences the nature of a second body, so as wholly to change its properties. It causes the elements of organic compounds to enter into new arrangements, by which they produce a totally different substance. The catalytic body, the present body, the changing body itself, suffers no change, except, perhaps, in some cases of ferments, whose activity depends upon their being in a state of decomposition, while the changed body loses nothing of its substance. It often gains oxygen and hydrogen, or the elements of water. For example, starch is converted into sugar by oil of vitriol. The acid suffers no change. It acts by catalysis, and converts the starch to sugar, simply by the addition of water, or its elements. So the peculiar principle found near the eye of the potato, converts starch first into gum, called dextrine, and then converts this into sugar of starch. So malt, by its gluten, converts starch into sugar in the process of brewing beer. But the effect of this action may not be confined to organic compounds only. It has lately been extended, by an acute German chemist, to all chemical changes; and it has been maintained that all chemical decomposition takes place in obedience only to a third substance, acting by its presence. Hence, this extension of the principle, will allow the decomposition of the mineral elements of soil, to be attributed to the catalytic action of the plant.

138. Having considered the action of the organic and inorganic elements of soil upon each other, it is seen, that though great, this action would be but very little in centuries. 'I'he geine itself would be dissipated in air, were it not that, by this provision, it is combined with the earthy part of the 
soil, and there retained for the use of plants, which may grow near it.

139. Let plants be grown in the soil, whose action has been considered. This introduces life into the process, and it gives life to all around it. It is not pretended to explain what the action of life is. It has many relations with chemical processes. By the refined chemistry of the present day, many products are formed, which have been usually, and in fact, are now considered products of living action only; the peculiar product of life, urea, is formed artificially; so of other products, and out of carbon, nitrogen, and water, nay be formed as many, and as complex products as are ever elaborated by a living process; yet life is not a chemical process, and were it attempted to explain how, out of the four simple elements, carbon, hydrogen, oxygen, and nitrogen, all the variety of regetable products are formed, it might be said that life is a catalytic power. The vital principle by its presence, impresses the same power on the food we take, that the peculiar principle in malt and in potato, called diastase, impresses on starch. It merely, by its presence, gives to the elements power to enter into new combinations, and then these combinations occur in obedience only to the well-known, established, eternal laws of chemical affinity.

140. So, too, the presence of a growing plant, of the root, of a seed, where life is, impresses on the soil, both on the organic and inorganic elements, power to enter into new arrangements. The soil, then, is not external to the plants; so far as life is concerned, it is as much internal as if the plant had a mouth and stomach, through and into which the soil might be fed.

141. Call this power life, electricity, galvanism, or by any other name, still the great fact, that the mere presence of a 
living, growing plant in soil, in one year effects a greater amount of its decomposition, than all atmospheric influences, in many years, is one of the very highest interest, in a practical view. It is, perhaps, of more value than all the other actions which have been considered.

142. It is this decomposing action of living plants, on the inorganic elements of soil, which affords a reasonable explanation of the action of salts in agriculture. The catalytic power of life dissociates the elements of salts. They enter iuto new combinations. The base and the acid are separated by the action of the living plant.

143. On no subject in agriculture are opinions more divided, than on the manner how salts or mineral manures act. Their amount in soil is small. That is soon exhausted. They cannot be artificially supplied, in excess, without inducing very serious injury, and, in fact, often produce barrenness; yet are often decidedly beneficial. It is not less diffcult to account for the good, than fur bad effects of salts. Among all the variety of substances acting as salts, a distinct theory is generally framed and adopted for each. If any attempt has been made to arrange all the facts relating to this subject, it has ended in this, that they are stimulants. They are to the plants what condiments are to the food of man. This may do very well as an illustration, and the author has elsewhere said, that "the soil is the plate, the geine the food, the salt the seasoning."

144. This leads to no practical result, except it be this, that if salts are seasoning, like the seasoning of our food, they must be used sparingly. Some general law is wanting, which shall at once account for the effects of salts, and while it points out how so very minute a portion as the four-hundredth part of one per cent. of the soil produces unquestionably good effects, one per cent. will be injurious. Some 
general principle is wanted, which will enable the farmer to say what the action of a salt will be; and whether he may apply one, or less than one per cent. of it, without risking his crop.

145. Such a general principle can be deduced from the known chemical action of the elements of soil, aided by the living plants, upon each other. It is this tenth principle of agricultural chemistry, THE BASE OF ALL SALTS ACTS EVER THE same in agriculture. Peculiarity of action depends ox THE ACID OF THE SALT.

146. Forget, reader, all other principles which have been presented to you. Banish from your mind, if you will, all that has been said, on the origin and nature of soil. Put it down, all, all to the account of book farming. Let it be branded all as theory, and that too as the worst of theories, theory fruitless, a goodly blossom bearing no fruit, a Dead Sea apple; but do not condemn the principle now enunciated. Let that stand alone, by itself, for itself. In all its length and breadth, it is the great practical principle of agricultural chemistry. It opens veins rich in results, more precious than mines of gold.

147. The action of salts in agriculture, is to be regarded in a twofuld light. First, a large proportion of salts is found in plants, composed of alkalies and alkaline bases of earths, united to a mineral acid, such as sulphuric, muriatic, phosphoric. These salts are taken up by the roots ${ }^{\circ}$ of plants when dissolved in water, and thus form a constituent of vegetables. Secondly, a large quantity of alkali and alkaline earths is united in plants, with a vegetable acid. In this case the salts of the soil have been decomposed by the living plant. What is the consequence? The base, if alkali, lime, alumina, magnesia, iron, acts upon geine, rendering that soluble, and it is then taken up as such, or it 
forms an alkaline or earthy, or metallic geate, which, entering the plant as such, is there decomposed by the vegetable acid produced in the living plant; while the acid of the salt thus let loose in the soil, acting on the silicates, forms new salts, which, in their turn, play a similar part to that produced by the original salt.

148. The effect of this action of salts is, that they continually reproduce themselves. The effect may be illustrated by yeast, which added to dough, begets a new portion of the fermenting principle, which again added to new dough, still begets new leaven, and this without end. It is not to be understood, from this illustration, that the action of salts is fermentation.

149. But let this action be farther illustrated; suppose there is added a salt, composed of muriatic acid and soda, that is common salt, to the soil. By the action of the living plant, this is decomposed. Its soda, or base, then acts on geine. If this has been long in an insoluble and perfectly useless condition, it is now rendered soluble, and hence supplies plants with food. A very marked and decided effect is perceived from applying a small quantity per acre, of a salt, which certainly of itself contains no nutriment for plants.

150. The effects here produced, may be due to the small quantity of alkali, acting on an indefinite quantity of geine; but the effect so often observed, of the minute quantity of salts, say one-hundredth of one per cent. of the soil, seems hardly compatible with the explanation. So far as it goes, this is its action; but very probably the quantity of alkali in the salt sown, is taken up as a geic salt, and immediately carried into the plants. The base then is withdrawn, yet the action continues. It continues through the whole time the fruit is forming. Some other source, therefore, of the per- 
manence of this action must be sought. That is due to the acid constituent of the salt. That, when the plant decomposed the salts, was let loose, and now acts on the silicates of the soil. It decomposes these, uniting first with the alkalies, and thus reproducing itself. It is again decomposed by the growing plant. The same round of action continues. Suppose all this had been witnessed on a worn-out, almost barren field. It is concluded at once, that there is some peculiar virtue in the salt applied, that it is of itself food, or manure; whereas the whole action is in obedience to a general law applicable to all salts.

151. Suppose plaster or gypsum has been applied; the effects of a bushel of plaster per acre, or even the one fourhundredth part of one per cent. of the soil, produces effects on alluvial land, which shows its good results, as far as eye can reach. It seems almost incredible that so minute a portion of a mineral can act at all, yet how beautifully is this result explained, by the principle that plants decompose, first, this salt; the lime, for plaster is a sulphate of lime, then acts on geine, which is thus rendered soluble; while the acid, the oil of vitriol or sulphuric acid, immediately acts on silicates. If silicates of alkali exist in the soil, we have now changed sulphate of lime for an alkaline sulphate, and if silicate of lime is also present, the potash or alkali, having been exhausted, plaster of Paris is formed anew. So long as there is in the soil organic matter, this action continues; and will continue till the plant has gradually withdrawn for its own.use, the acid of the salt which was introduced.

152. Fertility depends wholly on salts and geine. Without the last there is no fruit formed; without the salts the geine is locked up, is insoluble. Consider now the application of this principle, that the base of the salts acts always in one uniform way, its action is wholly upon geine; that 
the acid of salts acts upon silicates. Apply this principle to all mineral manures, as they are called. They are all connected by one common mode of action of their base. There is no speculation, there is no mystery, as to the mode how they act. The effect produced by such wonderfully minute quantities is no longer astonishing. It is no more wonderful than that leaven should make dough rise; it is even less mysterious.

153. Apply this principle to acids, which have sometimes been used. Sprinkle a small portion of oil of vitriol on the soil ; supposing no free base present, the silicates are decomposed by the oil of vitriol, and sulphates of alkalies, and alkaline earths are formed. These new formed salts are, in their turn, decomposed by the living plants; and the action on geine commences, as has been explained.

154. Consider how salts and geine are linked. It is at once seen how essential to the action of salts is the presence of organic matter, or geine in the soil. It is the want of a principle like that which has been stated, which has led to a waste of time and money, in applying mineral manures to worn-out and barren soil. Whereas, the principle (145) leads to the application of both salts and geine. The salts alone would be useless. Their first effect in either case, would be the same on silicates; but with geine, this action, like fermentation, goes on, begetting new sults; without it, this action ceases after the first chemical changes have occurred. In the first case, it goes on. In the second, it stops.

155. Salts without geine, act only on silicates of the soil. If, now, these silicates contain any portion of aqueous rock (11), they usually contain also distinct traces of organic matter. This matter is due, for the most part, to the geine, held in solution in the water, from which the rocks were deposited. It is certainly within the bounds, not only of a 
chemical possibility, but of a high degree of probability, that the carbon, under the influence of growing plants, may unite with oxygen or hydrogen, that is, with the elements of water, and form thus food for plants. Hence, on such soil, the mere application of salts, or of mineral manures, has produced, yea, and does produce, marked and wonderful effects. This would be the effect of salts, applied to soil produced by the decomposition of slate; even gneiss soil, which occurs occasionally in extensive patches, would be benefited, but much less by such application. But such soil forms an exception, both to the general law which has been stated, of the uniformity of mineral composition, and to the necessity of applying salts and geine in conjunction. These remarks may explain a seemingly possible anomaly to the principle, that the base of all salts acts in one uniform manner upon geine, and that peculiarities of action depend on the acid of the salt. The effects of the first part of this "proposition (145), have been explained; the effect of the second, is now to be considered.

156. Perhaps no principle in agriculture is better established than that an excess of any salt in the usual acceptation of that term, is a cause of barrenness. Yet it is quite as well established that the quantity of different salts admits of some latitude, and that some salts do produce better results than others. Referring to the acid constituents of these salts, it will be found that some acids are organic. They consist of hydrogen, carbon, oxygen, all which, under the influence of the living plant, may be dissociated, and their elements form geine. Other acids consist of oxygen and nitrogen, essential constituents of plants ; others consist of chlorine; others of sulphur and oxygen, and others of carbon and oxygen. In other words, the acids are composed of elements which form food for plants, or of elements 
which enter, in a small proportion only, into the composition of plants.

157. In the first case, the salts admit of a larger quantity being applied, than in the second. By the first, plants are fed, by the second, they are poisoned; for the base of all salts acting as has been explained, the acid is eliminated; if this is set free in large quantities, and its elements can be taken up and converted by the plant, well, good effects follow; if, on the other hand, the elements of the acid are such as the plant does not demand, they act like poison on the animal economy.

158. Let salts be divided, on this principle of the peculiarity of action depending upon the acid of the salts, into two classes; the first nourishing, the second poisoning plants. The first class contains, a. carbonates, b. nitrates, c. phosphates.

159. The action of the first class is to be studied under its three divisions. (a. 158), Carbonates. These include a very large portion of all salts used in agriculture. It includes limestone (14), marble, old mortar, shells, shell marl. In all these cases, the base or lime let loose by the action of the living plant, acts at once, as caustic lime upon insoluble geine, and unconverted vegetable fibre, changing these into soluble vegetable food; while the carbonic acid acts immediately upon silicates, decomposing these, and upon the geates in the soil, converting these into super-geates. Carbonates of alkalies, as ashes, \&c., act at once. They are soluble, their alkali acts immediately upon the geine. Their carbonic acid acts upon silicates and geine. Immediate and decided good effects follow their application; while carborate of lime acts slower. It often requires many years to bring out the good effects of carbonate of lime, and though ultimately these effects, it is believed, have never failed of 
being witnessed; yet so slowly, that its use has been often condemned. The principle which is herc discussed, may account for this apparent discrepancy. Suppose a barren, worn-out, exhausted soil, containing yet, a portion of insoluble geine and decayed vegetable matter, between the state of wood and insoluble geine, or even a portion of undecayed dead wood. It seems too unpromising to give it manure; little of that is to be spared, and that is bestowed upon better land. If this is in a country where lime is cheap, that is purchased, and freely applied, as it is in England, at the rate of about a cask to the rod. Even in this case no change is produced, the soil is as unproductive as ever. The experiment has failed, and is charged to book farming.

160. The properties of lime, and geine, are here to be remembered. Lime in excess, renders geine insoluble, granting it to have been in a soluble state. Lime changes vegetable fibre into soluble geine, but being applied in excess, it forms an insoluble salt. Now, by the supposition, there was no great excess of vegetable matter, and the lime rendering only a small portion of that soluble, is itself, then, always in excess, and though it converts, it at the same time locks up that geine which it had convorted. The reasoning will hold good, whether a cask to the acre, or a cask to the rod, has been applied.

161. The lime has been, perhaps, in a caustic state, fresh from the kiln, and as soon as it falls into powder it is spread and covered in. It is greedy of carbonic acid; so long as it remains caustic, it absorbs this gas, and slowly becomes carbonate of lime. It is now like shell marl, clam, oyster and muscle shells. The mode of reasoning applies to all these forms. Slowly, but surely, it may not be for some years, u gradual improvement in the limed soil of the exhausted field is perceived. The carbonate of lime begins to act on the 
silicates; and the alkalies of the silicates are eliminated. These solve or decompose the geine and geates, which the lime had locked up; at the same time the silicic acid acts on the carbonate of lime, volumes of carbonic acid are let loose. The carbonic acid itself reacts on silicates, eliminating a fresh portion of alkali, and upon the geates, converting these into super-geates. A round of change goes on, till perhaps every particle of vegetable food is withdrawn; crops are no longer raised. Having witnessed, though slow to believe it, good effects from liming, the farmer again applies it to the exhausted field; but no good effects can now follow, unless manure or decayed vegetable matter is also applied. This may be furnished in two ways, either artificially or naturally, that is, by allowing the scanty crop of all sorts of weeds, grass, mullein; \&c., to decay on the soil where it grew. But this subject will be considered in another place.

162. It has been attempted to show how the contradictory and anomalous effects of lime are explicable, on the principle (145); and here the general theory of the action of lime may be adverted to, much of which has been anticipated. Lime is a general term, it includes all forms of calcareous matter. It is the lime, the base of the salts which acts, and that always, as lime, no matter how it is applied; whether as inarble, as marl, shells, air-slacked lime, bones or plaster. In a restricted and usual acceptation of the term, lime refers only to that which has been burned, or stone lime. Its action is threefold, each distinct, first, as a neutralizersecondly, a decomposer-thirdly, a converter.

1st. Wherever free acids exist in soil, lime acts as a neutralizer. It has been asserted, on undoubted authority, that occasionally free phosphoric, muriatic, geic, acetic, and malic acids exist in soil.

2d. Soil may contain abundant geates, particularly geate 
of alumina, the least of all demanded oy plants. Long formed and sun-baked, they are scarcely acted on by rain or dew, and are almost useless. Here, lime, by decomposing these earthy and metallic geates, forms a combination which, in its nascent state, is readily dissolved. If the carbonate of lime acts better than the hydrate, it is because, following a well-known law, double decomposition is easier than single. If any acid geine exists in the soil, or any free acids, carbonic acid is then liberated, it acts on the geate of lime, super-geates result, and these are easily soluble.

3d. The great use of lime is as a converter, turning solid and insoluble geine, even solid vegetable fibre, into soluble vegetable food. Here is the point, where philosophy seems to give the choice, to refer this action to one of the rumcrous cases of catalytic change, which are every day becoming more and more familiar; or to explain the whole process by referring it to saponification. This word is used as conveying at once what is meant, but it is not meant to say that the product of lime and vegetable matter is soap. The action of lime on geine may be similar to its action on oil and fat. It is well-established that animal and vegetable oils and fats are converted into acids by the action of alkalies, earths, oxides, and even by vegetable fibre itself. The general law is, that whenever a substance capable of uniting with the acid of fat or oil, is placed in contact with fat or oil, it determines the production of acid. Now, it has been shown that alkali produces a similar change on geine, it develops acid properties. If alkali has converted vegetable oil and geine into acid, it is a reason why a similar action may be produced by all those substances which act thus on oil. Hence lime, earths, and metallic oxides, convert geine into acid; as fast as this takes place, so fast it becomes soluble. Then, too, the long action of air on insoluble geine render- 
ing it soluble, is it not analogous to the action of air on oils ? Both evolve, in this case, vast volumes of carbonic acid, the oil becomes gelatinous and soluble in alkali; does not a similar change occur in geine? It is possible that during the action of lime on geine, a soluble substance may be produced, bearing the same relation to this process that glycerine does to saponification. These views need to be followed out experimentally, and may be possibly hereafter considered.

163. In the acid soil, lime acts to eliminate carbonic acid, which then acts on silicates and geine, as has been explained. All fat acids, or fats and oils, act in the same way upon silicates, partly by their own acid properties, and partly by the evolution of carbonic acid gas, which is evolved during their conversion into the acid state. The quantity of carbonate of lime which may be applied is unlimited, and the quantity of alkali depends on the presence of insoluble geine. The more abundant is the last, the more freely may alkalies be applied. The carbonates include ashes of all kinds, and agriculturally viewed, all kinds of lime, for the quick soon becornes mild. The value of ashes in agriculture, depends upon its being a combination of salts derived from plants, all of which have a powerful and decidedly beneficial effect. The question is often asked, What is the relative value of spent or leeched and unleeched ashes? It may be answered by reference to the analysis of ashes.

Burning reduces organic substance to two classes, ashes and volatile salts. The last are found in soot. The ashes are formed of salts and silicates. These vary in quantity and quality, not only in different plants, but, as is well known, in different parts of the same plant. Let us take oak, beech, basswood, birch. as the types of the composition of hard 
wood ashes; yellow pine-(pinus abies) -as the type of soft wood ashes; and wheat straw as the type of the ashes of the grasses.

The average quantity of ashes from 100 parts of dry oak, beech, birch, \&c., is 2.87. Ashes are divided imperfectly by the simple process of leeching, into two parts, one soluble, and the other insoluble in water. 100 parts of hard wood ashes would afford, of soluble, 13.57; of insoluble, 86.43 parts, if perfectly separated.

\section{0 parts of the soluble contain:}

Carbonic acid, . $\quad . \quad \therefore \quad . \quad 22.70$

Sulphuric acid, : $\quad$ • $\quad$. $\quad$ - 6.43

Muriatic acid, . $\quad . \quad$. $\quad .182$

Silex, • . . . . . . . $\quad .95$

Potash and soda, . $\quad$ : $\quad . \quad$. $\quad . \quad 67.96$

99.86

100 parts of the insoluble contain:

Carbonic acid,

Phosphoric acid, . $\quad$. $\quad$. $\quad$. 3.40

Silex

Oxide of iron,

Oxide of manganese,

Magnesia,

Lime, . 
100 parts of the soluble contain:

Carbonic acid,

Sulphuric acid,

Silex

Potash and soda,

Water, .

$$
\begin{array}{ccc}
\cdot & \cdot & 13.50 \\
\cdot & \cdot & 6.90 \\
\cdot & \cdot & 2 . \\
\cdot & \cdot & 69.70 \\
\cdot & 7.90 \\
\hline & 100 .
\end{array}
$$

\section{0 parts of the insoluble contain:}

Carbonic acid,

Phosphoric acid,

Silex

Magnesia,

Oxide of iron,

Oxide of manganese, Lime,
- 21.50

1.80

- 13.

8.70

- 22.30

- 5.50

- 27.20

A bushel of common hard wood ashes weighs about 50 Ibs.; $6.75 \mathrm{lbs}$. are soluble in water, and consist of

Potash and soda, Sulphuric acid, . Muriatic acid," Carbonic acid, Silica,

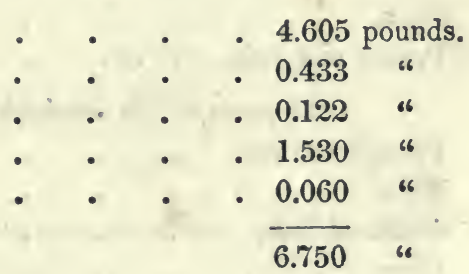

43.25 lbs. are insoluble in water, and consist of

Carbonic acid, Phosphoric acid,
- 15.59 pounds.

- 1.47 " 


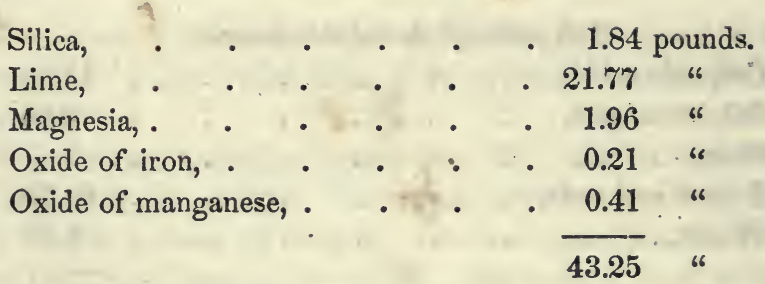

It is evident from these tables that the common opinion of the inferiority of pine ashes is unfounded. Though pine yields less weight of ash than hard wood, in proportion of .83 to 2.87 , yet, in equal weights, pine ash affords four times more alkali than the ash of hard wood.

$50 \mathrm{lbs}$. hard ash yields $6.75 \mathrm{lbs}$. soluble, of which 4.60 lbs. are alkalies.

50 lbs. soft ash yields 25 lbs. soluble, of which $17.42 \mathrm{lbs}$. are alkalies.

Wheat straw -100 parts yield 4.40 lbs. of ashes; 100 parts of which afford, of soluble, 19; of insoluble, 81 .

100 parts of the soluble contain:

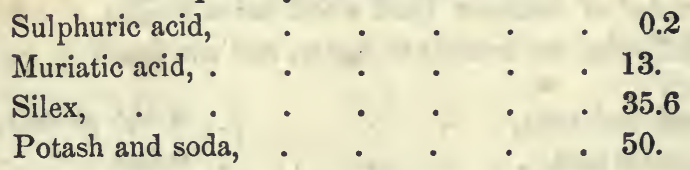

100 parts of the insoluble contain:

Phosphoric acid, . . . . $\quad$. 1.20

Silex, . • . . • . . 75 .

Oxide of iron, . . . . $\quad . \quad 2.50$

Lime, • . $\quad . \quad$ • $\quad . \quad 5.80$

Charcoal, . . . . . 15.50

The above tables of wood and straw ashes are calculated on the analyses of Berthier. The elements are stated singly, because we have thus, at one view, the amount of each, and 
it is the base chiefly which acts. The agricultural value of ashes may be determined by reference to these tables. In what state these elements may be combined in plants, we can only determine theoretically. Thus, the phosphoric acid, by its affinities, would be united in the hard woods as above, with the lime and iron, forming in each 100 parts of the insoluble portion of ashes, phosphate of lime, 5.40; phosphate of iron, 1.86.

The average composition of the ashes of hemlock, spruce, chestnut, white elm, black birch, black cherry, and red beech, calculated on the analyses of Prof. Emmons, is as follows:

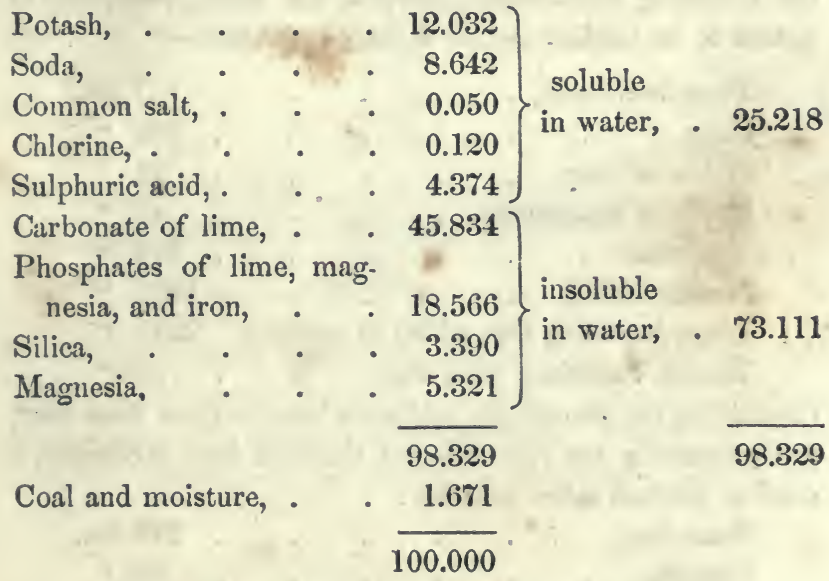

In the leach tub, the separation into soluble and insoluble would take place as above.

The composition of the insoluble part of ashes gives nearly the constituents of leached ashes. If the soap boiler's process was as perfect as that which the chemist employs, still his leached ashes would show more lime than the above 


\section{$4584 .: 184.00$}

tables, because he always employs a portion of lime to make his lye caustic. This is a variable portion; whatever it is, it adds so much to the value of the leached ashes. Besides, the soap-maker always leaves a portion of alkali, which is combined with the silex. Exposure to air decomposes this, and then the alkali can be extracted by water. This is one great source of the active power of leached ashes.

164. A bushel of good ashes contains about $4 \frac{1}{2} \mathrm{lbs}$. of real potash. In leaching ashes, generally about one pound of lime is added to each bushel of ashes, and as it loses no bulk during the operation, a cord of leached ashes contains about the following proportions, allowing the usual proportion of potash to be leached out, or 4 lbs. per bushel :-

Phosphoric acid, .

Silex,

Oxide of iron,

Oxide of manganese,

Magnesia

Carbonic acid,

Lime, including that added in leaching,

Potash, combined with silica,

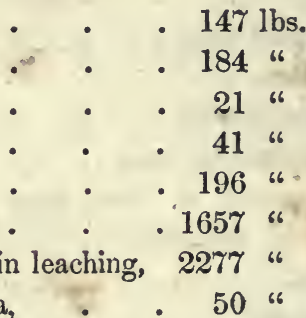

Combining the phosphoric acid with lime to form bone dust, and converting the remainder of the lime into carbonate, a cord of leached ashes contains :

Bone dust,

Potash,

Magnesia,

Silica,

Oxide of iron,

Oxide of manganese,

Carbonate of lime,
319 lbs.

50 "6

- 196 "

- 184 "

- 21 "

- 41 "

.3766 "6 
A cord weighs about 9000 lbs., and hence one half the weight is water.

Sprengel has determined the components in 100,000 pounds of dry leached ashes thus:

Silica, . . $\quad 35.000$ or per cord wet 1575.00 lbs. Caustic lime, . . 35.010 " " 1575.45 " Magnesia, - . 2.330 " " 104.85 " Alumina . • 1.500 " 67.50 " Oxide of iron, . 1.700 " $4 \quad 76.50$ " Oxide of manganese, 1.840 " " 82.80 " Potash as silicate, . 0.500 " " " 22.50 " Soda as silicate, 0.180 " 0.10 " " Sulphuric acid, . 0.190 " " 08.55 " Phosphoric acid, . 3.500 " " 157.50 " Common salt, - . 0.090 " $\quad 004.05$ " Carbonates of lime and magnesia, $\frac{18.160}{100.000}$ " " $\frac{817.20 "}{4500 .}$

Calculating from Sprengel's numbers the proportions for 2500 lbs, in a cord wet from the soap boiler, the result is expressed above in the right-hand column. Reducing some of these to phosphate and carbonate of lime the result is per cord :

Phosphate of lime or bone dust, . $340 \mathrm{lbs}$. Carbonate of lime, . . . 3302 "

Spent ashes, therefore, belong to the class of carbonates. Peat ashes abound in carbonate, sulphate, and especially phosphate of lime. Free alkali may be always traced in peat ashes; but alkali exists in it, rather as a silicate, as in leached ashes. Anthracite coal ashes contain in 100 parts : 


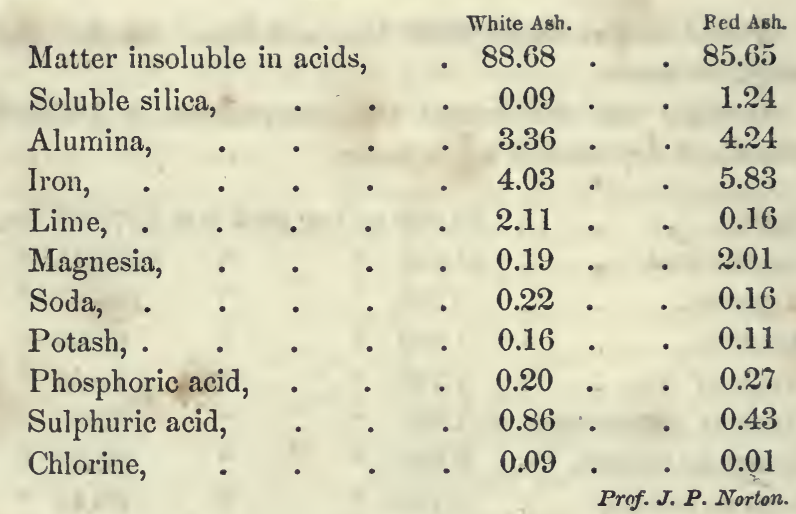

One hundred pounds of anthracite coal ashes contain:

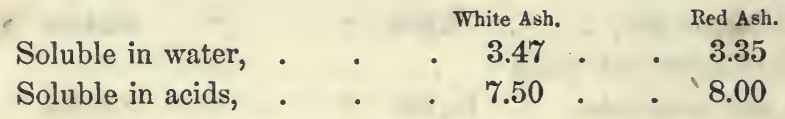

Hence, from 4 to 8 pounds in every 100 are valuable to the farmer; but the ashes are not worth the carting to any great aistance. Indeed, it is seen that the composition of anthracite ashes is very nearly that of soil deprived of its geine.

165. It may be here remarked in relation to silicate of potash, that this substance forms a greater part of the residuum produced in the conversion of pot into pearl ashes, for the purposes of glass manufactures, \&c. This residuum has been used with the most signal success, when mixed in the proportion of a barrel of this material with ten horse-cart loads of soil alone. (See Colman's Fourth Report on the Agriculture of Massachusetts, p. 344.) The silicate of potash, acting entirely by its conversion into carbonate of potash, is properly considered in the class of carbonates. 
166. The second class of salts belonging to the first division, or nourishers (b. 158), are the nitrates, including not only saltpetre, both East Indian and South American, or nitrate of potash and nitrate of soda, but also all composts of lime, alkali, and animal matter. The last produces ammonia, which, without the alkali, would act on geine and render that soluble. Ammonia, by the mere act of presence, hastens decay; but without the influence of lime, or alkali, ammonia is changed to nitrate of ammonia (126), for this base, by the oxygen of the air, is changed into aquafortis, or nitric acid. While a portion of acid and base are present, they unite and form a salt. A portion of ammonia is thus continually withdrawn. If lime or alkali is present, the nitric acid unites with these, leaving the ammonia to act on geine.

167. Thus, in a compost of animal matter without alkaline bases, all the geine has not been rendered soluble, as is usually supposed, by the action of ammonia. Before the full action of that element has been exerted on the organic matter, it has been converted into a nitrate. But if the lime exceeds that which the nitric acid can saturate, then the soluble geine is seized upon and becomes inert. Nitrates act under the influence of the growing plant; the base let loose, acts on geine; the acid is decomposed, and its nitrogen given up to the plant, becomes one of their essential elements. The elements of nitrate of ammonia are all taken up, both acid and base. If there are any salts which can be called vegetable food, they are the nitrates. The organic constituents of plants are hydrogen and oxygen, carbon and nitrogen. By their union, the two first form water; the two middle carbonic acid; the first and last ammonia. Water, ammonia, and carbonic acid, then, or their elements, compose the organic part of all plants. Water and carbon exist 
in geine, and nitrogen in its ammonia compounds. Geine thus contains the elements of water, anmonia, and carbonic acid, or the whole organic food of plants. The nitrogen, also, exists in the air. It forms 80 per cent. of it. In this state it cannot be assimilated by the plant till that has put forth its leaves. Its only source for the roots and for the germinating seed, is that arising, either from the geine, or from ammonia evolved by the fermenting dung, or from nitrates. In either case, whether the nitrogen arises from the geine or from the nitrates, decomposition takes place by the action of the living plant.

168. Under this view, nitre is found to be one of the most active, bland, and beneficial salts. Nitre consists of an alkali, and an acid composed of one part of nitrogen to five of oxygen. The plant decomposes these. The disposition of the alkali, or of the base, has been already considered. What becomes of its acid? That, too, is slowly decomposed. What becomes of its elements? The one part of nitrogen is taken up by the living plant, or it may, under the combined influences to which it is now subjected, be in part reconverted into ammonia, by the hydrogen of the geine, and so act on that as alkali. What becomes of its five parts of oxygen? The answer is full of the highest interest. It is a key, unlocking the chambers of mystery. The oxygen acts, first, on the geine of the soil, and secondly, on the silicates. And first; on geine; let it be supposed that this is wholly insoluble, perfectly inert. It has been already said that air converts this into soluble geine. This action depends on the oxygen of the air acting on the carbon, by which carbonic acid is formed; the geine is thus rendered soluble, while the carbonic acid escaping, acts on the silicates of the soil, and these are thus decomposed. There is no mystery now in the action of saltpetre, or nitrates of 
alkalies. The immediate effects are due to the liberated alkali, acting on the geine. Its permanent effect, for experience has proved permanency of effect, due to nitrates, is owing to the liberation of an immense duse of oxygen which is produced from the gradual decomposition of the acid. Now, the insoluble geine condenses this in its pores, like charcoal. This condensation, like that of gas by charcoal, produces heat; it is like fermenting manure, while the condensed oxygen acts slowly on the geine, and forms carbonic acid. It has upon the geine, buried in the soil, the same effect that tillage would have, rendering it soluble, with this additional advantage, that its carbonic acid, instead of escaping, acts on the silicates. New portions of alkali are thus liberated, supplying for years that which was first applied as a part of saltpetre. The nitrates, then, hold the very first place among salts in agriculture.

169. The third class (c. 158) of the nourishers are the phosphates. This class includes bones, horns, nails, hoofs, claws, and a large portion of the salts found in the liquid excretions of animals. These act much like nitre, the acid forming a constituent of the plants. It is not probable that the acid in this class is decomposed. It has not yet been proved that carbonates and nitrates exist, already formed, except in a very few plants. The quantity of salts which may be applied, will be greater for the carbonates, less for the nitrates, and least for the phosphates. The quantity of any salt which may be used, will, after the largest amount which can be safely employed has been ascertained, depend upon the furmer's ability to produce it. Carbonate of lime may be used to any extent, according to the farmer's idea of its value. Carbonates of alkali may be used with benefit. The largest quantity which has been known to be used without injury, has been 53 bushels of ashes per acre, which are 
equal to $240 \mathrm{lbs}$. of potash. The quantity of a carbonate of alkali which may be used, will be stated more fully hereafter. It is not the object of this work to state quantities to be used, so much as to point out the principles on which salts act. The quantities used must be determined by experiment, and perhaps when the largest amount, which has been stated, is taken for a new starting point, the ultimate quantity will be found limited only by the geine in the soil, or applied in conjunction with the salt.

170. If we now turn to the other division of salts (158), the poisons, that is, those whose acid forms but a small portion of the elements of plants, we find there two classes : First, sulphates, as plaster, copperas, Glauber's salts, all of which, in small quantities, are beneficial.

Secondly, muriates or chlorides, as they are strictly called, as common salt, muriate of lime, bittern, spent lye from soap-works. An explanation, which attributes the action of sulphate of lime or plaster, to its power of decomposing and fixing in soil, carbonate of ammonia ought to show, 1st, the actual presence of that salt in air; 2d, that sulphate of ammonia is not decomposed by the resulting carbonate of lime in the cold; $3 \mathrm{~d}$, that common salt would, in equivalent quantity with plaster, produce equally good effects. It never has, and therefore this explanation is not correct. Common salt has been found beneficial when applied at the rate of 30 bushels per acre; and at $\mathbf{1 4}$ bushels per acre, was found to produce effect, next best to 53 bushels of ashes per acre, but quicklime at 26 bushels per acre on the same land, produced no good result.

171. In all this action of salts, it is seen that the presence of life seems almost essential. Whatever the vital principle may be, it may be best represented as analogous to electricity and galvanism. In this point of view, the salts pre- 
sent themselves in a new relation, in which, alone, they may be said to be stimulants or excitants. Plants and soil act, it may be supposed, for illustration, by forming galvanic batteries, or piles with each other. The most active element in the pile, is the growing plant. It is an acknowledged fact, that chemical action, if not the source, is ever attended by electrical effects. An acid, in contact with an alkali, or metal, always produces chemical action; but the silicates of the soil are already combinations of acid and metals; hence, as such, they have no tendency to act on each other. If there be added to these a salt or an acid, chemical action, decomposition begins. The electricity is, we may say, excited by salts; they are in this sense, and in no other, excitants or stimulants. The very first act of vegetation, the germination of seeds, induces this electric action, this decomposition of the elements of soil. Germination produces carbonic acid, by decomposing water. This has been so abundantly proved, by late experiments in France, that it appears to be a good argument against the theory, that the only action of humus is its production of carbonic acid, to supply the wants of the plant, before nature has clothed it with those organs of aspiration, the leaves, by which the carbonic acid is withdrawn from the air. It seems hardly probable that nature should require the presence of humus or geine, merely as a laboratory of carbonic acid, to supply the wants of the young plant. The very first act of life in a seed is to evolve carbonic acid, by its carbon combining with oxygen of air, and its second act is to decompose water. Its oxygen combines with the carbon of the seed; a single bean produces many times its bulk of carbonic acid gas, and in the soil would surround itself with an atmosphere of carbonic acid. This evolved, begins its action upon the silicates. The living seed begins the electric action, and the 
plants exert and keep up this influence. Salts act in a similar way, but above all, over all, influencing all, is the living plant. This electric action induced, extends to undetermined distances; hence there is a transfer, as is usual in all cases of galvanic decomposition, of substances remote from the plant, to its root, where they are taken up. It is not the potash and lime, \&c., immediately in contact with the root, which alone supplies the plant, but under the galvanic influence, an undetermined portion of soil is decomposed. This decomposing agency of plants wholly destroys all confidence in experiments, undertaken to prove that pure water alone can nourish plants. The containing vessel, that is the vessel in which the experiment is made, is itself always decomposed. If, to guard against an error, glass is used, it has already been shown that this is only a combination of silicates, and these will be transferred from the glass to the plant.

By the experiments of Weigmann and Polstorff, it appears that plants constantly discharge, while growing, carbonic acid from their roots. This acid decomposed the silicates in a soil, which had resisted the action of nitromuriatic acid. It eliminated elements from supposed pure quartz, whose existence there had been proved in no other mode. 


\section{CHAPTER VI.}

MANURE.

172. The true farmer, no less a sage than the ancient orator, who gave to action, the first, second, and third place in eloquence, will answer, if it is asked him, what is his first requisite? Manure. What second? Manure. What third ? Manure. These answers are to be united. Action and manure are the first and last requisites in agriculture; and in the attempt to show what is the last, and how it acts, will be offered every inducement to action.

173. Manures are compounds of geine and salts. They. of course contain the whole elements of fertility. Having discussed the nature and mode of action of salts, and of geine, the way is prepared for the discussion of manures. The proportion in which these elements exist in manures is now to be examined.

174. The immense variety of substances, used and recommended for manures, would seem to render this subject both extensive and complicated. It is capable of simplification. Manures are generally considered and treated of, under the division of animal and vegetable. This common and ancient division, indicating little of the nature of manures, actually confounds those, whuse elements are essentially alike. Manures are to be divided by their elements, into three classes :-

1st. Those consisting chiefly of geine. 
$2 \mathrm{~d}$. Those consisting chiefly of salts.

$3 \mathrm{~d}$. Mixed, or consisting of salts and geine.

175. This seems to be a rational and practical mode of elassifying a vast amount of materials, and the explanation of their action in classes, is preferable to a specific account of each individual substance composing these classes.

176. By far the greater part of manures belongs to the third class. Such are all composts, all stable manure, and all the usual products of the cow-yard and hog-pen. In discussing, therefore, this subject, there ought to be some starting point, some standard common measure of value, to which can be referred all manures, and by which their worth can be determined.

177. In selecting a manure for this purpose, if it can be ascertained how much of geine, what salts, and in what proportion these salts enter into its constitution, what gases it evolves, what chemical action it induces upon silicates, it u ill determine the relative value of all manures; they will approach or depart from the standard, in exact proportion to the geire and kind of salts they contain.

178. Manures, then, are the elements of fertility. They contain besides the inorganic salts, the organic elements of plants, oxygen, hydrogen, carbon, nitrogen. The quantity of ammonia which each manure can afford, will be in direct proportion to the quantity of nitrogen which each contains ; and perhaps the only true and scientific view which should be taken of manures is that which states their components not as compounds, but as simple elements; a statement which should give at a glance the exact quantity of the four organic elements which enters into their composition. To a limited extent this can be done, and in the attempts to illustrate this subject, this mode of stating the value of manures, will be united with a more detailed account of their ingredients. 
179. And first, for the choice of some substance which shall form the type of manures, and be considered the standard of value. Let it be pure, fresh fallen cow-dung. What is its composition? Water, hay, and bile, with a few salts. The author has repeatedly analyzed this form of the food of plants, and it is found that the water is a very uniform quantity at all seasons and with various food. Others have found a few per cent. less than that which will be here stated; while some late and distinguished German chemists have given results agreeing with this statement, within a fraction of one per cent.

180. The proportions of organic matter, salts and water, in 100 lbs. of cow-dung, are-

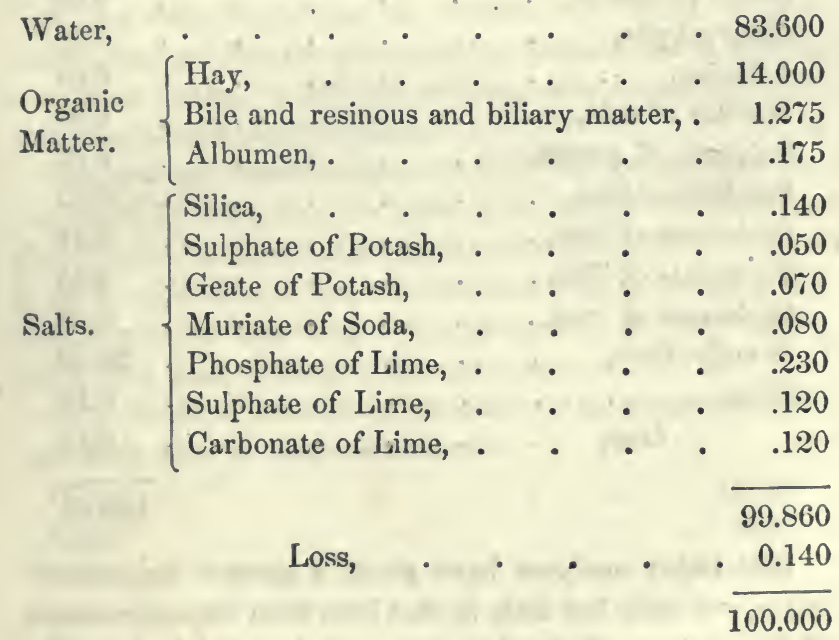

181. 100 parts of cow-dung by Morin's analysis, consist of

Water, .

Vegetable fibre, . $\quad . \quad$. $\quad 24.08$ 
Green resin and fat acids, $\quad$. $\quad$. 1.52

Undecomposed biliary matter, . . . 0.60

Peculiar extractive matter, • • . $\quad$. 1.60

Albumen, • . . . . . . 0.40

Biliary resin, . $\quad . \quad$ • $\quad$ • $\quad$ • $\quad$. 1.80

100.00

Morin probably includes the salts in the vegetable matter. 182. 100 parts of cow-dung, by the analysis of M. Penot, in 1835 , consist of-

Water, .

Bitter matter, . • . . . . 0.74

Sweet substance, • $\quad$ - . $\quad$ - . 0.93

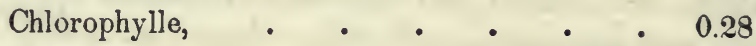

Albumen,

Muriate of soda

Sulphate of potash,

Sulphate of lime,

Carbonate of lime, .

Phosphate of lime, .

Carbonate of iron, .

Woody fibre,

Silica, .

$$
\text { Loss, }
$$

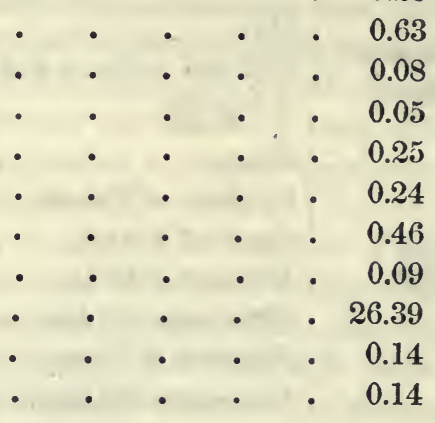

100.00

183. Other analyses have given a greater amount of water, and differ but little in that item from the experiments of the author. Truly this statement does not lead one to suppose, that a very good selection has been made, in the choice of the standard of value for manure. Here is a substance, $83 \frac{1}{2}$ per cent. of which is pure water. Let that be 
thrown out of the account; there are 14 per cent. of hay; this is very little altered, it seems only bruised and chopped, but it has lost some of its albumen, gum, \&c. Now the last is that portion of nutriment which the animal has extracted from the hay.

184. It is found that hay which has thus been passed through living organs, has its elements much less disposed to remain combined, or, in other words, decay, that species of fermentation which forms geine, takes place much more rapidly in the hay of cow-dung, than in common hay. The catalysis of life has impressed its power of disassociation on the hay of cow-dung. The hay may therefore be considered geine.

In the same class may be included the biliary matter, deducting from this the green resin of hay associated with it, and there remains in $100 \mathrm{lbs}$. of dung, only a small proportion of salts and biliary matter.

The albumen, from its great tendency to spontaneous decomposition, may also be ranked as geine. It produces abundance of ammonia during decomposition, and probably is the great source of the evolution of that gas, during the fermentation of cow-dung. Its proportion is very small, being only about a sixth of one per cent.

185. Without violence to chemistry, the composition of cow-dung may be stated as follows-

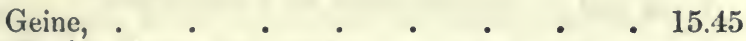

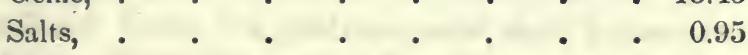

$$
\begin{aligned}
& \text { Water, . } \quad . \quad \text { • } \quad . \quad \text {. } \quad \text {. } 83.60 \\
& 100.00
\end{aligned}
$$

In $100 \mathrm{lbs}$. hardly $\frac{1}{6}$ of any value in agriculture! Only about $\frac{1}{6}$ of cow-dung affords geine. The insoluble is converted to soluble by the action of the evolved atnmonia. 
Girardin states the composition thus-

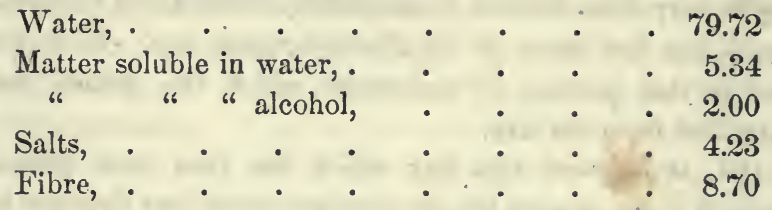

186. An important question here presents itself. How much ammonia will $100 \mathrm{lbs}$. of cow-dung produce? The ultimate analysis of this substance, that is, that analysis which gives the proportion of the organic elements, is the following:

\section{In 100 parts of cow-dung,-}

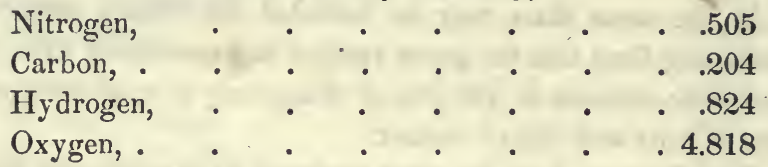

187. From these data may be calculated how much ammonia will be formed; for one part of nitrogen unites with three parts of hydrogen, to form ammonia, or in the atomic proportions by weight:

14 of nitrogen, or 1 equivalent.

3 of hydrogen, or 3 equivalents.

- 17 of real or pure ammonia, or 1 equivalent.

100 parts of fresh fallen cow-dung will afford, therefore, 0.607 , or $\frac{5}{8}$ of a pound, nearly, of pure ammonia, or 2.18 lbs., or about $2 \mathrm{lbs} .2 \mathrm{oz}$. of bi-carbonate of ammonia of the shops, called sal-volatile, or salts of hartshorn, the carbonic acid and water being 44 parts to 17 of ammonia.

188. Cow-dung, then, the type of manures, resolves itself into geine, free alkali and salts. The salts, considering the 
nitrogen as carbonate of ammonia of the shops, will form about 3 per cent. of the weight of the dung; or a bushel of $86 \mathrm{lbs}$. will contain, in round numbers, $2 \frac{1}{2} \mathrm{lbs}$. of salts of ammonia, potash, soda and lime.

189. The cow, then, is the great manufacturer of salts and geine, and it is a question of the highest interest, What is the daily produce of her manufactory? In order to determine this, the following experiment was conducted with great care, at the barn copnected with the print-works of the Merrimack manufacturing company, in Lowell. A single cow, being only an average producer of the article in question, was selected from the 50 cows usually kept at the establishment. She was fed as usual, and as the other cows were. The food and water were accurately weighed for seven days. She consumed, in this period,

Water, $612 \mathrm{lbs}$.
Potatoes, 87 "
Hay, 167 "

Total, 866 " food and drink, and voided, free from her liquid evacuations, $599 \mathrm{lbs}$. of dung.

From the facts which have been now stated, it is evident that one cow prepares, daily, from 24 lbs. of hay, and $12 \frac{1}{2}$ lbs. of potatoes, about one bushel, or $85.5 \%$, lbs. of dung. This affords only 14.04 lbs. of solid manure, composed of salts and of hay, so acted on by the digestive organs, as to form geine, when united with ammonia, produced by putrefaction.

One cow daily forms, therefore, about

13 lbs. geine.

$\frac{1}{5}$ " say 3 oz. of bone-dust, or phosphate of lime.

$\frac{1}{10}$ " say $1 \frac{1}{2}$ oz. of plaster of Paris, or sulphate of lime.

Io " say $1 \frac{1}{2}$ oz. of chalk, or carbonate of lime. 
Or, per year :

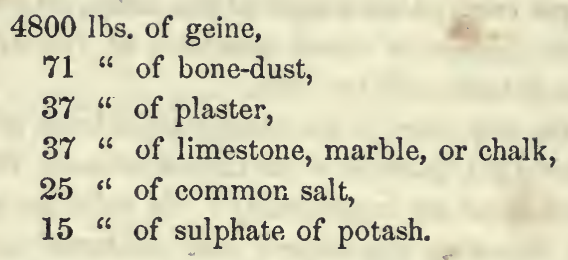

This is the product of one cow. A cord of green cowdung, pure as dropped, would be formed, daily, by 108 cows. A cord of dung weighs $9289 \mathrm{lbs}$, which, $\div 86 \mathrm{lbs}$. (or 1 cow, $=108$ cows. And one cow daily produces, in exerements, salts of lime sufficient for $4 \frac{1}{2}$ bushels of corn.

190. Multiply the quantity produced by one cow, by the number of cows kept, and it may easily be calculated how much salts and geine are annually applied to soil in this form. This is better done than the estimate by cords or loads. The manure from one cow is a definite comprehensible quantity.

191. Estimating the nitrogen as ammonia, the yearly product of one cow is $156 \mathrm{lbs}$. of nitrogen, equal to $189 \mathrm{lbs}$. of pure ammonia, or equal to $677 \mathrm{lbs}$. of bi-carbonate of ammonia of the shops. A single cow will therefore give, annually, fed on hay and potatoes, $31,025 \mathrm{lbs}$. of dung, containing

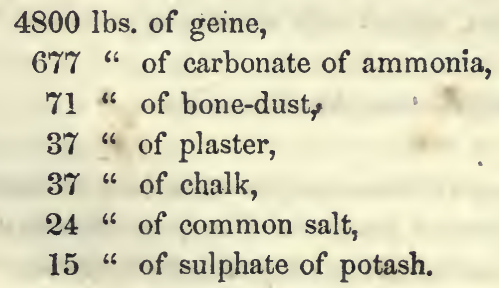


192. It is perfectly evident, from this view, that the main agricultural value depends on the ammonia or nitrogen, and the geine. The lime, in its forms of salts, goes but little way towards this value, yet valuable, so far as they exist. It is evident, from section 74 , that the lime in the above salts of lime, the annual product of one cow, is sufficient to supply the grain and straw of a crop of 140 bushels of rye.

193. If these, then, are the elements of plants which are found in cow-dung, is it to the organic or the inorganic portion that the enriching power is due? The great value of dung as a manure, has been supposed to be due to its animal matter. The common idea of animal matter inincludes substances which contain much nitrogen, but is it to the nitrogen, or to salts, that the chief value of manure is due? To the nitrogen, chiefest and first, and that, too, as it exists in the albuminous portion of dung. The nitrogen of the hay contributes very little to the value of manure. The hay furnishes the geine. That it is the nitrogen of dung only, the part not contained in the hay, which evolves ammonia, is evident; for if the nitrogen of the hay only, was the essential element of dung, then hay, which contains about one per cent. of nitrogen, could supply its place : 50 pounds would be equal to 100 pounds of dung. It is well known that such effect is never produced by planting on hay.

194. It is not to the nitrogen only, in dung, to which can be referred the action of this manure. It depends on its other elements, salts and geine. The action of nitrogen is referred to its power of forming ammonia, and this then acts in two ways. First, upon geine, or the hay part; secondly, upon silicates. First, it is a powerful alkali. Now it has been shown that all alkaline earths convert insoluble into soluble geine. Secondly, it is a well-established fact, that the production of nitre is not necessarily dependent on 
the presence of animal matter; under the influence of porous materials, aided by alkalies, or lime, the elements of air combine and form nitric acid and nitrates, when bases are present. This action is greatly assisted by ammonia, which acts by catalysis. The great use of the animal matter is to produce this alkali, or ammonia. If no alkaline base is present, it becomes the source of the formation of nitrate of ammonia. This salt being decomposed by the living plant, its nitric acid acts on the silicates, and saltpetre or nitrate of potash is produced. The ageney of this, as a manure, has already been considered $(167,168)$. The action, also, of other salts in dung, will be easily understood by reference to the fifth chapter.

195. There is still a powerful effect due to the geine, or to the hay in its conversion to that state. During this process, a great quantity of carbonic acid is liberated. The decomposing action of this upon silicates of the soil, and the consequent liberation of their alkali, has also been explained (133). All these actions are to be remembered, in accounting for the action of cow-dung. The geine, salts, nitrogen, each acts; the geine has an action, the salts an action, the nitrogen an action. They all contribute to one end. Three substances, but one result, viz., vegetation.

196. The nitrogen, then, in dung, is that organic element to which must be attributed its chief enriching quality. The nitrogen is the basis, both of the production of ammonia, and of the formation of nitrates. Hence, the quantity of nitrogen in manures will form a very good element for the estimation of their value. Manures will be found rich, in proportion to their quantity of nitrogen, or their power of forming nitrates. This is the great and first cause of the enriching power of dung. Though the action of all excrements has been referred to their inorganic parts only, com- 
mon experience tends to the explanation which has been given of the joint action of all their parts.

197. The source of nitrogen in dung is an interesting question. It is evident that it must have been introduced into the animal's system by the food, perhaps also by the drink; for all water contains absorbed air, of course, nitrogen. Hence, the kind of food greatly influences the amount of nitrogen in dung.

198. If a cow assimilated all the nitrogen of her hay, $25 \mathrm{lbs}$. of hay would increase her weight daily, by about $8 \mathrm{lbs}$.; but no one expects such a result, and the balance of the nitrogen goes off in milk, or in liquid excretions. Hence, a milch cow fats not. So long as a greater part of the nitro gen is voided by milk or otherwise, a cow fats not. If she is not parting with nitrogen in milk, a greater portion goes off in dung. Hence, a common observation, that the manure of fattening cattle is richer than that of milch cows, or of cattle not fattening.

199. The difference in the quantity of bile, slime, \&c., in a cow fed on hay or on meal, is not very great. A cow was fed six days on meal and water. She consumed in this period,

$$
\begin{array}{lrl}
\text { Indian meal, } 96 \text { lbs., or per day } 16 \text { lbs, } \\
\text { Hay, } \quad 30 \text { " } & \text { " } 5 \text { " } \\
\text { Water, } \quad 330 \text { " } & \frac{55}{76 \text { lbs, }}
\end{array}
$$

There were voided during this period $330 \mathrm{lbs}$. of dung, or $55 \mathrm{lbs}$. daily. She scoured and lost flesh. The evacuation had all the appearance of night soil, and soon evolved a great quantity of ammonia, and though covered in an earthen pot, was soon studded with a crop of exquisitely beautiful fungi. Compared with hay dung, its composition was, 


$\begin{array}{lrr}\text { Geine, } & 17.43, & 14.45 \text { in common dung. } \\ \text { Salts, .93, } & .95 & \text { " } \\ \text { Water, } 81.64, & 83.60 & \text { " }\end{array}$

Probably the nitrogen was $2 \frac{1}{2}$ per cent., or five times that of common cow-dung.

200. Doubtless the value of all excrements will depend somewhat upon the food of the animal, and the manner of feeding. It may be stated as a general fact, that the manure of cattle, summer-soiled, is nearly twice the strength of that from the stalls in winter; and all fattening cattle, whether in winter or summer, produce, as has been stated, a still richer vegetable food. Animals fattening on oil cake, gave manure, 12 loads of which exceeded in value of crops raised, 24 of common stock. These remarks show, that some allowance is to be made for the food. The standard refers only to hay and potatoes. But the value due to different food, may not be so great as is commonly supposed. The actual amount of nitrogen, even where vegetable and animal food is concerned, is not materially different. There were two dogs, which were fed, the one on vegetable, the other on animal food; at the appointed time, these animals were sacrificed on the altar of physiological experiment, and the chyle examined. The following were the results :

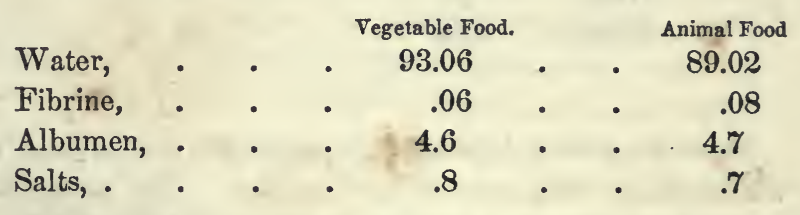

These are the sources of ammonia, if the chyle had been allowed to putrefy.

201. The ammonia in dung, as has been explained, is the source both of the rapid conversion of the hay into soluble 
geine, and of nitrates. The action of unfermented dung needs no explanation after this exposition. The geine, the salts, carbonic acid, and ammonia, must be formed among the silicates and roots of plants on which they are to act.

202. Having determined the mode of expressing the value of manures, and fixing the standard of value, other manures containing salts and geine, may now be compared with that, and their value determined, by detailing their constituents.

203. Horse-dung contains :

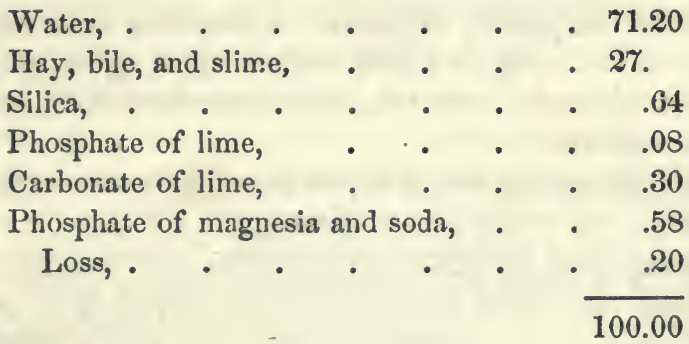

The food of the horse will of course affect these results, and hence there is found a great discrepancy in the amount of the elements, at different times.

Girardin's analysis of horse-dung affords :

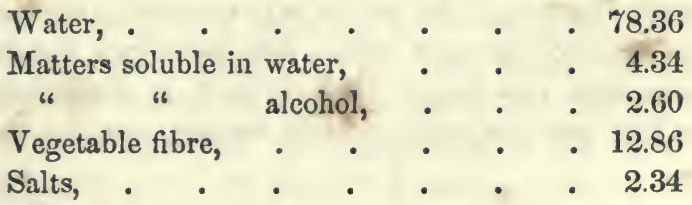

Boussingault found that the following was the composition of the dung of a horse fed on hay and oats: 


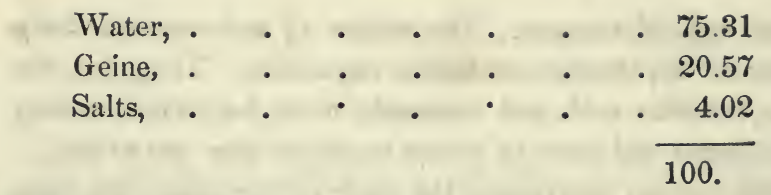

The organic portion, or the geine, gave,

$$
\begin{array}{lllllllr}
\text { Carbon, . } & . & . & . & . & . & . & 956 \\
\text { Hydrogen, } & . & . & . & . & . & . & 1.26 \\
\text { Oxygen,. } & . & . & . & . & . & . & 9.31 \\
\text { Nitrogen, } & . & . & . & . & . & . & .54
\end{array}
$$

Horse-dung quickly ferments. It should be immediately removed and composted with cattle-dung, or sprinkled with plaster. It loses in a month, at least one-third of its weight by fermentation.

204. Expressing the value compared with cow-dung, we have-

$$
\begin{aligned}
& \text { Geine, • • • • • • • • } \quad \text { • } 27 .
\end{aligned}
$$

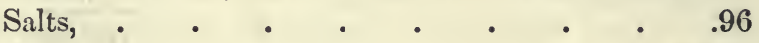

$$
\begin{aligned}
& \text { Water, . . . . . . . } 71.20
\end{aligned}
$$

The geine, then, is nearly double that in cow-dung, and the salts, which are mostly phosphates of lime, magnesia, and soda, are about the same. If the nitrogen is regarded, it is found about 50 per cent. greater than in cow-dung. Hence, during the chemical actions of the production of ammonia and nitrates, if the heat is in proportion to that action we may possibly assign a reason, why horse-dung is a hotter manure than cow-dung. The nitrogen in horse-dung is about $\frac{3}{4}$ of one per cent., or this manure contains, in 100 parts :

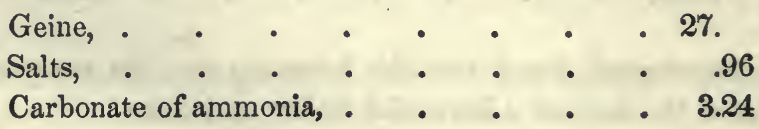


But though horse-dung is considered as a hotter manure than cow-dung, this is true of horse-dung only in its fresh state. Fermented horse-manure is really of less value than cow-dung. This is the voice of experience. Thrown out with the litter, and moistened as it is with little urine, compared with that of cattle dung from the barn, it rapidly ferments and decays. By the time horse-manure has fermented, so as to be converted into a uniform mass of muck, it loses, at least, nine-tenths of its weight, and nearly two-thirds of its nitrogen has disappeared. Hence, without care, horsedung rapidly loses its value. Now this quick heating is owing to the ready decomposition of the dry droppings; and if these are kept properly moistened, a manure is produced when the horse-dung is half-rotted, which is fully equal to cow-manure. It has ever required much management to get good yard-manure from horse-stables. The pile should be broad, well trodden down, and kept constantly moist with water. Each layer, as it is formed, should be sprinkled with a little ground plaster.

All the water which drains from the heap should run into a pit and be mixed with a little plaster, and returned upon the pile.

In the course of two or three months, a rich pasty manure may be thus formed, equal to the best farm-yard manure from cattle.

The evacuations of cattle and horses are usually mixed in the farm-yard. These, with the litter, form yard-manure. The nature of the litter, fermentation and age affect the quality and quantity of yard-manure. This causes its practical division into long and short, or strawy and fat muck.

Age reduces the quantity of fresh manure nearly as follows. It has been found by one observer, that, 
100 loads lose in bulk, in 81 days, 25.7 , or become 73.3

$\begin{array}{lllllll}\text { " } & \text { " } & 254 & \text { " } & 35.7 & \text { " } & 64.3 \\ \text { " } & 384 & \text { " } & 37.5 & \text { " } & 62.5 \\ & 393 & \text { " } & 52.8 & \text { " } & 47.2\end{array}$

Or to state the result differently from another source, 25 cwt., recent dung yield,

At the end of six weeks, . . . . $21 \mathrm{cwt}$.

After eight weeks, - . . . . 20 "6

When half rotted, - . . . 15 to 17 "

When fully rotted, . . . 10 to 13 "

Turning our attention to the quality of yard-manure, it has been found that the composition of that six months old is per 100 parts :

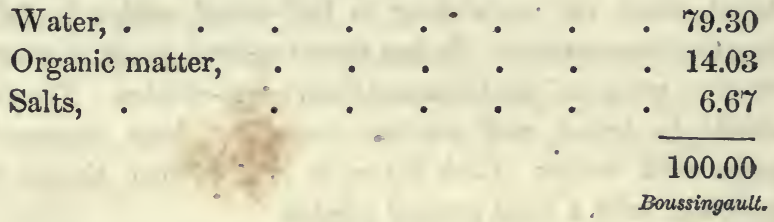

Cattle only afforded yard-manure of the following composition, per 100 parts :

Wate

Albumen, urea, slime, bile, sweet and extractive matter,
salts, potash, and soda,

Resins and fatty matter,

Starch, . . . $\}$ Insoluble in water,

Salts of lime and magnesia,

Vegetable fibre,

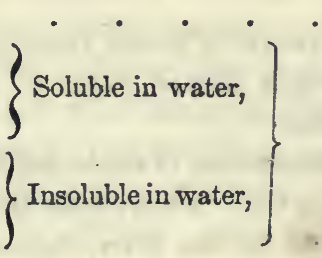

75.

5.

Richardson of Newcastle, England, has also aetermined the composition of yard manure. His results are as follows : 
MANURE.

Fresh, ready for the ficld.

Ashes consist of

Water,

64.96

6) Potrsh, . .

Organic matter, 28.71 Soda, . $\quad . \quad$. 2.73

Salts, • . 10.33 Lime, . . . $\quad 0.34$

Dried, at $202^{\circ}$.

Magnesia, • • 0.26

Carbon, . $\quad 37.40$ Sulphuric acid, ..

Hydrogen, . 5.27

Oxygen,. . 25.52

Nitrogen, . 1.76

Chlorine, . .

- 3.27

- 3.15

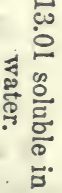

Ashes,

Silica, . . . . 0.04

$\begin{array}{lr}\text { Silica, } & .27 .01 \\ \text { Phosphate of lime, } & \text { - } 7.11\end{array}$

30.05 Phosphate of lime,

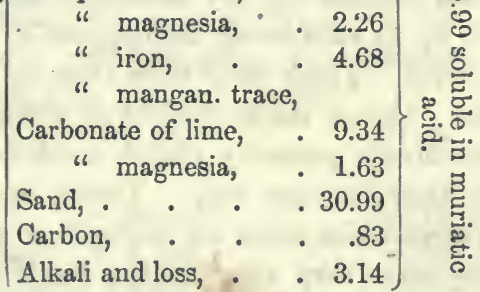

$\stackrel{\infty}{\infty}$

Soubeiran has recently examined farm-yard manure, about to be laid on the field. It was made from the dung of the horse-stables, cow-houses, sheep-folds, and pig styes, at Grignon, heaped up, and wetted with urine. It was not rotted so much as to form fat muck, and contained 30.6 per cent. dry dung. The fresh dung contained per 1000 parts :

\begin{tabular}{|c|c|c|c|}
\hline Water, • . & - & & . 694 . \\
\hline Organic matters, . & - & & 192. \\
\hline Soluble alkaline salts, . & - & & 8.75 \\
\hline Carbonate of lime and magnesia, & & & 17.50 \\
\hline Sulphate of lime, . & & & 13.13 \\
\hline Ammonia-phosphate of magnesia, & & & 11.50 \\
\hline Phosphates, principally of lime, & & & 4.65 \\
\hline Earthy matters, . & & & 66.47 \\
\hline
\end{tabular}

The quantity of nitrogen was 13.91 , which was divided, thus : 
Nitrogen of the soluble ammoniacal salts, . $\quad$. 1.67

Do. of the ammonia-phosphate of magnesia, .64

Do. of the organic matter, . . 11.60

13.91

It will be noted, that Soubeiran finds a much larger per centage of nitrogen in manure than other analysts. He objects to the estimates usually made, because these have been founded on dry manure, which thus has lost ammonia by its salts being decomposed by the carbonate of lime present. Fresh dung loses thus by drying $\frac{3}{5}$ of its ammonia. Hence, the equivalent of poudrette and all fermented manures is generally placed much too low, when calculated on their nitrogen only. Taking into view all the circumstances which affect the nitrogen in yard-manure, the quantity must vary exceedingly; but it has been estimated by Payen and Boussingault to be 0.41 per cent.; hence its carbonate of ammonia becomes equal to about $1.78 \mathrm{lb}$. in each $100 \mathrm{lbs}$. The weights of equal bulks of ox and horse-dung, from the barn yard and stable, as usually prepared, are as follows :

Ox-manure, old and fat, one cubic foot weighs $58 \mathrm{lbs}$.

Do. fresh, 66 " 48 "

Horse-manure, old and fat, "

Do. fresh, "6, $39 \quad 6$

" 30 "6

It has been ascertained that an ox in France affords 5,600 lbs., and a horse and a half, or ten to fifteen sheep, an equal amount of yard-manure per year.

But yard-manure too often is exposed to rain. Its salts are thus washed out, or the natural liquids mixed with it drain away, and are thus lost. It is a positive money-loss, for the composition of an imperial gallon of this muck-water, 
as determined by Johnston, in two samples, is as follows :

From cow-dung washed From yarl-dung watered by rain. with cow's urine.

$1^{\circ}$ Ammonia, 9.60 grs. . . 23.30 grs Solid organic matter, . 200.80 " . . 77.60 " Solid inorganic or ashes, 268.80 " . . 518.40 "

479.20 grs. $617.30 \mathrm{grs}$.

$2^{\circ}$ The ashes of a gallon consisted of alkal. salts, .

Phosphate of lime and magnesia, with a little phosphate of iron,

207.80 grs.

420.40 grs.

25.10 " . . 44.50 "

Carbonate of lime, " magn. and loss, . 4.30 " . . 3.40 "

Silica and a little alumina, 13.40 " . . 19.00 "

268.80

518.40

These results speak for themselves. They show rills of wealth gushing from the farmer's manure, which no prudent man will allow to run to waste. It is the concentrated food, organic and inorganic, of plants, all which they need.

205. Human excrement has been analyzed by Berzelius.

In its pure state, its composition may be thus stated :

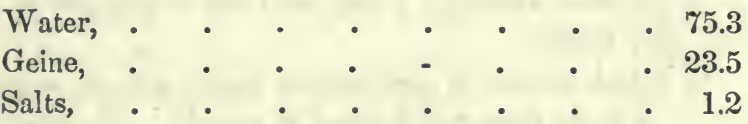

Nearly three-fourths of the salts are composed of carbonate, muriate and sulphate of soda, the remainder is composed of phosphates of lime and magnesia; the latter is particularly abundant in feces. The average quantity of nitrogen is 
about $3 \frac{1}{4}$ per cent. Human excrement contains, per 100 parts :

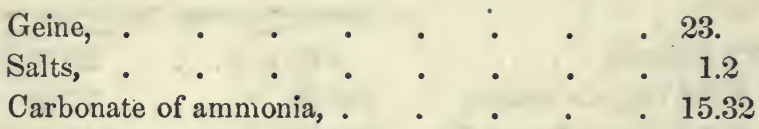

A later analysis of human excrement has been made by Fleitmann in Rose's laboratory. The feces of a young man, in health, for four days, dried at $212^{\circ} \mathrm{F}$., weighed 2607 grains, or nearly six ounces. In 100 parts of the salts or inorganic constituents were,

Chloride of sodium (common salt), . Chloride of potassium, . . . . . 0.07

Potash, and hydrate of potash, . . . 22.49

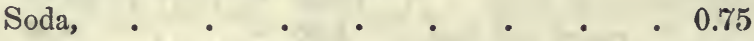

Lime, • . . . . . . . 21.36

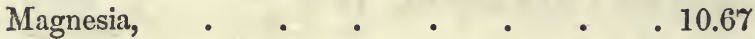

Peroxide of iron, $\quad$ • $\quad$. $\quad$ • $\quad$. 2.09

Phosphoric acid, . $\quad . \quad$. $\quad . \quad 30.98$

Sulphuric acid, $\quad$ • $\quad$ • $\quad$ • $\quad$ • $\quad$. 1.13

Silica, $\quad . \quad \cdot \quad \cdot \quad \cdot \quad \cdot \quad \cdot \quad \cdot 1.44$

Carbonic acid, . $\quad . \quad$. $\quad . \quad 1.05$

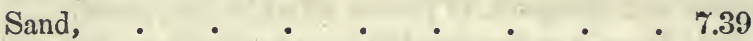

The sand was supposed to have been, in part, swallowed during the time while the young man was in exercise in the fields near Berlin.

The potash existed in combination partly with an organic substance in the feces, which acted as an acid. The quantity of phosphate of magnesia is remarkable, and all the phosphates are composed of three of base to one of acid.

The urine was separately collected. Its inorganic salts exceeded daily more than six and one-third times those of 
the solid feces. Now, the mixture of urine and feces, the fluids and solids, is known under the name of night soil. No substance is more varied in composition, depenđing as it does upon the food and habits of those whose accumulations are removed from their usual receptacle. A French farmer found to his cost, that the night soil of a Parisian restaurateur was much superior to that of the Parisian military barracks. The former was a very rich manure, the latter almost worthless.

A family consisting of three men fiom 29 to 60 years of age, of one woman, from 30 to 35 years, and a boy from 6 to 8 years, will ordinarily produce, daily, about 18 pounds of excrements, consisting of

Urine, $12.25 \mathrm{lbs}$

Feces, 5.75 lbs.

CoNTAINING

Dry organic matter, . 2560 grains.

Nitrogen, . . 750 "

Chlorine,. • • 249 "

Salts, . . . 675 "

1550 grains. 1426

traces.

320 "

The salts are composed, according to the analysis of the ashes of urine and feces by Prof. J. A. Porter, as follows:

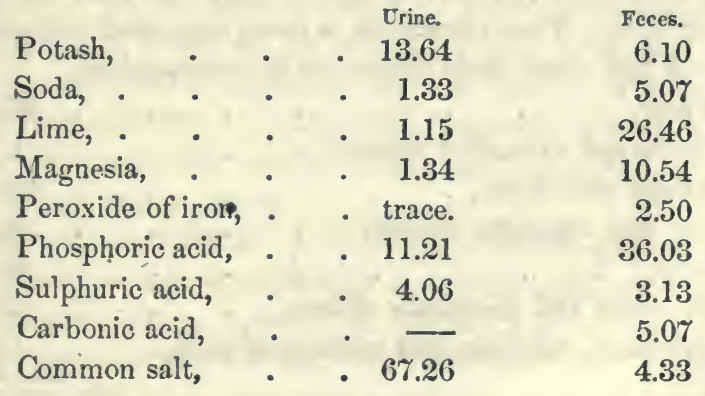

Allowing each person of the family namea above, by ab. 
sence and other causes, to omit sixty-five days in a year, the contribution to this domestic savings bank, the deposits will amount, annually, to 3682 pints of urine, and 1650 pounds of solid excrements, containing $10 \mathrm{lbs}$. of chlorine, $42 \mathrm{lbs}$. of salts, $176 \mathrm{lbs}$. dry organic matter. In the last there are 38 pounds of nitrogen; this is equal to forming $46 \mathrm{lbs}$. of pure ammonia, or $119 \mathrm{lbs}$. of carbonate of ammonia of the shops.

Hog-manure, in its characters, approaches night-soil sufficiently, to be ranked with it for the present purpose. It is the manure of fattening swine only which is to be classed with night-soil. The estray and running animals produce only a "cold" manure of little value. The manure of the penned animal is always combined with his liquid evacuation. This, whose vulue is stated (247), gives hog-manure a value which places it with night-soil.

Boussingault found in recent hog-dung-water 81, nitrogen, 0.63 , in one hundred parts, nearly as much as in horsedung, and from the experiments of Schwerts, hog-dung appears superior to that of the cow.

Sheep-dung may be placed with night-soil and hog-manure. Sheep may be said to digest better than cattle. They cut their food finer, and chew it better; they void thus less vegetable fibre. Their excrement is more converted into geine. Fed on hay alone, their excrement is composed of:

Water, • . . . . . . . 67.9

Bilious and extractive matter, . $\quad$. $\quad 1.7$

Humus with slime, . $\quad$. $\quad$. 128

Hay and vegetable matter, . $\quad$. 8.0

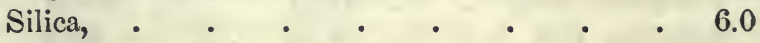

Carbonate and phosphate of lime, : . . 2.0

Carbonate, sulphate, and muriate of soda, . $\quad 1.6$ 
Others have found

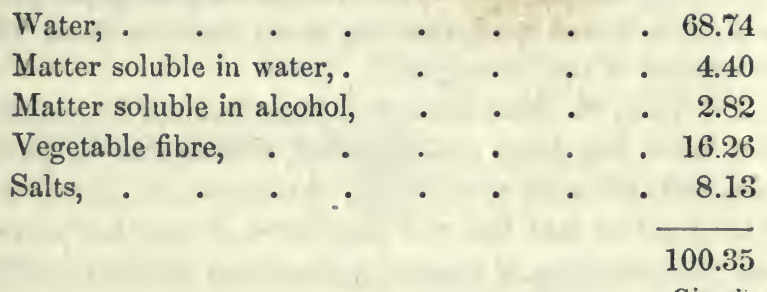

The salts were composed of phosphate of lime and magnesia, carbonate of lime, silicate of potash, common salt and silex.

The nitrogen is abundant, and the amount of matter containing this, nearly three-fifths greater than that of cattledung. The whole is finer divided, and hence speedily putrefies, and evolves ammonia. It is thus one of the hottest of all manures. But containing, as it does, little water, and being in fine compact balls, air cannot act upon it as it would upon cow-dung. Hence, unless moisture is present, sheep-dung undergoes little change. Great care is required in its use. Its ammonia is abundant; hence, if uncombined with geine, it burns up the crops. Hence, when there is little geine, little sheep-dung must be used. Where the soil is wet, and that too with little vegetable matter in it, there decomposition rapidly occurs, and the virtue of the dung, its ammonia, is lost.

It is said that 1000 sheep, folded on an acre of ground one day, would manure it sufficiently to feed 1001 sheep, if their manure could all be saved. So that, by this process, land which can, the first year, feed only 1000 sheep, may the next year, by their own droppings, feed 1365. So said Anderson, forty years ago (Rural Essays). Sprengel allows that the manure of 1400 sheep, for one day, is equal to manuring 
highly, one acre of land. This is about four sheep per year. In France, it is allowed that one sheep manures about $10 \frac{1}{2}$ feet square of land per night.

206. Thus, the most common substances used for manure, cow, horse, hog-dung, and night-soil, are reduced to geine, salts, and carbonate of ammonia, or nitrogen, its equivalent. It need not be said that the experience of ages has proved that these varieties of manure possess very different fertilizing properties. These depend, not on the salts alone, whose amount and quality is nearly the same in all; nor on the geine, for that is nearly the same in human and horse excrement. Their fertilizing power, then, depends not, as has been asserted, on the salts which would render their agriculcultural value equal. All experience would prove such an assertion unfounded. But it is said that their relative value depends on their power of producing ammonia.

If the value of manure depended on its salts only, then its ashes alone would be as effectual as the manure. Perhaps - no experiment determines this question more satisfactorily, than that of Mr. Lawes, in England. 28 tons of yard manure were divided equally; 14 tons were burned to ashes, and afforded $32 \mathrm{cwt}$. The manure, 14 tons, and the $32 \mathrm{cwt}$. of ashes were applied, each to one acre of land, and one acre of the same land was left unmanured. The crops were as follows :

1. Manure,

1276 lbs. dressed wheat, or 22 bushels.

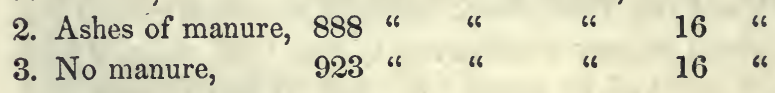

Straw and chaff:

1. 1476 lbs.

2. 1104 "

3. $1120 "$ 
Increase of grain by manure, No. 3 being $=1000$.

$$
\begin{aligned}
& \text { 1. } 1382 \mathrm{lbs} . \\
& \text { 2. } 962 \text { " }
\end{aligned}
$$

Increase of straw, by manure :

\section{1. $1381 \mathrm{lbs}$. \\ 2. 985 "}

It is evident that the salts alone of manure do not meet the wants of the farmer.

Numerous experiments, proving the inefficacy of salts without nitrogenous and organic matters, might here be cited. They would confirm only the experience of practical farmers. It may be useful to state what is the composition of the ashes of several excrements, as determined by Mr. J. Rogers.

\begin{tabular}{|c|c|c|c|c|c|c|}
\hline Silex, $\quad$. & - & - & 13.19 & 62.54 & 50.41 & 62.40 \\
\hline Potash, & & & 3.60 & 2.91 & 8.32 & 11.30 \\
\hline Soda, & & & 3.44 & 0.98 & 3.28 & 1.98 \\
\hline Chlor. sodium, & & & 0.89 & 0.23 & 0.14 & 0.03 \\
\hline Phos. sesqui ox. & iron, & & . 10.55 & 8.93 & 3.98 & 2.73 \\
\hline Lime, & & & - 2.03 & 5.71 & 18.15 & 4.63 \\
\hline Magnesia, : & - & & 2.24 & 11.47 & 5.45 & 3.84 \\
\hline Acid, phosphoric & & & 0.41 & 4.76 & 7.52 & 8.93 \\
\hline " sulphuric, & . & & 0.90 & 1.77 & 2.69 & 1.83 \\
\hline " carbonic, & . & . & 0.60 & & & 2.13 \\
\hline Sand, $\quad$. & . & . & - 61.37 & & & \\
\hline
\end{tabular}

Pig. Cow. Sheep. Horse.

When it is said that nitrogen measures the value o. manure, it must be remembered that the nitrogen should exist as ammonia, or in a state of combination which permits its ready conversion into ammonia.

It is the result equally of chemical and agricultural experience, that salts are decomposed with more or less ease, 
that their stability is greater or less. Nitrates are less stable compounds than sulphates, sulphates less stable than chlorides, or muriates, and these last less stable than earbonates. Hence, the ease with which the nitrogen of a salt is yielded, affects the result. Time, then, is required to produce from equal amounts of nitrogen, equal effects from different salts containing that element.

This is true, also, of organic, nitrogenous manures. The nitrogen is effective in proportion to the rapidity of decay. Hence, the nitrogen in horns, hair, feathers, hoofs, leathershavings, woollen rags and flocks, produces not the same effects in the same time, with an equal amount of nitrogen in flesh and blood. Nitrogen in soil may be useless from its state of combination.

It has been proved by Krocker that rocks, and even barren soils, at the usual depth of tillage, contain an amount of ammonia exceeding per acre that of any fair crop, raised by the aid of best farm-yard manure, on an acre of the best soil. It is not enough that tons and tons of ammonia are already existent in soil, if that ammonia can be extracted only by chemical processes, and human manipulation. No matter how much of this element may be in rain, how much may exist in the soil, aided by the inorganic salts, fair average crops may be raised by these natural sources of arnmonia. To obtain truly profitable crops, an excess beyond the natural supply is absolutely essential. To keep up this excess, and to obtain the largest returns for the seed sown, nitrogen in the shape of salts, or of readily decomposing organic matter, must be supplied with inorganic salts. The nitrogenous principle gives at once an energy to vegetation, enabling it to unfold early and largely those organs, the roots and leaves, by which the earth and air contribute their portion to the growth of plants. 
Nitrogen gives salts power to do more work in the same time. It is a labor-saving machine, enabling the farmer from the same ground, and with the same time and labor, to reap larger rewards. Natural vegetation is a low-pressure enginê,, but it will bear any amount of pressure, so beautifully built is it in all its parts. Inorganic salts are the water, geine the fire which raises the steam to drive this machine, filling the thousand cylinders which are distributed throughout plants. Nitrogen is the regulator of this engine. Nature has everywhere put her machine into the hands of man. She keeps it in working order, by her gentle steam. She takes man as her apprentice, and her generous hand supplied the daily bread while man was learning the construction of the valves, the working of pistons, the real power of the engine, the source of the steam. These, even though dimly seen, nature demands should be worked up to full pressure, when the apprentice sets up for himself, and is determined that the sweat of his brow, while it feeds his body, shall also purify, enlarge and strengthen his intellect.

In making agricultural trials with pure ammoniacal salts (166), in which the nitrogen exists as ammonia, or as an acid united with ammonia, and with nitrates, in which the nitrogen exists as an acid, it is to be remembered that the base with which this nitrogen acid is combined, acts an important part. The influence of the base is to be deducted from that rightly due to the nitrogen, as determined by experiments. What then is the influence of pure salts of ammonia? It has been proved, again and again, especially by Jacquemart, in France, and by Kuhlmann, in Flanders, that pure salts of ammonia act like ordinary nitrogenous manures. Their energy of action, their relative value, is almost in direct ratio to their nitrogen.

This is a doctrine, which, limited by the circumstances 
referred to above, is substantiated by experiment. Salammoniac, or muriate of ammonia, and sulphate of ammonia, were used by Kuhlmann as a top-dressing on mowing ground. The field was apparently in the same condition in every part, and equally exposed. It was laid out in plots of four square poles, separated by trenches. Alternate patches were reserved unmanured, and as the whole was in grass, all accidents of culture were avoided. The season was rainy and quite wet. The salts were applied at the rate of $240 \mathrm{lbs}$. per acre, and the grass cut and cured on each plot at the same time. The yield of hay, over unmanured plots, for every $100 \mathrm{lbs}$, of sal-ammoniac used, was at the rate of 580 lbs. per acre; and for every $100 \mathrm{lbs}$. sulphate ammonia, $419.6 \mathrm{lbs}$. or as 1 to 0.723 .

This is nearly in direct ratio to the nitrogen, which, per 100 parts, in the muriate of ammonia, is 26.439 ; in the sulphate of ammonia is 21.375 ; or the nitrogen is as 1 to 0.808 , while the crop is as $1: 0.723$.

In the same field, and at the same time, was used boneliquor, that which had been boiled on bones, to extract their fat. The last being removed, the liquor is a weak solution of glue or gelatin, containing, when dried, 16.980 parts of nitrogen in 100. It was used at the rate of 2000 gallons per acre. What, then, is the value of this bone-liquor, estimated on the per centage of nitrogen? It is as $26.439: 16.980$. Now 26.439 nitrogen in sal-ammoniac, gave $580 \mathrm{lbs}$. hay excess over unmanured. Hence, 16.980 should give 372.8; and this was the actual amount for every 100 lbs. of dry matter in this liquor. Here, an organic manure, rapidly decomposing, formed ammonia by its nitrogen, which afforded a product equal, pro rata, to that of an easily decomposable salt, in which ammonia was already formed.

- Doubtless, had the salts employed been equally easily 
decomposable, their nitrogen would have given equal results.

To observe, then, the difference between salts of ammonia unequally decomposable, let the amounts of hay produced by 100 parts of nitrogen from each salt be compared. Uninfluenced by the considerations which have been offered, these should be alike.

The sal-ammoniac gave, for every 100 parts of nitrogen,

The sulphate gave, for every 100 parts of nitrogen,

24,395 parts of hay. 21,660 parts of hay.

2,735

Now, this difference is attributable to the greater stability of sulphate of ammonia. It gives up its alkali slower. The plant does not so readily dissociate the elements of the salt.

If, on the other hand, the bone-liquor is examined, it is fourd that, because it was readily decomposed, 100 parts of its nitrogen produced 24,355 parts of hay, coinciding almost exactly with the product from sal-ammoniac, and confirming thus the principle that nitrogen measures the value of a manure.

When all circumstances are equal, 100 nitrogen always produce like effects, no matter what may be its origin. Among the most important circumstances which influence manure, are drought and wet. The season has its influence, and years differing by temperature, moisture, and dryness, show different results from the same manure.

But it is not as muriate or sulphate that the ammonia of manure is ordinarily found.

Putrefaction gives rise to carbonate of ammonia. It has been proved that the degree of saturation has no effect on the result. It is of no practical importance whether the 
ammonia be partly or wholly saturated with carbonic acid. Even the excess of that acid does not prevent-it ought rather to increase-the good effects of this compound. Taking, therefore, carbonate of ammonia, which is more readily decomposed than even the muriate, let its effects be compared with that of sulphate, each salt being used in such quantity that the amount of nitrogen shall be equal.

Jacquemart, carefully conducting this comparative experiment, in France, mixed the solution of carbonate of ammonia with charcoal or peat, so as to bring it into a dry state, like the sulphate.' The salts were sowed with wheat in the fall, on the same field, and under circumstances apparently the same. The field had been cleared of bushes, grubbed up, and, after two crops, was limed and marled. Now this liming and marling, though alike in all parts, had a special effect on the sulphate of ammonia ; it imbibed it, and gradually evolved carbonate of ammonia. Hence, in the first year, the sulphate yielded less than portions' of the same field unmanured.

But the year following, the experiment was repeated, and the salts, as before used, were again sown with wheat on the same places in which each had been before applied. The sulphate was therefore in a state to act with more efficiency, but still the lime interfered.

The product was 71 with the sulphate to 70 unmanured. The product, with carbonate and peat, compared with that with sulphate, was as 94 to 71 , or as 1 to 0.74 . In Kuhlmann's trials, uninfluenced by lime, it was as 1 to 0.88 . Let it be remembered that Kuhlmann used muriate of ammonia, a salt not so easily decomposed as carbonate. To show the influence of lime on sulphate of ammonia, a solution of that salt in the same quantity as before used, was absorbed to dryness by chalk, arid sowed with oats. 
The product was as $\mathbf{7 9}$ to $\mathbf{7 4}$ over the unmanured. The same ground being again sowed with wheat and salts as before prepared, yielded the second year, as 90 to 70 over the unrnanured. Two seasons seem therefore necessary to the full efficacy of sulphate of ammonia on limed soils.

That nitrogen measures the value of manures, is proved also by nitrate of soda. Here soda, the base, also acts; but if nitrate of soda be used in unequal doses, then the product is nearly in direct ratio to the nitrogen employed.

Now on the same field on which Kuhlmann performed his experiments, which are above related, he tried at the same time nitrate of soda in two proportions, at the rate of 240 and $120 \mathrm{lbs}$. per acre.

The yield of hay over unmanured suil was, for .

240 lbs. nitrate soda, 1550 lbs. per acre.

120 " " 784 " "

This is in direct ratio of the nitrogen employed. If now the effect of nitrate of soda is compared with sal-ammoniac or bone-liquor, it is seen that the addition of the soda base has given the nitrogen great activity. The combination has given the plant power to absorb a greater quantity of food from earth and air, than either the nitrogen or the base singly could have effected.

The yield has been for every 100 parts of nitrogen used, 40.056 parts of hay; nearly double that produced by a simple ammoniacal salt, and four times that which an equal amount of nitrogen ordinarily produces.

These facts prove the strength of the principle adopted for estimating the relative value of manures. No manure, no salt, no combination of salts, gives full vigor to vegetation, while nitrogen is absent. Nitrogen not only measures, but gives the value to manures. It has been asserted, on high authority, that nitrogen in animal manure is always in a 
definite proportion to the phosphates; hence it may measure their quantity. Nitrogen makes manure hotter or colder. This causes change among the particles to begin, and to be carried on in the manure. Motion begins here, and is communicated to seeds and plants. Hence, crops are in proportion to the energy of these changes and motions.

207. This is a practical view of a practical subject. The nitrogen present in the manure-expresses its true value. This position is substantiated by the experience of practical men. The experiments undertaken by order of the Saxon and Prussian authorities, to ascertain whether the contents of the sewers of the cities of Dresden and Berlin, could be applied to fertilizing the barren lands in their vicinity, may be offered to prove its correctness. These varied in every form, and continued for a long period, prove that if a soil without manure yields a crop of three for one sown, then the same land yields, dressed

With cow-dung,

" horse-dung, 10 " 10 " "

Now the nitrogen in these has been shown, taking the minimum of nitrogen in the human, at $1 \frac{1}{2}$ per cent. is as $1: 1.50: 3$, whilst the above numbers are to each other, as $1: 1.43: 2$.

Considering how varied is the composition of night-soil, and how much diluted by various mixtures, this agreement is as near as ought to have been expected, in experiments whose objects were so totally different from that of ascertaining the quantity of nitrogen in each different manure.

208. Many modes of using night-soil are in use, all depending on convenience, and modified by locality, and other circumstances. Perhaps no mode is preferable to that long used in Flanders. It has the sanction of a people whose 
agriculture is, and has been for ages, pre-eminent. Flemish manure, or gadou, contains the whole efficacy of night-soil, both solid and liquid; and as used in Flanders it may be easily produced anywhere. Gadou cannot be too highly recommended for those who reside in the vicinity of a dense population, and who cannot procure dried peat, or charred matter to mix with night-soil. It is even questionable whether the products of the market-garden are not earlier and more luxuriant, and the yield greater with gadou, than with night-soil in any other shape.

An essential requisite for forming Flemish manure, is a brick or stone cistern, laid in mortar cement, and covered with an arch of the same. Two openings are left in the arch, one for the introduction of the night-soil, the other for an air-hole, which must be kept open. Night-soil, as collected during the season allotted to this work, is thrown into this reservoir, and then allowed to ferment several months. Gadou sells in Lisle for about 24 cents per barrel of 32 gallons; of this, about $\frac{3}{4}$ are expenses of manufacture. It is then in a liquid state, slightly viscid, with the odor of very weak hydrosulphuret of ammonia. This salt is rapidly converted by exposure and air into sulphate of ammonia. Gadou may be used before or after planting, or as a topdressing to grass.

A hogshead, mounted so as to be easily moved, is kept in the field, and filled from the cart with gadou, and from the hogshead it is ladled out all around, by means of a longhandled scoop, such as is commonly used by night scavengers, and, by successive removes of the hogshead, the whole ground is watered with gadou.

This manure, like all the highly nitrogenous, is an annual, acting more rapidly in proportion to its fluidity.

In Flanders, about 22 gallons, or 2 cwt., are equal to 
about 5 cwt. of farm-yard dung. But no comparison between the two can safely be made. The one runs its course rapidly, the other acts slowly. The one exerts all its influence in a season, the other reserves its fire. and acts for two or more seasons.

When it is determined what portion of farm-dung acts in a year, then may that fraction be compared with gadou. If the fraction is $\frac{1}{2}$, then 50 of farm-yard dung are equal to 100 Flemish manure. The proportion of azote in the last being 0.22 per cent, the real relation becomes to ordinary yardmanure which contains 0.41 per cent., as 182 : 100 . Hence, it is on certain crops only, that this and similar rapidly decomposing manure should be applied. For lightening, breaking up, and loosening the soil, ameliorating its condition, farm dung is better than gadou; and even where that is fully applied, an occasional dressing with yard-manure is considered essential.

Each substance used for a manure cannot be considered in detail. The composition only, will be mentioned. Among the mixed manures, poudrette and guano rank next to gadou. Poudrette is night-soil partly dried in pans, and nixed up with variable quantities of charred earth, peat charcoal, or ground peat and plaster. Its value will depend on the circumstance, whether its ammonia and salts are saved, or lost, in the manufacture. If sulphate or muriate of lime is added before drying, then the volatile carbonate of ammonia will be changed into sulphate of ammonia, and sal-ammoniac. Thus, not only the most valuable portion of night-soil will be retained, but the salts of lime will be much increased. The peat not only retains a portion of gaseous ammonia, but its geine by this act is rendered more soluble. All night-soil from vaults has begun to evolve ammonia, hence the advantage of mixing ground peat or plaster with 
night-soil, before drying. But, however prepared, poudrette varies much in quality. Analysis alone can determine its true value. Four samples of dried night-sóil, examined by Professor Johnston, afforded as follows, per 100 parts :
1.
2.
3.
4.

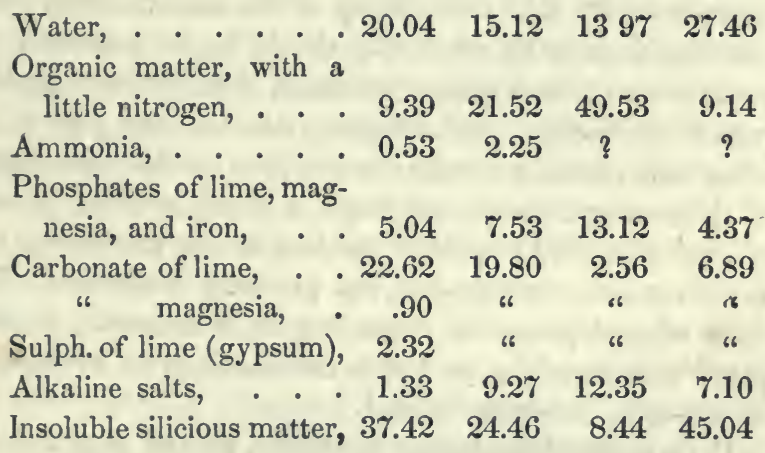

Very recently, Soubeiran has analyzed the poudrette of Montfaucon, near Paris. Taking into view the state in which ammonia exists in manure, Soubeiran has, with great skill, separated that which exists as putrescible animal matter, or as an easily soluble ammoniacal salt, from that which exists as a less soluble compound of ammonia, magnesia, and phosphoric acid, a triple salt, which is slowly decomposed in the soil. Fresh and warm poudrette, as sold at Montfaucon, to farmers, in November, 1847, contained in 100 parts,-

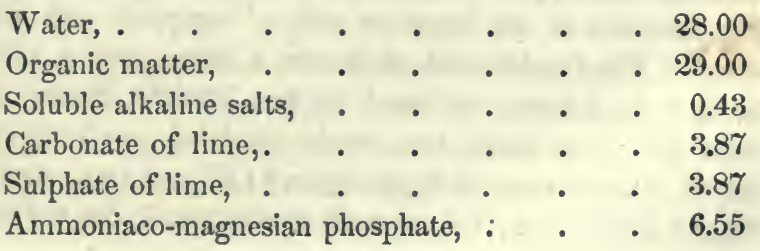


Bone phosphate of lime, . ‘ . . . $\quad$ - 3.46

Earthy matters, . . . . . . 24.82

100.00

209. It is evident, therefore, that the value of poudrette depends on the skill and honesty of the manufacturer. But allowing these to be what they should be, no consumer of poudrette will think himself wronged, if he discovers ground peat in the article; and allowing this, and the plaster, or other salts added, and water to compose one-half the weight of this manure, the farmer buys, in every hundred pounds of poudrette, 200 pounds of the best human excrement, and in a form not only portable, but perfectly inoffensive. The value of good poudrette, depending on its ammonia, is, compared with cow-dung, as 4 to 1 , calculated on the average of its nitrogen, cow-dung being 1 .

Paris is the birth-place of poudrette, as well as of fashion. Poudrette is one of the French fashions founded on good taste. Rude in its first manufacture, like a French dish, it has been improved by science, and its manufacture has attracted the attention of the most eminent chemists, who have conferred on this important interest the highest benefit. One is astonished at the vastness of the works devoted to the preparation of poudrette, at the forest of Bondy, and at Montfaucon. There arrive daily at this establishment, six hundred cubic yards of night-soil. This quantity affords one hundred cubic yards of poudrette after undergoing the various processes in the immense vats of reception and subsidence. The liquids, and of course a large portion of the salts, were formerly allowed to run into the Seine. But even with this waste, the simply air-dried poudrette was worth to the farmer and gardener, $\$ 1.62$ per ewt., containing, on the average, 1.6 per cent. of nitrogen in the ordinary 
poudrette, 2 per cent. in the middling, and 2.67 in the first quality.

The immense loss sustained by agriculture, by the wasteful and hateful mode of making poudrette, as above described, demanded reform. The liquid portion of night-soil at Montfaucon, is worth to agriculture nearly three times the value of its poudrette. Chemistry taught that urine could be easily converted to sulphate of ammonia, at a rate, calculating its value on its nitrogen, cheaper than poudrette. Practice has shown that sulphate of ammonia is effective, in proportion to its nitrogen, which is about 21 per cent. It can be made at $4 \frac{1}{2}$ cents per lb. Now, at $\$ 1.62$ per cwt. for poudrette at 1.6 per cent. of nitrogen, the relative money value of sulphate of ammonia and poudrette is as 1 to 13.

It has been estimated that the urine at Montfaucon would annually produce $4,000,000 \mathrm{lbs}$. of sulphate of ammonia. The nitrogen in this amount is equal to $52,000,000 \mathrm{lbs}$. of poudrette, or to $2,029,270$ lbs. yard-manure, or about 225 cords, containing 0.41 per cent. nitrogen; about $\frac{1}{5}$ less than that of pure cow-dung. Still it was desirable that all the liquids of night-soil should be saved for agriculture, without undergoing a process of separate manufacture, however cheap its product might be. A process was wanted which could be universally and easily applied, even by the humblest of those who go about in darkness, and by night "gather samphire, dreadful trade;" a process equally applicable to a single load, or to the annual product of a crowded city.

With the hope that the nuisance of night-men may be abated, when it is seen that agriculture and health will be equally benefited, by adopting better processes for the conversion of the contents of our vaults into manure, a general account of the mode of effecting such a desirable result 
may be here set before agricultural and sanitary committees.

It had long been known that sugar-house black, the oonecharcoal refuse from the sugar refinery, was a valuable manure, having properties which could not be attributed solely to its bone-dust, or phosphate of lime. Something was due to the charcoal, something to the blood added to clarify, and something to the matter extracted by both from the crude sugar. A constant and gentle production of ammonia goes on in sugar-refinery bone-black, giving that a value superior to its per centage of ammonia. The porous charcoal induces by condensation the formation of ammonia from the air, and by changes occurring in the extractive matter, and the charcoal itself. It was attempted to imitate refinery-black, by mixing charred turf, or peat, or even mould, with the water of city sewers. This, under the name of " animalized black," proved a powerful manure, very like refinery-black, affording like that, an enduring and constant gentle evolution of ammonia. Carbonized earth, charred peat, charcoal, or mould, mixed with urine, and the liquid portion of the settling vats of poudrette inanufactories, formed also a manure similar to sugar-house black.

The greatest improvement yet introduced into the poudrette processes, depends on the above principles. The whole contents of Parisian vaults are now at once mixed with charred matters, by which they are completely deodorized, and easily reduced to a dry state, in which they may be pulverized, barelled, transported, without offensive exhalations. The substance selected for charring should contain, like peat, or turf, or swamp muck, or pond mud, abundance of vegetable remains. These several substances are preferable. Vegetable mould or loam charred will answer, and, when previously to being charred, these are mixed with saw- 
dust, small chips, shavings, or tanner's spent bark, they become quite equal to peat charcoal.

Whatever substance is chosen, after it has been charred, it should easily fall to powder. If a too clayey loam is used, it forms lumps in the charring process.

The process of forming poudrette thus becomes inoffensive and simple, and the materials being collected, they are to be mixed, as follows, in a pit sunk for the purpose. To every load of night-soil, add an equal bulk of the charred material, mixing evenly the two, by rakes and stirrers, like a mason's mortar mixing tool.

The liquids are absorbed, it becomes a stiff mass, which is to be heaped up, and the watery portion allowed to drain out. If the centre of the pit is raised, of course the fluid collects round the edges, and this is to be again mixed with the charred matter, till the moisture is absorbed. The whole mass is now to be air-dried under sheds.

When pretty dry, add again its volume of night-soil, and so repeat as long as the night-soil is deodorized, or till the charcoal matter is only about one-fourth the whole mixture.

The whole may be finished in five or six weeks. It is a dry powder, which may be carried about in a snuff-box, with as little offence as the pulverized weed; and, when recently prepared, has been actually handed round on a china plate, at an evening party of sensitive, and very sensible ladies and gentlemen, without their suspecting the origin of the new article of commerce submitted to their inspection and criticism.

From the variety of materials which may be used, no one whose enterprise and interest impel him to collect night-soil, can say that he has not, or may not have the material for charring. He may object to the process as too expensive for an individual like himself to undertake such a matter. 
Happily in this part of our country, peat bogs, hassocks, turf, sa w-dust, spent and decayed bark, underbrush of pines, and the rubbish left after gleaning the fagots where wood land has been cleared, are abundant. Make these into small piles with loam, giving enough combustible matter to allow the whole, when covered with sods and fired, to burn slowly like a charcoal pit, a slow, smothered fire, burning without consuming, till the whole soil with which the peat or earth, \&c., were mixed, has been baked quite up to a low, red heat, just visible in the night.

This mass of baked soil and charcoal will answer very well for the speedy conversion of the few loads of night-soil, which small farmers may collect into a dry, useable manure, on the plan which has been laid down.

To those who undertake the removal of larger quantities, a general account of the furnace used for charring soil, the mode of conducting the whole process, from the collection of the raw material, from its legion of city and town depositories, to its final state of a dry, inodorous manure, full of sgricultural vigor, may be an inducement to undertake its preparation.

First. Be it understood, that a few pounds of copperas, dissolved in a pail of water, say half a pound to a gallon, will, when thrown into an ordinary vault, while its contents are being removed, completely deodorize that, no noxious gases escape, polluting the air, and making night more terrible than day to the dweller in crowded cities.

This would be an incidental benefit to all, but to him who, by contract, abates the nuisance of an overflowing vault, it is money in his pocket. The addition of copperas-water actually adds a direct value to the night-soil. The ammonia sn :volatile, the sulphuretted compounds so horrible, are seized by the copperas water, they are retained long enough to be 
transported to the spot where the further conversion of the night-soil is to take place. Both the ammonia and sulphuretted hydrogen are too valuable to be lost. No grain ever grew which did not contain sulphur compounds.

Secondly. The night-soil being deodorized, as above, it is to be removed or transported, by day or by night, as may be most convenient, to the pit prepared for its reception, and ther mixed in the mode which has been above set forth, with the charred material.

Thirdly. The furnace for charring is to be constructed of several hoppers, or very shallow pans, with inclined sides, set one above the other, and surrounded with brick work, so that the fire may play all around the hoppers. The hoppers must be so constructed as to swivel, so that the contents of each may be easily dropped into the pan immediately below.

The bottom of each pan is made of thick cast-iron, the lowest pan has a bottom of fire-brick, and is stationary over the grate; a door leads to it, and its end is movable, so as to allow the charred material to be withdrawn.

The height of the furnace will be regulated by the number of tiers of pans. It is a large chimney stack, with a fire at its bottom, the flame, smoke, \&c., passing among the hoppers.

The pans are charged with the materials intended to be baked, and the fire is kept up constantly.

The earth or peat on the lowest hopper, when of a brownish red color, and somewhat hot, is to be withdrawn into sheet-iron cylinders, furnished with a tight cover, and cooled while shut up. The materials in the several hoppers are to be successively dropped into thuse below them, and the upper one recharged with fresh matter. The charge is repeated about once in an hour, the earth, \&c., having been previously screened and made fine. 
The materials should be moist when put into the furnace. This prevents combustion on the lower plate, and the steam from the moisture pervading the whole furnace, excludes the air, and so carbonization takes place without combustion. A furnace 18 feet high, will char 15 to 18 cubic yards in twenty-four hours, and in France it has been found that the cost, per cubic yard, is 96 cents-say, $\$ 1$.

The whole cost of an establishment, capable of converting into poudrette, the night-soil of a city of 20,000 inhabitants, is about $\$ 4000$ to $\$ 5000$. Theactual cost of the manufacture, including all expenses, is about 20 cents per year for each inhabitant.

The product is about 136 cords, or 17,000 bushels annually. The poudrette contains about 3 per cent. of nitrogen, and under the name of "animalized black," it sells for about 34 cents per bushel. This leaves a profit of between $\$ 1700$ and $\$ 1800$ per annum.

Experience determines the value of manure. Its decisions are without appeal. It has proved that from 22 to 28 bushels per acre of animal black, are equal to four tons of yardmanure.

The preparation of poudrette so extensively pursued in France, Continental Europe, and England, has been also attempted in this country with varied success. Many establishments, unfortunately, have been abandoned, but the "Lodi Manufacturing Company," situated about three miles from the city of New York, perseveres and produces a good article, which is entitled to the farmer's confidence. It is sold at the works at about $\$ 1.50$ per barrel, of four bushels, or $37 \frac{1}{2}$ cents per bushel.

210. There is yet another form of poudrette, which, though much used in France, has not been introduced here. It contains more than $\frac{4}{5}$ animal matter, and it is formed with- 
out any offensive evolution of gas, by boiling the offal of the slaughter-house, and other refuse animal substance, by steam, into a thick soup, and then mixing the whole into a stiff paste, with sifted coal ashes, and drying. If putrefaction should have begun, the addition of ashes sweetens the whole, and the prepared "animalized coal," as it is termed, or poudrette, is as sweet to the nose, as garden mould. It is transported in barrels from Paris to the interior

This manure is prepared at "horse boiling" establishments in France. The carcasses of horses are cut in quarters, and steamed, to separate the fat. Unfortunately the flesh loses some of its salts by this treatment. The composition of the commercially cooked flesh was found by Soubeiran to be

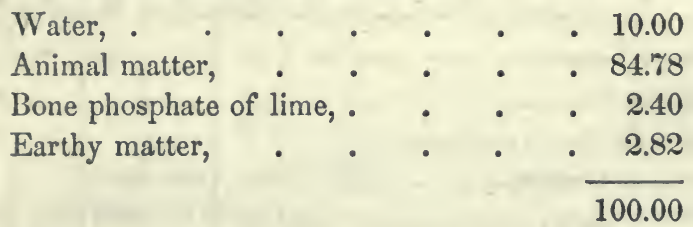

In this state it is said to be a cold manure, very poor in alkaline salts. It wants ammonia.

Blood is also converted into manure by the "horse boilers." It is coagulated by steam, and then dried in the air. Thus treated, it contains

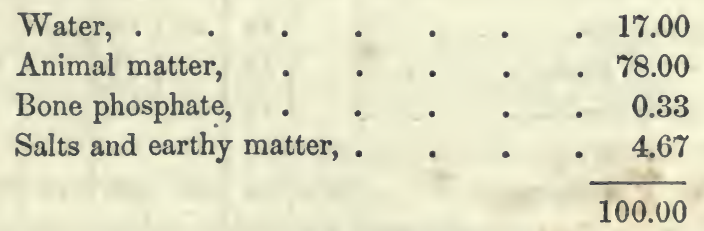

211. Guano is the excrement of sea-birds. It is found on our northern rocks and islands, but its great deposit is on the islands of the Southern Ocean, between $13^{\circ}$ and $21^{\circ}$ south 
latitude. It there forms immense beds, from 60 to 80 feet thick. What a length of time must have elapsed, or how incredible the number of birds, to have produced that pile of guano, whose base, washed by the sea, was observed by our countryman, Mr. Blake, to stretch a mile in length, and to tower 800 to 900 feet high! The composition of ancient guano, countenances the idea of its being the excrements of birds.

212. The following table presents the constituents of guano, as determined by several chemists.

\begin{tabular}{|c|c|c|c|c|c|c|}
\hline 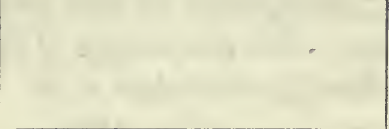 & 淧 & 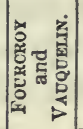 & 총 & 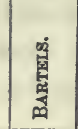 & 愢 & 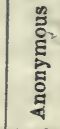 \\
\hline Urate of Ammonia,................. & 16. & 9. & 9. & 3.24 & * & \\
\hline Ammonia,$\ldots \ldots \ldots \ldots \ldots \ldots \ldots \ldots$ & & & & & & 15. \\
\hline Uric Acid,$\ldots \ldots \ldots \ldots \ldots \ldots \ldots \ldots$ & & & & & & 15. \\
\hline Oxalate of Ammonia,...$\ldots \ldots \ldots \ldots$ & & 10.6 & 10.6 & 13.35 & & \\
\hline " " Lime,$\ldots \ldots \ldots \ldots \ldots \ldots . . . .$. & 12.75 & 7. & 7. & 16.36 & & \\
\hline Phosphate of Ammonia,............. & & 6. & 6. & 6.45 & $13 . \dagger$ & \\
\hline " $\quad$ "Lime,................ & 10. & 14.3 & 14,3 & 9.94 & & \\
\hline " Ammonia and Magnesia, & & 2.6 & 2.6 & 4.19 & 25. & 30.5 \\
\hline " "Soda, $\ldots \ldots \ldots \ldots \ldots \ldots$ & & & $r$ & 5.29 & & \\
\hline Muriate of Soda, .................. & 0.5 & t & & 0.10 & - & \\
\hline Sulphate of Soda, ................. & & 3.3 & 3.8 & 1.19 & 1 & \\
\hline " $\quad$ "Potash,$\ldots \ldots \ldots \ldots \ldots \ldots$ & & 5.5 & 5.5 & 4.22 & & 3. \\
\hline Muriate of Ammonia,............... & & 4.2 & 4.2 & 6.50 & & \\
\hline Clay and Sand,.................... & 32. & 4.7 & 4.7 & 5.90 & $1 . \ddagger$ & \\
\hline Water and organic matter,$\ldots \ldots \ldots \ldots$ & 28.75 & 32.3 & 32.3 & 28.31 & $61 . \S$ & 36.5 \\
\hline $\begin{array}{l}\text { * Included with water and organic } m \\
\text { † Oxalate amm. included. } \\
\text { †rom crop of the birds. } \\
\text { Includes urate of amm. and 11. wa }\end{array}$ & matter. & & & & 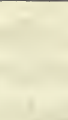 & \\
\hline
\end{tabular}


The samples examined by Ure were from the purest guano, furnished by the governments of Peruvia and Bolivia.

Of the 32.3 parts of organic matter, \&c., examined by Voelkel, about 12 parts are soluble in water.

An analysis of one sample indicates little of the general character of the deposit. Its value depends chiefly on its volatile constituents. Two samples from the same parcel, yielded Professor Johnston:

\section{No. 1.}

Water, salts of ammonia, and organic matter, . $\quad 23.5$

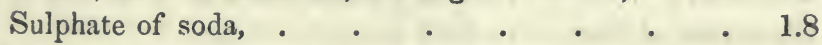

Common salt and phosphate of soda, . . . 30.3

Phosphates of lime and magnesia, and carbonate of

lime, . . . . . . . . 44.4

$\overline{100.0}$

No. 2.

Water and volatile matter, . $\quad$. $\quad$. 51.5

Ammonia, . . . . . . . . 7 .

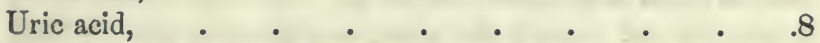

Common salt and sulphate and phosphate of soda, . 11.4

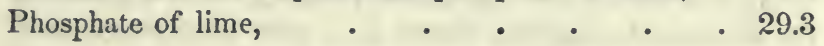

100.0

The average of several hundred analyses of guano from South America and Africa, afforded Professor Johnston, per 100 parts :

Water, from

Organic matter and salts of ammonia, . 28.9 to 35.9

Phosphates, . . . . . 26.8 to 38.6

Ammonia is the most valuable ingredient; next, a peculiar 
acid, called urio acid, which gradually affords ammonia, after these the bone earth of guano, gives it a permanent effect. The volatile matter acts in the earlier stage of vegetation. It is continually escaping. Hence, fresh fallen guano is always best. It is probably like the recent droppings of the present race of fish-eating birds. These consist almost wholly of uric acid. The excrement of the sea eagle gave in the

Solid Evacuations.

Liquid Evacuations.

Ammonia, . . . $9.20 \mid$ Uric acid, . . . 59.

Uric acid, . . . 84.65 Other salts, . . 41.

Phosphate of lime, . . 6.13

100.00

100.

Compared with these, guano contains $\frac{1}{6}$ to $\frac{1}{7}$ of its original organic elements. No manure yields more substances for the wants of plants, in all stages of their growth, than guano.

Guano is an article of commerce. There are three varieties known in trade. The white, the dark gray, the red brown, which is the most common. The white is the most recent, the red brown the most ancient, and decomposed, the gray intermediate. The actual money value of guano to the farmer, in England, where it is now extensively used, does not exceed $\$ 5$ per cwt. The price has fallen at the present time to about $\$ 2.50$ per cwt. Beyond this, practical men, who have used it, say that the farmer cannot afford to employ it. Mr. Blake thinks it may be afforded for $1 \frac{1}{2}$ cent. per pound, delivered in the United States. It is much used in Peru, where a spoonful is applied to each hill, as soon as the corn shows itself. The effects are what the most sanguine could expect, from this natural, concentrated poudrette, consisting both of salts and geine. Allowing, as has been asserted, that the land itself in Peru, contains not a particle 
of organic matter, guano can be no proof that plants require not geine, containing as it does, by analysis, 12 per cent. of soluble organic matter.

But this soluble matter will avail nothing without moisture; hence, in Peru, from the days of the Incas, till now, it is the practice, according to Dr. Von Tschudi, (Travels in Peru,) a few weeks after the sceds begin to shoot, to dig a little hollow round each plant, which is filled up with guano, and covered with earth. After 12 or 15 hours, the whole field is laid under water for some hours. In a few days the growth of the plant is doubled.

Guano is applied in best proportion in England and in this country, at the rate of about 3 to $4 \mathrm{cwt}$. per acre. It is still better applied mixed with one-half yard-manure. It should be applied annually in small doses ; 3 to $4 \mathrm{cwt}$. are considered equal to 20 or 25 tons of manure.

213. The dung of all domestic fowls, and of birds in genral, contains salts similar to those in guano; and while this subject is under consideration, the fact may be mentioned, that it has experimentally been proved, that the dung of pigeons is $\frac{2}{7}$ ths stronger than horse manure. And for stoved mulberries, vines, peaches, and other plants, the droppings of the.barn-yard fowls, 1 part to from 4 to 10 of water have been found to produce excellent results; the trees having, at the end of two years, the most healthy and luxuriant appearance imaginable. The poultry yard is, to a careful farmer, a rich source of vegetable food. How much a single hen can contribute to increase the crops, may be seen from the following account, from Vauquelin.

214. In ten days a hen ate $\mathbf{7 4 7 4}$ grains of oats, which contained of

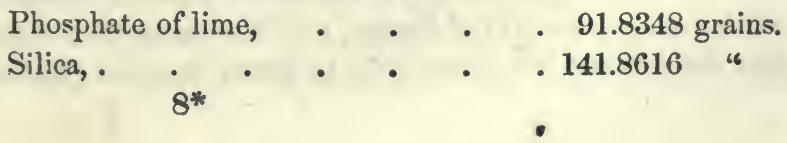


During this time four eggs were laid, whose

shells weighed,. . . . . 308.814 grains.

And contained phosphate of lime, . . 17.5975 "

Carbonate of lime, . . . . . 276.7095 "

Gluten, . $\quad$ • $\quad$ • $\quad$ - 9.8725 “

The excrements during the same time, gave

of ashes, . . . . . . 348.521 "

Composed of carbonate of lime, - . 39.3511 "

Phosphate of lime, • • • . 184.5348 "

Silica,. . . . . . . 124.6351 "

Thus voiding in eggs and excrements,

Carbonate of lime, . $\quad$ • . $\quad 315.0606$

- Phosphate of lime, . . . . 202.1323 "

Now this is 17.2265 grains of silica less; and in round numbers, 110 grains of phosphate, and 315 grains of carbonate of lime more than the food eaten contained. Probably in all such experiments, where confined to food different from usual, and deprived of their customary habits, all animals draw upon, and, in such cases, may be said to eat themselves. The daily amount of bone-dust, however, which one hen thus produces in her various droppings, is about $18 \frac{1}{2}$ grains, and of carbonate of lime, 3.9 or an annual amount in round numbers, of these two salts, of 1 pound and 3 ounces. Estimating the salts only, it is found that the agricultural value of a single hen per annum, equals the salts contained in sereral bushels of wheat. This places in a strong light, the very great effects produced by a spoonful of guano, to a hill of corn. In Belgium, the annual value of the dung of 400 or 500 head of pigeons, much used in manuring flax, is $\$ 25$ to $\$ 30$. Under the name of columbine, pigeons' dung is much used in the north of France, and it is stated by Dumas, that the annual droppings of six to seven hundred pigeons 
are sold for 100 francs, or about $\$ 19$. Columbine is applied at the rate of about 900 lbs. per acre, ordinarily. In France the expense of this manure, per acre, is from $\$ 9.60$ to $\$ 15.56$.

The composition is as follows, per 100 parts :

Soluble matter in ?

Pigeons' dung. $\int$
Recent.
DAVY.

23
Six months old. After formontation. SPRENGKL. DAVY.

The salts and other matters are similar to those in guano. Pigeons' dung has been imported from Egypt into England. Its composition per 100 parts was found by Johnston to be:

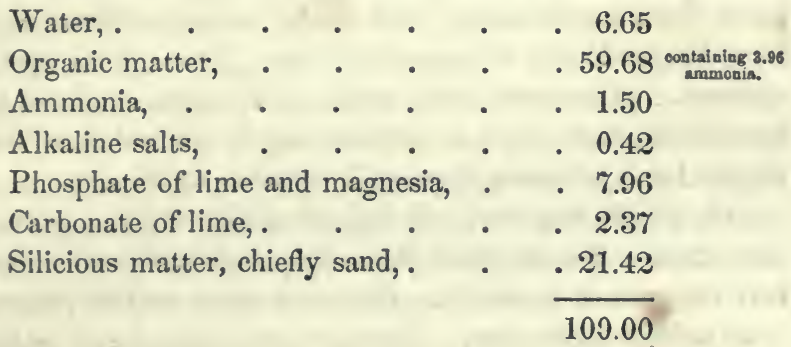

All fowl droppings should be kept dry to avoid fermentation. It is best to compost this manure with peat, or charred earth, as noticed under the head of poudrette making.

215. And here, having adverted to eggs, attention may be called to a sadly overlooked fact. All around is heard the requiem of departed wheat-fields. The burden of the chant is, carbonate of lime! carbonate of lime! The wail is, it is gone ! gone! The want of this is the grand characteristic of our soil. The sole cause, in the estimation of some, of all our barrenness, and fruitless attempts, as they say, and would have us believe, at raising wheat. An egg-shell shall put such reasoning or dreaming to flight. A common sized 
hen's egg weighs about 1000 grains, of which the shell is about 106 grains. Two per cent. of the shell is albumen, or animal matter ; 1 per cent. phosphate of lime and magnesia, and the balance or 97 per cent. carbonate of lime. At an egg a day, this is equal to $1 \frac{1}{2}$ ounce of dry chalk per week. Whence comes this? From soil, from brick-dust, from grain, meal, \&c. But it exists not in soil as carbonate of lime. Animals, like plants, decompose the silicate of lime of soil, and recombine the base with carbonic acid, to form egg-shells. Considering the countless thousands of eggs which are produced by the birds of every feather in New England, how big a bit of chalk would their shells produce! So of fresh water clams; their shells, common throughout New England, are carbonate of lime. These facts speak volumes. Whenever birds cease to lay eggs, or clams to form shells, then, and not till then, may it be said that New England soil is barren, because it contains no lime.

216. Flesh, fish, fowl, all animal solids, muscle, gristle, skin, sinews, \&c., all afford geine, by putrefaction, and evolve vast volumes of ammonia. Salts are more or less present in all animal substances. There are uniformly found, in the soft or fluid portions, some of the following salts :

\section{MINERAL SALTS.}

Sulphate and phosphate of lime.

Phosphates of soda, magnesia and ammonia.

Sulphate and muriate of potash and soda.

Carbonates of potash, soda, lime, and magnesia.

\section{VEGETABLE SALTS.}

Benzoate of potash, soda, lime.

Acetate, " " "

Oxalate, " " "




\section{ANIMAL SALTS.}

Urate of ammonia.

Lactate of ammonia.

Oxides of iron, manganese, and silica.

In a word, are found, in animals, the inorganic parts of soils, the elements of silicates, united with the inorganic acids which existed in the soil, added to the organic, produced by the animal itself. These salts are common to animals and plants, but except in bones, they form only a small part of the living body.

21\%. In plants there are certain principles, as albumen and gluten, so like animal products, that they have received the name of vegeto-animal. But very late discoveries have proved that they are identical with the fibrine and albumen of animals. That these animal and vegetable products are modifications of a principle called proteine, has been alluded to (page 118). The late analyses of these various products, shed a clear light over the multiform substances, from the animal kingdom, used for manure. They show how like products arise from the decomposition of plants, and thus assimilate animal and vegetables in the process of forming composts.

Fibrine, or the basis of flesh, or muscular fibre, albumen, and caseine, or the curd of milk and basis of cheese, are composed as follows, by Mulder's analysis :-

Fibrine.

Albumen.

Caseine.

$\begin{array}{lrrrr} & & \text { of eggs. } & \text { of serum. } & \\ \text { Carbon, } & \mathbf{5 4 . 5 6} & \mathbf{5 4 . 4 8} & \mathbf{5 4 . 8 4} & 54.96 \\ \text { Nitrogen, } & \mathbf{1 5 . 7 2} & \mathbf{1 5 . 7 0} & 15.83 & 15.80 \\ \text { Hydrogen, } & 6.90 & \mathbf{7 . 0 1} & 7.09 & \mathbf{7 . 1 5}\end{array}$


MANURE.

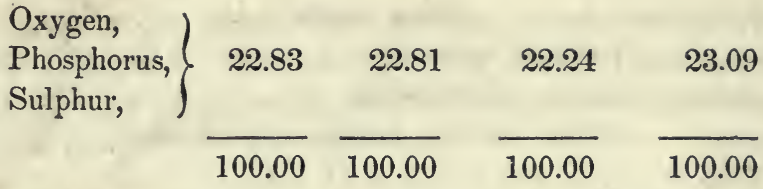

The corresponding products of vegetables are, 1st, gluten, and 2d, its peculiar principle, detected by Liebig, called vegetable fibrine; $3 \mathrm{~d}$, vegetable albumen; $4 \mathrm{th}$, legumine, or vegetable caseine. The two last are identical in composition and properties, with the albumen and caseine of animals. Indeed, it has been suggested, that animals never create either of the above, but draw them ready formed from plants. The composition of the vegetable principles authorizes such a conclusion. By the analyses of Drs. Scherer and Jores, in the laboratory of Liebig, these are constituted as follows :

\begin{tabular}{|c|c|c|c|c|}
\hline - & Gluten. & $\begin{array}{c}\text { Vegt. fibrine. } \\
\text { Average of } \\
3 \text { triale. }\end{array}$ & $\begin{array}{l}\text { Albumen. } \\
\text { of rye, whenat, } \\
\text { and plants.. }\end{array}$ & Caseine. \\
\hline Carbon, & 55.22 & 54.345 & 54.86 & 54.138 \\
\hline Nitrogen, & 15.98 & 15.733 & 15.88 & 15.672 \\
\hline Hydrogen, & 7.42 & 7272 & 7.31 & 7.156 \\
\hline Oxygen, & & & & \\
\hline Sulphur, & 21.38 & 22.647 & 21.95 & 23.034 \\
\hline & 100.00 & 100.00 & 100.00 & 100.00 \\
\hline
\end{tabular}

Caseine contains no phosphorus, but both animal and vegetable principles, comprised under the above names, are always combined with alkalies, lime, magnesia, iron, sulphur, and phosphoric acid. The above are the organized principles of living bodies, and are distinguished from all others by their nitrogen. Substances not containing this element are said to be organic, but not organized. 
218. The above substances, which form the great bulk of animals, and no small part of plants, deducting their inorganic elements, compose proteine, whose constituents are:

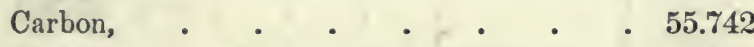

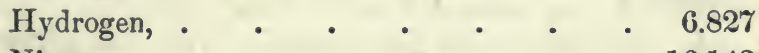

$$
\begin{aligned}
& \text { Nitrogen, } \quad \cdot \quad \cdot \quad \cdot \quad \cdot \quad \cdot \quad \cdot \quad \cdot 16.143 \\
& \text { Oxygen } \bullet \quad . \quad . \quad . \quad . \quad . \quad .21 .288 \\
& 100.00
\end{aligned}
$$

This compound is the basis of the animal solids, and soft parts : fibrine, or flesh, and albumen, are only compounds of this, with sulphur and phosphorus. All the parts of the animal frame are modifications only of proteine.

The peculiar principle of glue, or size, or jelly, called gelatine, never exists in the healthy animal body. It is the product of catalysis. Boiling water is the catalytic agent, and produces it from tendon, ligament, cartilage, skin and bone.

\begin{tabular}{|c|c|c|}
\hline & Tendon. & Cartilage, or gristle from ribs \\
\hline Carbon, & 50.874 & 50.895 \\
\hline Hydrogen & 7.152 & 6.962 \\
\hline Nitrogen, & 18.320 & 14.908 \\
\hline Oxygen, & 23.754 & 23.235 \\
\hline
\end{tabular}
The composition of these will show at once their relation to proteine :

Scherer.

Horny matter is equally allied to proteine. Its several variations have been divided into two clisses : 1st, soft, and 2 d, compact. The first includes skin, or the outer part, called cuticle; and the delicate lining membrane of the internal passages, and sacs; and these substances are like constituted. The cuticle of the sole of the foot is composed of- 


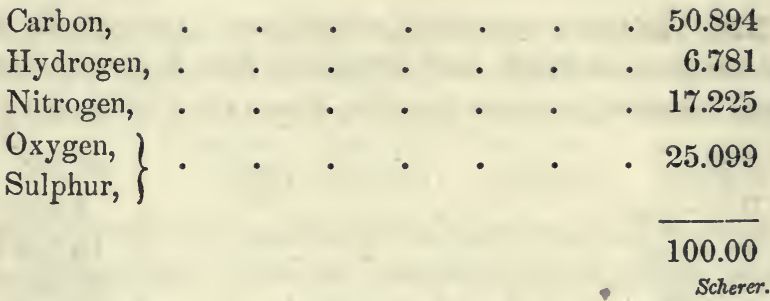

Compact horny matter includes hair, horn, nails, claws, hoofs, scales. Like all the other compounds of proteine, these contain sulphur, lime, magnesia, \&c., and from $\frac{1}{2}$ to 2 per cent. of bone earth. The effect of these as phosphates has been adverted to, section 169 . These all give varied portions of ashes. The beard gives about 0.72 per cent.; blond colored hair, 0.3, and the black hair of a Mexican, 0.2; nails, 0.5 ; wool, 2 ; and gelatine of bone, 0.7 per cent. of ashes. These all evolve ammonia by caustic alkali, an effect which might have been predicted from their composition, which is, according to Scherer :

\begin{tabular}{lrrrr} 
& Hair. & \multicolumn{1}{c}{ Horn. } & \multicolumn{1}{c}{ Nails. } & Wool. \\
Carbon, & 50.652 & 51.540 & 51.089 & 50.653 \\
Hydrogen, & 6.769 & 6.799 & 6.824 & 7.029 \\
Nitrogen, & 17.936 & 17.284 & 16.901 & 17.710 \\
Oxygen, & 24.643 & 24.397 & 25.186 & 24.608 \\
Sulphur, & & & &
\end{tabular}

Hair affords a substance, in addition to its proteine, and to which feathers are analogous. The composition of the last is,

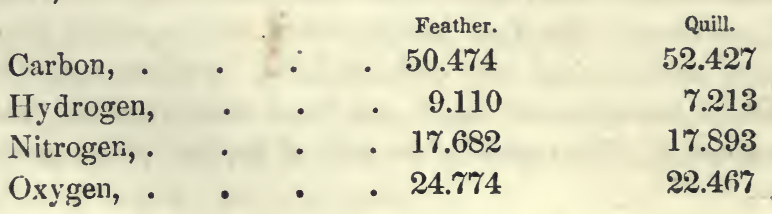


Bone itself is allied to proteine by its cartilage, which composes nearly one-third the weight, and which boiling water, under pressure, completely extracts in the form of gelatine, or glue.

219. All these varied forms of proteine may be tabulated so as to express, at a glance, their relation to each other, if the elements, Carbon, Hydrogen, Nitrogen, and Oxygen, are expressed by C. H. N. O., and to each are added figures which represent the number of atoms entering into the compound. This is called chemical notation, and each set a chemical formula. (55.)

Proteine, . . . . . $\mathrm{C}^{48} \mathrm{H}^{36} \mathrm{~N}^{6} \mathrm{O}^{14}$

Gelatine of tendons, . . . $\mathrm{C}^{48} \mathrm{H}^{41} \mathrm{~N}_{2}^{11} \mathrm{O}^{18}$

Chondrine, or gelat. of rib cartilage, $\mathrm{C}^{48} \mathrm{H}^{40} \mathrm{~N}^{6} \mathrm{O}^{20}$

Compact horny matter, hair, . . $\mathrm{C}^{48} \mathrm{H}^{39} \mathrm{~N}^{7} \mathrm{O}^{17}$

Feathers, - . . . $\mathrm{C}^{48} \mathrm{H}^{99} \mathrm{~N}^{7} \mathrm{O}^{16}$

But the great practical lesson, taught by this similarity of constitution, is, that it enables the chemist to present at one view, animal and vegetable substances, 'as carbon, water, ammonia, and carburetted hydrogen. This is the view which the farmer takes, for he knows that these are the elements of manure. Proteine may be resolved into:

Hydrogen.

Carbon, $\} \begin{aligned} & 4.242+0.707= \\ & 51.500 \\ & 51.500 \text { Carbon. }\end{aligned}$

Oxygen, $\quad 21.288+2.661=23.949$ Water.

Nitrogen, $\quad 16.143+3.459=19.602$ Ammonia.

$93.173+6.827=100$. Proteine.

This is the agricultural view, and expresses at once that this great variety of substances is compared to cow-dung as 32 to 1 , when used dry as manure, dung being 1 , and pro- 
teine being calculated on its nitrogen. The physiological view is this :

If ammonia and water, known compounds of nitrogen, hydrogen, and oxygen, are added in certain proportions to proteine, all the gelatinous tissues, hair, horn, \&c., will be formed.

Let Pr. represent proteine, then

Proteine. Ammonia. Water. Oxygen.

Fibrine, albumen $=\operatorname{Pr}$.

Arterial membrane $=\mathrm{Pr}$.

Chondrine

$=\mathrm{Pr}$.

Hair, horn

$=\operatorname{Pr}$.

Gelatinous tissues $=2 \mathrm{Pr}$.

$\begin{array}{rrr} & +2 & \\ & +4 & +2 \\ +1 & & +3 \\ +3 & +1 & +7\end{array}$

By this view, horny matter exceeds by 16 per cent., and the gelatinous tissues by 25 per cent., the value of the proteine of flesh, blood, \&c.

220. For the purposes in view, all animal and vegetable products may be divided into two classes : first, that which does, and second, that which does not, contain nitrogen. The action of these is very distinct, on the elements of soil, and as manures. The first class putrefies, the second does not. The first class forms alkali, the second forms acids. The action of the first depends on nitrogen, that of the second on carbon.

221. The first class contains flesh in all its varieties; blood, skin, sinew, gristle, cartilage, tendons, hair, feathers, wool, hoofs, horns, nails, scales, and one-third, nearly, of bones and teeth. The second class contains fats and oils in all their variety.

222. It is easily understood, then, how woollen rags and fiocks become powerful manure. They afford ammonia, and $100 \mathrm{lbs}$. containing 17 of nitrogen, should be $\mathbf{3 4}$ times 
stronger than $100 \mathrm{lbs}$. of fresh cow-dung. Connected with flocks and wool, there is a very valuable product, rich in all the elements of manure, which is often lost or not used for agricultural purposes, namely, the sweat, or natural soap of wool. Fresh clipped wool loses from 35 to 45 per cent. of its weight by washing. This is due to a peculiar matter exuded from the wool, and which consists chiefly of potash, lime, and magnesia, united to a peculiar animal oil, forming an imperfect soap. It is remarkable that this soap of lime, in all other cases insoluble, is here soluble in water. The experience of the best French agriculturalists, is full of testimony to the good effects of this wool sweat. It has been calculated that the washings from wool, annually consumed in France, are equal to manuring 370,000 acres of land.

223. Bones consist of variable proportions of cartilage, bone earth, and carbonate of lime. The bone earth may be estimated at one-half the weight. It is a peculiar phosphate of lime, containing 3 parts of lime to 1 of phosphoric acid. A great part of the value of bone as manure, depends on its cartilage. The animal part of bones being one-third of their weight, the ammonia is equal to 8 or 10 times that of cowdung, while, if we regard the salts only, $100 \mathrm{lbs}$. of bonedust contain nearly 66 times as much as an equal weight of cow-dung. Such statements while they express the chemical facts, are almost, if not quite, supported by the testimony of those who have, in practical agriculture, applied these concentrated animal manures. It is a common opinion, that bones from the soap-boiler have lost a large portion of their animal matter. It is erroneous. Boiling, except under high pressure, extracts very little of the gelatine, and not all the fat and marrow. Heads and shoulder-blades and the smaller bones still contain, after boiling, $3 \frac{1}{2}$ per cent. of fat and tallow. If the phosphate of lime of such bones is dissolved 
out by acid, the anımal portion remains, with all the form and bulk of the bone. Bones which are offered in the market, are quite as rich in the elements above stated, as are unboiled bones. The phosphate of lime is rendered quite soluble by its combination with gelatine and albumen. The class of mixed manures, containing nitrogen, has thus been considered. The principle of their action and the foundation of their value, pointed out. The action of the second class, or that not containing nitrogen, remains to be explained.

224. All fats and oils exposed to air give off a quantity of carbonic acid, and end by becoming acids. As their ultimate elements are the same as those of plants, it may be inferred, that under the influence of growing plants, fats and oils are decomposed and become vegetable food. But there is another action of fats and oils on silicates; they not only let loose the alkali of silicates by the carbonic acid, which they evolve, but the oils now become acids, immediately combine with this alkali, and imperfect soaps are formed. Soaps are truly chemical salts, and hence we have at once a clew to the action of oil and fat.

225. Among the most powerful of manures in the class composed of geine and salts, is soot. There is no one substance so rich in both. Its composition allies it to animal solids, and is as follows :

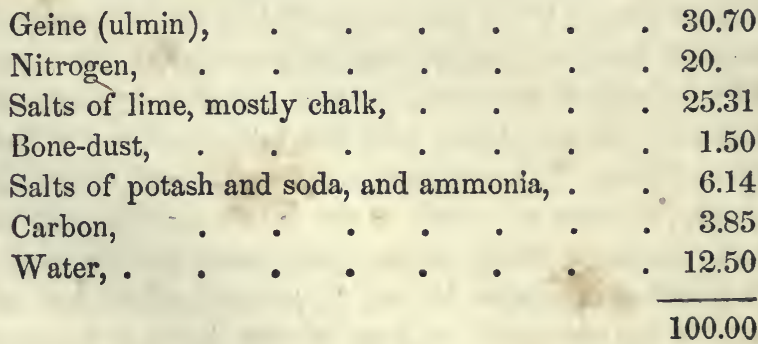


On the principles adopted for determining the value of manure, the salts in $100 \mathrm{lbs}$. of soot are equal to 1 ton of cow-dung. Its nitrogen gives it a value, compared with cowdung, as 40 to 1 .

226. Soot forms a capital liquid manure for the floriculturist. Mixed with water, in the proportion of 6 quarts of soot to 1 hogshead, it has been found to be a most efficacious liquid, with which to water green-house plants; and being not only a come-at-able, but a comely preparation, it may recommend itself to the cultivator of flowers, by these ladylike qualities.

The most decided good results have been produced in England, on Stinchcombe farm, containing 200 acres of arable land, by soot, barn-yard manure, and sheep-dung. The rotation is turnips, potatoes, wheat. The average produce of the potatoes, 315 bushels; of the wheat, 28 bushels per acre. The turnips are manured by that produced by 12 oxen and 5 horses, 4 of which are employed in carting the crops to market and hanling back soot, often a distance of 25 miles. The turnips are fed off by sheep; and each acre in turnips receives at the rate of the manure of 2000 sheep for one day (205). The potatoes and wheat are each manured with soot only, at the rate of between 11 and 12 bushels per acre. The annual quantity used being about 3000 bushels, at the cost of about a $6 \mathrm{~d}$. English, say $12 \frac{1}{2} \mathrm{cts}$. per bushel. By this treatment, for 30 years the quantity of crops and the quality of the land have improved year by year. Anthracite coal-soot, as it may be called, contains no geine. It contains abundant salts of ammonia. Mixed with swamp muck and alkali, at the rate of two bushels per cord, there can be no doubt that the good effects of soft coal, or wood soot, would be produced. The fine dust which collects about the flues of boilers, when anthracite is used, thus 
becomes of great agricultural value. From an accurate experiment on 106,504 lbs. of coal, I find the quantity of this ash, collecting about flues, is 5.09 per cent. of the coal consumed.

227. Among the mixed manures, is the salt, or spent lye of the soap-boiler. It seems to offer a natural passage from this class to those consisting of salts only. To understand its components, the chemical composition of oil and fat must be briefly studied. No products of life are now better understood than the fatty bodies. They are all acids, combined with a peculiar organic base, which acts the part of an oxide. This is never obtained except in combination with oxygen and water. In this state it has long been known under the name of glycerine. The acids combined with it, are stearic, margaric, and oleic. By the union of these acids with glycerine, stearine, and margarine, or fats, an oleine or oil is produced. In soap-making, the alkali used decomposes stearine and oleine, combining with their acids, which thus are converted into stearates, margarates, and oleates of alkali, or soap, while the glycerine remains free in the spent lye with the salts which that contains.

228. The proportion of glycerine in fat and oil, is about 8 per cent. Its composition is-

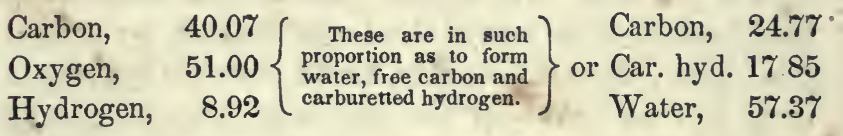

Glycerine is transparent and liquid, and was called the sweet principle of oils, from its sweet taste.

229. The glycerine is thus the organic, or geine part of salt lye. Its proportion in that will vary, if the spent lye is boiled. as is usual, upon a fresh portion of tallow, which adds 
its quantity of glycerine, in proportion to the alkali in the lye.

230. The salts are various, and depend on the kind of alkali used to form the lye. The alkali is derived from barilla, from soda or white ash, from potash, or from ashes. Hence, no general statement can be given which shall express the value of spent lye salts. That some idea may be formed of its components, it may be divided into two kinds: 1st, that produced from soft soap, or from ashes, or potash; 2 dly, that from hard soap, barilla, or soda-ash. A boil of $2000 \mathrm{lbs}$. of soft soap requires 150 bushels of ashes, and its spent lye contains, in addition to a little free potash, the following salts, derived from ashes:

$$
\begin{array}{r}
130 \text { lbs. of sulphate of potash, } \\
6 \text { " of muriate of potash, } \\
36 \text { " of silicate of potash, }
\end{array}
$$

allowing the ashes to have been a mixture of oak, bass, and birch woods. Besides these, in the process of soap-making, in order to make the soap "grain," common salt is added. A chemical change is thus induced, the potash soap is changed to soda soap, or the soft to hard. The soda of the salt entering the soap is replaced by the potash, which combines with the acid of the salt, that is chlorine, or muriatic acid. In other words, common salt, or chloride of sodium, or muriate of soda is changed to chloride of potassiurn, or muriate of potash, which is thus added to the spent lye. The proportion of salt added, varies, but it may be stated in general, 7 bushels, or 500 lbs. to 150 bushels of ashes. In a boil, then, of 2000 lbs. of soap, 1200 lbs. of fat, or tallow, containing $100 \mathrm{lbs}$. of glycerine, 150 bushels of ashes, 7 bushels of salt, afford about 200 gallons of spent lye. This contains the glycerine and salts above (230), and affords, per gallon, 
Geine, or glycerine, $\frac{1}{2} \mathrm{lb}$. Salts, $\left\{\begin{array}{l}\text { Muriate of potash, } 5 \frac{1}{3} \mathrm{lbs} . \\ \text { Sulphate of potash, } 1 \frac{1}{3} \mathrm{lb} \text {. }\end{array}\right.$ Silicate of potash, $2 \frac{1}{2} \mathrm{oz}$.

231. The spent lye from soda soap, contains the sulphate and muriate of soda, of the soda ash, which rarely amounts to 12 per cent. As less salt is here added, the spent lye is less rich in salts. In a boil of $2000 \mathrm{lbs}$. of hard soap, 600 weight of white ash are used. lncluding the one bushel of salt usually added, the spent lye contains,

Sulphate of soda, $84 \mathrm{lbs}$. or, per gallon, $6 \frac{8}{4} \mathrm{oz}$.

$\begin{array}{llll}\text { Muriate of soda, } & 106 \text { " } & \text { " } & \frac{1}{2} \mathrm{lb} \text {. } \\ \text { Glycerine, } & 100.6 & \text { " } & \frac{1}{2} \mathrm{lb} .\end{array}$

232. The value of spent lye has been tested for a series of years. It has shown its good effects on grass lands for four or five years after its application. There is great advantage in carrying it out upon snow. It has then the effect of converting any carbonate of ammonia in the snow into salammoniac, or a volatile into a fixed salt.

233. When it is thus understood on what the value of spent lye depends, it would seem probable that the farmer may himself prepare it; and, unless he resides in the neighborhood of a soap-boiler, at a cheaper rate than he can buy and cart home this liquid manure. A hogshead of spent lye, of 100 gallons, contains, if from ashes,

50 pounds of glycerine or geine, 53 " of muriate of potash, 13 " of sulphate of potash.

The salts may easily be supplied. It becomes a highly interesting question, whether the glycerine has any specific 
action, any action which the light of chemistry may not kindle in similar substances. By reference to (228) its chemical constitution approaches geine, and they are here presented side by side.

$\begin{array}{lcc} & \text { Glycerine. } & \text { Geine of soil. } \\ \text { Carbon, } & 40.07 & 58.00 \\ \text { Hydrogen, } & 8.92 & 2.18 \\ \text { Oxygen, } & 51.00 & 39.90\end{array}$

234. The glycerine resolves itself into water, free carbon and carburetted hydrogen, or the gas of marshes or stagnant pools; the geine into carbon and water. In the series of changes which they may undergo, let it be supposed that carburetted hydrogen gas is evolved by glycerine. There is no reason for assuming, as do some, that carbonic acid is the only source of the carbon of plants. The volumes of carburetted hydrogen produced in the decay of plants, may be intended, as well as carbonic acid, for their nutriment. Suppose, of which there is no doubt, that carburetted hydrogen of glycerine contributes to this effect, there remains then free carbon, which, being perfectly insoluble and changeless, acts only by condensing gases in its pores.

235. Geine, by tillage, air and moisture, evolves also carbonic acid. As gas, no one will deny that it thus affords carbon to plants; its carbonic acid is absorbed and its carbon assimilated, and hence, if either glycerine or geine afford carbon, the circumstances under which they may be applied to the land, are less favorable to the production of carburetted hydrogen, than of carbonic acid. The balance then is in favor of geine.

236. There are two circumstances wherein geine and glycerine differ. The latter is soluble to any extent in water, it is applied to the land in spent lye, already dissolved. The 
action so evident, is due to one of two causes, or to their joint action. Spent lye acts either by its organic, or by its inorganic part; by its glycerine, or by its salts. Those who take the ground, that humus or geine never is taken up by plants, will then attribute all the decided good effects of spent lye to its salts. Glauber's and common salts applied in equal quantity to that contained in soda spent lye, should produce equally good effects. It is well known that such is not the fact. Nor will those who maintain this doctrine, admit that glycerine acts by its evolving gases, for then an equal weight of peat would answer. It is well known that such is not the fact.

23\%. If spent lye then acts neither by its salts, nor its evolved gas, it acts by the perfectly dissolved state of its glycerine. That such is the case admits not of a doubt, and goes to show that plants appropriate the geine or humus of soil, by absorbing it as geine or geates.

238. The spent lye acts both by its salts and its geine. The action of salts has been explained. The soluble state of geine is the most important fact to be borne in mind, if it is attempted to make spent lye on a farm. Swamp muck, or peat, ashes, and common salt, will afford all the elements of spent lye, and the following may be proposed as an imitation of that from soda soap:

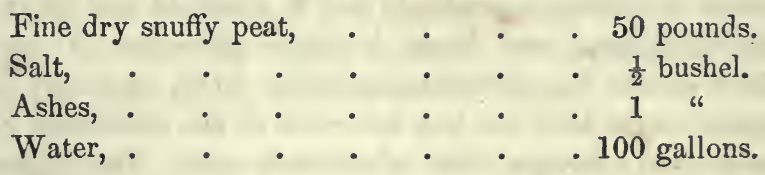

Mix the ashes and peat well together, sprinkling with - water to moisten a little. Let the heap lie for a week. Dissolve the salt in the water, in a hogshead, and add to the brine the mixture of peat and ashes, stirring well the while. 
Let it be strrred occasionally for a week, and it will be fit for use. Apply it as spent lye, grounds and all. Both ashes and salts may be doubled and trebled, with advantage, if convenient. The mixture of lye must be used before it begins to putrefy; this occurs in three or four weeks. It then evolves sulphuretted hydrogen gas, or the smell of gas of rotten eggs. This arises from the decomposition of the sulphates in the water and ashes, by the vegetable matter. A portion of the geine is thus deposited from the solution. (See Appendix for the trial of this lye.)

239. Having thus considered the class of mixed manures, or those composed of geine and salts, those consisting of salts only are to be now explained. They are next in value to the mixed manures. They are chiefly the liquid evacuations of animals, and when artificially combined with geine, their value exceeds that of the solid evacuations. These liquids equal, in fact, the mixed manures of the most fertilizing energy. The liquid evacuations are truly salts only, dissolved in water; but they are salts of a peculiar character in many cases; and are formed of an animal acid. This is it which renders a detailed account of these manures interesting to the farmer. It is not enough for this purpose to refer the action of these liquids to the general effect of salts or mineral manures.

240. The peculiar animal acid to which reference has been made, becomes, like nitric acid in nitrates, the food of plants. The element from which it is derived gives a marked and highly valuable character to the liquid evacuations of the farm-yard and household. This peculiar animal principle is urea. It may be obtained from these liquids in transparent but colorless crystals, of a faint but peculiar odor. Cold water dissolves more than its - weight, and boiling water an indefinite quantity of crystals of urea. The pure crystals 
undergo no change when dissolved in pure water, but if they are mixed with the other ingredients of the urine, decomposition rapidly ensues, and they are resolved almost entirely into carbonate of ammonia. Alkalies and alkaline earths induce similar changes on urea. The practical value of this fact will be easily understood.

241. Pure urea has no distinct alkaline properties. It unites with aqua fortis, or nitric acid, and forms a sparingly soluble salt, composed of about equal parts of each of its ingredients.

242. Urea is composed, according to Dr. Prout, of carbon 19.99, oxygen 26.66, hydrogen 6.66, nitrogen, 46.66 . These elements are so beautifully balanced, that they afford only carbonic acid and ammonia; though the chemistry of every reader may not understand how these elements produce cyanic acid and ammonia. The salt cyanate of ammonia, has actually been formed by modern chemistry, which has thus succeeded in forming a true organic product, or product of living action, or rather of chemical action guided by living principle. In all animal evacuations containing urea, that may be considered as so much carbonate of ammonia of the shops. Hence it is the urea in urine which gives that liquid so great a value. Urine is richer in ammonia than flesh or blood.

243. The peculiar animal acid which has been mentioned as forming so essential a part in these liquid excretions, is called uric acid. It is not, like urea, changed by exposure into ammonia. It contains a large portion of nitrogen, which, under the influence of growing plants, is let loose, and may then form ammonia. Its composition is as follows : carbon 36.11 , hydrogen, 2.34, oxygen 28.19 , nitrogen 33.36 . - The peculiar principles of the liquid evacuations having been explained, their constitution may be now stated. They 
are, it will be remembered, at the head of the class of manures composed of salts. First, the liquid evacuation of cattle, what is its agricultural value as a manure? Its composition will form the answer.

Cow's urine was long ago examined by Rouelle and by Brandt, whose results have formed the basis of all calculations of its value for almost half a century. The results are evidently defective. The more exact analysis of cattle urine, by Sprengel, who has devoted particular care to the subject, gives, as the average of many trials, the following, in 1000 pounds:

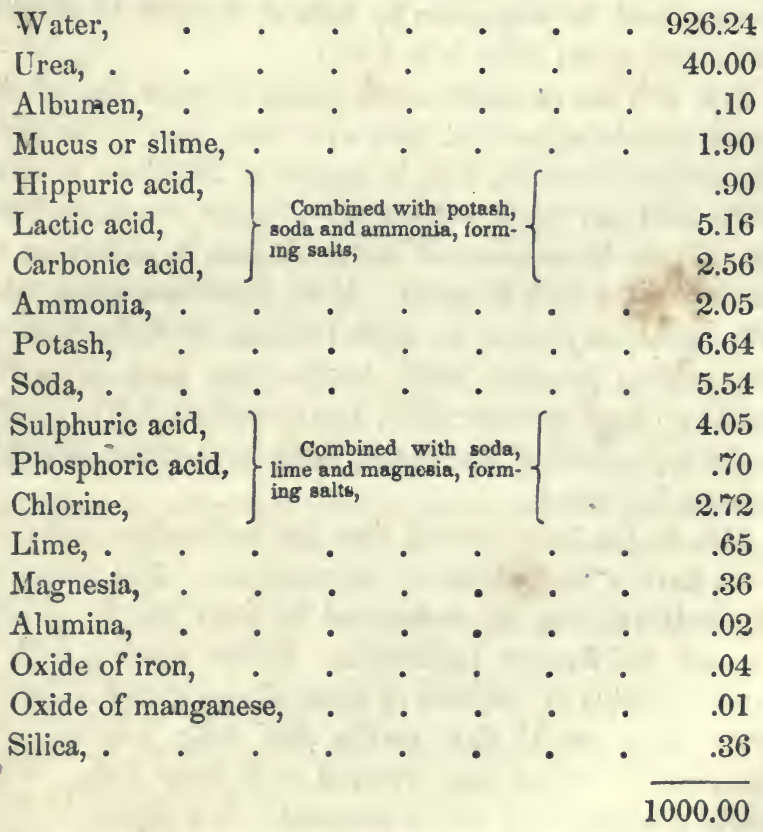

Let this now be compared with the standard of value, 
cow-dung. $100 \mathrm{lbs}$. of that afford $2 \mathrm{lbs}$. of carbonate of ammonia; while this evacuation gives $4 \mathrm{lbs}$. of ammonia in its urea, besides that in its other ammoniacal salts.

244. The quantity of liquid manure produced by one cow annually, is equal to fertilizing $1 \frac{1}{4}$ acre of ground, producing effects as durable as do the solid evacuations. A cord of loam, saturated with urine, is equal to a cord of the best rotted dung; and the fresh urine of one cow is valued in Flanders at $\$ 10$ per annum. If the liquid and the solid evacuations including the litter, are kept separate, and the liquid is soaked up by loam, it has been found they will manure land, in proportion by bulk of 7 liquid to 6 solid, while their actual value is as 2 to 1

245. $100 \mathrm{lbs}$. of cattle urine afford about $8 \mathrm{lbs}$. of the most powerful salts which have ever been used by farmers. The simple statement then, in figures, of difference in value of the solid and liquid evacuations of cattle, should impress upon all the importance of saving the last in preference to the first. Let both be saved. If the liquids contained naturally, geine, they might be applied alone. It is the want of that guiding principle which teaches that salts and geine should go hand in hand, which has sometimes led to results in the application of the liquor, which have given this substance a bad name.

246. It has been proved that the ammoniacal salts of urine have a forcing power on vegetation. The value of ammonia was long ago understood by Davy, and its carbonate was his favorite application. Plants watered with a simple solution of sulphate of ammonia, an abundant salt in cow's urine, are 15 days earlier than those watered with pure water. Grass land watered with urine only, yields nearly double to that not so manured. In a garden on land of very poor quality, near Glasgow, urine diluted with water, 
nearly doubled the grass. But upon wheat, sown on clay land, it did no good; it injured barley, potatoes grew rank and watery, and on turnips the effects were only half as good as mere unfermented dung. The circumstance of the suil in this last case, was probably a deficiency of geine.

247. The liquid evacuation of the horse is composed, according to Boussingault, of

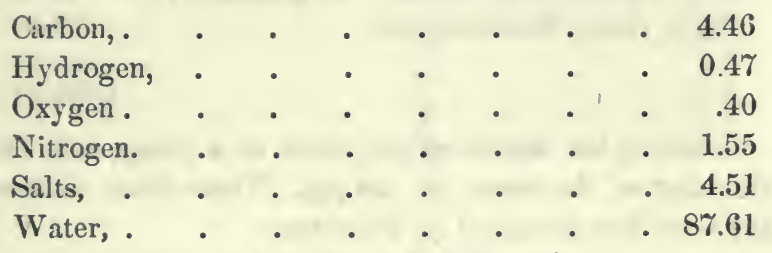

Other analysts have found in horse urine, Water,

Urea,

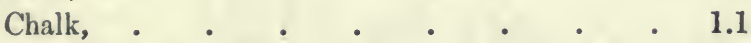

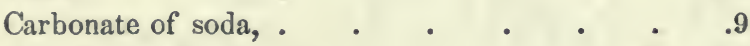

Hippurate of soda, . $\quad$ - $\quad$ - $\quad$ - $\quad$ - 2.4

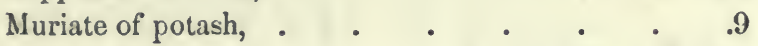

The hippuric acid is not peculiar to the horse. The urine of most herbiverous animals contains hippurate, formerly called benzoate of soda, its acid having the fragrance of gum benzoin. If man takes benzoic acid, hippuric replaces uric acid in the urine. According to the composition, horse stale, pound for pound, is equal to the value of cow-dung. Sprengel found the urine of sheep to afford, in $1000 \mathrm{lbs}$.,

Water, . . . . . . . . 980

Lirea, with some albumen,. $\quad$ • $\quad$. $\quad$. $\quad$. 28

Salts of potash, soda, lime, magnesia, with traces of silica, alumina, iron and manganese, - $\quad 12$ 
No animal affords more urine than the hog. Owing to a peculiar volatile and unexamined substance, it gives plants and roots a disagreeable taste. Fed on grains and bran, the urine in $1000 \mathrm{lbs}$. affords,

$$
\begin{aligned}
& \text { Water, . • • . • • . } 926 . \\
& \text { Urea, with a little slime and albumen, . } \quad 56.40 \\
& \text { Salts, common salt, muriate of potash, gyp- } \\
& \text { sum, chalk, Glauber's salts, • • } 17.60 \\
& 1000.00
\end{aligned}
$$

Fromberg has examined the urine of a sheep, and Von Bibra that of the horse, ox, and pig. These later analyses have been thus tabulated by Johnston: 


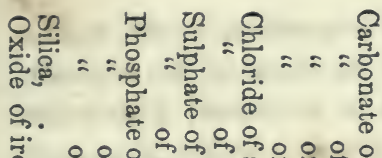

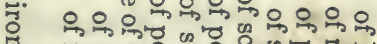

. $3=\omega^{\circ}$

-

․

유.

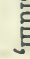

:

$-0=25=\omega 00000$

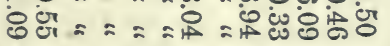

官 n

\section{(1)}

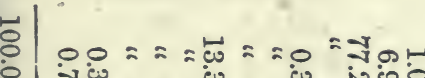

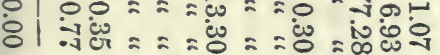

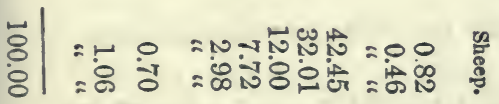

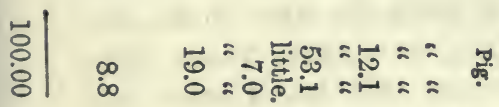

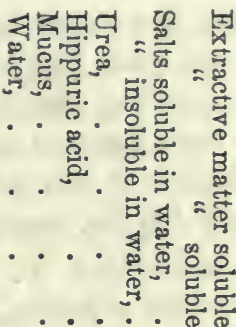

$5^{\circ}$ '

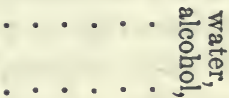

ora

๘ุ

एक

$\Rightarrow 8$

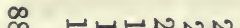
은 N o용요

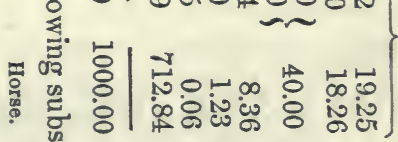

〜

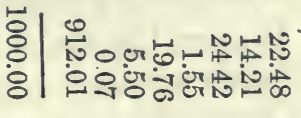

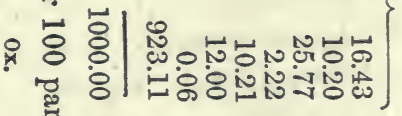

में है।

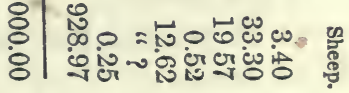

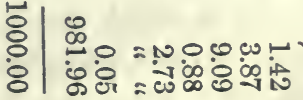

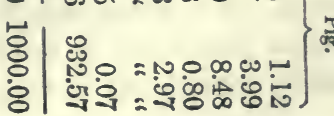


248. But rich as are the liquid evacuations of the stable and cow-yard, they are surpassed by those of the farmer's own dwelling, especially when it is considered with what ease these last may be saved. According to Dr. Thomson, 1000 parts of this substance, the human liquid evacuation, contain $42 \frac{1}{2}$ lbs. nearly of salts, which are,

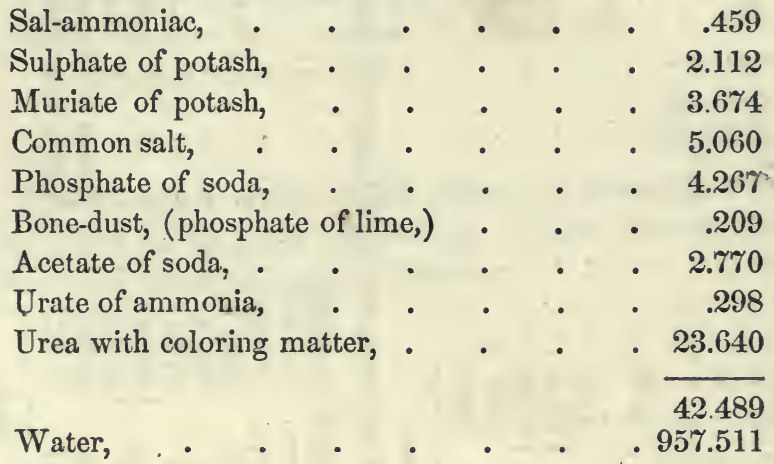

There is scarcely a single element in this liquid which is not an essential ingredient of plants.

In every $100 \mathrm{lbs}$.

Of cattle urine, are . . . 4. lbs. of urea.

Of horse urine, . . . . . $\quad .70$ " "

Of human urine, . • . . 2.36 " "

Of sheep urine, • • . . 2.80 " "

Of hog urine, . • • • • $\quad$ • 5.64 " "

It is at once seen how valuable are swine as manufacturers of manure.

It will be noted, that by the table (247), pigs' urine, like human, contains phosphates, of which the urine of the ox, horse, and sheep, are destitute, or contain traces only. Hence pigs' urine is more valuable than that of horses and cattle, not only by its urea, but by its salts. 
249. The urea being called equal to ammonia, it is seen that the ammoniacal salts in human urine are very nearly the same as those in cow-dung, but its effects in actual practice are found to be nearly double those in cow-dung. The actual amount of salts in 100 parts of human, cow, and horse-dung, is in round numbers, 1 per cent., while in the liquids it averages 5.88 , being in the cow 7.4, and in the human 424 per cent., horse 6 , according to Sprengel.

250. All urine of course varies with the food of the arimal, the season, and its age. White turnips give a weaker liquor than Swedish. Green grass is still worse. Distillers' grains are said to be better than either of these. The more water the animal drinks, the poorer the urine. Doubtless the liquids of fattening kine are richer in ammonia during this period, for it contains a part of that nitrogen not carried away in milk. In winter, urine contains much less urea than in summer, sometimes only one-half. Putrefaction changes urea to ammonia. The time required for this varies. Urine putrefying for a month, contains double the ammonia of fresh urine. It does not wholly decompose in a month; but during all this time, gives off ammonia. Unless then mixed with loam, or peat, or swamp muck, or where kept in tanks, with thrice its bulk of water, or with oil of vitriol, 3 lbs. to 160 gallons of urine, or with plaster, copperas, or other substances which will form a fixed salt with ammonia, that will escape. Urine is fully ripe, when it contains neither caustic ammonia, nor urea.

Fuod, exercise, age, condition, and sex of the animal, alter the quality, and affect the quautity of the urire discharged. It becomes therefore an interesting question, What is the quantity and quality of urine which various animals discharge daily and yearly?

On the average, a healthy 
Solid Ibs.

Man excretes in 24 hours, 3 pints or 1000 lbs. per annum, giving 30 to 170 Horse " " " 3 " 1000 " Cow " " 40 " 7000 to 12000 " 490 to 1440

Unless she is a milch cow, when the quantity is affected by that of the milk; the more milk, the less urine.

The abundant urine of a cow, though containing less solid matter than that of a horse, yet agriculturally, it is more valuable. Quantity more than compensates for quality.

The quantity of liquid drank affects little that of the urine discharged by cattle and other animals, while in man the result is different.

Man discharges nearly all the water drank, as urine; while a horse which drank in 24 hours 35 pints of water, evacuated 3 pints of urine, and a cow which drank in 24 hours 132 pints of water, evacuated 18 pints of urine, and gave 19 pints of milk. By the late trials of Barral, common salt appears to increase the amount of nitrogen and urea in the excrements. An important hint for the use of salt in feeding animals.

It has been proposed by Stenhouse, to add milky lime (slacked lime diffused in water) to urine, to stir it well, and let it settle. A portion of phosphoric acid is thus separated, as phosphate of lime. Air-slacked lime may be also thus used, the powder being sprinkled into the urine, and well stirred. The clear liquor may be run off, but this is a loss. Phosphates only are thus saved. Hence that great practical farmer and chemist, Boussingault, has proposed to add a solution of magnesian salts to urine. For this purpose Epsom salts may be employed, while those who live near salt works may use the "Bittern" liquor, or muriate of magnesia, for this purpose. By this process, both a portion of the ammonia and phosphoric acid are separated and fall 
down from the urine, as ammonia-phosphate of magnesia. This is a valuable manure for potatoes.

Each pint of human urine will produce a pound of wheat. Each pound of ammonia is equal to a bushel of grain. Whatever may be the food, it is evident from the above statements, that rivers of riches run away from farms, from want of attention to saving that which ordinarily is allowed to be wasted.

251. Each man evacuates, annually, enough salts to manure an acre of land. Some form of geine only is to be added to keep the land in heart, if the farmer has but the heart to collect and use that which many allow, like the flower unseen, "to waste its sweetness on the desert air."

252. But with all the farmer's care, with every convenience for collecting and preserving these animal products, still the amount which can be so collected, is often wholly inadequate to the wants of the farmer of small means. All these accumulations presuppose a goodly stock of animals on the farm.

This again is limited by the means of keeping, and so one influences the other. The farmer wants some source of manure, which while it produces the salts and geine of an unlimited amount of stock, hogs and hens, shall yet require no more barn-room, fodder or team, than every man who means that his hands and lands shall shelter, feed, and clothe him, can easily command. 


\section{CHAPTER VII.}

ARTIFICIAL MANURES, AND IRRIGATION.

253. THE class of salts, as manure, is to be distinguished from the salts called mineral manures, by this circumstance, that they contain large portions of peculiar animal products called urea and uric acid. These afford ammonia in large quantity by their decomposition. Having considered the relative value of the two classes of manure, those composed of salts, and of salts and geine, that consisting chiefly of geine is now to be explained.

254. First and foremost in this class, is swamp-muck, mud, or peat. This class includes, also, dry leaves, dry vegetables of all sorts; ploughing in of green or dry crops, irrigation. These are fruitful topics. The principles only of their action can be pointed out. The application of the principle must be left to the farmer. The why of things has been or will be shown; the how must be deduced from the why by practical men.

255. Peat is too well known to render it necessary to say that it is the result of that spontaneous change in regetable matter, which ends in geine. Peat is, among manures consisting chiefly of geine, what bone-dust is among manures consisting of animal matter. Peat is highly concentrated vegetable food. When the state in which this food exists is examined, it is found not only partly cooked but seasoned.

256. Peat consists of soluble and insoluble geine, and salts. 
The proportion of these several ingredients must be known before the value of peat can be compared with similar constituents in cow-dung. This proportion is exhibited in the following table of constitution of Massachusetts peat per 100 parts :

\begin{tabular}{|c|c|c|c|c|}
\hline Locality. & $\begin{array}{l}\text { Soluble } \\
\text { Geine. }\end{array}$ & $\begin{array}{l}\text { Insoluble } \\
\text { Geine. }\end{array}$ & $\begin{array}{c}\text { Total } \\
\text { Geine. }\end{array}$ & $\begin{array}{l}\text { Salts and } \\
\text { Silicates. }\end{array}$ \\
\hline 1. Dracut, & 14.00 & 72.00 & 86.00 & 14.00 \\
\hline 2. Sunderland, & 26.00 & 56.60 & 82.60 & 14.40 \\
\hline 3. Westborough, & 48.80 & 43.60 & 92.40 & 7.60 \\
\hline 4. Hadley, & 34.00 & 60.00 & 94.00 & 6.00 \\
\hline 5. Northampton, & 38.30 & 44.15 & 82. & 17.55 \\
\hline 6. $"$ " & 32.00 & & & 10 \\
\hline$\%$ & 12.00 & 60.85 & 72.85 & 27.15 \\
\hline 8. & 10.00 & 49.45 & 59.45 & 40.55 \\
\hline 9. & 33. & 59 & 92.00 & .00 \\
\hline " & 46.00 & 46.80 & 92.80 & 7.20 \\
\hline Average, & 29.41 & 54.73 & 84.14 & 15.55 \\
\hline 1. Watertown, & & & & 86.00 \\
\hline 2. Danvers, " & 8.10 & 6.50 & 14.60 & 84.40 \\
\hline
\end{tabular}

257. Under the general name of peat, are comprised sev. eral varieties, which may be distinguished as, 1st. Peat, the compact substance generally known and used for fuel, under this name. 2d. Turf, or swamp-muck, by which is to be understood the paring which is removed before peat is dug. It is a less compact variety of peat. It is common in all meadows and swamps, and includes the hassocks. Both these varieties are included in the above, from No. 1 to No. 10. It includes, also, the mud of salt marshes. 3d. Pond mud, the slushy material found at the bottom of ponds when dry, or in low grounds, the wash of higher lands. This seldom 
contains more than 20 per cent. of geine. Nos. 11 and 12 are of this description.

258. These varieties comprise probably a fair sample of all the peat and swamp muck and pond mud which occur in the various parts of the country. The results stated (256), are those of the several varieties when dried at a temperature of $240^{\circ} \mathrm{F}$. The composition of peat ashes has been alluded to (163). They contain, in fact, all the inorganic principles of plants which are insoluble, with occasional traces of the soluble alkaline sulphates, and of free alkali. Twenty samples of peat, from various localities in Rhode Island, afforded Dr. C. T. Jackson an average of 72 vegetable matter, 24 ashes, in 100 parts, dried at $300^{\circ}$

Silica formed $\frac{3}{4}$ of the ashes. The remaining salts were similar to those which have been mentioned.

259. It is well known that all peat shrinks by drying, and when perfectly dried at $240^{\circ} \mathrm{F}$., loses from 73 to 97 per cent. of water. When allowed to drain as dry as it will, it still contains about $\frac{2}{3}$ of its weight of water. It shrinks from $\frac{2}{3}$ to $\frac{3}{4}$ of its bulk. A cord wet becomes $\frac{1}{4}$ to $\frac{1}{3}$ of a cord when dry. To compare its value with cow-dung, equal bulks must be taken, and hence, to dry peat a bulk of water must be supposed to be added, in proportion above stated, or still better, because easier done, the pile of dry peat is to be estimated by the pit left after digging. It will be found, on the above data, that 100 parts of fresh dug peat, of average quality, contain,-

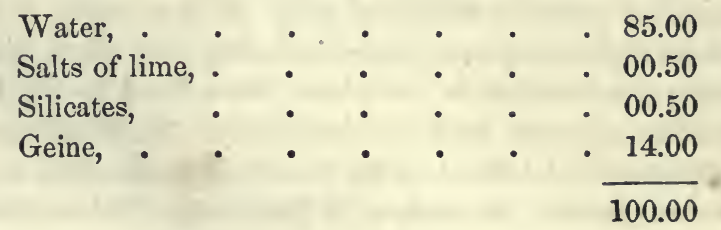


This does not differ much from fresh cow-dung, so far as salts, geine, and water are concerned. The salts of lime are actually about the same, while the alumina, oxide of iron, magnesia in the silicates added to the salts of lime, make the total amount of salts, in round numbers, equal that of cow-dung.

If the bulks of these are compared, it will be found that, at $90 \mathrm{lbs}$. per bushel, full measure, and 103 bushels being allowed to a cord, each contains and weighs as follows, in pounds:

$\begin{array}{lcccccc} & \text { Weight. } & \begin{array}{c}\text { Soluble } \\ \text { Geine. }\end{array} & \begin{array}{c}\text { Insoluble } \\ \text { Geine. }\end{array} & \begin{array}{c}\text { Total } \\ \text { Geine. }\end{array} & \begin{array}{c}\text { Salts of } \\ \text { Lime. }\end{array} \\ \text { Dung, * } & \text {. } & 9289 & 128 & 1288 & 1416 & 92 \\ \text { No. 9 peat of table, } & 9216 & 376 & 673 & 1049 & 91 \\ \text { No. } 10 \text { " " } & 9216 & 519 & 529 & 1048 & 81\end{array}$

A cord of pond mud, (No. 11,) weighs when dug, 6117 lbs., and contains solid matter, 3495 lbs., composed of geine, $495 \mathrm{lbs}$., of silicates and salts, $3005 \mathrm{lbs}$. The salts of lime in pond mud are $2 \frac{1}{2}$ per cent.

260. The salts and geine of a cord of peat are equal to the manure of one cow for three months. It is certainly a very curious coincidence of results, that nature herself should have prepared a substance, whose agricultural value approaches so near cow-dung, the type of manures. This subject may have been now sufficiently explained. Departing from cow-dung and wandering through all the varieties of animal and vegetable manures, we land in a peat-bog. The substance under our feet is analyzed, and found to be cowdung. without its musky breath of cow odor, or the power of generating ammonia, except in some varieties of peat. These always heat when piled. The various transformations of geine have not ceased in peat which naturally ferments, such is always preferable in agriculture. But generally the power of forming ammonia has ceased to be active. That 
process is generally over, a part of the ammonia remains, still evident to the senses by adding caustic potash. It exists in part, either as a compound of crenic and apocrenic acid, or other forms of geine, or as phosphate of ammonia, and when the presence of ammonia is added to the salts, whose existence has already been pointed out, it may be said that peat approaches dung moistened with the liquid evacuation of the animal.

261. The power of producing alkaline action, on the insoluble geine, is alone wanted to make peat as good as cowdung. Reviewing the various matters, from whatever source derived, solid or liquid, which are used as manure, all possess one common property, that of generating ammonia. The conclusion then of this whole matter is this : the value of all manures depends on salts, geine, and ammonia; and it is directly in proportion to the last; it follows, that any substance affording these elements may be substituted for manure.

262. The great question comes, How is to be given to peat, a substance which, in all its other characters, is so nearly allied to cow-dung, that lacking element ammonia? How is that to be supplied? Without it, cow-dung itself would be no better than peat, nay, not so gcod; for in peat, nearly onehalf of the geine is already in a soluble state. Passing by the fact, already alluded to, that peat contains traces of ammonia, which, evolved when treated with caustic potash, exerts its usual action, it may be added that, possibly in the process of vegetation, when the decomposing power of the living plant is exerted on peat, and the silicates, caustic potash is produced, and ammonia evolved. Considering peat as a source of nitrogen only, it is evident that the action of alkali is of the highest practical importance.

263. In this part of the subject of manure, probabilities and possibilities are no longer admissible. There are two 
facts well established by experience, relating to the action of ammonia in dung. First, it has been shown (166) that dung produces nitrates. Porous substances and alkali possess the power of forming nitrates; alkali and porous substances act like spongy platina, they induce a catalytic power, and the consequence is, that the elements of the air, oxygen and nitrogen, unite and form nitric acid, this combines with the alkali, and consequently nitrates are produced. The other well-established fact, in relation to the action of ammonia in dung, is the power of dissolving and converting geine, which has been explained in Chap. IV. The most valuable of these two properties is that of producing soluble geine. The formation of nitrates may be quite, and ordinarily is prevented. It is the alkaline action which is sought.

264. By the addition of alkali to peat, it is put into the state which ammonia gives to dung. The question then arises, How much alkali is to be added to swamp muck or peat, to convert that into cow-dung? Recurring to the doctrine of chemical proportions, whose value to the farmer is thus made evident, it will be remembered that the equivalent of pure potash and soda, that is, that portion of one which can take the place of the other, is as 2 to 3 ; that is, 2 parts of pure soda are equal to 3 of pure potash. If either of these is compared with ammonia, it will be found that one part of pure ammonia is nearly equal to two of soda. When these substances are met with in commerce, it is in the state of salts, as carbonate of ammonia of the shops, white ash, or soda ash, or potash and pearlash. The equivalent of these is deduced from determining the pure alkali of eảch, and adding the equivalent of carbonic acid. It is found that,

$59 \mathrm{lbs}$. of pure carbonate of ammonia are equal to

54 lbs.

70 lbs.
"

“ soda, or to

potash. 
But unless the impurities of the commercial alkalies are known it may not be prudent to substitute pot or pearlashes, and soda or white ash, either for one another, or for ammonia in the usual state, in the above proportions. All alkalies in the market are now much purer than formerly.

1st quality pot and pearlashes contain, on the average, 83 per cent. of carbonate, and no perfectly caustic alkali. 2d quality pots and pearls average 71 per cent. carbonate. English soda ash contains in its perfectly dry state 81.5 per cent. of pure carbonate, and about 2.75 of caustic soda $=$ 4.68 carbonate, or the total carbonate is equal to 86 per cent., which, in the commercial state of fair soda ash is equal to 80 per cent.

The proportions then become,

59 pure carb. ammonia $=61$ commercial,

$\begin{array}{llll}54 & \text { " soda } & =67 \text { soda ash of } 80 \text { per cent. } \\ 70 & \text { " } & \text { potash } & =84,1 \text { st qual. pots or pearls, } \\ 70 & \text { " } & \text { " } & =98,2 \mathrm{~d} \text { " " }\end{array}$

Fortunately for agriculture, rigid accuracy is not here required. The farmer need not fear to use the commercial alkalies because he knows not their chemical composition.

265. For all agricultural purposes, it may be considered, that salts of hartshorn, or carbonate of ammonia, and white or soda ash, are equal, pound for pound, and that pots and pearls may be taken at one-half more.

266. If all the nitrogen in dung becomes ammonia, then, as has been shown (187), each 100 lbs. affords $2 \mathrm{lbs} .2 \mathrm{oz}$. Discarding fractions, let it be called 2 lbs. Hence, if to $100 \mathrm{lbs}$. fresh dug peat, there are added $2 \mathrm{lbs}$. soda ash, or $3 \mathrm{lbs}$. of pot or pearl ashes, all the good effects of real cowdung will be produced. Peat or muck thus requires 2 per cent. of soda ash, or $\mathbf{3}$ per cent. of potash. 
267. By (259) a cord of green peat weighs 9216 lbs.; 2 per cent. are $184 \mathrm{lbs}$. Hence a cord requires that amount of soda ash, or $276 \mathrm{lbs}$. of potash. But if the peat is quite dry, so as to have lost $\frac{8}{4}$ of its bulk, then $736 \mathrm{lbs}$. of soda ash, or 1104 lbs. potash will be necessary. Two per cent. of alkali seems enormous. It is stated, in the hope that it may lead to experiments on the free use of alkali. But as it will be hereafter shown, that this is to be reduced by mixing with loam or other. matter, this quantity, even if applied to one acre, will probably produce very good effects. It has repeatedly been proved for other purposes, that a cord of fresh dug peat neutralizes $100 \mathrm{lbs}$. of soda ash, or $400 \mathrm{lbs}$. to a dry cord. Further, dry peat, by boiling with, neutralizes $12 \frac{1}{2}$ per cent. of its weight of potash, and in actual practice, alkali to the amount of 6 per cent. of the weight of the geine, in pond mud, has been used. It would therefore appear to be safe to use the theoretical proportion.

268. But the nitrogen in cow-dung does not all tell. It is impossible but that some portion of the elements of ammonia enter into other combinations, and part also escapes as gas. Besides, it is not all brought at once into action, and hence a less portion of alkali than above indicated may be used. It is probable that not a third of the ammonia acts. Let it be taken at that quantity. Then the equivalents are $100 \mathrm{lbs}$. fresh peat, and $10 \frac{2}{3}$ ounces soda, or $1 \mathrm{lb}$. of potash, or 1 per cent. of the weight of the peat in commercial potash.

269. This proportion will allow, in round numbers, to every cord of fresh dug peat, 92 lbs. pot or pearl ashes, or $61 \mathrm{lbs}$. of soda, or 16 to 20 bushels of common house ashes.

Having no guide here from experience of the quantity. which may be used per acre, yet, in order to arrive at conclusions which can be recommended safely, the alkali has been calculated in the quantity of saltpetre which has been 
used with such signal success by O. M. Whipple, Esq., of Lowell. On the principles which have been developed, when saltpetre is used, the whole alkali is let loose by the action of the growing plant. The experience of Mr. Whipple is a guide to the quantity of alkali which may be safely used. He has used from 50 to $150 \mathrm{lbs}$. saltpetre per acre. The real alkali in saltpetre may be called $\frac{1}{2}$ of its weight; or the real alkali used has been from 25 to $75 \mathrm{lbs}$. $=36 \frac{1}{2} \mathrm{lbs}$. and $109 \frac{1}{2}$ lbs. pure carbonate, or, in round numbers, an average of commercial 1st and $2 \mathrm{~d}$ quality, of 49 to $147 \mathrm{lbs}$. per acre, giving an average of 99 lbs., nearly, which is nearly 1 per cent. of the weight of a cord of green peat, which agrees with the estimate (268). If, then, this is mixed with the usual proportion of geine, which the dung used contains, equally good effects per acre ought to be produced.

270. There are other practical facts which may help to a solution of the question, How much alkali is to be added to a cord of peat? According to the experience of the late Mr. Phinney, of Lexington, an authority which may rot be questioned, a cord of green dung converts twice its bulk of peat into a manure, of equal value to itself-that is, a cord of clear stable-dung, composted with two of peat, forms a manure of equal value to three cords of green dung. Indeed, the permanent effects of this compost, according to $\mathrm{Mr}$. Phinney, exceed those of stable-dung. Equal bulks are here about equal weights. On these facts, $2 \mathrm{lbs}$. of ammonia in 100 of cow-dung, should convert $200 \mathrm{lbs}$. of fresh dug peat into good cow-dung. The equivalents of these, as has been shown (265), are $2 \mathrm{lbs}$. of soda ash, or $3 \mathrm{lbs}$. of potash. Allowing the gaseous ammonia to be here retained by the peat, and consequently all effective, it is divided equally among the $300 \mathrm{lbs}$. of dung and peat, in proportion of $10 \frac{2}{3}$ oz. of soda ash, or $1 \mathrm{lb}$. of potash to $100 \mathrm{lbs}$. of fresh peat. 
Now this calculation, deduced from actual experiment, confirms the theoretical proportions (268), supposing only $\frac{1}{3}$ of the nitrogen to act, though that was made before the author met with the statement of the great practical farmer.

271. There is a coincidence here of proportions, which makes it quite certain that the quantity recommended (269) is a perfectly safe basis for agricultural use. By theory the proportions are, 1 cord peat, $61 \mathrm{lbs}$. soda ash, $92 \mathrm{lbs}$. potash. As deduced from the compost of dung and peat, 61 lbs. soda ash, $92 \mathrm{lbs}$. potash. This proportion gives each cord of peat a value equal to that of cow-dung. If $\frac{1}{8}$ only of the nitrogen of dung acts, the alkali and peat may be composted, as that is, with loam, or still better, mixed up at once with its proportion of peat. If this is done, then the result will be, in round numbers, 1 cord of fresh dug peat, $20 \mathrm{lbs}$. of soda ash, $30 \mathrm{lbs}$. potash, 5 to 7 bushels house ashes. In March, 1849, the author, in a letter addressed to the commissioner for the agricultural survey of Massachusetts, threw out the following hint, which was published in the second report of Mr. Colman:

"Take 100 lbs. of peat as sold, or the fine part from the bottom of a peat stack; at uny rate, bruise the peat fine, put it into a potash kettle, and $2 \frac{1}{2} \mathrm{lbs}$. of white ash, and $130 \mathrm{gal}-$ lons of water; boil for a few hours; let it settle, dip off the clear for use, add $100 \mathrm{lbs}$. more of peat, $2 \frac{1}{2} \mathrm{lbs}$. white ash, fill up with water, as much as you have dipped off, boil again, settle and dip off. This may be repeated five times. How much oftener I know not; probably as long as the vegetable part of peat remains. The clear liquor is an alkaline solution of geine. The three first boilings contain geine, alumine, iron, magnesia, and sulphate or phosphate of alkali. The dark colored solution cortains about half an ounce per gallon of vegetable matter. 
" It is to be applied by watering grass lands. The 'dregs' may be mixed up with the manure, or spread as a top-dressing, or put in the hill. Experience will teach; I only suggest."

The principle which should guide the farmer in the making of artificial manure has now been considered. The author of these pages is not a practical farmer; agriculture is not his pursuit, and he has studied its chemistry only as a recreation from the daily duties of life. He has thrown out suggestions, the result of researches undertaken with reference to a totally different object, and these suggestions have been acted upon by practical men, whose results confirm his previous anticipations. He has no theory on this subject to maintain; his opinions must stand or fall by practice, speak for themselves. Yet, he is not altogether indifferent to the practical results which may follow his suggestions, and he would consider that he had inflicted a serious injury on agriculture, by the publication of erroneous opinions. When a man's character is to be established in a court of evidence, what is the good old English rule? To call upon the bystanders, the country present, taken indiscriminately from all who may have known the person. Do not summon persons whose interest may throw a shadow of suspicion on the testimony of the witness. And so here; let it be proved, if it can be, whether the principles here advanced are of practical value, by calling upon the stand those gentlemen who have tested the author's opinions, and of some of whose operations and results he was ignorant, till he met with them in the agricultural publications of the day, or in accidental conversation; others have been requested to state by letter their results, after these pages were prepared for the press. The evidence on this point is contained in the Appendix to this volume. 
272. Attention might here be called to the extensive use of peat, composted with lime and animal manure; but it will be observed that it is wished to direct the thoughts at this time to a compost of artificial manure, without lime or animal manure. The author does not go for lime, but for soluble alkali. Carbonate of lime alone is not expected to produce immediate results, and seldom has produced, or can be expected to produce visible effects in the first year of its application. 'The why and the wherefore of this has been already explained, and it is merely adverted to now to guard against any inference favorable to the action of lime being deduced from the following facts. Mr. George Robbins, of Watertown, an extensive manufacturer of soap and candles, and of starch, employs the refuse of these trades in enriching and gladdening his land. It is believed his crops will compare with any of the best cultivators around him. He has not used for four years a spoonful of manure made by any animal, walking either on two legs or on four. $\mathrm{He}$ keeps a large number of horses and hogs, and several cows, and usês not a shovelful of their manure, but selling that, uses peat and swamp muck mixed with his spent barilla ashes. The proportions are, one part of spent ashes to three of peat, dug up in the fall, mixed in the spring. After shovelling two or three times, it is spread and ploughed in. The effect is immediate, and so far, lasting. The effects of this spent ashes alone on sandy loam are excellent; it makes the whole quite "salvey."

273. The composition of spent ashes has already been alluded to; a certain portion is carbonate of lime; it is well known, that as such, it would produce no better effects than so much chalk. A large part of silicate of soda exists in the spent ashes. This is decomposed by the carbonic acid of the air, the alkali then acts on geine, but this action is 
greatly assisted by the carbonate of lime. It is perhaps the most powerful agent in the decomposition of the silicate of soda. Here then the action of carbonates on silicates tells. And it may be worth while to be reminded here, that this action was explained in detail, in order that it might be understood how spent ashes could act so rapidly on swamp muck.

274. Alkalies and peat, or swamp muck, are within the command of almost every farmer. Lime is not within reach, and besides, requires no small skill in its management. In the preparation of manure, price is everything. Let the cost be estimated per cord, of artificial manure, prepared in the proportions stated (270). Peat or muck may be called worth fifty cents per cord, and the labor of digging, say one dollar,

$\$ 1.50$

$92 \mathrm{lbs}$. potash, 6 cts. or, 61 lbs. soda ash, or white ash, 4 cts. or 24 bush. ashes, $12 \frac{1}{2}$ cts., 3.00 J

$\$ 5.52$

2.44 average of alkalies, 3.65

3) 10.96

$\$ 5.15$

\subsection{5}

Were they really good hard wood ashes, about 16 bushels would be sufficient, but an excess here is allowed, to compensate for variation in quality. This may appear a very high price, but it is to be remembered, that its value is to be compared with that of a cord of clear cow-dung. What is the value of cow-dung? It appears from the barn account of the Merrimack Manufacturing Company, that for $9 \frac{1}{2}$ years, ending October, 1838, a bushel of clear cow-dung costs $21 \frac{1}{3}$ cents. During the same time dung of inferior quality 
was delivered at the Print-works, by the neighboring farmers at 20 cents per bushel. Clear dung is delivered at the Print-works in Dover at $12 \frac{1}{2}$ cents per bushel, and at several of the Print-works in Rhode Island, at 16 cents per bushel, giving an average of $\mathbf{1 7 . 4 5}$ cents per bushel, and as a cord contains, in round numbers, 100 bushels, its price is

$\$ 17.45$

Deduct from this the price of an artificial cord,

5.15

$\$ 12.30$

It is hence evident that an artificial cord is only about onethird of the price of a natural cord, and if the last may be mixed with two parts of Joam or swamp muck, so may the first, which will reduce the price of a cord of artificial manure, to $\$ 2.71$. Now this is equal, according to all experience, cord for cord, to stable manure; the value of that may be estimated at $\$ 5$, so that an artificial cord costs only about one-half. The best plan for preparing the artificial manure is to dig the peat or swamp muck in the fall ; in the spring of the year let this be mixed in the proportion of 30 lbs. of potash, or $20 \mathrm{lbs}$. of soda ash, or 8 bushels of com. mon house ashes, to every cord of fresh dug peat, estimating this by the pit dug out, and allowing nothing in the spring for shrinking. If ashes are used, they may be mixed in at once with the muck, but if soda ash or potashes are used, they 'must be dissolved in water, and the pile evenly wet with the solution. The pile is then to be well shovelled over, and used as is other manure. But it has been found by experience, that the peat may be dug in the spring, immediately mixed with the alkali, and used forthwith. If spent ashes are used to prepare this muck, add one cord of spent ashes to three cords of peat or swamp muck.

275. But there are still other forms of cheap alkali from 
salt and lime, which may be recommended, though this may appear inconsistent with what has been advanced respecting lime, but in this case the lime is converted into a perfectly soluble salt. The soda is eliminated caustic, acts on the geine, renders it soluble. During the exposure to the volumes of carbonic acid evolved from the peat, the caustic soda becomes carbonated. This carbonate of soda immediately decomposes the soluble salt of lime, and an insoluble salt of lime with a soluble salt of soda is the result. The effects of these various actions, are, first, the geine is made soluble, ammonia evolved, which is converted into a nitrate, carbonate of lime produced, which acts as that does in spent ashes, and a soluble salt of soda or common salt remains in the mass, producing still farther good effects, when its alkali is let.loose by the action of growing plants. Here are. rounds of changes taking place, which though the farmer may not readily understand, he may easily produce, with lime and common salt. It may be stated, in farther explanation of these changes, that common salt is a compound of soda and muriatic acid, or muriate of soda, using here the old language of chemistry, which is more intelligible to the farmer, though not philosophically correct. By mixing quicklime with common salt, its soda is let loose, the acid combines with the lime, forming a soluble salt of lime, and as long as the soda remains caustic it has no effect on the muriate of lime, but as soon as the soda becomes mild or carbonated, decomposition of the muriate of lime is produced, and the common salt regenerated. Commencing then with quicklime and salt, we pass on to a soluble salt of lime and caustic soda, and from that, to mild soda, and to carbonate of lime and the original common salt; and these in decaying soil are mutuallv decomposed, and reform carbonate of soda. 
2\%6. If these various changes take place in the midst of peat, or geine, it is evident that the caustic soda acts upon the geine, and also evolves ammonia from that substance; secondly, that the muriate of lime in its finely soluble state insinuates itself among all the particles of the geine, that the soda also is equally diffused, and that when the soda becomes carbonated, it produces an almost impalpable carbonate of lime throughout the whole mass, which, by its equal diffu. sion through the soil with the geine, acts upon the silicates, as has been heretofore explained. In order to produce these effects, take

\section{1 bushel of salt, \\ 1 cask of lime.}

Slack the lime with the brine, made by dissolving the salt in water sufficient to make a stiff paste with the lime, which will be not quite sufficient to dissolve all the salt. Mix all the materials then well together, and let them remain together in a heap for 10 days, and then be well mixed with three cords of peat; shovel well over for about 6 weeks, and it will be fit for use. Here, then, are produced 3 cords of manure, for about the cost of $\$ 2.10$ per cord.

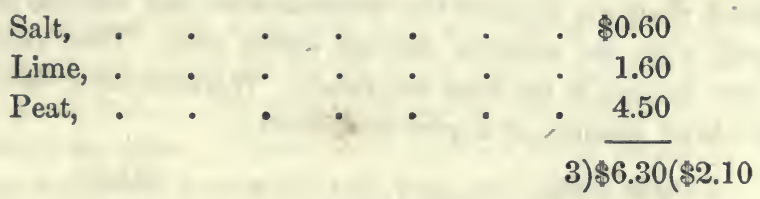

From experiments made in a small way, it is believed that this will be found an effectual manure; the author suggests it, in the hope that it may lead to cautious experiment.

Lime and salt have been also commended by other writers. Sir John Sinclair, in his "Scotch Husbandry," says that sea water evaporated to a saturated solution, that 
is, till the salts fall, may be used to slack limc. 32 bushels thus slacked, mixed with 40 loads of peat, aild spread on one acre of poorest fallow, were equal to any manure.

Mr. Mitchell, a surgeon in Ayr, recommends 3000 gallons sea water to be evaporated to 600 gallons, and this is to be used to slack 64 bushels of lime. This may be applied to two acres.

Salt water peat mixed with lime, has been very successfully used in some places in England. The peat being saturated with sea-water by its natural position, is dug out, partially dried, and mixed with about $\frac{1}{7}$ its bulk of slacked lime. It soon heats, ferments strongly, and when used soon after as manure, produces excellent effects. Doubless, all peat saturated with strong brine, and then mixed with lime, would be equally as effective as submarine turf.

But there is still another form in which this artificial manure may be prepared, that is by the addition of ammonia. Take

\section{3 cords of peat,}

61 lbs. sal-ammoniac, $\frac{1}{4}$ cask, or about 61 lbs. lime.

Slack the lime, dissolve the sal-arnmoniac, and wet the peat well with the solution through every part. Then shovel over, mixing in the lime accurately. We have here, then, 3 cords of manure, at a price as follows :

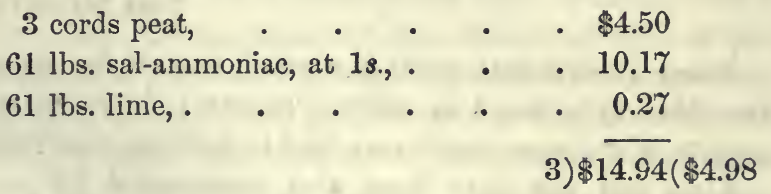

It will be observed that three cords are used in these calculations, because the quantity of salts used is equivalent to 
the ammonia in a cord of dung, and that is supposed to be composted 'with 2 cords of loam, or meadow mud. Whether the estimates are correct, each one will determine by the value he may place on his peat and manure, and will apply his own estimate. When a cord of stable or barnyard manure is usually estimated worth $\$ 4$, the price of a cord of clear pure cow-dung will not be thought high at \$17. In fact, it probably, when mixed with the usual proportion of litter, straw, stalks, and the usual loss by waste of its value, would become worth only about $\$ 5$. But these questions do not affect the principle-that from alkali and peat, as cheap a manure may be prepared, and as good, as from stable-dung; for let that be called $\$ 5.00$ then adding 2 cords of peat,

3.00

$3) \$ 8.00$

$\$ 2.66$ per cord.

277. There are other sources of alkali, for converting peat into soluble manure. Of these the chief is animal matter. Here we have ammonia produced. It has been actually proved by experiment, that a dead horse can convert 20 tons of peat into a valuable manure, richer and more lasting than stable dung; "a barrel of alewives is equal to a wagon load of peat." The next great and prolific source of ammonia is the urine. The urine of one cow for a winter, mixcd up as it is daily collected with peat, was sufficient to manure $\frac{1}{2}$ an acre of land with 20 loads of manure of the best quality, while her-solid evacuations, and litter, for the same period, afforded only 17 loads, whose value was only about one-half that of the former.

278. It need only be added in confirmation of all that has been advanced, that those who have had the prudence to fill 
their yaras and hog-pens with meadow mud, which has thus become saturated with ammonia, have in nowise lost their reward. If they have been satisfied with their practice, perhaps they will be no less firm in their belief of success, when science offers them a reason for the faith that is in them.

Peat or turf has begun to excite attention in France, as a manure in itself, and not simply as a vehicle for supplying ammoniacal salts (206). Soubeiran, in his prize essay on manures, \&c., in 1847 , says, that from his own experiments he can find no difference between the humus of mould and turf; he asserts that it is equally fit for encouraging vegetation, and "If we consider the service which humus spread on land renders to vegetation, we must regret that turf, which is so abundant in certain localities, should not be more frequently employed as an adjunct to other manures. Suitably modified by air and alkalies, it would incontestibly render important services to agriculture." Fresh turf when mixed with $\frac{1}{6}$ its weight of dried flesh, Soubeiran found was slowly decomposed, forming with turf a compound similar to fermenting dung.

Peat or turf has been used in France as a convenient substance when in dry powder, to absorb solutions of ammoniacal salts, thereby reducing that to a state approaching poudrette. For this purpose M. Jacquemart, in 1843, compared such prepared turf powder with poudrette, using such quan. tity that each should represent the same amount of nitrogen, or its equivalent ammoniacal salts. The poudrette contained in 3 bushels, or $132 \mathrm{lbs}$., nitrogen equivalent to $9 \frac{1}{2} \mathrm{lbs}$. sulphate of ammonia crystals. Of the nitrogen, 53 per cent. existed as ready formed carbonate of ammonia, and 47 per cent. as part of the organic matter of the night-soil.

This poudrette, used at the rate of 25 bushels per acre, represented therefore $82 \mathrm{lbs}$. of erystals of sulphate of am- 
monra; solutions of carbonate and bi-carbonate of ammonia, equivalent each to $82 \mathrm{lbs}$. of crystals of sulphate, were absorbed to dryness by peat powder. These several manures were sowed with oats and covered in, under similar circumstances, of soil, time, and exposure. The yield was as follows-poudrette representing 100 :

$\begin{array}{ccc}\text { No. 1. Poudrette, . . } & \text { Grain. } & \begin{array}{c}\text { The straw being } 100, \text { the } \\ \text { grain is to the straw as }\end{array} \\ \text { "2. Carbonate of am., . } & 94 . & 65 . \\ \text { " 3. Bicarb. of am., . . } & 95 . & 69 . \\ \text { " 4. No manure, . . . } & 74 & 77 . \\ & 74 .\end{array}$

The next year wheat was sown, and the equivalent of sulphate of ammonia increased to $103 \mathrm{lbs}$. A mixture of No. 1 and 2 in equal portions gave results equal to poudrette.

From these results, it is believed that a manure may be prepared with the ammoniacal liquor of gas works and peat, in a portable form, which may be confidently recommended to the farmer and gardener.

Gas liquor, alone, applied by the water-cart, at the rate of 400 gallons per acre, and the land a few days after sowed with barley, has given results equal to stable manure. Much of this liquor is allowed to run to waste. With the hope that it may be saved for the mutual benefit of agriculture and the gas manufacturer, the following suggestions are. submitted to their consideration.

From experiments which were tried by Jacquemart, with those above detailed, it appeared that sulphate of ammonia and peat powder produced very little effect. The conversion into that salt is to be avoided if it is intended to be used as will be here recommended. Sulphate of ammonia, mixed with other manures, is known by repeated experiments to 10 * 
produce good results, but for the purpose of preparing "peat poudrette" at the gas works, carbonate of ammonia is preferable. If sulphate of ammonia is used, then about $2 \mathrm{oz}$. of chalk or whiting in powder should be added to each gallon of gas liquor, before mixing, as hereafter described. Whatever portion of ammonia is converted to sulphate, an equivalent of chalk powder must be used. Carbonate of ammonia and sulphate of lime result by slow decomposition. The gas liquor is variable in quality; but that from Pictou coal contains about 5 per cent. of ammonia. This is equal to about $14 \frac{1}{4} \mathrm{lbs}$. sulphate of ammonia crystals, per 100 gallons, or $2 \frac{1}{4} \mathrm{oz}$. per gallon; hence, at the rate of $82 \mathrm{lbs}$. per acre, 600 gallons of gas liquor should be used. But from later trials than those cited above, it has been proved that much less than this quantity is an effectual manure. The transportation of the liquor in any quantity will not pay the expenses. How then may the farmer use gas liquor? It is recommended to dry peat, and then powder it. It may be dried by the spare heat from the gas retorts. The temperature should not exceed $240^{\circ} \mathrm{F}$. At $300^{\circ}$ it will be apt to take fire. To one ton dried peat, or 50 bushels, add 150 gallons gas liquor.

Peat, as has been shown (259), contains about 15 per cent. solid matter. At the average weight of a cord, fresh dug, the amount of solid matter of $1 \frac{1}{2}$ cord, will be about 2137 lbs., or one ton; this when dried as above, will absorb two-thirds its weight, or 150 gallons gas liquor, without becoming pasty; it forms a moist powder only like damp sand. If it is found that it becomes too wet to work up moist, this is caused by imperfectly roasted peat, and then as proposed (209) the gas liquor must be added at intervals, drying between in open air. The whole will weigh about $3400 \mathrm{lbs}$. and the bulk will equal 100 buskels. At 5 per 
cent. of ammonia, 150 gallons of gas liquor contain equal to 27 lbs. carbonate of ammonia of commerce, or 21 lbs. sulphate of ammonia. Hence the compost above contains $=8$ per cent. carbonate of ammonia, and one bushel 'may be considered equal to $\frac{1}{2}$ peck of good poudrette. The total, whatever may be the bulk, is equal to $1 \frac{1}{2}$ cord of fresh peat mixed with $27 \mathrm{lbs}$. of soda ash, or about nearly in the proportions recommended (271) to make a cord equal to a cord of stable manure.

If, by repeated drying under sheds in the open air, 50 bushels of roasted peat are made to absorb 600 gallons gas liquor, it produces 75 bushels gas poudrette, whose ammonia equals that in 25 bushels of the best poudrette from nightsoil, and, used by itself, 3 for 1 of that produces $\frac{95}{100}$ of its effects, or, when mixed $\frac{3}{4}$ to $\frac{1}{4}$ of poudrette, produces equal effects to one of the night-soil article. It may not be questioned that gas poudrette may be cheaply prepared in a form so concentrated that bushel for bushel its ammonia may equal that of poudrette; and when mixed with a little stabledung, to set up an active fermentation, it may be expected to act equally well with the best commercial poudrette.

- For this purpose the peat should be dried at the lowest possible temperature which will expel the moisture. It must not be charred. The ammonia should all be in the state of sulphate. The moistened peat powder may then be dried, and thus reduced to nearly its original bulk, without danger of losing ammonia. When dry, to every 100 parts of erystals of sulphate-ammonia used, add $65 \mathrm{lbs}$. of powdered chalk. It will be seen that this will gradually become equal to about $100 \mathrm{lbs}$. of dry plaster of Paris, giving off ammonia during all this time. Charring stops all further action of the elements of peat. In Jacquemart's experiments, probably the whole effect is due to the ammonia carbonate 
No ammoniacal salt, according to Kuhlmann, acts till reduced to that state. Fermentation has such effect. Hence, carbonate of ammonia, mixed with charcoal powder, had the same good effects as when mixed with over-dried peat. With this view the cinders and sparks collected by locomotive engines may be mixed into a dry powder with gas liquor. So may be used also charred saw-dust, and spent tan. But, it will be observed that, by the mode recommended in this work, the active power of peat is intended to be preserved. It differs from the "peat charcoal" movement of the day in this point. That makes vault poudrette; this, gas poudrette.

Composts may be formed without peat or stable-manure. That substance being omitted, speedy decay and rapid fermentation may be induced in all straws, green twigs, weeds, and green vegetable matter of all kinds, by piling them up, moistening the heap with a solution of organic matter in the state of decay, and adding various salts. A rich and valuable manure may be thus speedily prepared, if certain precautions are observed to retain the volatile ammonia, the product of fermentation (100) by converting it into fixed salts.

The rapid decay in all such composts depends upon the same principle as the fermentation of dough, viz., the addition of some body, as yeast, actually undergoing chemical change. This change communicates motion to the particles of the whole mass which thus act by induced fermentation.

A process of making manure on this principle was originally proposed by Jauffret, in France. Variously modified, it has been used both there and in other countries with signal success. Manure made by his original recipe costs more than stable-dung, but the following, based on the principle above stated, forms an economic manure. The quantity of the materials are intended for manuring one acre: 
3 tons of green straw, ferns, bean-stalks, pea-vines, potatotops, weeds, leaves, \&c.,

90 lbs. of ground plaster,

2 " of common salt,

3 " of saltpetre,

$2 \frac{1}{2}$ bushels of house ashes;

$2 \frac{1}{2}$ " of charcoal powder,

5 " of night-soil.

Make the pile of vegetable matter near a puddle of stagnant water, if possible; if this is not convenient, sink a pit by the edge of the pile, fill it with common water, throw into it the night-soil, mix it well by stirring, add the ashes, then the charcoal, lastly the salts.

With a bucket furnished with a long-pole handle, like a tanner's scoop, water the pile several times daily with the above mixture, taking care that the drainage runs into the pit, to be again returned upon the pile. In two or three weeks in warm weather the heap is sufficiently converted for use.

The yeast, as it may be termed in this process, is the night-soil, and the putrescent matter in the stagnant water.

Referring now to $(100)$, it will be at once seen here is a ready and cheap mode of producing geine, ammonia, nitrates, which, with the salts already added, form a manure whose efficacy and economy alike recommend its use to those who have not peat or swamp-muck at command.

There is a choice, if it may be exercised, in the kind of straw best for such a compost as is above recommended. The straw of beans, peas, and all pod or leguminous plants, is richer in nitrogen than straws of grain, or cereal plants. Pod-plant straw contains more vegetable matter, and a greater quantity of potash salts, than grail straw; the first 
form more geine, more ammonia by putrefaction, and are therefore preferable for composts. Oat straw contains more potash, and buckwheat straw more magnesia than other straws.

The following table exhibits straws as arranged according to their practical compost value, by Sprengel, and also their proportion per cent. of organic matter, salts and nitrogen; the last as determined by Payen and Boussingault:

\begin{tabular}{lrrl}
\multicolumn{1}{l}{ Straw. } & Organic matter. & Salts. & Nitrogen. \\
1. Buckwheat, & 96.797 & 3.203 & \\
2. Bean, & 96.879 & 3.121 & \\
3. Millet, & 95.145 & 4.855 & 0.78 \\
4. Pea, & 95.029 & 4.971 & 1.79 \\
5. Barley, & 94.759 & 5.244 & 0.23 \\
6. Wheat, & 96.482 & 3.518 & $0.49\}_{0.24}^{\text {old and }}$ new \\
7. Rye, & 97.207 & 2.793 & 0.17 \\
8. Corn-stalk, & 96.015 & 3.985 & 0.28 \\
9. Oat, & 94.266 & 5.734 &
\end{tabular}

279. Having thus considered all the classes of manure, and shown the possibility of enriching barren fields, without the aid of animals, other subjects, intimately counected with this discussion, may be here introduced.

These are, the application of manure in the form of rain, snow, and by overflowing streams, and the humble attempt to imitate these natural processes, by irrigation. The effects in these cases are alike. They are due to two distinct causes, first, to the air of the water, and secondly, to the salts and other materials dissolved by, or suspended in the water. First, before it can be understood how irrigation acts, let it be considered how pure water acts; it is not said rain water, for that acts in a double way, both by its purity and impurity. The more impure, the better manure is water. The purer water is, the less is it fit for irrigation. 
280. Pure water acts only by its air. All water exposed to air, absorbs different proportions of its oxygen and nitrogen. This is a very slow process. It is found that most natural waters give out, by boiling, from every hundred cubic inches of water, $3 \frac{1}{2}$ cubic inches of air. This air contains 8 or 9 per cent. more oxygen, than an equal bulk of common air. Water is generally filled or saturated with air; it will take up no more by a month's exposure. If this water is boiled, and again exposed to the air, it will absorb, in 24 hours, as follows:-let there be taken any number of measures of air, which are composed of 20 of oxygen and 80 of nitrogen. If 100 measures are absorbed by water, it is in this proportion :

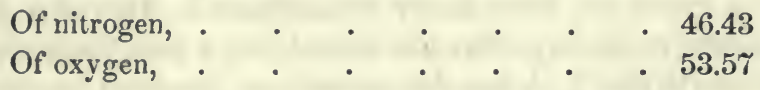

so that oxygen is three times more absorbable than nitrogen. 281. If now, there is expelled by boiling, the air from pond or river water, it is found to contain,

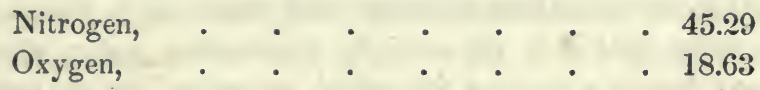

so that two-thirds of the oxygen have disappeared; this is the only fact which concerns the farmer. The oxygen has been absorbed by natural waters and two-thirds retained. What has become of it? It has gone, it is not said all of it, but in irrigation a large portion to convert insoluble into soluble geine. Irrigation is chiefly employed on grass-lands. The green sward here may not be broken up. What if it was? What if by ploughing, it was exposed to the action of the air? Remember the properties of geine. Air converts the insoluble to soluble, by forming carbonic acid, that is, the air combines with the carbon of the geine, and forms 
that gas. Give the geine this oxygen, condensed in water: wet it with this concentrated oxygen, crowd it into geine, as would be done by overflowing a meadow with water. It penetrates every crack and cranny, and every mole's-eye hole; it expels the carbonic acid imprisoned under the sod. It is doing the same work upon the untouched green sward, which would be effected by ploughing and tillage. The long and the short of the whole action of irrigation with pure limpid water is, that its absorbed oxygen converts insoluble to soluble geine. Is this explanation which science offers, confirmed by practice? The appeal is made to all who have attended either to the theory or practice of irrigation, to bear witness to its truth. Is it not admitted that the running waters are alone fit for this purpose? That after remaining a few days they are abated, and a new flood must cover the land? Is not this necessity of renewing at short periods the covering of water which shows no deposit, a proof that it has given up some invisible agent to fertilize the earth? This invisible agent is oxygen. Is it not evident from the extreme slowness with which air is absorbed by water, that if it were not for the running water, which every few days replaces that which has acted, that the practice of irrigation with pure water could be never successful?

282. This is the principle, a principle which, having been wholly overlooked, has led to a waste of time and money, and has given to irrigation, in many minds, the odor, if not of a bad, at least of a useless practice. Where, guided by this light of science, grass lands can be irrigated, let it be done. If the experience of the most enlightened agriculturists in Europe is not all deception, by simple irrigation with running water, the farmer may cut two tons of hay where he toils and sweats to rake off one.

283. But by far the most fertile source of increased crops 
by irrigation, is found in the impurity of water; the salts and suspended matter, the slime and genial mud of freshets. Perhaps the effect due to this cause, cannot be better illustrated, than by a statement of those substances, and their amount, which fill the waters of the Merrimack; a flood of blessings! which rolls by those engaged in the din and hot haste of manufactures, as unheeded as was the earthquake which thundered and trembled, and rolled away under the feet of the fierce soldiery in an ancient battle. In the year 1838, during twenty-three days of freshets, from May till

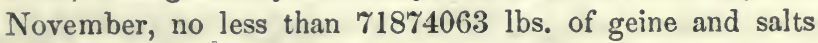
rolled by the city of Lowell, borne seaward. During the five days of the great freshet, from January 28th, to February 1 st, 1839 , no less than $35970897 \mathrm{lbs}$. of the same matter rolled by at the rate of from $112128 \mathrm{lbs}$. to $20405397 \mathrm{lbs}$. per day ; each cubic foot of water bearing onwards, from $1 \frac{1}{2}$ to $30 \frac{1}{2}$ grains. This is only the suspended matter. That which is chemically dissolved by the waters, the fine filmy deposit, which occurs in a few days after the coarser and grosser matters subside, and the matter ordinarily suspended in the water of the river added to the above for the year 1838 , give a grand total of 839181 tons of salts and geine, which were rolled down in the water of the Merrimack river.

284. What is this matter? Is it of any agricultural value? The answer to the first question will answer both. The dissolved salts are sulphate and geate of lime, and the fine deposit occurring after the water has settled, is composed of one-half geine, and the remainder of salts of lime and silicates. The great agricultural value is found in the clayey deposit, which occurs in the first few days. The coarser part, that which collects about the foot of rocks, and falls, and eddies, is composed as follows : 


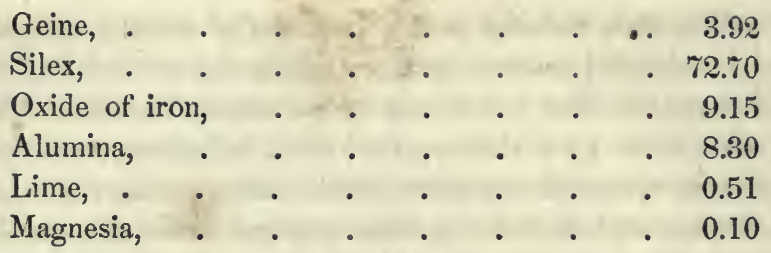

But considering the elements as we have usually treated them as silicates, salts and geine, the composition of the sev eral deposits is shown in the following table:

\begin{tabular}{|c|c|c|c|c|c|}
\hline & \multicolumn{2}{|c|}{ Geine. } & \multirow{2}{*}{$\begin{array}{l}\text { Sulphate } \\
\text { of lime. }\end{array}$} & \multirow{2}{*}{$\begin{array}{l}\text { Phos. of } \\
\text { lime. }\end{array}$} & \multirow{2}{*}{ Silicates. } \\
\hline & Soluble. & Insol. & & & \\
\hline $\begin{array}{c}\text { The coarse de- } \\
\text { posit above, }\end{array}$ & 2.06 & 1.86 & 0.74 & 0.90 & 94.44 \\
\hline Freshet, 1839 , & 5.40 & 6.50 & $\cdot 2.34$ & 1.20 & 84.66 \\
\hline $\begin{array}{l}\text { Freshet, July } \\
\text { 7-18, '39, }\end{array}$ & 8.80 & 6.30 & 3.20 & 0.60 & 81.20 \\
\hline
\end{tabular}

285. If the doctrine of the action of silicates, salts and geine, upon each other, when aided by growing plants, is considered, it cannot fail to be perceived, that the fertility of soils, periodically overflowed by turbid waters, is owing to the elements, salts and geine, which it contains, and to the exquisitely finely divided state of the silicates which form the bulk of the deposit. The carbonic acid of the air acts on each atom of silicate, while owing to the geine having been, as it were, irrigated, the oxygen of the air and water must put that into a state to evolve carbonic acid. Hence, the silicates are at once decomposed, and their alkali liberated. How beautiful! It seems like a special interposition of that beneficent Power, whose blessings, while they fill us with wondering admiration, at the infinite skill which directs every change in the material universe, should teach us also, that these changes are held up to us, not only to admire, 
but in some humble degree to imitate. Whenever man"the faithful servant and interpreter of nature," has thus learned the lessons propounded by an Infinite Mind, he finds, when he humbly imitates nature's laws, she is a kind and indulgent parent. She opens her hand liberally, and gives fertility by irrigation, and rivers and streams like holy water sprinkled by a reverend father, fructify all they bedew. With hearts thus attuned, by the observation of the laws of nature, they respond to the gentle vibrations caused by the descent of genial and fertilizing showers.

286. Rain is only natural irrigation; the water is found, like that of rivers, rich in oxygen, and organic matter. The fertilizing power of rain is referred to the same causes which lead to irrigation, to the salts and geine, which rain water contains. Several chemists have proved the existence of saline matters and organic substances in the air. The falling rain carries down with it salts of ammonia, of soda, of lime, ard organic matter. These all may be supposed floating in the air. The dry soils give to the winds an impalpable dust, its silicates and geine. When hailstones which have been formed in the regions of perpetual frost, exhibit almost the same substances which are contained in rain water, the height at which these matters float, would almost compel the supposition that they exist in a gaseous state. From the examination of hailstones, by Girardin, a French chemist, it appears, that no sensible trace of ammonia was detected during the evaporation of their water, but there was found a notable quantity of lime and sulphuric acid; and, above all, a large proportion of an organic substance containing nitrogen. Melted hailstones have the appearance of water, containing a drop or two of milk; by standing, the water grows clear, and the flocky matter which settles, burns with the smell of animal rnatter, and evolves ammonia. 
It is a question whether this is not the source of the am. monia discovered in rain water. It is taken for granted, that the ammonia in rain water exists as a volatile carbonate, because it was found to pass over in distillation. So does a volatile product, which always discolors the crystals of sal-ammoniac, procured by adding muriatic acid to the distilled water. This discoloring matter was noticed a century ago by Margraff. Later chemists have also detected ammoniacal salts in rain water, but no volatile carbonate of that base. It is well known that muriate of soda arises in evaporation, so does chromate of potash, and several other salts. If, in distilling rain water, the ammonia did not pass over in the volatile organic discoloring product, it may have gone over as muriate of ammonia. It is not questioned that ammoniacal salts exist in rain and snow water. The fact that it there exists as carbonate seems to be assumed, and is incompatible with the salts which have been heretofore obtained, from rain, snow, and hail. The subject has of late excited much attention, and as the existence of salts in snow is intimately connected with the old saying that "Snow is the poor man's manure," it may be worth while to examine the foundation of this proverb. Like all others of this class it will be found to rest on observation, and is supported by experiment. In 1751, Margraff, in the neighborhood of Berlin, after it had snowed several hours, collected in glass vessels as much falling snow as afforded 3600 ounces of water. This, earefully evaporated, afforded 60 grains of calcareous matter, with some grains of muriatic acid, and traces of nitrous vapor. An equal quantity of rain water afforded 100 grains ealcareous matter, with some muriatic acid; and in both cases the matter was discolored by an oily substance. A similar result was obtained long ago in Ireland, by Dr. Rutty, who found in a gallon of snow water, 
4 grains, and in one gallon of rain water, 6 grains of calcareous matter. This is about the proportion found by Margraff, and would give for each inch of snow water about $10 \mathrm{lbs}$. of salts per acre. From the existence of free acids in this case, it is evident that no carbonate of ammonia could have there existed. There are some experiments performed by our countryman, Dr. Williams, formerly Hollis Professor of mathematics and natural philosophy in Harvard College, and detailed in the first volume of his History of Vermont, where the experiments were performed. In 1791, 6 gallons of fresh falling snow water afforded by evaporation 11 grains calcareous matter, 2 grains of saline matter, 5 grains of a dark brown oily matter. In January, 1792, 6 gallons of snow water, from snow lying three inches deep on the grass, on an area of 16 square feet, where it had lain 59 days, covered with a depth of 27 inches of snow, afforded the same salts as above, and 105 grains of this oily matter. This is the most remarkable fact, and may afford some weight to the suggestion before made, that organic matter exists gaseous in the air. It must have been drawn up by capilary attraction, or evolved from the surface of the earth. It is there condensed by the snow and returned to the earth, impregnated with its salts of lime and ammonia. The snow is " the poor man's manure." It not only adds salts and geine, but prevents the escape of the last. But is it possible that it should escape in the cold? Doubtless it does when the ground is not frozen. The snow by its warm mantle actually prevents the earth growing colder, and, as has been ingeniously suggested, keeps up an imperfect vegetation. The snow thaws frozen ground. In 1791, Professor Williams found that the ground which had been frozen 6 inches in depth before the snow fell, not only had this frost extracted in a few weeks by snow, but that the ground, 6 inches below 
the surface, had a temperature of 39 degrees. This slight elevation of temperature was enough to allow the gaseous exhalation of organic matter, which was fourd to exceed that of fresh fallen snow by 20 times. This quantity, in snow 3 inches deep, would give per acre $40 \mathrm{lbs}$., and to this are to be added $5 \mathrm{lbs}$. of salts. If this geine is not a natural addition in weight, it has undergone a transformation and become soluble. Besides, every inch of fresh fallen snow actually adds a little of this same matter; it will not be extravagant to estimate the total addition of geine at $50 \mathrm{lbs}$. per acre for the winter. This, added to the warming effects of snow, shows that it may have a genial and enriching power on vegetation, independent of its anmonia. The old notion of the existence of nitre in snow is not supported by evidence; but in whatever view we consider the salts of lime in snow and rain water, it is difficult to believe that carbonate of ammonia exists in atmospheric air.

28\%. There are still other sources of manure, or the elements of fertility, which the farmer can command. Among these are paring and burning and the ploughing in of green and dry crops.

It is not intended to go into the detail of these operations. All experience proves their great fertilizing power. Their whole action, mysterious as a part of it may appear, depends for its success upon the formation of geine, salts, and silicates. And first,--burning, in which is to be considered the effects of simply burning the earthy parts of soils. In the description of silicates, Chap. II., the frequent occurrence of pyrites, or sulphuret of iron, was described, and this is especially the case in all clays. The effect of burning is, to disengage sulphurous acid, and the red and seared appearance of the foliage in the neighborhood of a brick kiln, which may be often observed, is due to the disengagement of acid gases, 
during the process of burning the bricks. This acid gas being liberated, in the operation of burning soils, hastens the formation of sulphates and salts. "It divides the silicates, and thus reduces them to a state in which the carbonic acid of the air more easily decomposes them. If we go one step further, and burn the vegetable matter of the soil, a portion of geine is lost, and ashes are formed, whose operation has been already considered (Chap. IIJ.) They dissolve any geine in soil; hence the practice of burning the parings of a peat meadow, whose ashes bring the balance into cultivation. The whole practice of burning vegetable soil for its ashes is wasteful. The original mode of paring and burning, and which forty years ago was so common in Europe, is still followed in many places in England, where the paring, from the operation, is called push ploughing. It has been more often given up, from the excessive crops it has produced, exhausting the soil, than any inherent $\sin$ in the practice itself. Instead of paring and burning; it should rather be called paring and roasting. The process should never go beyond a good scorching. The effects of scorching insoluble geine and inert vegetable fibre, may be illustrated by reference to the effects of roasting coffee, or rye. A tough green berry, or dry seed, which is quite insoluble, is made by this process very soluble. Toasting bread has a like effect, and so has baking on the dough. Though in roasting coffee, a large portion of charcoal seems to be made, yet in the grounds of coffee, vegetable fibre is in that state in which air and moisture act, as they do on the geine of soils, converting the insoluble into soluble. If ever decided good effects have been witnessed from the application of charcoal, independent of rain water, they are due to the cause here pointed out.

288. Turning in green crops is returning only to the soil, the salts, silicates, and geine, which the plant has drawn out 
of it, together with all the organic matter the plant itself has elaborated, from oxygen and hydrogen, carbon, and nitrogen, from whatever source derived. It has decomposed, during the short period of its growth, as has been already pointed out, more silicates and salts than the air only could effect during the same period, which, being turned in, restore to the soil from which they grew, salts and silicates in a new form, whose action on vegetation is like that of alkalies. But, powerful as are the effects of green crops, ploughed in, it is the experience of some practical men, that one crop allowed to perfect itself and die where it grew, and then turned in $d r y$, is superior to three turned in green. The whole result is explained by the fact, that dry plants give more geine than green. Green plants ferment, dry plants decay. A larger portion escapes in fermentation, as gas and more volatile products are formed, than during decay. The one is a quick consuming fire, the other a slow mouldering ember, giving off, during all its progress, gases, which feed plants, and decompose the silicates of soil.

289. The power of fertility which exists in the silicates of soil is unlimited. An improved agriculture must depend upon the skill with which this power is brought into action. It can be done only by the conjunction of salts, geine, and plants. Barren sands are worthless, a peat bog is little better; but a practical illustration of the principles which have been maintained, is afforded by every sandy knoll made fertile by spreading swamp muck upon it. This is giving geine to silicates. The very act of exposure of this swamp muck, has caused an evolution of carbonic acid gas; that decomposes the silicates of potash in the sand; that potash converts the insoluble into soluble manure, and lo! a crop. That growing crop adds its power to the geine. If all the long series of experiments under Von Voght, in Germany, are to 
be believed, confirmed as they are by repeated trials by our own agriculturists, it is not to be doubted, that every inch of every sand knoll, on every farm, may be changed into a soil in 13 years, of half that number of inches of good mould.

290. That the cause of the fertility is derived from the decomposing power of the geine and plants, is evident from the fact, that mere atmospheric exposure of rocks, enriches all soil lying near and around them. It has been thought among the inexplicable mysteries, that the soil under an old stone wall is richer than that a little distance from it. Independent of its roller action, which has compressed the soil and prevented the aërial escape of its geine, consider that the potash washed out of the wall has done this, and the mystery disappears. The agents to hasten this natural production of alkali, are salts and geine. The abundance of these has already been pointed out in peat manure. Next to this, dry crops ploughed in; no matter how scanty, their volume constantly will increase, and can supply the place of swamp muck. Of all soils to be cultivated, or to be restored, none are preferable to the sandy light soils. By their porousness, free access is given to the powerful effects of air. They are naturally in that state, to which trenching, draining, and subsoil ploughing are reducing the stiffer lands of England. Manure may as well be thrown into water, as on land underlaid by water. Drain this, and no matter if the upper soil be almost quicksand, manure will convert it into fertile arable land. The thin covering of mould, scarcely an inch in thickness, the product of a century, may be imitated by studying the laws of its formation. This is the work of "Nature's 'prentice hand;" man has long been her journeyman, and now guided by science, the farmer becomes the master-workman, and may produce in one year quite as much as the apprentice made in seven. 


\section{CHAPTER VIII.}

\section{PHYSICAL PROPERTIES OF SOIL.}

291. IN all attempts at improving soil by manure, two objects are intended, which form the golden rule of applying salts and geine; to make "heavy land lighter, light land heavier, hot land colder, and cold land hotter." Are there then, notwithstanding all that has been offered and said, differences in soil ? Have not, it may be asked, all the preceding pages been based on the fact, that there is but one soil ? True, it has been so said, it is said so now. Chemically, the inorganic elements of all soil are alike. The silicates and salts are nearly the same in all; the organic portion, the geine, varies, and that to a greater degree than any other ingredient. While the silicates compose with great uniformity about 89 per cent., and the salts of lime, sulphate, and phosphate, \&c., 2 per cent., the geine varies from 1 to 20 per cent. The silicates may be firer or coarser, more sandy or more clayey. These circumstances affect not the chemical, but the physical properties of soil. The physical properties, then, are the foundation of the great diversity which soil exhibits. The subject of soil will have been very imperfectly treated, if a few pages are not devoted to this important subject.

Liebig has observed that, "it is the duty of the chemist to explain the composition of a fertile soil, but the discovery of its proper physical state or condition belongs to the agri- 
culturist." Evidently, in the opinion of the authority quoted, the composition and physical state of soils are independent of each other; and it may be thought that the author is exceeding the limits bounded by chemistry, when he touches this new field, thus appropriated to the agriculturist.

292. The physical characters of soil are embraced under the terms, cold, hot, wet, and dry land. These characters are dependent on four circumstances.

Firstly, the absolute weight of a given bulk of soil,

Secondly, its color,

Thirdly, its consistency,

Fourthly, its power of retaining water.

In other words, the physical characters of soil may be considered under,

Firstly, its relation to heat,

Secondly, its relation to moisture and gas,

Thirdly, its consistency,

Fourthly, its electrical relation.

The relation to consistency makes soil light or heavy; the relation to heat and moisture makes soil hot or cold, dry or wet. The great natural varieties of soil are, sand; clay, and loam; first, the great distinction in the scale of soil, is sand and clay: all intermediate varieties proceed from mixtures of these, with each other. Now the sand may be siliceous or calcareous, that is, composed of silicates, the distinguishing character of soil in this country, or mixed with a salt of lime, the feature of much European soil. By clay is meant common blue clay, or sub-silicate of alumina, consisting of alumina 36 , silica, 68 , oxide of iron, and salts of lime, and alkalies, 6 . 
Sandy clay is-clay and sand, equal parts. Loamy clay is $-\frac{3}{4}$ clay, and $\frac{1}{4}$ sand.

Peaty earth is-geine.

Garden mould is -8 per cent. geine.

Arable land is-3 per cent. geine.

Taking these several varieties, it is found, that sand is always the heaviest part of soil, whether dry or wet; clay is among the lightest parts; geine has the least absolute weight, so that while a cubic of sand weighs, in its common damp state, 141 lbs., clay weighs 115 lbs., and geine 81 lbs.; hence garden mould and arable soil weigh from 102 to $119 \mathrm{lbs}$. The more geine compound soil contains, the lighter it is.

293. Among the most important physical characters of soil, is the power of retaining heat; this will be found to be nearly in proportion to its absolute weight. The weight of soil determines, with tolerable accuracy, its power of retaining heat. The greater the mass in a given bulk, the greater is this power. Hence, sands retain heat longest, three times longer than geine, and half as long again as clay. Hence, the dryness and heat of sandy plains. Sand, clay, and peat, are to each other as 1,2 , and 3 in their power of retaining heat. But while the capacity of soil to retain heat, depends on the absolute weight, the power to be warmed, another very important physical character, depends on four principal circumstances : first, the color; second, the dampness ; third, the materials; fourth, the angle at which the sun's rays fall. First, color; the blacker the color, the easier warmed. White sand and gray differ almost 50 per cent., in the degree of heat acquired in a given time. As peat and the varieties of geine are almost all of a black, or dark brown color, it is seen how easily they may become warm soils, when dry; for secondly, dampness modifies the influence of 
color, so that a dry, light-colored soil will become hotter, sooner than a dark wet one. As long as evaporation goes on, a difference of 10 or 12 degrees will be found between a dry and a wet soil of the same color. Thirdly, the different materials of which soils are composed, exert but very little influence on their power of being heated by the sun's rays. Indeed, if sand, peat, clay, garden mould, all equally dry, are sprinkled with chalk, making their surfaces all of a color, and then exposed to the sun's rays, the differences of their temperature will be found inconsiderable. Color and dryness, then, exert a most powerful influence on the capacity of soil to be warmed.

Fourthly, the last circumstance to be noticed, is the different angle at which the sun's rays fall. The more perpendicular, the greater the heat. The effect is less in proportion, as these rays by falling more slanting, spread their light out over a greater surface. But this point, which seems external to soil, need not be enlarged on. Now, the great fact to be observed, in this relation, of soil to heat is, that geine exerts the most marked influence. If soil heats quickly, it is because it has a large proportion of geine. Does it cool quickly? It is the geine which gives up heat quickly, referring here to the soil in a dry state, the modification produced by dampness having been already considered.

294. The relation of soil to moisture and gas, is not less important than that of heat. All soil, except pure siliceous sands, absorb moisture, but in different degrees. Geine possesses the greatest power of absorption, and no variety of geine equals in its absorptive power, that from animal manure. The others rank in the following order, garden mould, clay, loam, sandy clay, arable soil. They all saturate themselves with moisture by a few days' exposure. It is a very interesting question, Does soil give up this absorbed 
water speedily and equally? Is its power of retaining water equal? As a general fact, it may be stated, that the soil which absorbs fastest and most, evaporates slowest and least. Geine evaporates least in a given time. The power of evaporation is modified by the consistence of soil; by a different degree of looseness or compactness of soil. Garden mould, for instance, dries faster than clay. As it has been already shown, that the power of being warmed is much modified by moisture, so the power of a soil to retain water makes the distinction of a hot or cold, wet or dry soil. In all the relations to moisture, as to heat, geine exercises the greatest influence.

295. Connected with this power of absorption of moisture, is the very important relation of soil to gas. All soil absorbs oxygen gas, when damp, never when dry. Of the ingredients of soil, geine forms the only exception to this rule. That absorbs oxygen, whether it be wet or dry. Geine has this power in the highest degree, clay next; frozen earths not at all. A moderate temperature increases the absorption.

When earths absorb oxygen, they give it up unchanged. They do not combine with it. They merely induce on the absorbed moisture power to imbibe oxygen. But when seine absorbs oxygen, one portion of that combines with its carbon, producing carbonic acid, which decomposes silicates, and a second portion of oxygen combines with the hydrogen of the geine, and produces water. Hence, in a dry season well manured soils, or those abounding in geine, suffer very little. The power of geine to produce water, is a circumstance of soil almost wholly overlooked. It is one whose high value will appear by a comparison with the quantity of water produced by a fresh-ploughed, upturned sward, with that from the same soil undisturbed. The evaporation from 
an acre of fresh-ploughed land is equal to 950 lbs. per hour; this is the greatest for the first and second days, ceases about the fifth day, and again begins by hoeing, while at the same time the unbroken sod affords no trace of moisture. This evaporation is equal to that which follows after copious rains. These are highly practical facts, and teach the necessity of frequent stirring of soil in a dry time. Where manure or geine is lying in the soil, the evaporation is from an acre equal to $5000 \mathrm{lbs}$. per hour. At $2000 \mathrm{lbs}$. of water per hour, the evaporation would amount in $\mathbf{9 2}$ days to 2208000 lbs. which is nearly equal to the amount of rain which would fall in the same time in this climate. But the evaporation from woodland actually exceeds the amount of rain which falls. The evaporation from an acre of woodland was determined by Professor Williams, (see his Hist. of Vermont, vol. I.,) as follows: two leaves and a bud of a branch of a growing maple were sealed in a bottle, while yet attached to the tree. The expired water collected and weighed, was found to amount in six hours to 16 grains. The tree was $8 \frac{1}{2}$ inches in diameter, and $\mathbf{3 0}$ feet high. It was felled, and the leaves carefully counted, were in number, 21192. Supposing these all to have evaporated like those in the bottle, they would have expired, in twelve hours, 339072 grains of water. A moderate estimate, and below the usual quantity of wood per acre of similar land, gave four such trees to a rod, or 640 per acre. Estimating 7000 grains to a pint, 3875 gallons of water, or 31000 lbs. were evaporated from an acre of woodland in 12 hours. At Rutland, in Vermont, where this experiment was made, in 1789, the Professor notes, that on the 26th of May, the maple leaves were $\frac{1}{6}$ of their full size, and on the 15th of September following, these leaves began to turn white. Throwing out the $\mathbf{1 5}$ days in September, and the 4 in May, the leaf may be considered as fully developed 
for three months. During these 92 days, the evaporation would have amounted, at 12 hours per day, to $2852000 \mathrm{lbs}$. The rain at the place during this period, was 8.333 inches or $43 \frac{4}{10}$ pounds to every square foot of surface, equal per acre of 43560 feet, to $1890504 \mathrm{lbs}$. The amount of evaporation during the time in which the tree was in full leaf exceeds that of the actual fall of rain, by nearly 1000000 of lbs. This excess arises from the decomposition of geine in the soil, and consequent formation of water, by the action of the living plant. If we allow the process to go on, during 15 hours per day, then in 92 days, as above, $3565000 \mathrm{lbs}$. of water would be evaporated. One may easily understand how exhausting a process must be vegetation, where every year all above ground is cut and carried away. Not only the geine, whose carbon and water have become parts of the plant, is thus withdrawn, but a still larger portion disappears as water and carbonic acid. In forests, the annual fall of leaves and wood, in fields, the ungathered crop, may add more than the amount thus withdrawn from soil. That plants do form from carbonic acid and water, a great amount of vegetable matter, is by all admitted.' This amount in dry or green crops turned in, increases the geine of soil.

There is yet another view of the effect of the conversion of geine into water. Allowing, as has been asserted, that all land, forest or cultivated, produces annually about the same amount of carbon, then the amount of water transpired above from woodland in $\mathbf{1 5}$ hours, is nearly equal to dissolving one-half of the geine, to produce that amount, leaving the balance to be derived from air. An acre of woodland produces, it is said, annually, about 1783 English pounds of carbon. If water dissolves only $\frac{1}{2500}$ part of its weight of humus, or geine, then 3565000 dissolves $1426 \mathrm{lbs}$., which, at 
58 per cent. carbon are equal to Leaving to be derived from air,
- $827 \mathrm{lbs}$.

- 956 "

1783 "

This is taking geine in its most insoluble state. The great increase of solubility when combined with alkali would render the annual amount of water transpired equal to dissolving, as geine, all the carbon which has been added to the plant.

The advantage of a light porous open soil is now evident; it lets in air, it lets off steam. This steam, charged with carbonic acid, acts on silicates, eliminates alkalies, waters and feeds plants. Salts, geine, and barren pine plains, are the elements of a western prairie. Nature never bestowed upon man soil of greater capability of being made lastingly fertile, than the sandy light soil of New England.

296. It is evident that the terms of heavy and light, given by the farmer to soil, do not refer to their absolute weight (293). These distinctions depend on firmness or consistency of soil. This produces a very marked difference in the fertility and tillage of land. The terms light and heavy, mean lighter or heavier to work. It is well known that clay lands are heavy to work, sandy soil the lightest and easiest, next to this is a soil containing a small portion of geine. All light soil becomes heavy when wet, but it is a well-ascertained fact, that heavy soil always becomes lighter by frost. Hence the reason of breaking up with a plough before winter. Moist earth then becomes frozen, and its particles being driven asunder by frost, it becomes lighter, in truth it has been found that the consistency of clay is diminished nearly one-half by frost, and loamy clay, one-half to two-thirds. It is essential to this change from heavy to light land, that the 
soil be wet enough to freeze. It is well known, that if, by frost, the nature of the soil is thus changed, that if it is ploughed while wet after freezing, the labor of the fall ploughing is lost. A lasting injury is done by ploughing land too wet.

297. In reference to the electrical relations of soil, the dry sands are non-conductors, the clays weak imperfect conductors, they are in the negative state. Geine is always positive towards the elements of soil.

298. In whatever view we regard geine, it is the basis on which rests the whole art of agriculture. It is this which causes the great difference of soil. It is a difference of physical characters. The chemical characters are uniform. If, then, geine is the soul of fertility, if it makes soil hot, cold, wet, dry, heavy or light, the proportion and state in which it exists in soil, becomes an agricultural problem of the highest value. This would lead to chemical analysis. The lectures in which the principles set forth in this book were explained, terminated with a practical exhibition of the process of analysis of soil. Having already greatly exceeded the limits to which it was intended to confine these pages, the subject of analysis, and several other topics, may be resumed at some other time. 


\section{CHAPTER IX.}

BONES, SUPERPHOSPHATE OF LIME, AND ITS PREPARATION.

299. Bones have been already partially adverted to (233); their use in farming has been long known and widely adopted in England and in Europe, and is beginning to be understood and valued in the older portions of the United States.

Bones are the only available home source of phosphate of lime. Next to guano, which owes a large portion, and sometimes all of its value, to phosphate of lime, bones enter largely into the composition of the artificial manure powders of commerce. The worth and employment of bones in firming demands an extended notice, and is now, for the first time, introduced into the fourth edition of the Muck Manual. It is one of those topics to which allusion is made at the close of the preceding section (298).

300. Bones consist of an organic or animal part, which forms about $\frac{1}{3}$, and of an inorganic or mineral part, chiefly phosphate of lime, which forms $\frac{2}{3}$ of bone. As remarked (217), gelatine or glue is derived from certain animal tissues, tendons, ligaments, gristle and bones, so, under the name of gelatine, it will be convenient to denominate the animal part of bones. It is under the form of gelatine that the bony tissue is extracted.

301. Bones force and quicken vegetation, or develop and form seed. 
The first action depends on the fermentation of the gelatine, which produces ammonia, and induces chemical motion. The second action depends on the phosphate of lime, an essential element in all roots and seeds. Hence bones are to be regarded as stem and leaf formers, or as root, seed, or grain formers.

If both objects are to be attained, then the whole bone must be used; if only root and grain growing is intended, then the phosphate of lime is to be regarded.

302. Bones, therefore, are to be studied, 1st, as entire.

2 , as deprived of a portion of their gelatine.

3 , as deprived of all their animal parts.

First, as entire bone. This comprises raw bones, butchers' bones, and such as are usually thrown aside as useless, or to the dogs, after the meat has been cooked and removed for the family.

The composition of entire bone may be stated as follows :

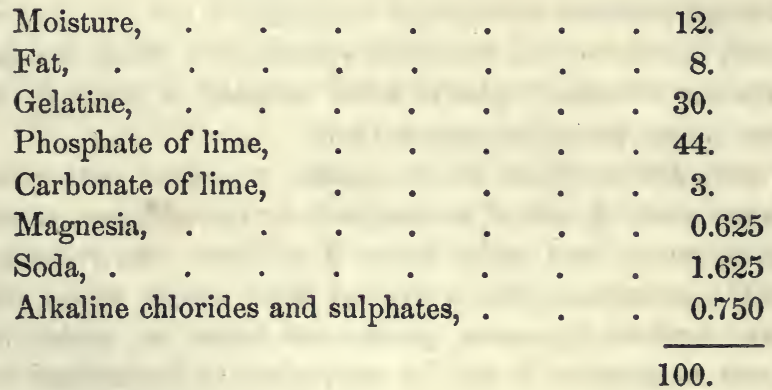

No practical use can be made of bones till they are crushed into very small bits; these, even of half-inch size, called half-inch bones, are now rarely used. Bones should 
be ground to meal, bone meal; the finer ground, the better. In this state, a pile of meal, if moistened, soon heats, fermentation sets in, and the gelatine evolves frcm 4 to 6 per cent. of its weight as pure ammonia.

Doubtless this fermentation has its, value, if excited in bone meal before using it as a manure. If ammonia escapes. which is easily known by the smell, this valuable element can be retained by sprinkling the pile with a few pounds of plaster, or with half a pint of oil of vitriol stirred into two gallons of water for every $100 \mathrm{lbs}$. of bone meal.

If it were easy to reduce bones, in their entire state, to powder, its animal part could be easily retained. But the practical difficulty of grinding raw bones is just beginning to be overcome, and however perfectly this process may be hereafter effected, still the amount of raw, or entire bones, will be always very small compared with bones from which a portion of the animal matter has been removed. This leads to the second head of the subject, bone as deprived of a portion of its gelatine.

This is effected by a continued and long boiling in the open air, skimming off the fat and gelatine as they arise to the surface of the water; or better, by steaming, under a pressure of 4 or 5 pounds on the inch, by which the gelatine is removed, and may be extracted as glue. This leaves the bone porous, and as the water immediately fills the pores, the bone weighs as much nearly as it did before boiling. By long boiling, or steaming and separating the fat and glue, bone becomes soft and pliable while warm, but hard and brittle when cold. In this state bone readily breaks, easily grinds.

The following is the composition of bone partly deprived of its gelatine : 
Water, . . . . . . . . 10 .

Animal matter, . $\quad$. $\quad$. . 20.2

Phosphates of lime and magnesia, . . 61.5

Carbonates of lime and magnesia, 8.3

100.

Ordinarily well-boiled bones would give nearly a similar result, but some extra boiled gave Prof. Way the following composition:

Water, - . . . . : . 10

Animal matter, . $\quad . \quad$. $\quad . \quad$. $\quad . \quad$. 16.

Phosphates of lime and magnesia, . . . 60.

Carbonates of lime and magnesia, . . . 11.

Sand,

3.

100 .

The animal part affords from 2 to 3 per cent. of nitrogen, equal to about 9 ounces of pure ammonia from every 100 pounds of bone. Practical experience has shown that bone meal in this half animalized state is its most valuable agricultural form. Though not as lasting as bone ash from burned bones, it works quicker and stronger. This bone meal ferments, and gives off anmonia, while the phosphate of lime by its combination with gelatinous matter, easily dissolves in rain water. Hence, it is the result of experience, that all bone meal acts best on soils moderately sandy and light; clay lands exclude air, sandy lands hold no water; on these bone meal acts only after two or three years, yet guano acts on these at once.

Bone meal, deprived of a part of its animal matter, is best employed when added to the compost heap at the rate of from 200 to $500 \mathrm{lbs}$. per acre. If used alone, it is best to sow it as top dressing during the early spring rains, after the 
frost is out an inch or two, or if used for root or grain crops, harrowed or lightly ploughed in.

Thirdly. Bone, deprived of all its animal matter, calcined or burned bone, bone ash, sugar house refuse, or bone black. Bones are easily reduced to the state of ash by piling them up with a little light wood or fagots, and firing the mass. The bones continue burning till reduced to whiteness, becoming brittle as pipe stems and very easy to grind. By this mode, all animal matter is burned up. If bones are heated in closed vessels, leaving a small vent, as in baking, bone black is produced, containing all the earthy part of the bone, mixed with the coal of the animal portion. This serves for decoloring sugar and other syrups, and after having served this purpose several times, by repeated burning, the spent bone black is sold to farmers and others as sugar house refuse; when mixed with the scum and other impurities arising during the clarification of sugar, it is more valuable for agriculture than simple sugar house black.

303. In the state of bone ash, phosphate of lime is more insoluble than as bone meal. It has been found, that by treating bone ash, as also bone meal, with certain acids, the phosphate of lime is brought into a highly soluble state. The cheapest acid, and that commonly used for this purpose, is oil of vitriol, which produces, by its action on bone, both plaster and soluble phosphate of lime, called superpiosPHATE.

In this acid state, bone acts quicker, goes farther and lasts longer than in any other form. Acid may, therefore, be economically applied to all forms of bone, entire, partially, or wholly deprived of its gelatine.

This application is often called dissolving bone in acid. There is no clear solution. It is a mere breaking up, it is a softening, pap-forming process, and bone, in this state, would 
more appropriately be called bone-pap. The bone is merely so far reduced that, when rubbed between the thumb and finger, no grit is felt. Bone cannot all dissolve, for the oil of vitriol, when added rightly, unites with the lime of carbonate and phosphate, and forms with that insoluble sulphato of lime, or plaster. It is this which gives the grayish white look to the bone porridge.

304. That this subject may be placed in a clear light to him who intends to prepare superphosphate for his own use, or for market, the properties of phosphoric acid must be adverted to. It is, like the acids found in geine, many based, requiring at least 3 portions of base to 1 of acid, for neutralization. These combinations should be well understood, and they may be illustrated by reference to the phosphates of lime; for

Phosphoric acid 1 part, lime 1 part, form superphosphate; acid.

Do. 1 part, lime, lime, 2 parts, form subphosphate ; less acid.

Do. 1 part, lime, lime, lime, 3 parts, form neutral phosphate.

In this last form it is found in bones; this forms pure bone earth. If to this neutral phosphate oil of vitriol is added, it combines with and removes a portion of the lime from the phosphoric acid, more or less according to the quantity added. No quantity will take away all the lime.

Each part of lime requires its equivalent of oil of vitriol. If to neutral phosphate of lime, oil of vitriol (which may be designated by $\mathrm{O}$. V.) sufficient to unite with one part of lime, is added, the result may be illustrated as follows :

Neutral phosphate of lime contains one proportion of acid and three of lime, or

Phosphoric acid, lime, lime, lime, Add, . . . O.V. 
Result is, phosphoric acid, lime, lime, plaster. Add to this, . . . O.V.

Result is, phosphoric acid, lime, plaster, plaster.

The neutral phosphate of lime is thus, by 2 equivalents of oil of vitriol, changed to two portions of plaster and one of super or acid phosphate of lime. Leaving out the plaster, if to the superphosphate is added enough $\mathrm{O}$. V. to unite with all the lime, $\frac{1}{3}$ of the superphosphate will remain unacted on ; while $\frac{3}{4}$ of the lime of the remaining $\frac{2}{3}$ of the superphosphate unite to the oil of vitriol, and form plaster, the other fourth of the lime combines with all the phosphoric acid, and forms superphosphate containing 1 acid to $\frac{1}{4}$ lime, or 4 acid to 1 lime. This may be considered as almost free phosphoric acid. It is a compound known to chemists as quadriphosphate of lime; that is, quadruple phosphate. Phosphoric acid dissolves its own weight exactly, and no more, of phosphate of lime; of course this compound of 4 acid to 1 lime, being almost free acid, dissolves that $\frac{1}{3}$ of the superphosphate of lime which had been unacted on by the $O$. V., and thus forms a true biphosphate or double superphosphate of lime, a compound of 2 acid to 1 lime.

This may appear somewhat complicated to those unacquainted with chemical changes. Perhaps the subject may be illustrated and elucidated by representing by words the substances, and by figures their weights, or equivalent numbers. Supposing the operations to be performed on pure bone earth, the mass remaining after the addition of the best commercial $\mathrm{O}$. V. will be represented as follows :

\begin{tabular}{|c|c|c|c|c|}
\hline & & Phosphoric acid. & Lime. & Limo. \\
\hline bon & lbs. & 72 & 28 & 28 \\
\hline
\end{tabular}


\begin{tabular}{|cc|cc|}
\hline $72+$ & 28 & 78 & +78 \\
form 100 lbs. superphosphates. & form 156 lbs. & $\begin{array}{c}78 \\
\end{array}$
\end{tabular}

If to the $100 \mathrm{lbs}$. of superphosphate thus obtained, $50 \mathrm{lbs}$. of $\mathrm{O} . \mathrm{V}$. are added to combine with the lime, the result will be as follows :

100 Ibs. superphosphate; deduct $\frac{1}{3}$ unacted on, 33

$67 \mathrm{lbs}$. superphosphate, containing $48.24 \mathrm{lbs}$. phos. acid, and $18.76 \mathrm{lbs}$. lime.

$\frac{3}{4}$ of the lime, or $14.07 \mathrm{lbs}$. unite with $25 \mathrm{lbs}$. of O. V., and form $39 \mathrm{lbs}$. of plaster, while $25 \mathrm{lbs}$. of $\mathrm{O}$. V. remain free. Of the lime, $\frac{1}{4}$ or $4.69 \mathrm{lbs}$. unite with $12.06 \mathrm{lbs}$. of the phosphoric acid, and form $16.75 \mathrm{lbs}$. of superphosphate, while the balance of the phosphoric acid, or.36.18 lbs., dissolves the $33 \mathrm{lbs}$. of superphosphate, which were unacted on, and form $69.18 \mathrm{lbs}$. of double superphosphate, or 2 acid to 1 lime.

Omitting fractions, the final result of adding to 156 pounds of pure bone earth, 150 pounds of $\mathrm{O}$. V. will be the production of

195 lbs. of plaster of Paris,

$25 \mathrm{lbs}$. of free oil of vitriol,

$86 \mathrm{lbs}$. of bi, or double superphosphate of lime, containing 72 lbs. phosphoric acid, 14 lbs. of lime.

Thus we have all the phosphoric acid of the original 156 lbs. of bone earth, with $\frac{1}{6}$ only of its lime, in this superphosphate. It is to be observed that oil of vitriol of commerce contains about $40 \mathrm{lbs}$. of real acid in $50 \mathrm{lbs}$., the balance is water, which enters into the composition of the plaster. 
The amount of oil of vitriol used above is by far too great. It has been calculated thus, to show that no amount of $\mathrm{O}$. V. added to the mixture above, will produce free phosphoric acid. That may be obtained by adding $\mathrm{O}$. V. to the clear liquor, which may be drawn from the mixture by leaching. Still an excess of oil of vitriol has its value, as will be hereafter shown. If the proportion is reduced for $100 \mathrm{lbs}$. pure bore earth, to $87 \frac{1}{2}$, or $\frac{7}{8}$ the weight of the bone earth, it will be seen, presently, that this will be an advisable proportion to be used, whatever form of bone earth may be used for conversion into superphosphate of lime.

So much for the chemistry of this subject. Before this knowledge can be practically applied, the composition of bone must be recollected. As has been shown (302), bone comprises other substances of mineral origin, besides bone earth. These also will combine with $\mathrm{O}$. V., and if it is intended that the 88 parts of bone earth in 100 parts of bone ash shall all be converted into superphosphate, these hungry mouths must be first satisfied, or else they will surely help themselves before the phosphate, their better, is served.

On referring to the composition of raw bones (302), it is seen that $200 \mathrm{lbs}$. will afford $100 \mathrm{lbs}$. of bone ash, composed as follows :

Phosphate of lime, $88 \mathrm{lbs}$, requiring $77 \mathrm{lbs}$. of oil of vitriol. Carbonate of lime, 6 " " $6 \quad 6$ " " " Magnesia, . 1.25 Soda, . . . 3.25 " 1.49 " "

Alkaline sulphates,

$$
\begin{aligned}
& \text { and chlorides, } 1.50 \text { " " " " } \\
& 100 \mathrm{lbs} . \quad 87.49
\end{aligned}
$$

Bone meal from

raw bones, . $100 \mathrm{lbs}$., require 43.75 " " 
Boiled or steam-

ed bones, $\quad 100 \mathrm{lbs}$. require $70.22 \mathrm{lbs}$. of oil of vitriol.

Sugar house refuse or bone black varies much in its composition, containing from 65 to 75 per cent. of phosphate, and from 10 to 12 per cent. of carbonate of lime; its composition should be always ascertained before conversion into superphosphate of lime.

As a general rule, bone black will require about the same weight of oil of vitriol as boiled bones.

306. If it is intended to convert bone ash into superphosphate, $100 \mathrm{lbs}$., as has been shown (305), require $87 \frac{1}{2} \mathrm{lbs}$. of oil of vitriol for all purposes. The product when dried in warm air, so as to crumble easily with slight crushing into a coarse powder, will weigh about 183 pounds, constituted as follows :

Superphosphate of lime, $\quad$ - . $\quad$. $\quad$ - 47.71

Sulphate of lime, . $\quad$ - . $\quad$ - . 120.07

" " magnesia,. . . . . 2.54

" " soda,. . . . . . 4.92

Alkaline sulphates and chlorides from the bone

ash, . . . . . . . . 1.50 .

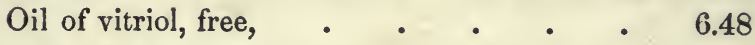

183.22

$100 \mathrm{lbs}$. of this crude mass, commercially termed superphosphate, are composed as follows :

Superphosphate of lime of which are solu-

(double), . . 26.04 ble in water, $2604 \mathrm{lbs}$. Sulphate of lime, . 65.53

" magnesia, . 1.38 . . . 1.38 " 
Alkaline sulphates and

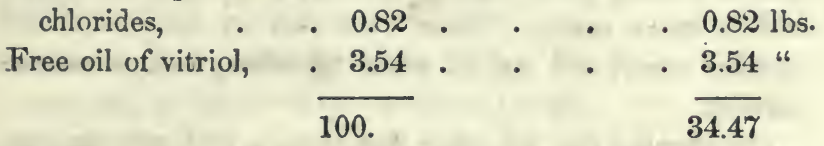

No account is here taken of the solubility of the sulphate of lime. It is all ultimately soluble in cold water. The actual amount of the crude superphosphate, readily soluble in cold water, is about 40 per cent. of which 5 , or $\frac{1}{8}$, is sulphate of lime. By repeated treatment with cold water, at least one-half of the air-dried superphosphate, as above constituted, is dissolved, and in the soil would minister immediately to the wants of plants. Ultimately, all the crude superphosphate would dissolve in soil.

307. Having thus explained the composition of bone in its various forms, and determined the quantity of oil of vitriol which is requisite to convert $100 \mathrm{lbs}$. to superphosphate, that process is to be conducted as follows, supposing bone ashes to be used:

Take a half hogshead tub, or any vessel of similar depth, which will hold from 80 to 100 gallons. If lined with lead it is better, but this is not essential for making a few hundred pounds.

1. Put $100 \mathrm{lbs}$. of burned bones, ground to fine powder, into the tub.

2. Wet the bone ash with $5 \frac{1}{2}$ gallons of cold 'water, mixing evenly.

3. Pour on this wet mass $5 \frac{1}{2}$ gallons, or $87 \frac{1}{2} \mathrm{lbs}$. by weight of best commercial oil of vitriol.

4. With a stout wooden paddle, stir the whole briskly, so as to mix thoroughly and evenly the materials. The mixture works, froths, and foams, becomes nearly boiling hot, steams 
like a boiling pot. Stir away till the mass thickens too stiff to move easily. Cover over with an old blanket and wooden cover, and let all stand 24 hours, with occasional stirring.

On opening the tub after that time, a stiff, gray mortar, moderately dry, will be found, which may be shovelled out and spread thin in a warm dry place. In two or three weeks it will dry so as to break down under a mullet or post-setter. The finer dust may be sifted out and used for drilling in with seed; or the whole, before drying, may be softened and broken down to an impalpable paste, in its weight of cold water, and then mixed with the compost heap, at the rate of $100 \mathrm{lbs}$. of the dry mass to one cord of compost. Ordinarily, there is obtained from $100 \mathrm{lbs}$. of bone ash and $87 \frac{1}{2} \mathrm{lbs}$. of oil of vitriol, about 183 to 185 lbs. of superphosphate dry enough to grind. It may be ground, after being cracked small, in a grist mill, or still better, in a Bogardus mill, such as is used for grinding ores.

The drying of the crude mass may be hastened, and the ease with which it may be pulverized promoted, by adding to it, before removal from the tub, absorbent substances. The best material is perfectly dry powdered peat or muck; or if obtainable, the charcoal cinders from locomotives at railway stations. Fine dry spent tan will answer, or the finest sifted parts of anthracite coal ashes. In lack of these, bone ash itself may be used. Any of these, added and stirred well in till the mass dries and granulates, speedily puts it into a state in which with slight drying, the mass will easily pulverize.

Supposing 183 lbs. have been obtained by thorough drying, the cost to the farmer who collects bones, or buys them of the bone boiler at $\$ 6$ per ton, will be as follows : 
$200 \mathrm{lbs}$. of raw bones burned, give $100 \mathrm{lbs}$. bone-ash, . . . . . . . $\$ 0.600$

Burning and grinding, . $\quad . \quad$. $\quad .250$

$87 \frac{1}{2} \mathrm{lbs}$. of oil of vitriol, at $3 \mathrm{cts}$. per lb., . $\quad 2.625$

$\$ 3.475$

or, per pound, .

If there is added for labor besides that for burning, \&c., . . . . . .

the cost is 2 cts. per $1 \mathrm{~b}$.

$\$ 0.2 .000$

This is for a superphosphate which contains all the phosphoric acid of bone in a soluble state.

It is this soluble state of phosphoric acid which is most to be desired by the farmer. Every care should be taken by him that his phosphoric acid falls not back into its insoluble state of phosphate of lime, magnesia, alumina or iron, when it comes in contact with these elements in soil, or in the compost heap. Lime, or leached ashes, would immedintely reduce the phosphoric acid to insoluble bone earth.

308. In the crude mass formed from bone ash and oil of vitriol, as above described, there is no longer any superphosphate of lime, or at most, only a very small quantity. It has been shown how very small a portion of lime is combined with phosphoric acid in the superphosphate, when that is made from pure bone earth. If to such a superphosphate of lime, an alkaline sulphate is added, as, for instance, sulphate of soda, or Glauber's salt, decomposition ensues, sul phate of lime, insoluble, is formed, and phosphate of soda, soluble, takes the place of phosphate of lime. Now, in operating on bone ash with oil of vitriol, alkaline sulphates are formed, which with those already existing in the ash, precip- 
itate the lime from the phosphoric acid, and that alone with soluble alkaline phosphates remains. By potash, soda, or ammonia, all the phosphoric acid may be converted into soluble, neutral phosphates, as will be presently shown.

Again, a portion of oil of vitriol, amounting to $3 \frac{1}{2}$ per cent. (306), is found in the crude mass termed superphosphate. It has its use. It prevents earthy bases in the soil, or compost heap, from uniting with the phosphoric acid. It combines with any free ammonia in the compost heap, to which the superphosphate may have been added, and forms mere sulphate of ammonia. If the superphosphate is mixed with guano, the same effect follows. The abundance of sulphate of lime in a very finely-divided state in the crude superphosphate contributes to the formation of sulphate of ammonia in compost, or guano, when all the oil of vitriol is exhausted, a little soluble sulphate of ammonia being likewise formed. Under every view, the tendency of the phosphoric acid is to remain free. But this free acid is not what the plant demands. Plants want soluble phosphoric acid salts, that is, alkaline phosphates, and therefore the farmer should see that all his phosphoric acid is converted to that state.

How may this be effected? In several: two or three of these may be mentioned, which the author has practically. proved to form as effectual a "superphosphate" as any article bearing that name in the market, whatever its prefix or suffix may be.

1. If a forcing, early effect is desired, united to the lasting operation of common bone meal, or supherphosphate of lime, mix as follows:

50 lbs. of crude superphosphate made as described (307), in dry powder. $25 \mathrm{lbs}$. of soda ash of commerce, of about 80 per cent. strength.

25 lbs. of Peruvian guano.

Mix well together the superphosphate and soda ash, then 
add the guano. Use about one pound of this mixture to five hills of corn, beans, squashes, cucumbers, melons, \&c., or for peas, turnips, or drilled crops, half a pound to every rod in length of furrow.

It may be mixed with two or three times its bulk of dry soil, or scattered over the bottom of the hills and covered with two or three inches of soil, and the seed is to be dropped on that.

Side by side with the "improved superphosphate" the above mixture has produced results every way equal to those of that excellent preparation.

The cost per $100 \mathrm{lbs}$. is, $50 \mathrm{lbs}$. superphosphate at 2 cts. $\$ 1.00$

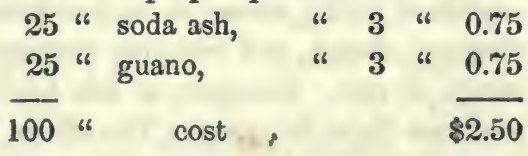

The soda ash may be replaced by an equal weight of dry house ashes, when soda is not at hand.

2. If an effect showing itself later, a seed-forming effect, and a good drought resister is desired, mix as follows:

80 lbs. superphosphate, at 2 cts., . . . $\$ 1.60$

20 " soda ash, at 3 cts., . . . . 60

$\overline{100}$ “ cost

$\$ 2.20$

3. An excellent mixture for all purposes, combining the virtues of the above, is formed as follows :

75 lbs. superphosphate at 2 cts., . . . $\$ 1.50$

$18 \frac{8}{4}$ "Peruvian guano, 3 " . . . . $0.56 \frac{1}{4}$

$6 \frac{1}{4}$ " soda ash, 3 " . . $0.18 \frac{3}{4}$

100 cost

$\$ 2.25$ 
In this case the superphosphate and soda, or house ashes, are to be mixed before guano is added.

Either of the above mixed with twice its bulk of soil may be used as a top dressing for grass, and it is to be sown or scattered during early warm spring rains, at the rate of from 100 to $300 \mathrm{lbs}$. per acre. At this rate they may be used for top dressing wheat or rye, or sown with oats and grass seed. For roots, it is best to add these compounds to the soil, before sowing, working well in, and then sowing with a seed planter. For cabbages, \&c., use $1 \mathrm{lb}$. to five plants when set out.

309. Nitrogen, whose conversion into ammonia has been explained (187), seems to be the great element introducing chemical change, and inducing chemical motion in the elements of soil. Nitrogen, as has been stated (206), always produces for a like weight, like effects, whatever may be the form in which it is introduced into the soil, or compost heap. Nitrogen is the element, which the crude superphosphate lacks, to make it a perfectly efficient artificial manure, when added either alone to soil, already rich in geine, or to peat or swamp muck, after these have been treated with ashes, soda, salt and lime, \&c., as has been before explained.

There is a source of nitrogen of which the farmer may. avail himself, which may be added to his superphosphate, and go far towards furnishing anew to burned bones the element of which fire has deprived them, or that element which is sought in guano. This source of nitrogen is found in saltpetre, either East Indian, nitrate of potash, or South American, nitrate of soda.

When it is considered that these nitrates alone, are among the most powerful and beneficial of all salts applied by farmers (168), and that, in the opinion of wise and careful English agriculturists, nitrates mixed with common salt may 
supplant guano itself, nitrates added to superphosphate may be expected to produce all the good effects resulting from the mixture of guano and superphosphate.

The following compound is therefore recommended with confidence. The amount of nitrogen in the nitrate here used, is about the same as that in the best mixtures of guano, salts of ammonia, and superphosphate of lime.

$40 \mathrm{lbs}$. crude superphosphate, 2 cts., . . $\$ 0.80$

10 " soda ash, 3 cts.,. $\quad . \quad$. $\quad . \quad .30$

50 " nitrate of potash, or saltpetre, $6 \frac{1}{2}$ cts., $\quad 3.25$

$\overline{100}$

cost

$\$ 4.35$

OR,

38 lbs. superphosphate, 2 cts., $\$ 0.76$

9 " soda ash, 3 cts.,. $\quad$. $\quad$ • $\quad$. $\quad$. 0.27

43 " nitrate of soda, (Chili saltpetre,) $5 \frac{1}{2}$ cts., 2.36

100 " cost

$\$ 3.39$

The cost of these per pound is greater than that of the mixtures before proposed, and above that of the commercial mixture. Still, it is believed that the mixture of nitrates with superphosphate, even at the above rates, will be found an economical manure, especially when one prepares for himself small quantities of superphosphate from such bones as may be collected in his neighborhood, and where guano is not to be had.

No cheaper or better addition can be made, in the small way, by the farmer, than the droppings of the hen-roost and poultry yard, home-made guano.

About equal parts of superphosphate, sprinkled with a little ashes, and of fowl droppings, may be recommended for trial. 


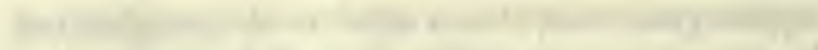

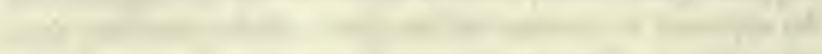
.

-
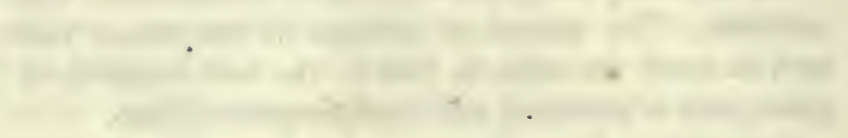

10

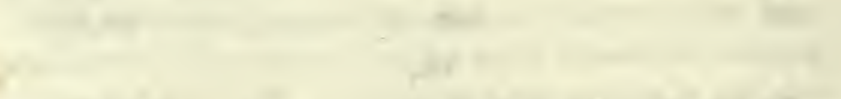

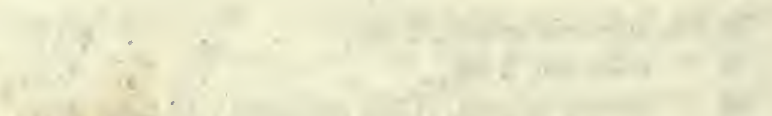

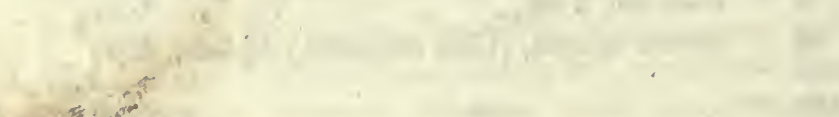

t.

$+1, i^{-1}$

. 


\section{A P P E N D I X.}

No. 1.

Dr. Nichols's Statements, from the Essex County Agricultural Transactions, $1839-40$.

To the Committee to whom was referred the Communication of Andrew Nichols, on the subject of Compost Manures, \&c.

Gentlemen :-Persuaded of the importance of the discoveries made by Dr. Samuel L. Dana, of Lowell, and given to the world through the medium of the reports of Professor Hitchcock and Rev: H. Colman, to the Legislature of Massachusetts, concerning the food of vegetables, geine, and the abundance of it in peat mud, in an insoluble state, to be sure, and in that state not readily absorbed and digested by the roots of cultivated vegetables, but rendered soluble and very easily digestible by such plants, by potash, wood ashes, or other alkalies, among which is ammonia, one of the products of fermenting animal manures, I resolved last year to subject his theories to the test of experiment the present season. Accordingly, I directed a quantity of black peat mud, procured by ditching, for the purpose of draining and reclaiming an alder swamp, a part of which I had some years since brought into a state highly productive of the cultivated grasses, to be thrown in heaps. During the winter I also had collected, in Salem, 282 bushels of unleached wood ashes, at the cost of $12 \frac{1}{2}$ cents per bushel. These were sent up to my farm, a part to spread on my black soil grass 
lands, and a part to be mixed with mud for my tillage land. Two hundred bushels of these were spread on about six acres of such grass land, while it was covered with ice, and frozen hard enough to be carted over, without cutting it into ruts. These lands produced from one to two tons of good merchantable hay to the acre, nearly double the crop produced by the same lands last year. And one fact induces me to think, that, being spread on the ice, as above mentioned, a portion of these ashes was washed away by the spring freshet. The fact from which $I$ infer this is, that a run below, over which the water coming from the meadow on which the largest part of these ashes were spread flows, produced more than double the quantity of hay, and that of a very superior quality to what had been ever known to grow on the same land before.

Seventy bushels of these ashes, together with a quantity not exceeding thirty bushels of mixed coal and wood ashes, made by my kitchen and parlor fires, were mixed with my barn-manure, derived from one horse kept in stable during the winter months, one cow kept through the winter, and one pair of oxen employed almost daily on the road and in the woods, but fed in the barn one hundred days. This manure was never measured, but knowing how it was made, by the droppings and litter or bedding of these cattle, farmers can estimate the quantity with a good degree of correctness. These ashes and this manure were mixed with a sufficient quantity of the mud above mentioned, by forking it over three times, to manure three acres of corn and potatoes, in hills four feet by about three feet apart, giving a good shovelful to the hill. More than two-thirds of this was grass land, which produced last year about half a ton of hay to the acre, broken up by the plough in April. The remainder was cropped last year without being well manured, with corn and potatoes. Gentlemen, you have seen the crop growing, and matured, and I leave it to you to say whether or not the crop on this land would have been better, had it been dressed with an equal quantity of pure, well rotted barn-manure. For my own part, I believe it would not, but that this experiment proves that peat mud, thus managed, is equal, if not superior, to the same quantity of any other substance in common use as a manure among us, which, if it be a fact, is a fact of immense value to the 
farmers of New England. By the knowledge and use of it, our comparatively barren soils may be made to equal or excel in productiveness the virgin prairies of the West. There were many hills in which the corn first planted was destroyed by worms. A part of these were supplied with the small Canada corn, a part with beans. The whole was several times cut down by frost. The produce was three hundred bushels of ears of sound corn, two tons of pumpkins and squashes, and some potatoes and beans. Dr. Dana, in his letter to Mr. Colman, dated Lowell, March 6, 1839, suggests the trial of a solution of geine as a manure. His directions for preparing it are as follows: "Boil one hundred pounds of dry pulverized peat with two and a half pounds of white ash, (an article imported from England,) containing 36 to 55 per cent. of pure soda, or its equivalent in pearlash or potash, in a potash kettle, with 130 gallons of water ; boil for a few hours, let it settle, and dip off the clear liquid for use. Add the same quantity of alkali and water, boil and dip off as before. The dark colored brown solution contains about half an ounce per gallon of vegetable matter. It is to be applied by watering grain crops, grass lands, or any other way the farmer's quick wit will point out."

In the month of June, I prepared a solution of geine, obtained, not by boiling, but by steeping the mud as taken from the meadow, in a weak lye in tubs. I did not weigh the materials, being careful only to use no more mud than the potash would render soluble. The proportion was something like this : peat, $100 \mathrm{lbs}$; potash, 1 lb. ; water, 50 gallons,--stirred occasionally for about a week, when the dark brown solution described by Dr. Dana, was dipped off and applied to some rows of corn, a portion of a piece of starved barley, and a bed of onions sown on land not well prepared for that crop. The corn was a portion of a piece of manured as above mentioned. On this the bencfit was not so obvious. The crop of barley on the portion watered, was more than double the quantity, both in straw and grain, to that on other portions of the field, the soil and treatment of which was otherwise precisely similar

The bed of onions which had been prepared by dressing it with a mixture of mud and ashes previous to the sowing of the seed, but which had not by harrowing been so completely pulverized, mixed 
and kneaded with the soil, as the cultivators of this crop deemed essential to success, consisted of three and a half square rods. The onions came up well, were well weeded, and about two bushels of fresh horse-manure spread between the rows. In June, four rows were first watered with the solution of geine above described. In ten days the onions in these rows were nearly double the size of the others. All but six rows of the remainder were then watered. The growth of these soon outstripped the unwatered remainder.

Mr. Henry Gould, who manages my farm on shares, and who conducted all the foregoing experiments, without thinking of the importance of leaving, at least one row unwatered, that we might better ascertain the true effect of this management, seeing the benefit to the parts thus watered, in about a week after treated the remainder in the same manner. The ends of some of the rows, however, which did not receive the watering, produced only very small onions, such as are usually thrown away as worthless by cultivators of this crop. This fact leads me to believe that if the onions had not been watered with the solution of geine, not a single bushel of a good size would have been produced on the whole piece. At any rate, it was peat or geine rendered soluble by alkali, that produced this large crop.

The crop proved greater than our most sanguine expectations. The onions were measured in the presence of the chairman of your committee, and making ample allowance for the tops, which had not been stripped off, were adjudged equal to 640 bushels to the acre. In these experiments, $7 \mathrm{lbs}$. of potash, which cost 7 cents a pound; bought at the retail price, were used. Potash, although dearer than wood ashes at $12 \frac{1}{2}$ cents per bushel, is, I think, cheaper than the white ash mentioned by Dr. Dana, and sufficiently cheap to make, with meadow mud, a far cheaper manure than such as in general used among our farmers. The experiment satisfies me that nothing better than potash and peat can be used for most if not all our cultivated vegetables, and the economy of watering with a solution of geine, such as are cultivated in rows, I think cannot be doubted. The reason why the corn was not very obviously benefited, I think must have been that the portion of the roots to which it was applied, was already fully supplied with nutriment out of the 
same kind from the peat ashes and manure put in the hill at planting. For watering rows of onions or other vegetables, I should recommend that a cask be mounted on light wheels, so set that like the drill they may run each side of the row and drop the liquid manure through a small tap-hole, or tub from the cask, directly upon the young plants. For preparing the liquor, I should recommend a cistern about three feet deep, and as large as the object may require, formed of plank and laid on a bed of clay and surrounded by the same, in the manner that tan-vats are constructed; this should occupy a warm place, exposed to the sun, near the water, and as near as these requisites permit to the tillage lands of the farm. In such a cistern, in warm weather, a solution of geine may be made in large quantities with little labor, and without the expense of fuel, as the heat of the sun is, I think, amply sufficient for the purpose. If, from further experiment, it should be found economical to water grass lands and grain crops, a large cask or casks placed on wheels and drawn by oxen or horse power, the liquor from the casks being at pleasure let into a long narrow box perforated with numerous small holes, which would spread the same over a strip of ground some six, eight, or ten feet in breadth, as it is drawn over the field in the same manner as the strects in cities arc watered in summer.

\section{ANDREW NICHOLS.}

I certify that I measured the piece of land mentioned in the foregoing statement, as planted with corn, on the 21st of September, 1839 , and found the same to contain two acres, three quarters, thirty-one rods.

John W. Proctor, Surveyor.

\section{Dr. Avdrew Nichols's Statemext of 1840.}

Gextlemen:-Having invited the attention of the Trustees of the Essex Agricultural Society to our continued use of, and experiments on, fresh meadow or peat mud, as a manure, it is of course expected that the result of these experiments should be laid before 
them. The compost with which we planted most of our corn and potatoes the present year, was composed of the same materials, and managed in the same manner as that which we used last year for the same purpose.

Four acres of corn, on the same kind of soil, was manured in the hill with this compost, and one acre of corn on a more meagre portion of the same field, was manured in the same manner, with a compost consisting of the same kind of mud, half a cord of manure taken from the pig-sty, and forty pounds of potash, second quality, dissolved in water, sprinkled over and worked into the heap, with the fork, in the same manner that the dry ashes were into the other compost. Of both kinds the same quantity, a common iron or steel shovelful to the hill, was used, and no difference in the crop which could be ascribed to the different manures, could be perceived. The hills were four by three feet apart on an average. In the borders and adjoining this piece of corn, one acre was planted with potatoes. The compost used in some portions of this consisted of rather a larger portion of coarse barn-manure composed of meadow hay, corn-fodder waste, \&c., wet with urine and mixed with the droppings of cattle, and less meadow mud. The whole six acres was hoed twice only after the use of the cultivator. The whole amount of labor, after the ground was furrowed and the compost prepared in heaps on the field, is stated by the tiller of the ground, $\mathbf{H}$. $\mathbf{L}$. Gould, to have been forty-nine days' work of one man previous to the cutting of the stalks. Pumpkins, squashes, and some beans were planted among the corn. The produce was four hundred and. sixty bushel baskets of sound corn, eighty bushels of potatoes, three cords of pumpkins, one and a half bushels of white beans. On one acre of the better part of the soil, harvested separately, there were one hundred and twenty baskets of corn ears, and a full proportion of the pumpkins. On one-eighth of an acre of Thorburn's tree corn treated in the same manner as the rest, the produce was nineteen baskets. A basket of this corn shells out seventeen quarts, one quart more than a basket of the ordinary kinds of corn. The meal for bread and puddings is of a superior quality. Could we depend upon its ripening, for, Thorburn's assertions to the contrary notwithstanding, it is a late variety of corn, (though it ripened per- 
fectly with us last season, a rather unusually warm and long one,) farmers would do well to cultivate it more extensively than any other kind.

The use of dry ashes on our black soil grass lands showed an increased benefit from last year. But our experiments with liquid manure disappointed us. Either from its not being of the requisite strength, or from the dryness of the season, or from our mistaking the effects of it last year, or from all these causes combined, the results confidently anticipated, were not realized; and from our experiments this year we have nothing to say in favor of its use, although we think it worthy of further experiments. On the first view of the subject, a dry season or a dry time might seem more favorable to the manifestations of benefit from watering plants with liquid manure, than wet seasons or times. But when we consider that when the surface of the earth is dry, the small quantity of liquid used would be arrested by the absorbing earth ere it reached the roots, and perhaps its fertilizing qualities changed, evaporated, or otherwise destroyed, by the greater heat to which at such times it must be exposed-it is not, I think, improbable that the different effects noticed in our experiments with this substance, the two past years, might be owing to this cause. It is my intention, should sufficicnt leisure permit, to analyze the soil cultivated and the mud used, and prepare a short essay on the subject of peat mud, muck, sand, \&c., as manure, for publication in the next volume of the transactions of the society.

Yours, respectfully,

ANDREW Nichols.

Danvers, December 20, 1840.

No. II.

Extract from Dr. Nichols's Letter.

Danvers, Jan. 28, 1842.

DEAR Sir :-I am sorry to say that I have no new facts to communicate. Nor have I anything that contradicts my former views on the subject of peat, as manure. We used it in compost on about 
nine acres of corn and potatoes last summer, one-half of which was the same land on which it was used the preceding season. Its effects seemed not to be lessened by this second trial in the same soil. The compost was as formerly composed by mixing the mud, barn-manure, ashes or potash together in the field, in spring, two or three weeks before the corn was planted; in a part of it, say the manure for two acres, about $20 \mathrm{lbs}$. of nitrate of potash were used. Wherever the nitre was used, worms were absent; other parts of the field were more or less injured by them. This was all the good that we could positively ascribe to the nitre. Our crops were in a most flourishing condition on the molning of the 30th of June ; in the afternoon and evening of that day, a violent tempest and two showers of hail blew down my barn, half my fruit trees, and prostrated and mangled the corn. I should have bargained readily with any one who would have insured me half the crop realized the preceding year from the same land and management. But the healing powers of nature and genial influences of summer suns and showers, in a few days restored the field again to a flourishing condition. A drought more severe than that of the preceding season followed in August; and our crop of corn per acre, was about $\frac{1}{4}$ less than the crop of that year. My farmer, H. L. Gould, from his success with the mud which you analyzed, was strongly impressed with the belief that other peat mud would not prove as good. I requested him to make an experiment, which he accordingly did, with two cart-loads of peat, such as makes good fuel, taken directly from the swamp, mixed with ashes, and used in the same quantity by meas- . ure, as the other compost. He planted with this four rows of corn through the piece. And, contrary to his expectations, if there was any difference, he acknowledged that these rows were better than the adjoining ones. The mud you analyzed, contained, you recollect, a large portion of granitic sand; this peat much less sand but more water, it being quite spongy. The same bulk, therefore, as taken from the meadow and used in our experiment, would probably have weighed, when dry, not more than $\frac{1}{3}$ or $\frac{1}{4}$ as much as the other. The quantity of geine in the shovelful of the two kinds, varies not very much after all. I regret that $\mathrm{Mr}$. Gould did not repeat his experiments with the solution of geine last season. My farm is 
Beven miles from my residence, and, like yourself, I turn no furrows with my own hand, nor can I oversee, in their various stages, experiments there. I suggest, advise, and leave him to execute. $\mathrm{He}$ found himself too much hurried with his work, to attend to this subject at the proper time. In answer to your question I say-that the solution the second year was not applied to the same land, and although used in much larger quantities, it was not as strong as that used the past year.

$$
\text { Yours, respectfully, }
$$

To S. L. Dana, M. D

ANDREW Nichols.

It will be observed that about three cords of swamp mud and 33 bushels of ashes have been used per acre, in 1839, and $40 \mathrm{lbs}$. of potash in 1840 .

The number of hills is 3630 per acre. Then calculating the real potash, there were given to each hill of corn about $\frac{1}{2}$ pint of ashes, or 32 grains of alkali, in 1839, and 45 grains in 1840 .

If three cords of swamp muck were used in 1840, about $6 \mathrm{oz}$. of dry geine have been applied per lill-the muck being like pond mud. Now, 45 grains of alkali and $6 \mathrm{oz}$. of geine, and $\frac{1}{2} \frac{1}{2}$ of a cord of pig-manure per hill, have here produced effects equal to guano. No new source of nitrogen has been opened to the corn. The effects are due, then, to the alkaline action on geine, and of salts upon silicates. The failure of the solution in the second year is probably owing to the formation of sulphuretted hydrogen; see section (238).

No. UII.

Letter from Hon. Williay Clark, Jr.

Northampton, 10th February, 1842.

DeAr Sir :-The results of the few trials I have made with alkalies to neutralize the acidity of swamp muck, have not been ascertained with that precision that is necessary to detcrmine conclu- 
sively which is best. I will, however, give you the experiments (if they deserve the name), as they were made, with the apparent results. The first was with fine well decomposed muck, from the swamp of which you had samples, numbered 5,6, and 7. In the spring of 1840, 16 lbs. of soda ash, or white ash, dissolved in water, were carefully mixed with two estimated tons of the muck, and the mixture applied as a top-dressing for corn. Two other estimated tons of the muck were served with eight bushels of dry wood ashes, all well mixed together and spread on one side of the muck that was served with the white ash, and further on, an equal quantity of fresh barn-yard manure was spread, and still farther on, an equal quantity of compost, made of one part barn-manure, and two parts muck, mixed and fermented before using.

The land was a light sandy loam, on the border of a pine plain, and the whole field was treated alike in all respects, except the different kinds of manure, all of which was spread on the turned furrow, and harrowed in before planting. The corn planted where the wood ashes and muck were spread, carly took precedence of all the other parcels, and continued apparently much the best through the season. Among the other parcels, no striking difference in growth or yield was manifest. The whole field was harvested together, without separate weight or measurement ; and the advantage which the ashes and muck apparently gave over the others, rests (where no experiment should rest) on the opinion of thoso whose attention was called to it while the corn was growing.

A similar trial of ashes and muck, and soda and muck, was made. the same season on grass land; and the advantage was decidedly in favor of the soda ash and muck, as on the corn land it was in favor of the ashes and muck.

Why the soda ash should act relatively, more favorably upon the muck spread on grass land than when spread on corn land, I am unable to determine, unless it be the partial shade which the grass affords to protect it from the direct rays of the sun, and measurably preserve its moisture and softness. This inference is strengthened by the fact that muck, treated as in the above cases-with soda ash in solution (which makes it somewhat pasty), in the only instance I have tried it-spread on the surface of an old field, without a pro- 
tecting crop, or subsequent harrowings to cover it in the soil, became apparently sun-baked so hard as to defy, for a time at least, the softening action of water. This hardening effect was not observed to take place with the muck treated with the dry ashes, or in the manure compost, and may have arisen from the insufficient quantity of alkali used in the case mentioned.

In another case, one lb. of soda ash, and one lb. of soft soap were mixed with four bushels of muck, and all put in a fifty gallon tub, and the tub filled with water, and left to stand five or six days witli an occasional stirring; at the end of that period, the dark colored water was dipped off and applied to various garden plants and vegetables, and the tub again filled with water, and the muck stirred up, and after a day or two the water was again dipped off and applied as before, and the tub again filled with water. This process was continued for two or three weeks in the early part of the season, and the muck, though gradually wasting, without additional alkali, continued to ferment from time to time, and yield black liquor, to appearance nearly as rich as the first. Rapid growth of the plants followed in all cases when it was applied, and its effects upon a lot of onions would have been ascertained with considerable accuracy, had not a "hired man" took it into his head that the few rows purposely left for comparison, were suffering by unwitting neglect, and gave them a "double dose," thereby equalizing the growth, and sacrificing the experiment to his honest notions of fair dealing, which required that all should be treated alike. In another case, a muck compost dressing, formed by previously slacking quicklime with a strong brine of common salt, to disengage the acid of the salt, that its soda might act on the muck when in contact, was applied as a top-dressing for corn, without any perceptible effect, perhaps for want of skill in compounding.

Facts abundantly testify to the fertilizing properties of swamp muck and peat, when brought to a right state, and the subject of your inquiry perhaps yields to no other, at the present time, in point of importance, to our good old Commonwealth. Taking your estimate of the weight of fresh-dug muck or peat, and Professor Hitchcock's estirnate of the quantity in the state, and the saving of one cent per ton in the expense of neutralizing its acidity, and fitting it 
for use in agriculture, when applied to all our swamp muck and peat, will amount to an aggregate saving to the industry of the Commonwealth, of over five and a half millions of dollars. Is there a reasonable doubt that more than ten times this one per cent. per ton will be saved over any present process, when chemistry has shed its full light on the subject?

The magnitude and importance of a small saving in this matter, must certainly have been overlooked by some who have given advice on the subject of making muck compost.

Respectfully,

Your most obedient servant,

William Clark, Jr.

S. L. Dana, M.D., Lowell, Mass.

\section{No. IV.}

Extract from a letter of Mr. Joseph A. Foster to the Author, relating to imitation spent Lye (238).

Attleboro', February 6th, 1844.

DeAr SIR :-I determined last spring to make a trial of the imitation spent lye, recommended in the "Manual," and the object of this communication is to give you the results.

I mixed the composition in the manner and proportion stated, with one exception, using two bushels of ashes instead of one. I then spread it upon grass land, seeded down to herd's grass and clover. The soil was rather a dry, gravelly loam. It was spread upon a picee of land about ten rods long, and two broad. It was spread the 27th of April. On the 8th of June, or a little more than five weeks after the application, as I find by the farm journal, the effects of it were distinctly visible. The grass was both much darker, or deeper green, and much taller. The spot was distinctly marked where the composition was spread. The difference continued to be much more apparent, and several persons who knew not that anything had been put on, pointed out the spot upon which it had been applied. The difference continued to increase till the dry weather came on, when, in common with other dry lands, the grass 
in a short time was completely scorched. The grass upon which this manure had been applied did not dry up any quicker than that around it. The grass had not attained half its growth when it was mown. The spot upon which the imitation was spread, had not the drought come on, would have yielded at least one-half as much more as an equal area by its side.

Respectfully yours,

Joseph A. Foster. 
$\rightarrow \rightarrow$

\section{$-2+2$}

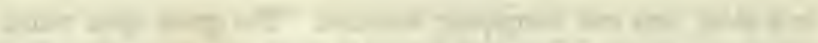

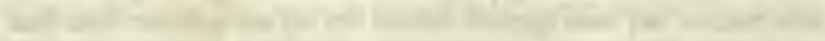
+

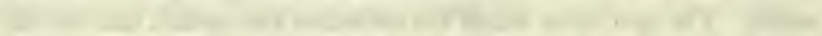

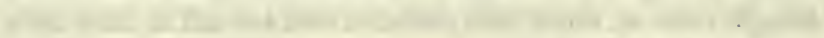
;

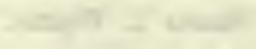


I N D E X. 



\section{N D E X.}

A.

Section.

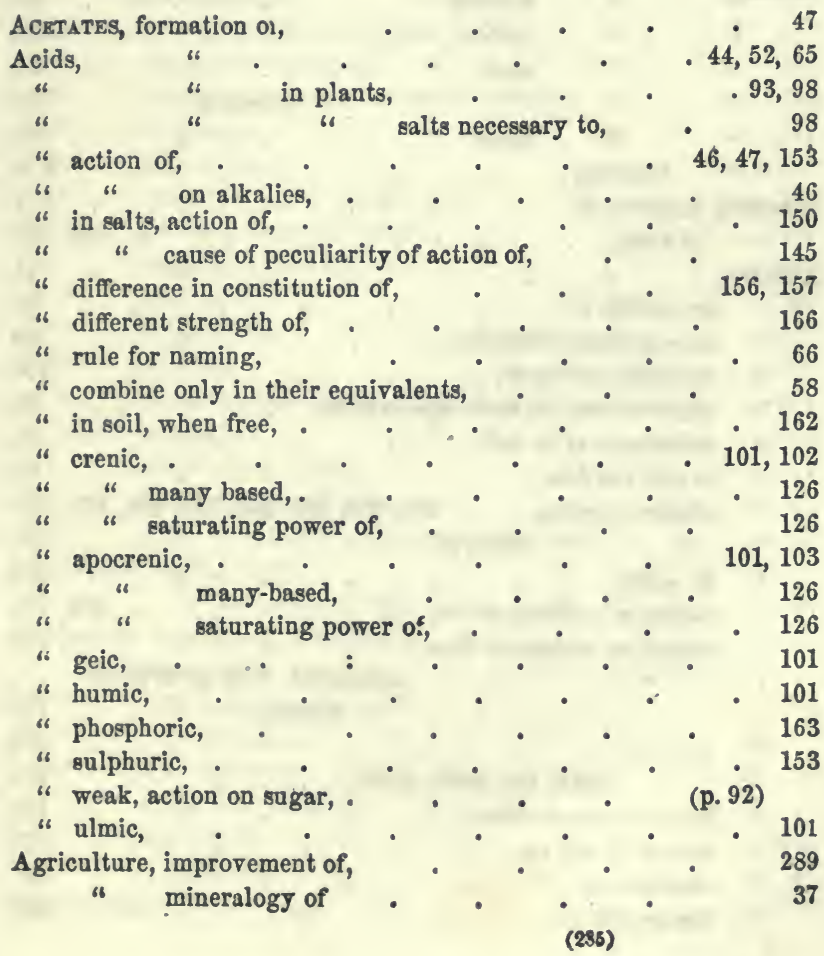


Agriculture, value of small discoveries in,

SECTTON.

“ relation to silicates and salts,

Agricultural Chemistry, aims of

"6
"6
"
"
"
" $"$
"

first principle of,

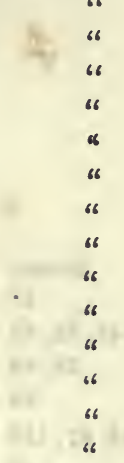

.

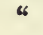

" second ". . . . 20

" third " . . . . 29

Albumen, analysis of,

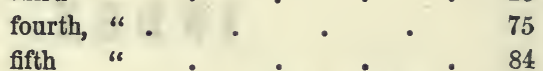

" fifth " . . . . 84

66

“

chemical proof of,

84

66

"6

agricultural " ninth "

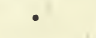

217

184, 201

" properties of,

" strong resemb

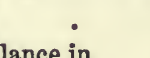

" catalytic action of, .

" combine only in their equivalents, . . . 58

" sufficiency of in soil, - . . . . . 75

" in soil not free, . $\quad . \quad$ : $\quad$ • $\quad$ • $\quad 76$

“ effects on geine, 126, 128, 136, 142, 162, 264, 276, 137 .

" " " cause of, . . . . 137

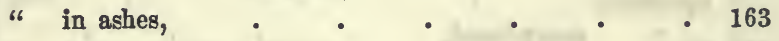

" action of carbonates on, . . . . 159, 169

" action on vegetable fibre; . . . . 136

" " " connected with growth of plants, - . 137

" soluble, .

" " within the reach of all, . . . 274

" other forms of cheap, . _ . . . 275

" action of salt on, . _ . . . . 275

" stearate of, . . . . . . . 227

" margarate of, . . . . . 227 
Alkalies, relative value of,

SECTION.

Alkaline geates,

264

bases, - $4 \quad$. 62

" " affinity of, for carbonic acid, . . 62

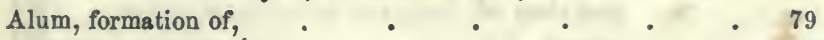

Alumina, geate of, . $\quad . \quad$. $\quad . \quad$. 121

" phosphate of, . . , . . 80

“ silicate of, . $\quad$ - . . . . . 48

" insolubility of, in water, . . . . 62

"quantity of, in rock, . . . . . 58

" combining weight of, . . . . . 56

" peculiarities of, . . . . . 64

Ammonia, in soil, unites with organic acid, . . 101

" changes to nitric acid, . . . . 126

" humate of, changed to apocrenic acid, . . 126

" in manure, . . . . . . . 178

" in cow-dung, . $\quad$. . . . . . 186,187

" produced yearly by one cow, . . . 191

" the mair value of manure, . . . . 192

" catalytic action of, . . . . 194

"6 sources of, . $\quad . \quad$. $\quad . \quad . \quad 200$

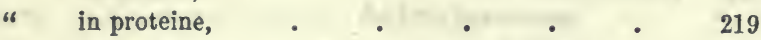

" in bone, . . . . . . . 223

" in all animal matters, . . . . . 216

" in peat, - . . . . . . . 260

“ action of, in dung, : . . . 263

" chemical equivalent of, . . . . 265

" equal to soda for agricultural purposes,. . 265

Ammoniacal salts of urine, . $\quad$ - . $\quad$ - $\quad 246$

" " and peat powder, . . . . 278

Analysis of horse-dung, Girardin's, - . . 203

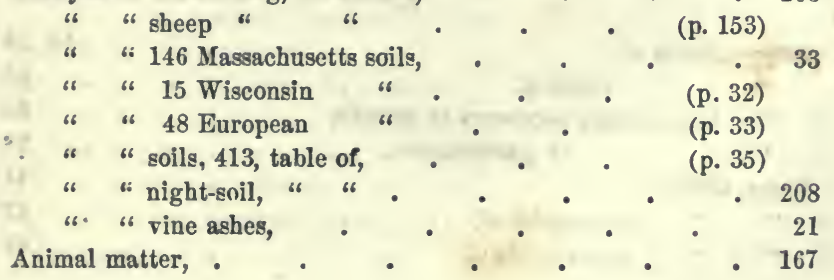


sECTIOx.

Animal matter, use of .

194

“ all affords geine, ammonia and salts,

" source of alkali for peat,

277

“ products may be divided into two classes,

"6

6. first class of,

221

"

"second "

221

Animalized coal, . $\quad$. $\quad$. . . 210

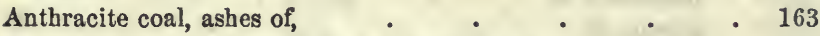

A pocrenates formed by nitric and humic acid, . . 126

Ashes, action on soil, $\quad . \quad \ldots \quad$. $\quad . \quad \ldots \quad .135$

" valne of, . $\quad . \quad$. $\quad . \quad . \quad 163$

" constituents of, . . . . . . . 163

" divisible in two parts, . . . . . . 163

" of hard wood, analysis of, . . . . 163

" " soluble part of, . . . 163

4 " 4 insoluble " . . . 163

" piue, analysis of, . $\quad . \quad \ldots \quad$. $\quad . \quad 163$

" of several American trees, analysis of, . . . 163

" wheat straw, . . . . . . 163

“ anthracite coal, . . . . . . . 163

" leached, value of, $\quad . \quad \ldots \quad$. $\quad . \quad . \quad 163$

" " contents of cord of, . . . . 164

"6 Ealts in, . . . . . 164

" of manure, value of, . . . . . . (p. 154)

" " " . . . . . (p. 154)

" " vine, analysis of, . . . . . 21

Atomic weight, $\quad . \quad$. $\quad . \quad$. 55

" " theory of, . . . . . 55

Atoms, combinations of, - . $\quad$ - . 55

Author, not a practical farmer, . . . . . 271

B.

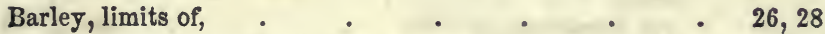

" " . . . . . . . 26

"6 temperature necessary to growtb, . . . 26

" " o germination, . . . 26

Bases, alkaline, . . . . . . . 41

" " properties of, . . . . . 62

* " equivalents of, . . . . 62 
Bases, alkaline, action on geine, .

" metallic,

" carbonates of, in ashes,

" separated from the acid,

142

" of all salts, acts ever the same,

Bones, constituents of,

" bone earth in,

"tallow in after boiling,

" liquor of, as manure,

(p. 158)

" their importance and value,.

299

6 in what way they act,

6 entire composition of

-6 partially deprived of gelatine,

" steamed and boiled, .

"ash,

" oil of vitriol to dissolve,

Bromine in seaweed,

Burning of crops,

C.

Carbon, chemical equivalent of,

Carbonates,

Carbonate of lime in leached ashes,

Carbonic acid, evolved by roots,

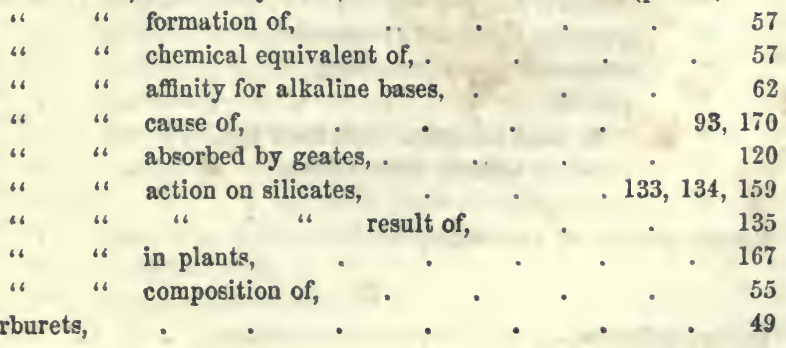


BECTIOX.

Cartilage of bone, as manure,

223

Caseine, analysis of,

Catalysis, action of,

Catalytic power

Chalk in eggshells,

$129,140,141,142$

"c clamshells,

215

Charred peat,

Chemical equivalent, definition of,

"6 formulæ, of proteine,

Chlorides,

" in granite rocks,

6

"Hayes on,

Chlorine in soil, .

Columbine, .

Combining number,

Compost of animal matter, . _ . . . . 167

Copperas,

Cotton, phosphates in,

Cow-dung, the type of manures,

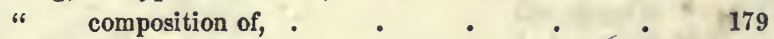

“ analysis of, . . . 180

c value of, dependent on food, . . . 200

“ water in, . . . . . . 183

" general analysis of, . . . . 105, 188

" ammonia in, . . . $\quad$. 107, 186

" - ultimate analysis of, . . . . 186

" quantity produced by one cow, . . . 189

" compared with horse-dung, . . . . 284

"cost of, . . . . . . . . 276

" from meal compared with from hay, . $\quad 199$

"r richer in summer than winter, . . 200

“ action of, . . . . 201

Crasso, analysis of vine ashes, . $\quad$. . . . 21

D.

Decay, definition of, . 
Decay, first product of, .

" hastened by potash and lime, . . . 136

" " . . . . . 136

"general products of, . . . . . . 101

Decomposition, as effecting value of manure, . $\quad$ (p. 56)

Deodorizing vaults, how done, . . . (p. 171)

Drought, its effects on manure, . . . (p. 159)

Dung, horse, how treated, . . . . . (p. 145)

" " fermentation of, . . . . (p. 145)

\section{E.}

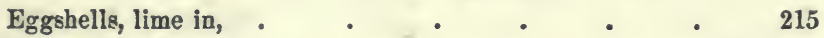

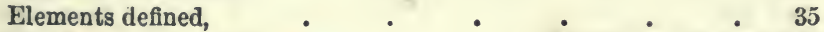

" number of, . . . . . . 40

" atomic, . $.5 . \quad . \quad 55$

" earthy and metallic, . . . . 40

“ volatile and combustible, . . . . 40

" division of, . . . . . 41

" " adopted, . . . . . 61

"unequal affinity of, . . . . . 54,55

" combinatior of, . . . . . . 55

" proportion of combination, . . . 56

" of soil, metallic and unmetallic, . . . 40

" " . . . . . . 130

" " . . . . . . 131

" 6 two classes of, . . . . . 101

" " first class of, . . . . . 102

" " . . . . . 103

"6 metallic, change to unmetallic, . . . 64

" mineral, cause of decomposition of, - $\quad-\quad 137$

“ number selected by plants, . . . . 87

"wherein plants do not obey chemical laws of, . 87

" susceptibility of change, . . . . 90

" number of, in organic parts of soil, . . $\quad 89$

" " inorganic parts of soil, . . 89

" organic, complex combination of, - . 99

"6 inorganic, simple $\quad 66 \quad$. $\quad$. 999

" organic, character of, . $\quad$. $\quad$. $\quad 99$

66 " products of decomposition of, . . 100 
sECTIOX.

Elements, organic, one constant,

" inorganic,

" organic, of plants,

relative weight of, $\quad . \quad+\quad \cdot \quad+55$

" of silicates, laws of combination of, . . $\quad 56$

Epsom salts, formation of,

European soils, analyses of, .

(p. 33,35$)$

Evaporation from soil,

$$
\text { "6 "woodland, }
$$

Excrement, human, analysis of, .

F.

Farmer, the, a chemist, .
66

66

66

66

66

66 philosophy of, . pole-star of, knowledge of terms, important fact to, . true field of action of, . first requisite of, .
39

36

36

36

79

103

172

224

224

224

218

(p. 150)

Fleitmann, on human feces, .

Flemish manure, .

Flowers, salts in,

Fluorine, in rye asbes,

Fruit trees, limits of, Furnace, for poudrette, . (p. 150)

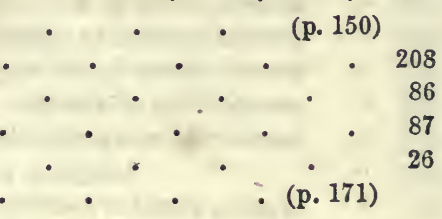

G.

Gadou, 
Gas poudrette, how made,

" liquor, value and use of, . . . . . $\quad 278$

Geates, character of,

“ properties of,

" formation of,

“ abundant in soil,

" action of lime on,

" of lime,

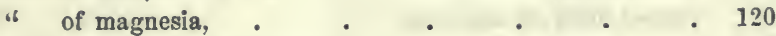

" of alumina, . . . . . . . . 121

" of iron, . . . . . . . . . 122

" of manganese,

Geic acid,

Geine, researches of Mulder,

101,116

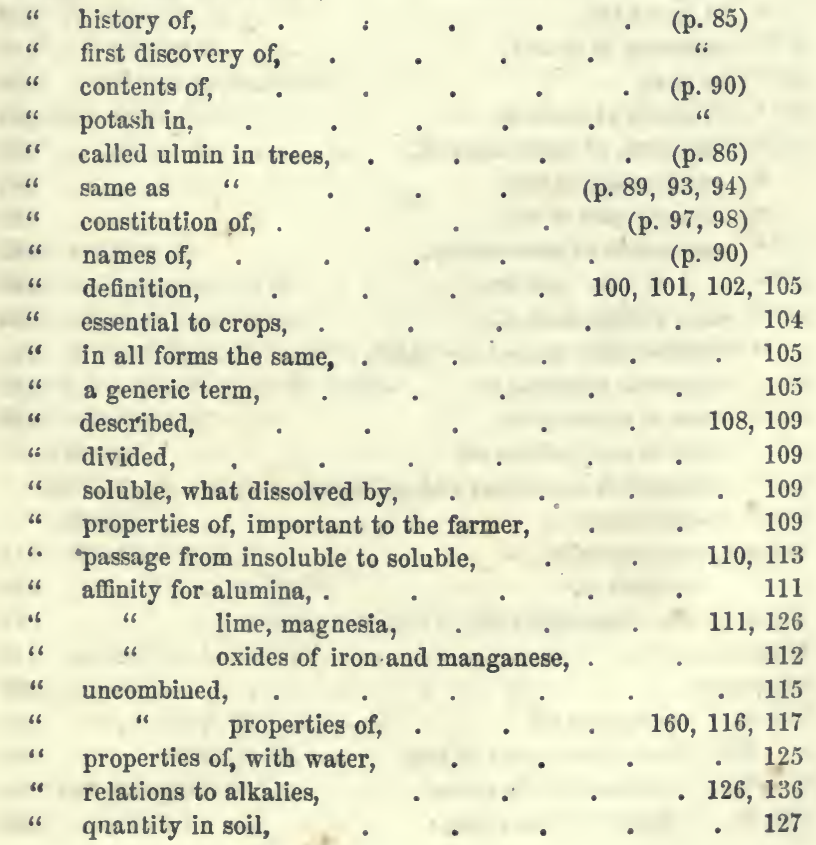


SECTION.

Geine, twofold action ot,

" cause of effect of alkalies on, . . . . . 137

"how retained in soil,

" fertility dependent on, . . . . 151

" necessary with salts, . . . . . . 153

" action of oxygen on, . $\quad$. $\quad . \quad . \quad 168$

" as required by nature, . . . . . . 171

"6 in cow-dung, .

185

"formed daily by one cow, . . . . $\quad$. 189

c. " " yearly " " . , . . 189

" the main agricultural value of manure, . . 191

": action of, in manure, . . . . 195

"in horse-dung, . $\quad$. $\quad$. $\quad$. $\quad$. $\quad 204$

" compared with glycerine, . . $\quad 233,234,235,236$

" in spent lye, . $\quad . \quad$. $\quad . \quad$. $\quad .238$

"necessity of in soil, . . . . . 127

" in peat, . $\quad . \quad$. $\quad . \quad$. $\quad .256$

" in rivers at freshets, . . . . . . . 283

" intention of application of, . . . . . 291

" varies much in soil, . . . . . . 291

" lightest part of soil, . . . . . . . . 292

" absorption of moisture by, . . . . . 294

" "6 $\quad$ gas by, . . . . . . 295

"slow evaporation of, . . . . . 294

" effect of conversion into water, . . . . . . 295

6 electrical relations of, . . . . . 297

"6 basis of agriculture, . . . . . . 298

" table of composition of, . . . (p. 97)

" comparison of natural and artificial, . (p. 97, 98)

" modifications of, . . . . (p. 99)

Gelatin, description of, : . . . . $\quad$ \& 218

"6 analysis of, . . . . . . . 218

Glass, green, composition of, . $\quad$ - . $\quad$. 71

Glauber's salts, . $\quad$. $\quad$. $\quad . \quad$. 170

Glycerine, . $\quad . \quad$. $\quad . \quad . \quad 227$

"6 composed of, . $\quad$ - . . . 227

" the organic part of lye, - . • . . 229

" compared with geine, . . 233, 234, 235, 236

6 different from geine, . . . . 236 


\section{INDEX.}

SECTIก,

Grain, crops of, in Massachusetts, . . . . . . 23

" northern boundary of, - . . . 26

" failure of, in Iceland, . . . . . . 26

" 6 " 6 cause of, . . . 26

" temperature " of germination, . . 26

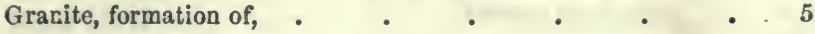

" composed of, . . . . . . 71,72

Guano, great quantity of, . . . . . . 211

" analyses of, . $\quad . \quad \ldots \quad . \quad . \quad 212$

" an article of commerce, . . . . 212

“ Johnston's average table of, . . (p. 175)

" table of various analyses of, . . . (p. 174)

" proportion to be used, . . . . 208

" use of, . . . . . . . . 212

" ammonia in,. . . . . . . 212

* varieties of, . $\quad$. $\quad$. . 212

" and superphosphates, . . . . 308

Gypsum, application of, . $\quad$. $\quad . \quad$. 151

" action of, . . . . . 151

H.

IIair, analysis of,

Hair, fertilizing power of

218

Hay, action of catalysis on,

" yield of by various salts,

(p. 158, 159)

Hayes, Dr., on chlorides in rocks, $\quad$ - $\quad$ - $\quad$. $\quad$. 88

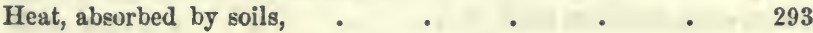

Hen, food of, . $\quad$ - $\quad$ - $\quad$ - . $\quad$. 214

4. analysis of, . . . . . 214

" eggs of, " . . . . . . . . 214

" excrements of,"

"6 6 salts in, . . . . . 214

" " and superphosphates, . . . 309

" agricultural value of, . . . . . 214

Hog manure, - . $\quad$. $\quad$. $\quad$. 205

" " 6 value of, . . . . . . 205

" " . . . . (p. 152)

" urine, analysis of, . $\quad . \quad$. $\quad . \quad$. 247

Horn, analysis of, . $\quad$ - . . . 218 
BECTION.

Hornblende, ingredients of, . . . . . 60

" action of, air and moisture on, . . 77

Horse-dung, analysis of, . $\quad$. $\quad$. $\quad . \quad 203$

" " value compared with cow-dung, . . 204

" " fermentation of, . . . . . 204

" " how to be treated, . . . (p. 144)

" boiling establishments, . . . . . 210

Hruschauer, analysis of vine ashes, _ . . . $\quad 21$

Iluman excrement, Fleitmann's analysis of, . . . (p. 150)

" " Berzelius's " . . (p. 149)

Humic acid, . $\quad$. $\quad$. $\quad$. . $\quad$ (p. 98)

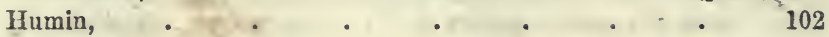

Humus, . $\quad . \quad$. $\quad . \quad$.

" constituents of, . . . . . (p. 94)

" formation of, . . . . . $\quad$ (p. 94)

Humin, formula of, . $\quad$. $\quad$. $\quad$. . . (p. 94)

Humic acid, " formation of apocrenates by, . . 126

Humate of ammonia, . . . . . (p. 95)

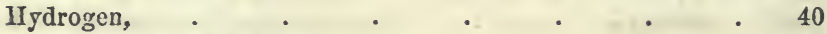

" in sandy soil, . . . . . . 127.

" considered as unity, . . . . 55

" combination of, . $\quad$. $\quad$. $\quad . \quad$. 55

" excess of, in decaying soil, . . . . 100

“ group, in organic bodies, . . . . 101

I.

Indian corn, northern limit of - • • • . $\quad 26$

" " temperature of germination, . . . 26

Iowa soils, analysis of, . $\quad . \quad$. $\quad . \quad$ (p. 33)

Iodine, in land plants, $\quad$. $\quad$. $\quad$ - $\quad$. $\quad$. 87

Irrigation, ․ . - . $254,279,281,282,283$

" most fertile source of benefit from, . . 283

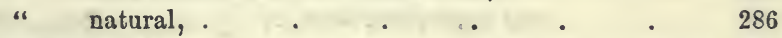

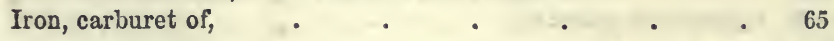

" geate of, . . . . . . . . . 122

". phosphate of, . . . . . . . 80

" silicate of, . . . . . . . 48

" sulphate of, formation, . $\quad . \quad$. $\quad . \quad$. 79

" " action, . . . . . 82 
SECTION.

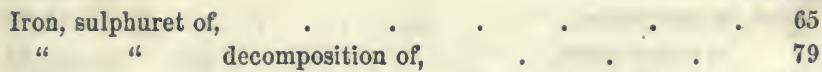

" combining weight of, _ . . . . . $\quad$. 56

Isinglass, physical properties of, $\quad$. $\quad$. $\quad$. $\quad$. 37

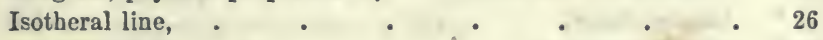

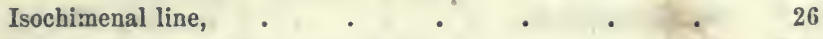

Isomorphism, law of, $\quad$. $\quad$. $\quad$. $\quad$ - 94

J.

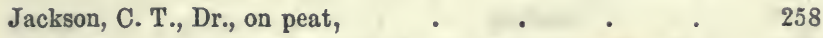

Jacquemart, on peat aud ammonia, . . . . 278

" " various manures, . . . (p. 160)

Jauffret's manure, principles of, . . . . 278

Johnston, Professor, analysis of yard-dung, - (p. 149)

" " " of night-soil, table of, . 208

" " soil not dependent on rocks, . . 21

K.

Krocker, on amount ammonia in soil,

Kuhlmann, on nitrogenous manures,

. (p. 157, 159, 160)

L.

Lawes, on the value of manure ashes, . . . ( . 154)

Law of substitution,

Life, a catalytic power, . $\quad$. $\quad$. $\quad$. $\quad . \quad 139$

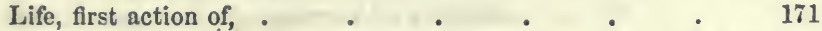

Lime, action of, . $\quad$. $\quad$. $\quad$. $\quad$. $\quad 159,161,162$

" " on vegetable fibre, . . . . . 160,162

" " on free acids in soil, . . . 162,163

" properties of, . $\quad . \quad$. . . 160

" secretion of, . $\quad . \quad$. . . 18

" in soil, . . . . . . . $\quad$. 30

" cufficiency of, in soil, . . . . . 75

" not frec " . . . . . . . 76

" combining weight of, . . . . 56

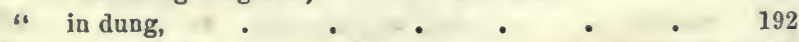

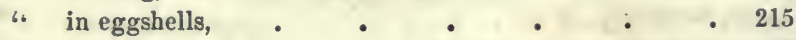

" in granite, . $\quad . \quad$. $\quad . \quad$. 72 
Lime, in pine plains,

sEcriox.

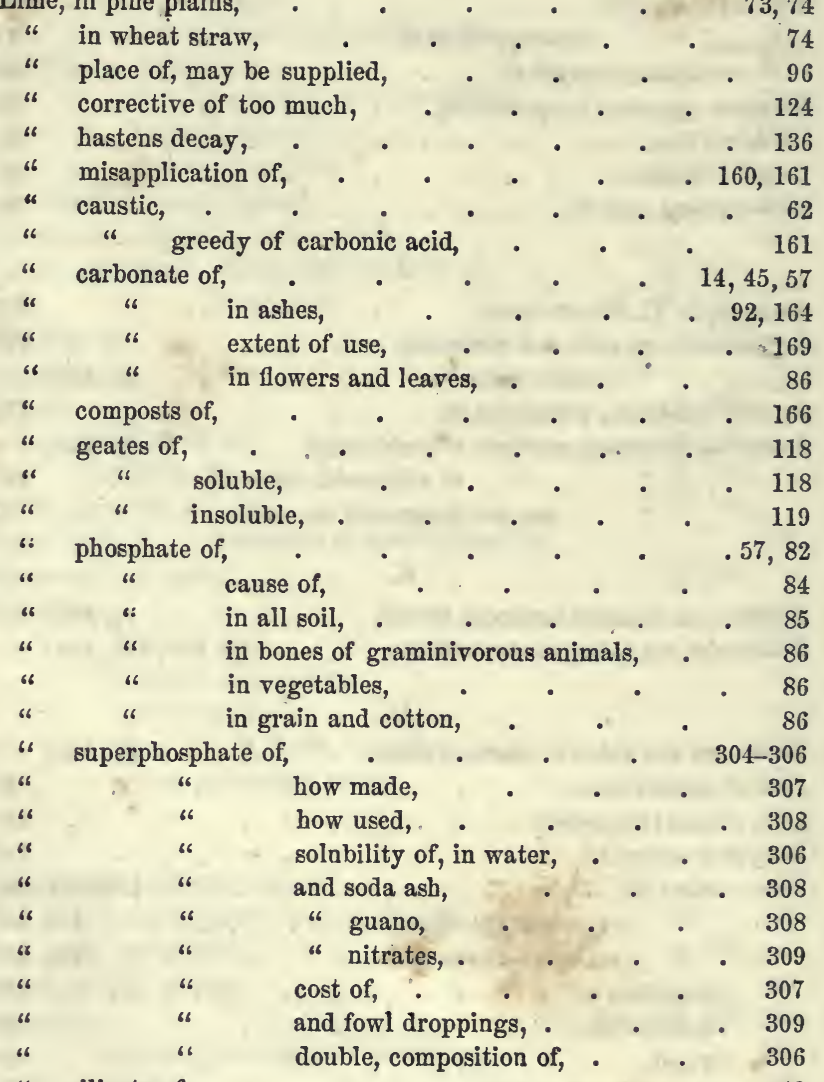

" silicate of,

" sulphate of,

" " in all soil, . 84

" muriate of, . . . . . . . . . 170

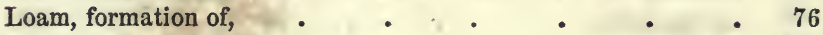

Locomotive cinders, as manure, . $\quad$ : . . $\quad$ - 278 
N.

Magnesia,

" combining weight of, . . . . . 56

" caustic, .

" may supply the place of lime, . . . $\quad 91$

" geate of, . . . . . . . . 120

" phosphate of, in vegetables, . . . 85

14 silicate of, . . . . . . 48

Man, the journeyman of nature, . $\quad$. $\quad$. $\quad$. 290

- Manganese, geate of, . . . . . . . . 123

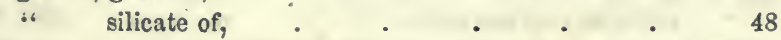

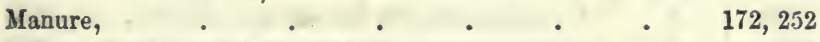

“ the farmer's first requisite, . . . . 172

" what composed of, . . . . . . 172

" immense variety of, . . . . . $\quad$. 174

“ divisible into three classes, . . . . . 175

" chiefly of the third class, . . . . . 176

" standard measure of, . $\quad . \quad$. $\quad . \quad 177,179$

" the elements of fertility, . . . . 178

" contents of, . . . . . . . 178

" the type of, . $\quad . \quad$. $\quad . \quad$. $\quad . \quad 179$

" " composition of, . . . . 179

" from one cow, . . . . . 189, 190, 191

" chief value of, . $\quad$. $\quad$. 193, 194, 195, 261

“ rich in proportion to nitrogen, . . . 196,261

" what reduced to, . . . . . 206

“ three varieties, different properties of, . . 206

" " " comparative value of, . . 207

“ long and short, . . . . . (p. 145)

" weight of cubic foot of, . . . . (p. 149)

" various sorts of, . . . . . . . 208

" dung of fowls, . . . . . . . 213

" “ " " good results from use of, . . 213

" not containing nitrogen, . . . . . 224

“ from salts only, . $\quad$. $\quad$. $\quad$. $\quad . \quad 239$

" " chiefly from liquid animal evacuations, 239

" of peculiar salts, . . . . . . 239

". of animal acids, . . . . . . . 239,240

" liquid of cow, composition of, . . . . 243 
gecriox.

Manure, liquid of cow, compared with dung,

243

" " " quantity annually from one cow, effects of, 244 " " $"$ of horse, . . . . 245

" " " of man, . . . . . . 248

" natural, insufficient for all, . . . . . 252

" artificial, . . . . . • 253

" " " distinction of, from animal, . . . 253

" " " first in this class, . . . . 254

" " " others "

" green, action upon peat, . . . . . 270

" artificial, cost per cord, _. . . 274,276

" " " compared with cow-dung, . . 274

" " preparation of, in best manner, . . . 274

" other sources of, . . . . . . . 284

" sheep, analysis of, . . . . . . . 205

" hog, . . . . . . . . 205

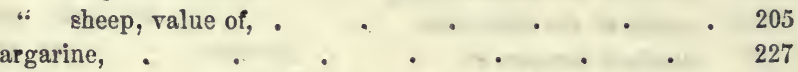

Margarine,

Margaric acid, . $\quad$. $\quad$. $\quad$. $\quad$. 227

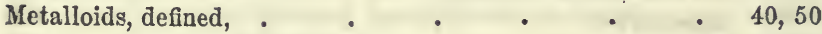

" number of, . $\quad . \quad$. $\quad . \quad$. $43,45,58$

" characters of, . $\quad$ c . . . $\quad 65$

" combinations of with oxygen, . . . 66

" action of air and water on, . . . 78

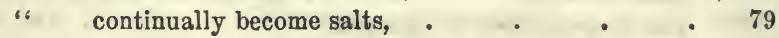

" selected by plants, . . . . . 87

Metalloid compounds, . . . . . . . . 40

Metals, . . . . . . . . . 41

Mica, properties of, . $\quad$ - . $\quad$. $\quad 37$

" ingredients of, . $\quad . \quad$. $\quad . \quad .60$

" action of air and wet on, . $\quad$. . . . 77

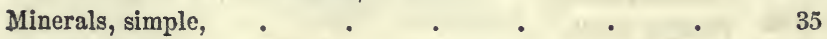

" " number of, . . . . . $\quad$. 38,59

" " $"$ " limited knowledge of, . . 38

" " elements of, . . . . . 39

" " table of constitution of, . . . $\quad 59$

" " three classes of, . . . . 60

Mitchell, on sea water, lime, and peat, . . . 270

Motion, in seeds and plants, remarks on, . . (p. 162) 
Motion, chemically induced in soil, .

Mould, regetable, defined,

" organic elements of, according to Berzelius, (p. 145)

Muck, action on sand,

Mud, value of,

" compared with dung, . . . . . 259

" of freshets, analysis of, . . . . . . . 284

Muriates,

N.

Nails, the, analysis of,

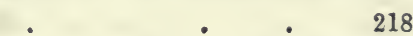

Nature, beneficence of,

Neutral group of organic bodies, . . . . . 101

Night-soil, table of analysis of, .

" Soubeiran's analysis of,

208

" composition of,

66

66

nitrogen in,

Nitrates, .

" acti

action of

" in soil, source of,

$\therefore$ of soda, its effects on grass,

Nitrification in soil,

Nitric acid, action of on humic,

6 " " on humate of ammonia, . . . 126

Nitre, composition of,

168

" one of the most active salts,

Nitro-humic acid,

(p. 99)

Nitrogen in soil,

in sandy soil,

" in geine,

" in air,

source of, for roots and seeds,

" in manure,

“ action of, .

" the chief enriching quality in manure, . . 196

" the basis of ammonia,

" in dung, source of, 
sicuor.

Nitrogen in hay, what becomes of, .

" in horse-dung,

"6 in night-soil,

" in cow-dung,

" distinguishing feature of organized bodies,

" measures, value of manure,

(p. 155)

" how limited in value,

Nitrogen effective, as decay is rapid,

: remarks on its effects on vegetation,

Norton, Professor J. P., on fertile soils,

O.

Oats, limit of,

"temperature of germination, 26,28

Oil of vitriol free in superphosphate of lime,

" " quantity for raw bones, . . . . 305

" " " 6 steamed bones, . . 305

" "6 ". bone ash, . . . . 305

"6 " 6 6 sugar house refuse, . 305

Oils, action of air on, . . . . . . . 224

" action on silicates, . . . . . . 224

Oleic acid,

Oleine,

Organic matter in cow-dung,

"6

"6

"s

6)

16

66

" according to Morin, .

" M. Penot,

182

Oxides, metallic, ultimate analysis of,

" of iron, combining weight of, . . . 56

" of manganese, .

Oxygen,

" combining weight of,

" in bases of organic acid salts,

" in sandy soil, .

" action of, on geine,

" " silicates,

" in water, action of,

c: group of organic bodies, 101

$\mathrm{Ox}$, quantity of manure from one, .
(p. 148) 
P.

Pearlash, properties of,

" to be used one-half more than soda-ash, . . 265 Peat,

" analysis of

" varieties of, . . . . . . . 257

" water in, . . . . . . . 259

" value of, . . . . . . . . $\quad . \quad 259$

" ashes, contents of, . $\quad . \quad$. $\quad . \quad . \quad . \quad 163$

" compared with cow-dung, . . . . . 254

" salts and geine in, . . . . . 260

" resemblance to cow-dung, . . . . 260

" ammonia in, . . . . . . . 260

"power wanting in, . . . . . . 261

" power wanting in, how to be given, . . . 262

" addition of alkali to, . . . . . 264

"quantity of alkali to hundred weight, . . 266

" " " cord, fresh dug, • . 267, 269

" " " dry, . . . 267, 269, 271

" dung to be added to, . . . . . 270,276

" action of dung on, . . . . . . . 276

" boiled with alkali, _ . . . . 271,272

" mixed with spent asbes, . . . . . 272

" charred, . . . . . . . . . . 278

" action of lime and salt on, . . . . . 276

" " Eal-ammoniac on, . . . . 276

- converted by other sources into soluble manure, . 277

" mixed with urine, . $\quad . \quad$. $\quad . \quad$. 277,278

" necessity of fermentation in, . . . . 260

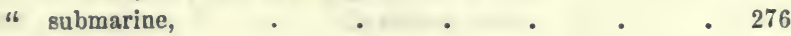

" and salt water, . . . . . . 276

Phosphates, . $\quad . \quad$. $\quad . \quad$. 52

" action of, $\quad$. $\quad$. $\quad$ - . 169

" proportional to nitrogen, . . . (p. 162)

Phosphorus, equiralent of, . $\quad$. $\quad$ • $\quad . \quad 57$

" existence of, . . . . . . . 84

Phosphoric acid, . $\quad$. $\quad$. $\quad$. $\quad$. $\quad$. 57

" equivalent of, _ . . . . $\quad . \quad 57$

“ properties of, . . . . . 304 
suctiox.

Phosphurets,

" action of air on,

Pigeon dung,

"6 value of,

Pine ashes, analysis of,

" plains, lime and potash in, . . . . . 73, 74

Plants for food, .

" limits of, what determined by, . . . . 52

6. laws of distribution of, - . . . . . 26

" irregularity of limits of, . . . . . 26

" limits of grain bearing on mountains, . . . 28

" earthy parts of, . . . . . . 39

" not all contain the same elements, . . . 88

"6 elements of, return to earth, . . . . . 88

" always contain salts and silicates, . . . 91

" always form acids, . . . . . . 93

" galvanic action of, . . . . . . 171

66 decomposing action of, . . . . . 171

" animal principles in, . . . . . 217

" " 6 6 analysis of, . . . 217

Plaster of Páris, formation of, . . . . . 79

" " 6 application of, . . . . 151

" " . . . . . 151,170

Plonghing in of crops, _ . $\quad$ - $\quad$. $\quad 287$

287
287

$\begin{array}{lllllll}\text { " } & \text { " great fertilizing power of, } & \ldots & 287 \\ \text { " } & \text { " } & \text { green, action of, } & & 288\end{array}$

" " compared with dry, . . . 288

Polstorff, experiments of, . . . . . (p. 130)

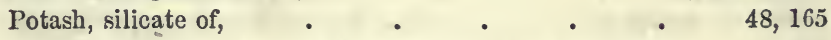

" combining weight of, . . . . 56

¿ solubility in water, . $\quad . \quad$. 62

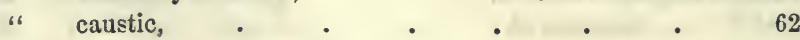

" in granite, $\quad . \quad$. $\quad . \quad .72$

“ carbonate of, in ashes, _ . . . . 92

"6 may supply the place of lime, . _ . . 96 
IXDEX.

Potash, hastens decay, . $\quad$ - $\quad$ - . 136

" to be used one-half more than soda, . . 265

Potassium, sulphuret of, . . . . . . 65

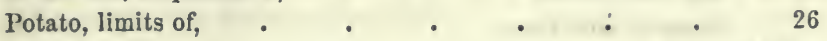

Poudrette, . . . . . 208, 209, 210

" mode of making, . (p. 166 to 172)

" composition of, . . . . . . 208

" ammonia in, . . . . . 208

" peat in, . . . . . . . . . 209

“ salts in, . . . . . . 209

Proteinc,

(p. 99, 100)

" description of, . . . . . . 218

" chemical formulæ of, . . . . . 219

" action of weak acid on, . . . (p. 99, 100)

Putrefaction, products of, _ . . . . 100

" table of products of, . . . . 100

Q.

Quartz, formation of,

" odor produced by friction, . . . . 84

R.

Rain, natural irrigation,

" fertilizing power of,

" ammoniacal salts in, . . . . . . 286

Replacemerit, of elements, . $\quad$ : $\quad$ - . $\quad$. 94

Richardson, analysis of yard-dung, . . . (p.146)

Rogers, J., on manure asbes, . . . . . . (p. 155)

Rule for estimating soil ingredients, . . (p. 37)

Rocks, primitive, $\quad . \quad \ldots \quad \ldots \quad$. $\quad . \quad 5,6$

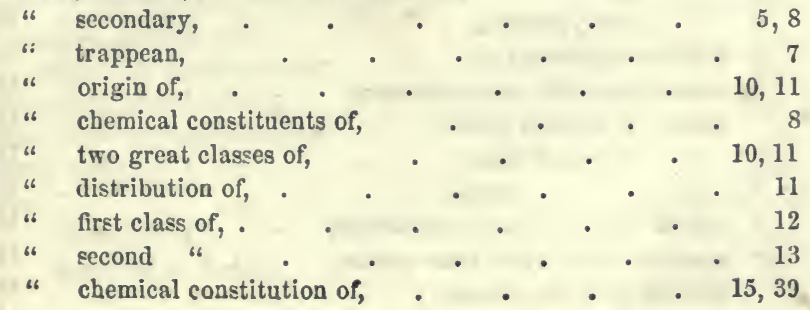


Rocks, chemical constitution of, difference in, . $\quad . \quad 15$

" fossiliferous, . . . . . . . 16

" non-fossiliferous, . . . . . 17

" cause of difference, . $\quad . \quad$. $\quad . \quad$. 18

" amount of "

" only one, in truth, . $\quad$. $\quad$. $\quad . \quad . \quad 19$

" not affect vegetation, . . . $\quad 20,26,27,28$

" what covered by, . . . . . . 30

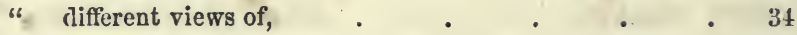

" compound, . . . . . . . . 35

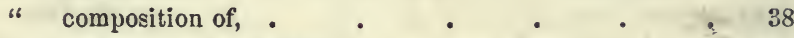

" number of elements in, . . . . . 40,45

" great bulk of, . . . . . . . 48

" enrich soil, . $\quad$ • . . . . . 290

" action of, on soil, _ $\quad . \quad$. $\quad . \quad$. 290

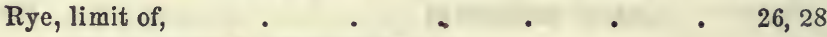

" temperature of germination, • . . . . 26

S.

Sal ammoniac, action of, $\quad . \quad$ • $\quad . \quad$ • 276

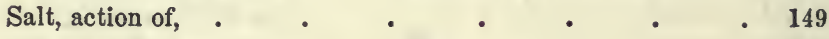

" use of, . $\quad . \quad+\quad . \quad . \quad . \quad . \quad 170$

Saltpetre, . $\quad . \quad$. $\quad . \quad$. 166

" action of, . $\quad . \quad$. $\quad . \quad$. 269

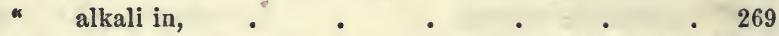

Salts, $\quad . \quad . \quad . \quad . \quad 40,44,45,46,50,76$

" super, sub, neutral, . . . . . . 57

" very insoluble, and abundant, . . . $\quad$. 80

" action on silicates, $\quad$. $\quad$. $\quad$. $\quad . \quad 133,171$

" " of, . . 143,144, 145, 146, 147, 148, 149, 150, 171

" " on of plants, . . . . . . 147

" fertility dependent on, . . . . . . 151

" connection with geine necessary, . . . 154

" action of, without geine, . . . . 155

" " on soil of slate, $\quad . \quad \ldots \quad . \quad . \quad 155$

" " " gneiss, . . . . . 155

" excess of, the cause of barrenness, . . . 156

" some of better effect than others, . . . 156

" divided into two classes,. . . . . 158 
Salts, first class, three divisions,

sirctios.

" constant in plants,

" second class of,

" quantity of, whi

hich may be used,

" two classes of, poisonous,

" in cow-dung,

" " " by Morin,

" 6 " " by M. Penot,

" in bushel of dung,

" formed daily by one cow, .

"formed yearly by one cow,

" in horse-dung

191

" in night-soil,

204

205

" in excrements of a hen, . . . . . 214

" in animal matter, . . . . . 216

" annually evacuated by one person, . . . 251

" in urine,

- 243,249

" in mud and peat,

6: in rivers, at freshets,

283

"in rain and snow,

280

" intention of application of, .

291

" of ammonia, value of,

" of crenic and apocrenic acids, sources of

- (p. 158)

Sand, improved by liming,

126

" composition of,

133

" action of muck on

13

" best to restore,

289

290

" heaviest part of soil,. . . . . . . 292

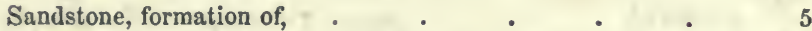

Science, definition of,

" application to agriculture, . . . 128, 129

Sea eagle, excrement of,

28,129

"water, for slacking lime, . . . . . 276

Serpentine, ingredients of, . . . . . $\quad$. 60

Seeds, beat and cold borne by, . $\quad$ - . . 26

Sheep, urine of, . $\quad$. . . . . 247

Silex,

"formation of,

" quantity of, in rock, 
Silex, as an acid in simple minerals, . $\quad$. $\quad$. 59

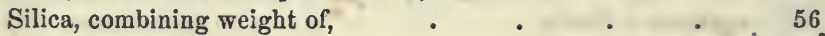

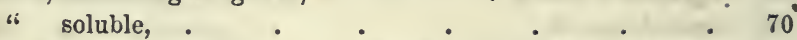

Silicates,

" decomposition of,

$40,41,42,45,46,76$

action of, carbonic acid on, $\quad . \quad .77,131,134,285$

" selected by plants, . . . . . . 87

" constant in plants, . . . . . . 91

" no action on each other, _ . . . . . 131

" of soil, stationary, . . . . . . . 132

" of potash, . $\quad . \quad$. $\quad . \quad . \quad+165$

" action of oxygen on, . . . . . 168

" of soda in spent ashes, _ . . . . . 273

" unlimited fertility of, . . . . 289

" uniformity of, . $\quad . \quad$ • . . . 291

" laws of combination of, . $\quad . \quad$. 56

Silicon, . $\quad . \quad$. $\quad . \quad$. 443

" action of, with oxygen, . $\quad . \quad$. $\quad . \quad$. 48

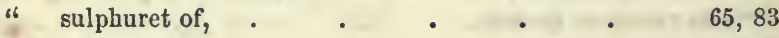

" properties of, . $\quad . \quad$. $\quad . \quad . \quad 67$

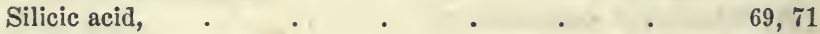

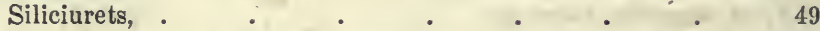

" action of air on, . . . . . 78

Sinclair, Sir John, on sea water, and peat, . . . . 276

Skin of the sole of the foot, an analysis of, . . . . 218

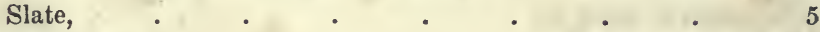

Snow, salts in, . $\quad . \quad . \quad . \quad . \quad . \quad$. 280

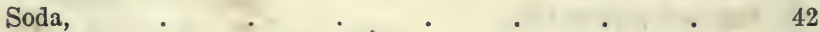

" silicate of, . $\quad . \quad . \quad . \quad . \quad 4 \quad 48$

" silicate of, combining weight of, . . . $\quad 56$

" may take the place of lime, . . . . . 96

"

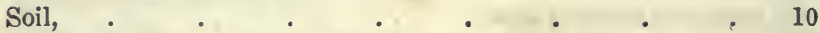

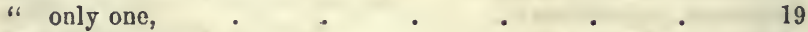

" all primary, . . . . . . . . 20

" transportation of, . . . . . 30,31

" chemical composition of, . . . . . . 32,33

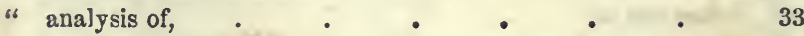

" bulk of, . . . . . . . 48 


\section{INDEX.}

sEctIo:.

Soil, elements in, . $\quad$. $\quad$. $\quad$. $\quad 40$

" unvarying, . . . . . . 58

" decay of, . . . . . . . 76

" organic parts of, . . . . . . . 88,89

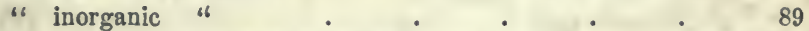

" " number of elements in, . . . . 89

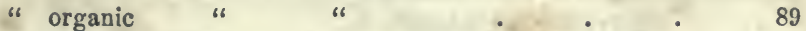

" inorganic, difference of, . . . . . 90

" carbonaceous, . $\quad$. . . . . . . 102

" not external to plants, : . . . . 140

" decomposed by plants, . . . . . 141, 147

" result of action of carbonates on, . . . . 135

" sandy, best to restore, . . . . . 290

“ physical properties of, . . . . 291, 298

" " " characters of, . . . 291

" " " what dependent on, . . 292

" " " 6 relations of, . . . 292

" varieties of, .

" sand heaviest part of, . . . . . . 292

" most important character of, . . . . 293

" " " " determined by weight, . 293

" color and dryness important to, . . . . 293

" relation to moisture and gases, . . . . 294, 295

" fresh ploughed, evaporation of, . . . . 295

‘. light, advantages of, . . . . . . . 295

" action of cold on, . . . . . . . . 296

" electrical relations of, . . . . . 297

" chlorine in, . . . . . . 298

" all fertile has certain elements, . . . 21

6: origin of four, growing grape vine, . . . 21

"Johnston on, . . . . . . . 21

"Norton on fertile, . . . . . . 21

" table of analyses of, 413 , . . . (p. 35)

"weight of cubic foot of, ingredients, amount per acre, rule for, . . . . . . . (p. 37)

" remarks on analysis of, . $\quad$. $\quad$. $\quad$. 33

" divided into soluble and insoluble, . . (p. 31)

Soot, a powerful manure, . . . . . . 225

" salts in, . . . . . . . 225 
Soot, analysis of, . $\quad . \quad \ldots \quad . \quad 225$

“ nitrogen in, . $\quad . \quad$. . . . 226

" capital liquid manure, . . . . . . 226

" good results of, in England, . . . . . 226

- of anthracite coal, . . . . . . 226

Soubeiran, analysis of yard-manure, . $\quad . \quad$ (p. 147)

" observations on nitrogen in, . . (p. 148)

" analysis of night-soil, . . . . 208

" " of animalized coal, . . 210

" on mould and turf, . . . . 278

" 6 ". " and dried flesh, . . 278

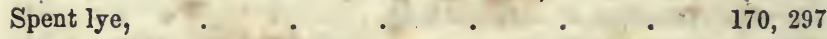

" " 6 salts of, . . . . . 230

" " alkali in, . . . . . . 230

" " two kinds of, . . . . . . 330

" " first kind, analysis of, . . . 230, 233

" " second " . . . . . . 231

" " * . . . . . . . . . 232

" " . . . . . 236, 237, 238

" " from soda soap, imitation of, . . . 238

Spent ashes, composition of, . . . . . 273

Starch, converted into sugar, . $\quad . \quad$. $\quad . \quad 137$

Stable manure, composition of, $\quad$ - . $\quad$. 176

Stearine, . . . . . . . . . . 227

Stearic acid, . . . . . . . . 227

Stinchecombe farm, . . . . . . . . 226

Straws, table of value of, . _ . . . (p. 147)

Substitution, of elements, _ . . . . . . 94 law of, .. $\quad . \quad \ldots \quad . \quad . \quad 65$

Sulphur, . $\quad . \quad 4 \quad . \quad 0 \quad .43$

" equivalent of, . . . . . . 57

Sulphates, . $\quad . \quad \ldots \quad$. $\quad . \quad 52,170$

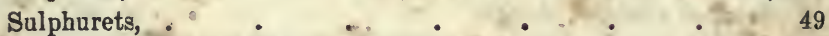

" action of air on, . . . . . 78

Sulphuric acid, formation of, . $\quad$ - $\quad 57$

"6 " $\quad$ equivalent of, . $\quad . \quad 57$

Sulpho-benzoic acid, . $\quad$. $\quad$ (p. 99)

Super-geates, .

Superphosphates, . . . . . . . 304-306 
Snperphosphates, how made,

Sugar, action of weak acid on,

\section{T.}

Table of products of putrefaction,

Talc, ingredients of,

Temperature, effects of, .

Theories, the evils of,

Turf,

Ulmin, composition of,
"6 production of,
"first called geine,

Ulmic acid, .

\section{U.}

" "formation of,

" "C composition of,

Urea, formation of,

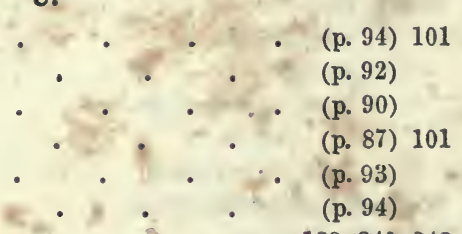

" properties of, .

. $139,240,242$

" composition of,

Uric acid,

" " composition of,

Urine of cow, composition of,

" of one cow, annually,

243

" salts in,

" effects of watering with, .

243

" of horse, analysis of, .

" "value of,

" human,

" " analysis of,

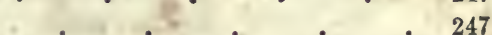

- 244

245,246

246

247

- 247

248

" co compared with horse and cow, . 248,249

" varies with food, . . . . . 250

" action of putrefaction on, . . . . 259

"6 mixed with peat, - . . . . $\quad 277,278$

" of hog, analysis of, . . . . . 247

bs sheep,

Vegetable mould, 
Vegetable mould, inorganic elements of, . . . $\quad 115$

" " brown powder of, . . . . 115

" " " " " properties of, . . 116

" products, two classes of, . . . . . 220

Vinegar, properties of, $\quad$. . . . . . . $\quad 246$

" action on pearlash, . . . . . 246, 247

Vital principle,

Volcanoes, cause of,

"6 products of,

Von Tschudi, on guano, . . . . (p. 177)

171

12

\section{W.}

Water, elements of, .

" composition of,

“ in plants,

" pure, action of, on land,

" " air in, .

. . . . 40

" with air expelled,

Weigmann, experiments of, .

52,55

167

280

Wisconsin, soils of,

280

Wheat, limits of,

" conditions necessary for,

" temperature of germination,

"straw ashes, analysis of,

Wood, hard, ashes, analysis of,

Woodland, evaporation of,

281

Wool, analysis of,

" natural soap of, for manure,

" " " 35 to 40 per cent. of, " " " used in France,

Woollen rags, powerful manure, " " stronger than cow-dung, .

\section{Y.}

Yard-manure, defined,

" how affected by age, \&c., .

" composition of,

" analysis, by Richardson, .

" " " Johnston,

(p. 147)

" " "Soubeiran,

" weight of cubic foot of.

(p. 148)

(p. 147)

(p. 148) 
(a)

\section{ran}<smiles>CCC</smiles><smiles>CCC</smiles>

,

$-2+2$

$$
\text { (20) }
$$

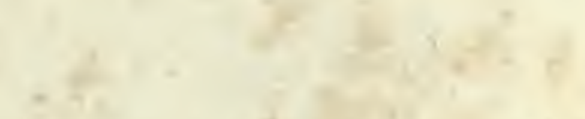

-

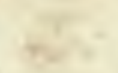

and<smiles>CCCCCCCCC</smiles>

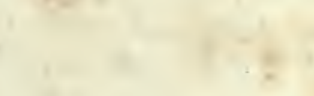





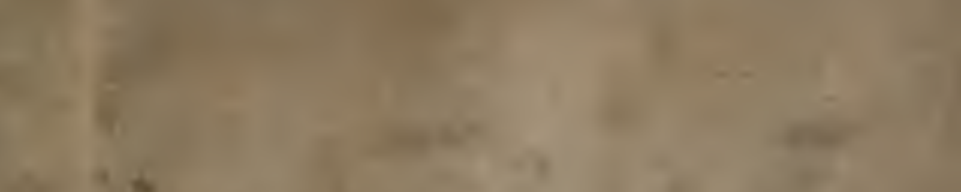

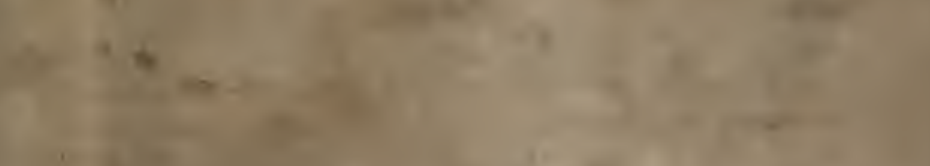

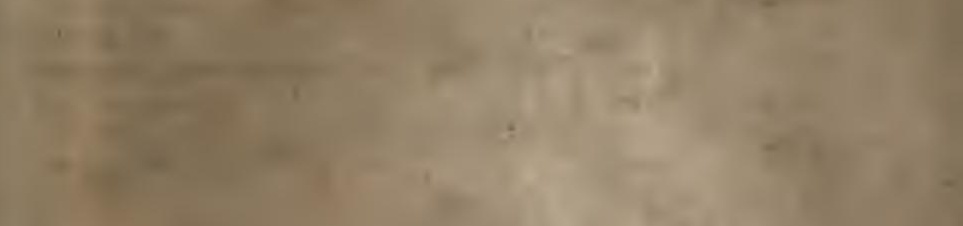

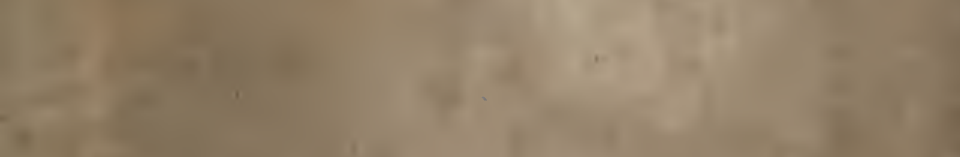

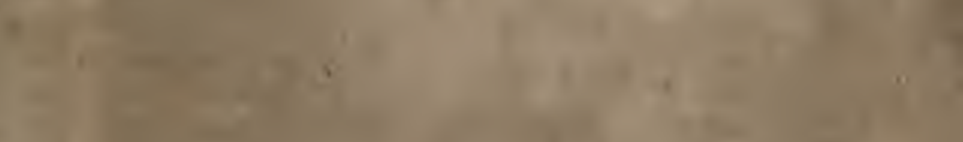

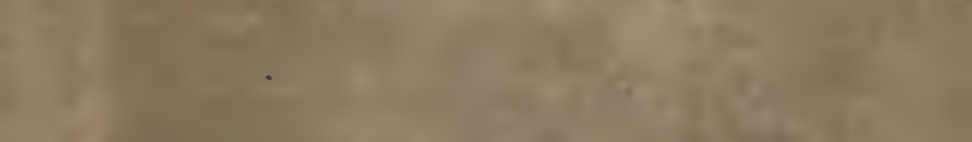

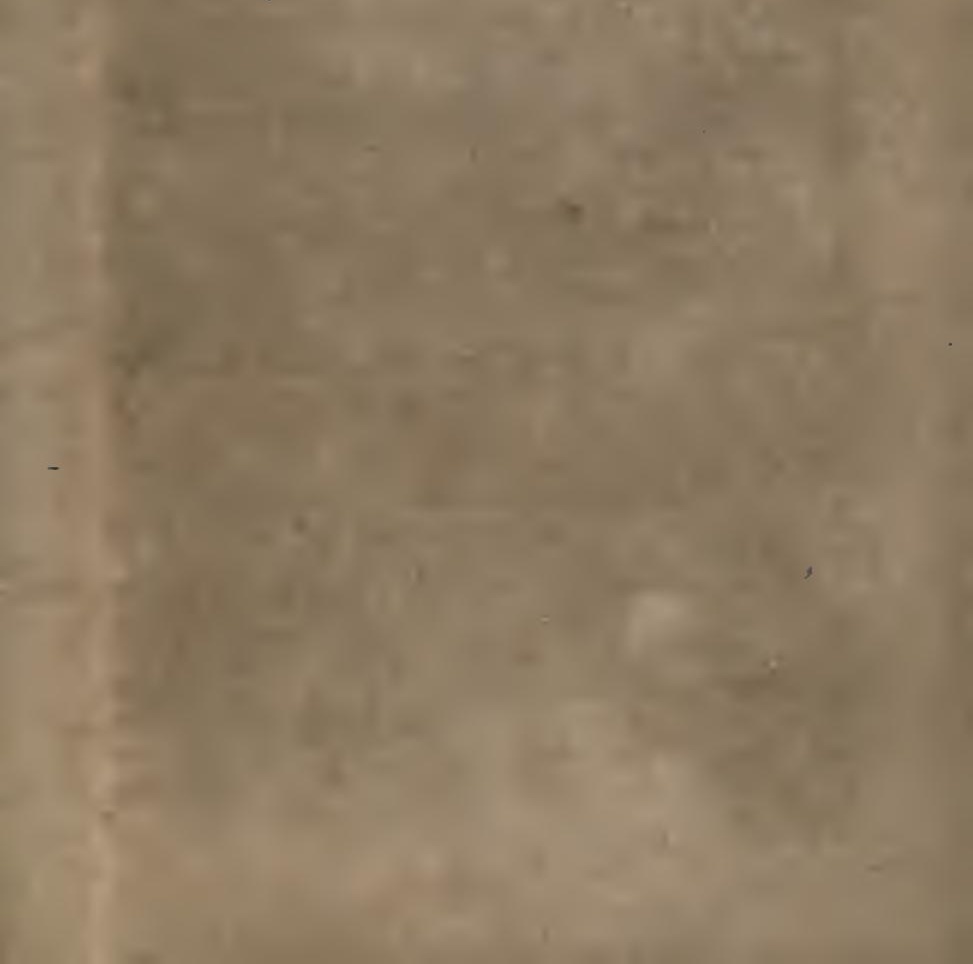




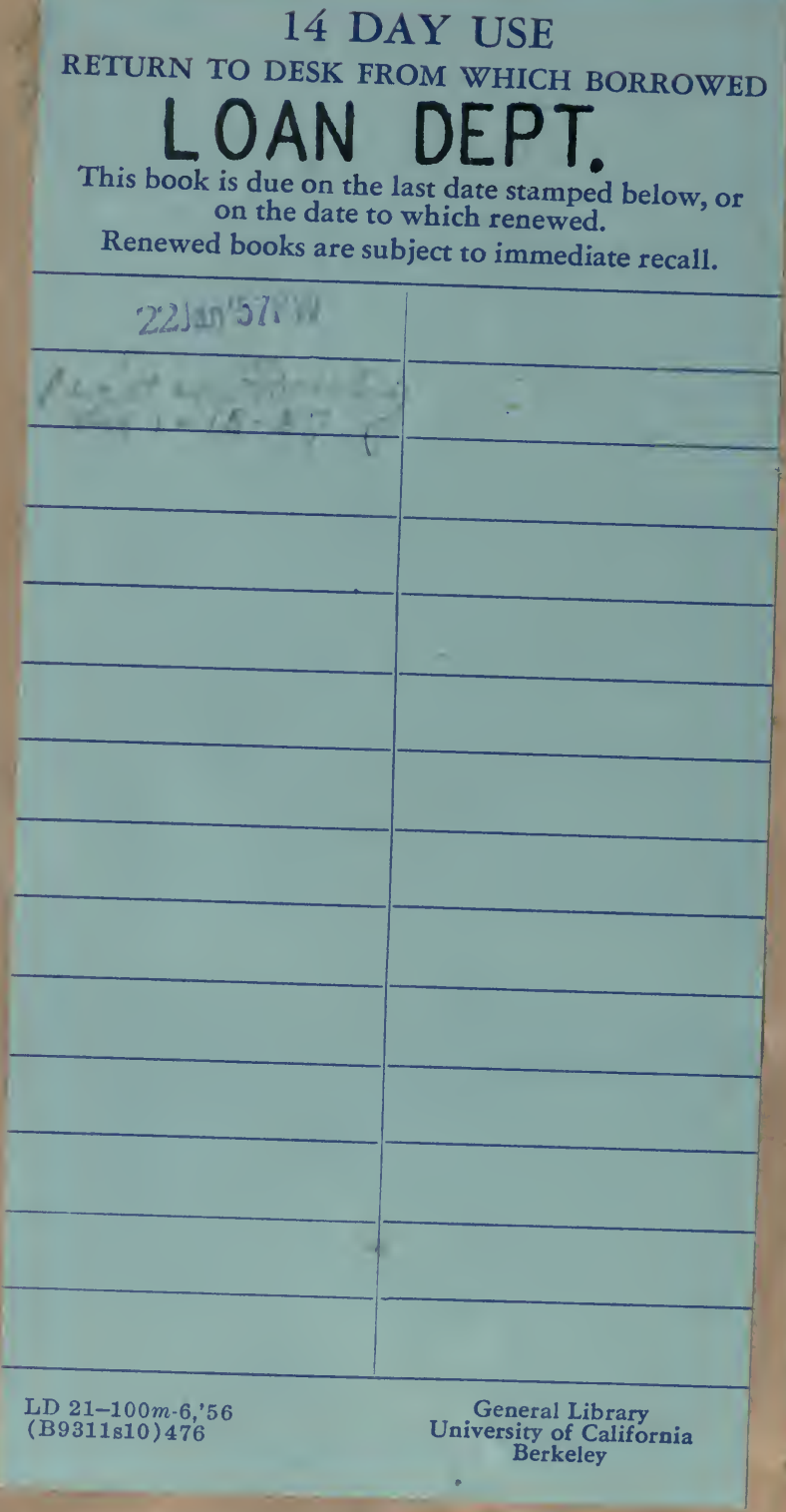


YB : 1064

Te O. $\mathrm{Ti}^{\mathrm{O} O} \mathrm{O}$

$$
\begin{aligned}
& 168 \\
& -\frac{64}{232} \cdot 168,001724 \\
& \text { 235) } \frac{1624}{260}
\end{aligned}
$$$$
678993
$$

UNIVERSITY OF CALIFORNIA LIBRARY 

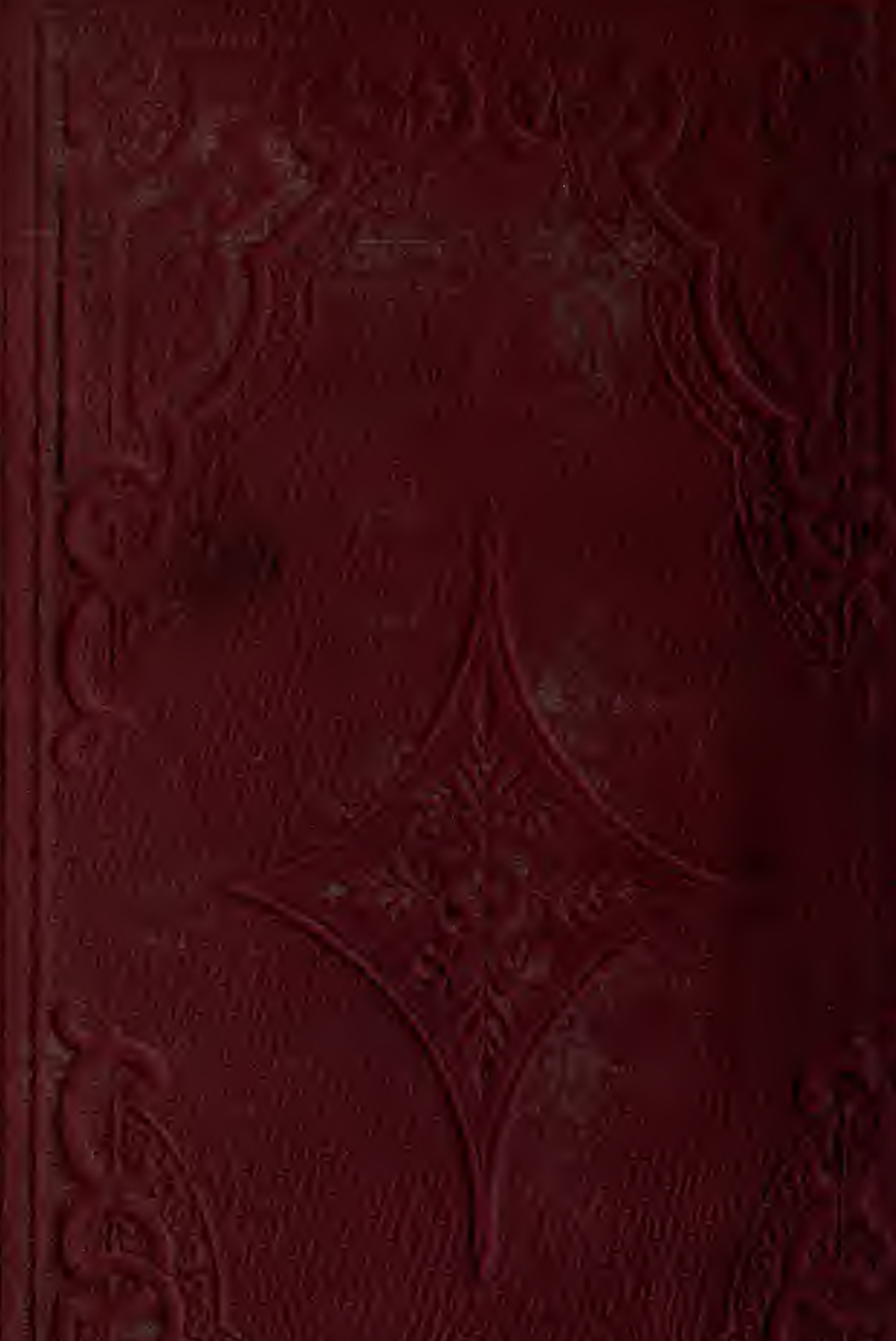

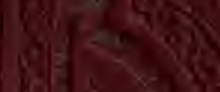

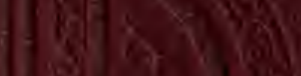

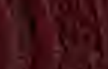

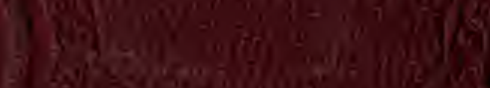

nilitios a)

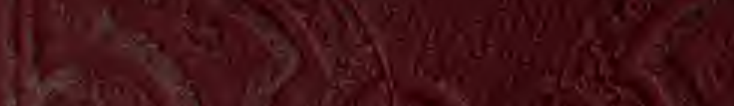

(3) 